
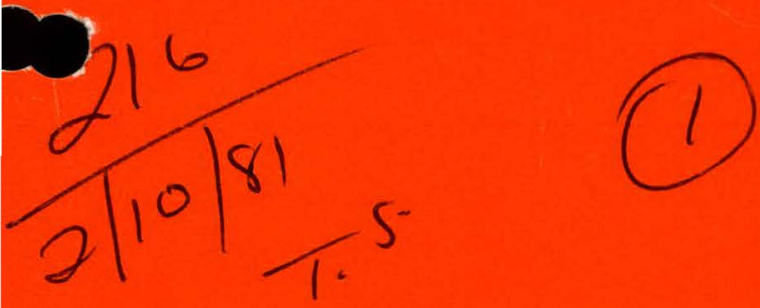

\title{
Interim Performance Criteria for Photovoltaic Energy Systems
}

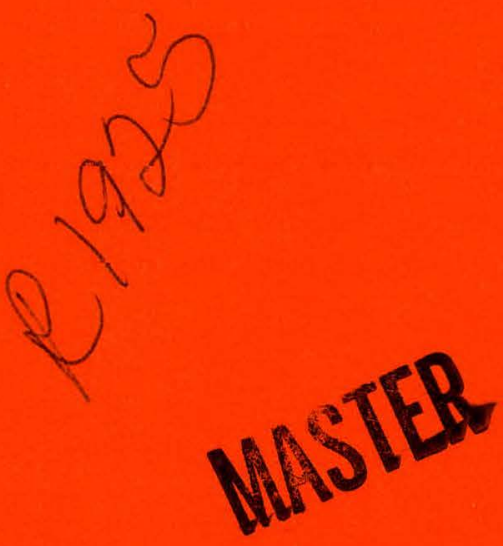

Richard DeBlasio (Solar Energy Research Institute) Steven Forman (MIT/Lincoln Laboratory) Steve Hogan (Solar Energy Research Institute) Gary Nuss (Solar Energy Research Institute) Hal Post (Sandia National Laboratories) Ronald Ross (Jet Propulsion Laboratory) Harry Schafft (National Bureau of Standards)
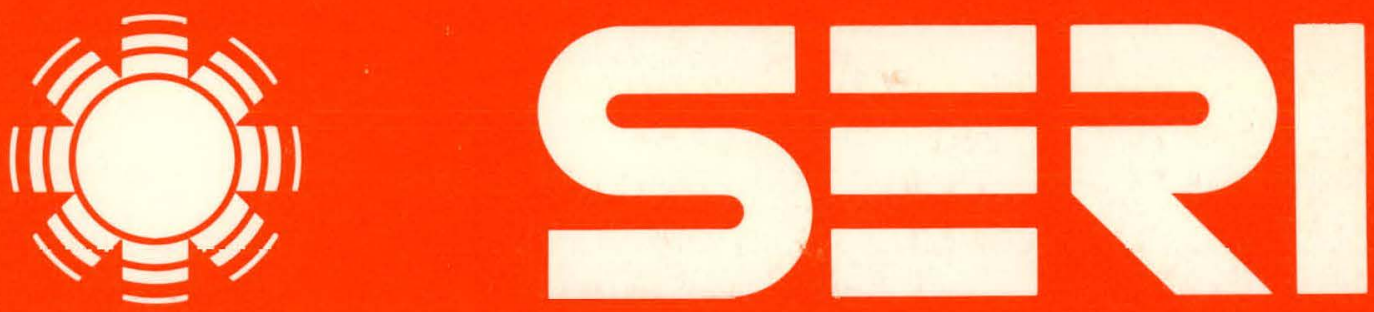

Solar Energy Research Institute

A Division of Midwest Researcil Irislilule

1617 Cole Boulevard

Golden Colorado 80401

Operated for the

U.S. Department of Energy

under Contract No EG-77-C-01-4042 


\section{DISCLAIMER}

This report was prepared as an account of work sponsored by an agency of the United States Government. Neither the United States Government nor any agency Thereof, nor any of their employees, makes any warranty, express or implied, or assumes any legal liability or responsibility for the accuracy, completeness, or usefulness of any information, apparatus, product, or process disclosed, or represents that its use would not infringe privately owned rights. Reference herein to any specific commercial product, process, or service by trade name, trademark, manufacturer, or otherwise does not necessarily constitute or imply its endorsement, recommendation, or favoring by the United States Government or any agency thereof. The views and opinions of authors expressed herein do not necessarily state or reflect those of the United States Government or any agency thereof. 


\section{DISCLAIMER}

Portions of this document may be illegible in electronic image products. Images are produced from the best available original document. 
Printed in the United States of America Available from:

National Technical Information Service

U.S. Department of Commerce

5285 Port Royal Road

Springfield, VA 22161

Price:

Microfiche $\$ 3.00$

Printed Copy $\$ 9.50$

\section{NOTICE}

This report was prepared as an account of work sponsored by the United States Government. Neither the United States nor the United States Department of Energy, nor any of their employees, nor any of their contractors, subcontractors, or their employees, makes any warranty, express or implied, or assumes any legal liabiilty or responsibility for the accuracy, completeness or usefulness of any information, apparatus, product or process disciosed, or represents that its use would not infringe privately owned rights. 


\section{ERRATA \\ Bifis;}

May 1, 1981
MAY I I $99 \%$

\section{Interim Performance Criteria for Photovoltaic Energy Systems}

By: Richard DeBlasio (Solar Energy Research Institute)

Steven Forman (MIT/Lincoln Laboratory)

Steve Hogan (Solar Energy Research Institute)

Gary Nuss (Solar Energy Research Institute)

Hal Post (Sandia National Laboratories)

Ronald Ross (Jet Propulsion Laboratory)

Harry Schafft (National Bureau of Standards)

Report No. SERI/TR-742-654

First printing: December 1980

The following corrections are to be incorporated into the subject document:

Page.

$1-5$

$1-5$

$1-7$

$1-8$

$1-8$

$1-8$

$3-11$

\section{Correction}

Under the subheading Electrical Attributes, in the third line after "... generation efficiency, ..." add "mismatch, ..."

Under the subheading Mechanical Attributes, in the seventh line, delete the word "... mismatch ..."

To Task Group No. 1 - PV Array, add "Richard Donovan, Martin Marietta Corp."

To Task Group No. 2 - Power Conditioning, Controls, Storage, and Cabling, add "Bronwyn Brench, MIT/LL; Lane Garrett, Ecotronics, Inc.; Robert Harr is, Underwriters Laboratories, Inc.; Stephen Hester, Pacific Gas and Electric Co.; Ramon Rosati, United Technologies, Inc.; Dana Sears, Windworks, Inc.; Hiry West, McGraw Edison.".

Under Task Group No. 2, correct the spelling of the name "Frank Masapina, ESB/Wisco, Inc." to "Frank Malaspina."

To Task Group No. 3 - Systems, add "Donald C. Carmichael, Battelle Columbus Laboratories; Stephen K. Young, Science Applications, Inc."

Under MO.E.3, Commentary, the last sentence in the second paragraph should read, "Under this condition, the over-currented cells dissipate power equal to the product of current and the reversed voltage that develops across the cells. The over-currented cells can be heated to elevated temperatures high enough to melt solder." 
$\underline{\text { Page }}$

\section{Correction}

3-15

Under MO.M.7, Commentary, the first sentence in the second paragraph should read: "Techniques that are useful in reducing stress levels include reducing interconnect thickness; increasing expansion loop height; increasing the distance (and thereby the interconnector length) between attachments to the cells by measuring across the intercell gap; selecting a material with a higher endurance limit; modifying the lateral dimension of the interconnection loop so that maximum bending no longer concentrates at a single point on the loop; and preventing solder from filling (wicking) and stiffening expansion loop radii [7]."

3-16 Under MO.M.9, Commentary, correct the ninth sentence (sixteenth line) to read, "... and site dependence." Delete the remainder of that sentence and delete the next three sentences.

Under MO.M.18, Evaluation, correct the first sentence to read, "Test TE.AR.M.8 . ..."

Under MO.D.2, Evaluation, correct the last sentence to read, ". . for concentrator receivers."

Under MO.D.3, Commentary, correct the last sentence to read, "Such cycling may cause: (1) dulling or obscuring of reflecting or transunitting uptles, or (2) corroding of cell metallizations or terminals," 
SERI /TR-742-654

UC CATEGORY: UC-63

INTERIM PERFORMANCE

CRITERIA FOR

PHOTOVOLTAIC ENERGY SYSTEMS

RICHARD DEBLASIO (SERI)

STEVEN FORMAN (MIT/LINCOLN LABORATORY)

STEVE HOGAN (SERI)

GARY NUSS (SERI)

HAL POST (SANDIA NATIONAL LABORATORIES)

RONALD ROSS (JET PROPULSION LABORATORY)

HARRY SCHAFFT (NATIONAL BUREAU OF

STANDARDS )

DECEMBER 1980

Prepared Under TASK No. 6128.10

\section{Solar Energy Research Institute}

A Division of Midwest Research Institute

1617 Cole Boulevard

Golden, Cólürado 80401

Prepared for the

U.S. Department of Energy

Contract No. EG-77-C-01-4042

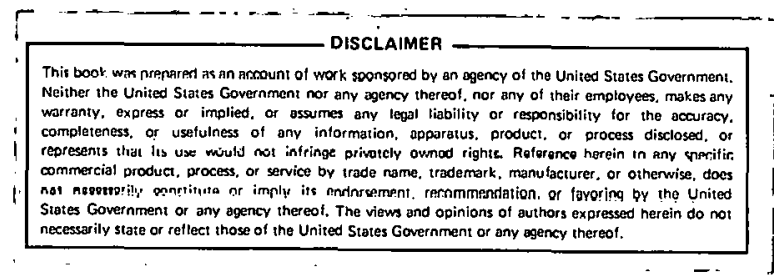

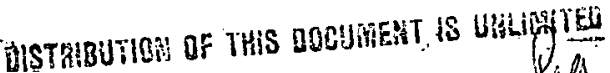

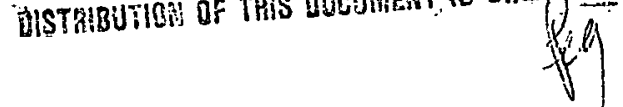


THIS PAGE

WAS INTENTIONALLY

LEFT BLANK 


\section{PREPACE}

This document was prepared in response to legislative directives of the Photovoltaic Research, Development, and Demonstration Act of 1978 (P.L. 95-590). It presents interim results of work funded by the Division of Photovoltaic Energy of the U.S. Department of Energy (DOE) to identify, develop, and promulgate performance criteria and test methods for photovoltaic solar energy conversion systems. This effort was managed by the Solar Energy Research Institute's (SERI) Quality Assurance and Standards Branch. The report is the result of joint efforts by individuals from national and private laboratories, industry, government, and public interest groups.

The study is intended to satisfy the goals of the National Photovoltaic Program by aiding the photovoltaic community's effort to accelerate the commercialization of photovoltaic systems, thereby creating a viable energy option for the future. This document assists in that acceleration by offering the performance criteria as a basis for standards development by voluntary consensus standards organizations. Equally important, it provides a common base for both manufacturers and purchasers to use in evaluating and characterizing performance traits of interest.

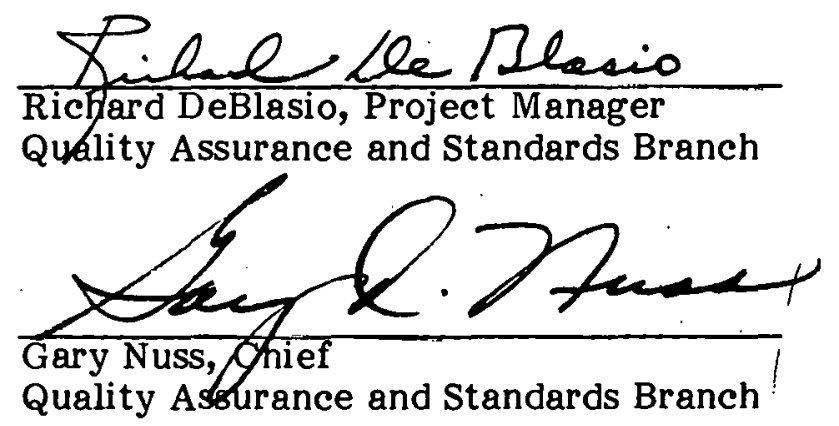

Approved for

SOLAR ENERGY RESEARCH INSTITUTE

Jon M. Veigel, Manager

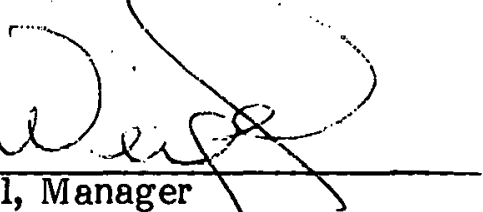

Planning Applications and Impacts Division 
THIS PAGE WAS INTENTIONALLY LEFT BLANK 


\section{SUMMARY}

This document is a response to the Photovoltaic Research, Development, and Demonstration Act of 1978 (P.L. 95-590) which required the generation of performance criteria for photovoltaic energy systems. Since the document is evolutionary and will be updated, the term "interim" is used. More than 50 experts in the photovoltaic field have contributed to the writing and review of the 179 performance criteria listed in this document. The performance criteria address characteristics of present-day photovoltaic systems that are of interest to manufacturers, government agencies, purchasers, and all others interested in various aspects of photovoltaic system performance and safety.

The performance criteria apply to the system as a whole and to its possible subsystems: array, power conditioning, monitor and control, storage, cabling, and power distribution. They are further categorized according to the following performance attributes: electrical, thermal, mechanical/structural, safety, durability/reliability, installation/ operation/maintenance, and building/site. Each criterion contains a statement of expected performance (nonprescriptive), a method of evaluation, and a commentary with further information or justification. Over 50 references for background information are also given.

A glossary with definitions relevant to photovoltaic systems and a section on test methods are presented in the appendices. Twenty test methods are included to measure performance characteristics of the subsystem elements. These test methods and other parts of the document will be expanded or revised as future experience and needs dictate. A subject index to the performance criteria is also included. 
THIS PAGE WAS INTENTIONALLY LEFT BLANK 


\section{TABLE OF CONTENTS}

$\underline{\text { Page }}$

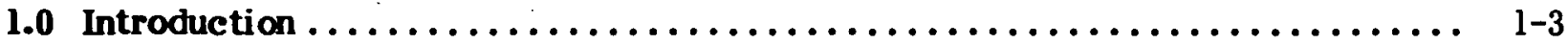

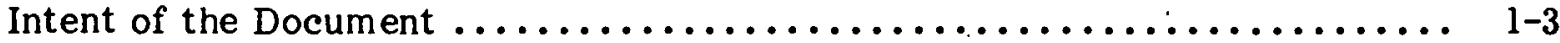

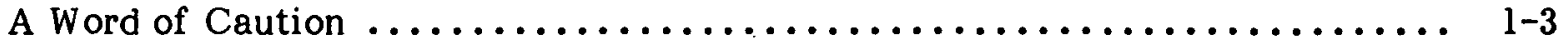

Scope..........................................

Organization and Format $\ldots \ldots \ldots \ldots \ldots \ldots \ldots \ldots \ldots \ldots \ldots \ldots \ldots \ldots \ldots \ldots \ldots \ldots$

Contributors.................................... 1-7

2.0 Photovoltaic System $\ldots \ldots \ldots \ldots \ldots \ldots \ldots \ldots \ldots \ldots \ldots \ldots \ldots \ldots \ldots \ldots \ldots \ldots \ldots \ldots \ldots, 2-1$

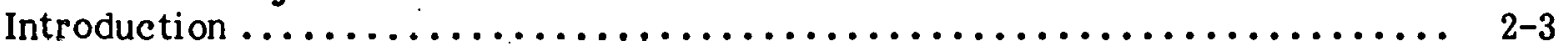

System Performance Criteria ............................. 2-5

System Monitor and Control Performance Criteria ................ 2-24

3.0 Array Subsystem $\ldots \ldots \ldots \ldots \ldots \ldots \ldots \ldots \ldots \ldots \ldots \ldots \ldots \ldots \ldots \ldots \ldots \ldots \ldots \ldots \ldots \ldots, 3-1$

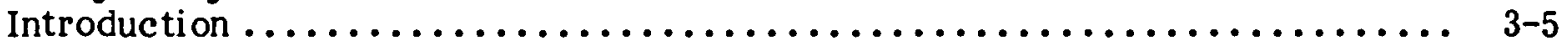

Solar Cell Performance Criteria............................ 3-5

Module Performance Criteria ............................... 3-10

Concentrator Optics/Receiver Performance Criteria . . . . . . . . . . . . 3-22

Array/Array Field Performance Criteria ........................ 3-26

4.0 Power Conditioning Subsystem $\ldots \ldots \ldots \ldots \ldots \ldots \ldots \ldots \ldots \ldots \ldots \ldots \ldots \ldots \ldots \ldots \ldots$ 4

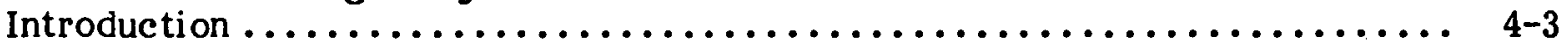

Performance Criteria ................................. 4-4

5.0 Power Conditioning Monitor and Control Subsystem ................ 5-1

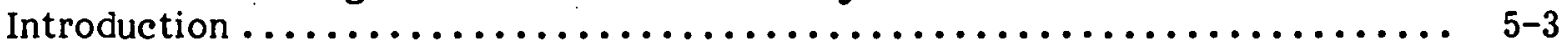

Performance Criteria .................................. 5-4

6.0 Storage Subsystem $\ldots \ldots \ldots \ldots \ldots \ldots \ldots \ldots \ldots \ldots \ldots \ldots \ldots \ldots \ldots \ldots \ldots \ldots \ldots \ldots, \ldots \ldots \ldots$

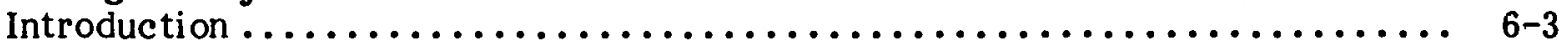

Performance Criteria ................................ 6-4

7.0 Cabling $\ldots \ldots \ldots \ldots \ldots \ldots \ldots \ldots \ldots \ldots \ldots \ldots \ldots \ldots \ldots \ldots \ldots \ldots \ldots \ldots \ldots \ldots \ldots \ldots \ldots \ldots$

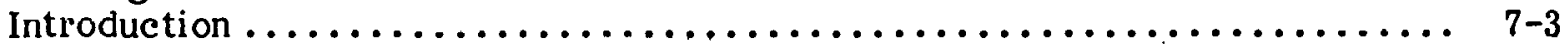

Performance Criteria ................................. $7-3$

8.0 Power Distribution Subsystem. $\ldots \ldots \ldots \ldots \ldots \ldots \ldots \ldots \ldots \ldots \ldots \ldots \ldots \ldots \ldots \ldots . \ldots . \ldots$

Introduction $\ldots \ldots \ldots \ldots \ldots \ldots \ldots \ldots \ldots \ldots \ldots \ldots \ldots \ldots \ldots \ldots \ldots \ldots \ldots \ldots$

Pcrformance Criteria ............................... 8-3

$\Lambda$ ppendix A. Glossary $\ldots \ldots \ldots \ldots \ldots \ldots \ldots \ldots \ldots \ldots \ldots \ldots \ldots \ldots \ldots \ldots \ldots \ldots \ldots$

Appendix B. Test Methods ................................. B-1

Nomenclature $\ldots \ldots \ldots \ldots \ldots \ldots \ldots \ldots \ldots \ldots \ldots \ldots \ldots \ldots \ldots \ldots \ldots \ldots \ldots \ldots$

Subject Index for Performance Criteria $\ldots \ldots \ldots \ldots \ldots \ldots \ldots \ldots \ldots \ldots \ldots \ldots$ 


\section{THIS PAGE}

\section{WAS INTENTIONALLY LEFT BLANK}




\section{LIST OF FIGURES}

$\underline{\text { Page }}$

2-1. Generalized Photovoltaic Power System Interface Diagram ............ 2-4

2-2. Integral Distribution of Solar Array Maximum Power

Point Pow er for Phoenix ............................. 2-7

3-1. Photovoltaic Array Hierarchy $\ldots \ldots \ldots \ldots \ldots \ldots \ldots \ldots \ldots \ldots \ldots \ldots \ldots \ldots$

LIST OF TABLES

Page

2-1. Minimum Clear working Space .......................... 2-20

4-1. Dielectric Withstand Voltages at Atmospheric Pressure.............. 4-14 


\subsection{INTRODUCTION}

\section{Page}

Intent of the Document $\ldots \ldots \ldots \ldots \ldots \ldots \ldots \ldots \ldots \ldots \ldots \ldots \ldots \ldots \ldots \ldots \ldots \ldots \ldots \ldots$

A Word of Caution $\ldots \ldots \ldots \ldots \ldots \ldots \ldots \ldots \ldots \ldots \ldots \ldots \ldots \ldots \ldots \ldots \ldots \ldots \ldots \ldots$

Scope.............................................. 1-4

Organization and For mat ...................................

Contributors.......................................... 1-7 


\section{THIS PAGE}

WAS INTENTIONALLY

LEFT BLANK 


\section{SECTION 1.0}

\section{INTRODUCTION}

\section{INTENT OF THE DOCUMENT}

This document presents the state of the art in defining performance criteria for photovoltaic (PV) systems and their components--such as the PV array, power conditioning, monitor and control, and storage subsystems. A performance criterion, for the purposes of this document, describes a performance need or expectation that represents a characteristic (distinguishing trait, quality, or property) of the PV system, subsystem, or component that is directly or indirectly related to performance or safety. Each performance criterion contained herein consists of a criterion statement, an evaluation statement that describes how compliance with the criterion statement is to be evaluated, and a commentary statement to provide necessary supportive or background information.

Performance criteria deal with the following seven attributes: electrical, thermal, mechanical/structural, safety, durability/reliability, installation, operation and maintenance, and building and site characteristics. They are directed not only to generic but to specific applications such as remote stand alone, residential, intermediate load centers, and central stations.

Performance criteria are not to be confused with performance specifications. Performance specifications are prescriptive; they specify the quantitative details of performance or design for a subject part. Performance criteria, such as are found in this document, are not prescriptive; they are performance oriented to allow for innovation and for $a$ variety of approaches to obtain desired objectives for a PV system or subsystem.

To the prospective user, the document is intended to be a resource that not only identifies performance considerations but also provides guidelines, recommendations; and important information applicable in the design, specification, procurement, installation, maintenance, and use of PV systems and subsystems. The user of this document may be anyone at any of the buyer-seller interfaces for PV materials and products; for example, a manufacturer, supplier, architect, designer, or knowledgeable user.

\section{A WORD OF CAUTION}

Although the collection of performance criteria is intended to provide a base for fair and uniform product characterizations and comparisons, a word of caution is included here for those who wish to use this document for the specification or procurement of PV products. This document is meant to be comprehensive in nature and application. By no means will all performance criteria be applicable or necessary for any given systcm or subsystem. These performance criteria are not intended for blanket use in regulatory or code documents. Furthermore, care must be exercised in selecting and applying individual criteria. Inappropriate or unnecessary application of performance criteria can lead to needless expense and system complexity; it therefore defeats the goal of cost competitiveness for PV.

It is also important to recognize that this document, with its performance criteria and evaluation statements, is in an evolutionary stage und is subject to modifications and refinement as PV technology and experience grow. Few of the evaluation methods cited 
in the evaluation statements are consensus standards. The remainder of those identified are at various stages of development and maturity. Several evaluation statements lack an existing applicable test method. These deficiencies in the test methods for PV are to be expected in a young, developing technology and industry. Test development needs are being addressed within the Department of Energy's National Photovoltaic Program and by several standards-writing organizations. In the interim, the test methods cited here must be applied with appropriate care. The most effective use of this document will be achieved through familiarity with the document itself, some expertise in PV technology, and a thorough understanding of proposed PV applications.

\section{SCOPE}

This document is evolutionary in the sense that it is the product of many members of the PV community who are continuing to prepare additions and refinements for inclusion in subsequent cditions. As the lechnology and the commercialization of PV continue to advance and as experience with PV broadens, it is expected that this document will change to reflect these advances.

Performance criteria in the document are oriented primarily to PV systems using singlecrystal silicon cell technology for flat-plate and concentrator array subsystems. Within this technology there are gaps; for example, in the tracking and control of PV arrays, in concentrator optics, and in combined PV and thermal modules and arrays. The preparation of performance criteria in these areas is under way. To the extent possible, the criteria were prepared so as not to exclude any of the developing cell technologies. As these new technologies advance commercially, appropriate performance criteria will be prepared and introduced in future editions.

Substantive comments on this edition and future ones are encouraged. All comments should be addressed to: Branch Chief, QA\&S Branch, Mr. G. Nuss, SERI, 1617 Cole Blvd.,. Golden, CO 80401 .

\section{ORGANIZATION AND FORMAT}

Performance criteria are organized according to the portion of the system to which they apply. This allows a reader interested in a particular hardware element to locate all applicable criteria quickly. The document is divided into sections dealing with the overall PV system and each of its major subsystems. Two sections are divided into subsections dealing with major subsystem elements.

Each performance criterion consists of three statements: a criterion, an evaluation, and commentury statement. 'Ihe scope of each statement is described below.

Criterion: A qualitative statement that addresses the user need or expectation for a given element. It is a general statement of what the element will be able to do. The criterion does not specify any levels of performance. Unless otherwise indicated, the criterion is intended for general application.

Evaluation: A statement that sets forth the test methods and other information on which conf ormance with the criterion shall be evaluated. It states the standards, inspection methods, analysis, review procedures, historical documentations, or test methods that are to be used. In some cases, the review of documentation of in-use performance or engineering analysis may be used as evaluative tools in lieu of testing. 
Commentary: A statement that provides background and presents the rationale for the selection of the criterion, or evaluation, or both. It also may suggest or provide, with supporting rationale, a basis for specific levels of performance that might be used. A major reason for including a commentary with each performance criteria statement is to assure a workable process for updating criteria by establishing a basis for selecting performance levels and methods of evaluation. This procedure should aid the reader when questions arise about the basis for a particular criterion. When appropriate, the commentary statement will provide particulars regarding the use of the performance criterion for specific applications.

The performance criteria in a given section or subsection are categorized according to seven attributes. Definition statements for these performance attributes are listed below.

Electrical Attributes are used to describe the ability of systems and subsystems to produce or manage electrical energy. Performance criteria include electrical power generation efficiency, power conversion efficiency, sensing, switching, ripple and transient control, and insulation to prevent electrical breakdown and excessive leakage.

Thermal Attributes are used to describe the ability of systems and subsystems to produce or manage thermal energy. Performance criteria include thermal energy generation and transport, thermal losses, heat transfer rates, and circulation control.

Mechanical/Structural Attributes are used to describe (1) the mechanical and material features of systems and subsystems that can affect their performance, or (2) the ability of systems and subsystems to withstand normal transport and service conditions that result in a mechanical stress, or (3) the ability of systems and subsystems to maintain their structural integrity under in-service conditions. Performance criteria include considerations related to: transportation; handling; mutual shadowing; orientation of arrays; thermal expansion; mismatch; fluid pressure; loading due to wind, snow, ice, hail, or earthquake; and maintenance personnel.

Safety Attributes are used to describe the mitigation of hazards in systems and subsystems that could result in property damage, personal injury, or death. Performance criteria include fragile, toxic, and flammable materials; high temperatures; and electrical shock, lightning, and high light intensity.

Durability/Reliability Attributes are used to describe the ability of systems and subsystems to perform functions designed for a specified interval under designated use conditions. Performance criteria consider degradation due to exposure to moisture, soilants, pollutants, ultraviolet radiation, thermal shock, and temperature cycling.

Installation, Operation, and Maintenance Attributes describe system and subsystem features for safe and proper installation, operation, and maintenance. Performance criteria consider installation instructions, operating instructions, routine scheduled maintenance, corrective maintenance, replacem ent, repairs, and access.

Building/Site Attributes relate to integrating a system with a building and site. Performance criteria are concerned about shadows from adjacent structures, accessibility to the building, penetration and loading of struclures, and drainage. 
An identifying code is used for the performance criteria and also for the test methods (Appendix B) specified in evaluation statements. The code is designed to allow the reader to recognize the hardware elem ent and the performance attribute addressed. The letter codes for hardware elements and performance attributes are listed below.

\begin{tabular}{lc}
\multicolumn{1}{c}{ Hardware } & Code \\
\cline { 2 - 2 } PV system & SY \\
PV system monitor and control unit & SM \\
Array susbsystem & \\
Cell & CE \\
Module & MO \\
Concentrator optics/receiver & CR \\
Array/array field & AR \\
Power Conditioning Subsystem & PC \\
Power Conditioning Monitor and Control Subsystem & MC \\
Storage Subsystem & ST \\
Cabling Subsystem & CA \\
Power Distribution Subsystem & PD \\
$\quad$ Performance Attributes & \\
Electrical & E \\
Thermal & T \\
Mechanical/Structural & M \\
Safety & S \\
Durability/Reliability & D \\
Installation, Operation and Maintenance & I \\
Building/Site & B
\end{tabular}

A performance criterion is assigned a code designation in the following manner: hardware element.performance attribute.numerical order

Examples:

SY.E.2 system. electrical attribute. second in the series MO.S.1 module. safety attribute. first in the series

ST.D.1 storage. durability/reliability attribute. first in the series

'I'he first criterion code appearing on a page is printed in the upper right-hand corner of each page to aid the reader in locating a given performance criterion.

A test method is assigned a code designation in the following manner:

TE.hardware element. pei-lurmance attribute. numerical order

Examples:

TE.AR.M.8 test method.array.mechanical/structural.eighth in the series

TE.PC.F.1 test method.pow er conditioning.electrical.first in the series

The code for the test methods appears in the upper right-hand corner of each page containing that test method, to aid the reader in locating it. 
A glossary is provided in Appendix A. Many terms in the glossary have well-established definitions; new terms are defined according to current knowledge and usage. Test methods referred to in evaluation statements are located in Appendix B. Not all necessary evaluation (i.e., test) techniques exist; therefore, a major secondary purpose of this interim document is to identify test methods that need to be considered in future technical development. The existing (nonstandard) test methods and those yet to be developed will then become the basis for consensus standards deliberations and development. A nomenclature list follows the appendices. A subject index of performance criteria is provided at the end of the document to facilitate the location of performance criteria of specific interest to the reader.

\section{CONTRIBUTORS}

This document represents the involvement, knowledge, experience, and dedication of many members of the PV community in research and developm ent, industry, universities, the consumer group, standards organizations, and government. It was developed and prepared for the U.S. Department of Energy (DOE) under the management of the Solar Energy Research Institute (SERI). Project manager for the development of this document was Richard DeBlasio. Major contributors to this docum ent were Ron Ross, Jet Propulsi on Laboratory (JPL); Steve Forman, MIT/Lincoln Laboratory (MIT/LL); Hal Post, Sandia National Laboratories; Harry Schafft, U.S. National Bureau of Standards (NBS); and Steve Hogan, SERI.

The organizational structure involved in the preparation of this document is described below. Three task groups prepared the performance criteria. This work, as well as the design and review of the document itself, was coordinated by the Task Group Steering Committee in consultation with the Coordinating Council. The design, review, and editing of the document were performed by the Technical Review and Editorial Team, with assistance from SERI staffpersons.

Developing and preparing this document required a team effort. The time and talent of all who took part in this effort are gratefully acknowledged. They are identified below by their role in the groups involved.

\section{TASK GROUP NO. 1 - PV ARRAY}

Henry Curtis

Ron Diamond

M.S. Imamura

Steven Gasner

Chuck Herrington

Alan Hoffman (Deputy Chairman)

Steve Hogan

William Kaszeta

Bruce Larson

Allan Levins

Steve Patrick

Gene Ralph

Ruin Ross (Chairman)

Tim Rule

B. D. Shaf er
NASA/Lewis Research Center

Appli ed Solar Energy Corp.

Martin Marietta Corp.

JPL

SERI

JPL

SERI

SES, Inc.

Motorola, Inc.

Underwriters Laboratories, Inc.

Wyle Laboratories

Spectrolab, Inc.

JPL

Arizona State University

Sandia National Laboratories 
Harry Schafft

Neal Shepard

Byard D. Wood

Gene Zerlaut

George Storti
NBS

General Electric Company

Arizona State University

DSET, Inc.

Solarex Corporation

This task group prepared the performance criteria in Section 3.0 and the test methods in Appendix $B$ that have the identification code TE.AR.

\section{TASK GROUP NO. 2 - POWER CONDITIONING, CONTROLS, STORAGE, AND CABIING}

John Barghusen

Jay Chamberlin

Clint Cristianson

David Curtice

Ralph Ferraro

Kay Firor

Steve Form an (Chairman)

Jack Harris

Jack Helfrich

David Klein

Stanley Krauthamer

Emanual "Manny" Landsman

Frank Masaspina

Hans Meyer

Alan Miliner

George O'Sullivan

David R. Smith

Walter Stolte

Joseph Vivirito

Gordon Young
Argonne National Laboratories

Sandia National Laboratories

Argonne National Laboratories

Systems Control

Electric Power Research Institute

SERI

MIT/LL

Texas Electric Service Co.

MIT/LL

MIT/LL

JPL

MIT/LL

$\mathrm{ESB} / \mathrm{W}$ isco Inc.

Windworks Inc.

MIT/LL (furmerly)

Abacus Controls

Sandia National Laboratories

Bechtel National Inc.

United Technologies

Ford, Bacon \& Davis (formerly)

This task group prepared the performance criteria in Sections 4.0, 5.0, 6.0, and 7.0, and the test methods in Appendix B having the identification codes TE.PC. and TE.ST.

TASK GROUP NO. 3 - SYBTEMS

Tom Basso

Ruilde Cull

Cary Jones

Hal Macomber

Ed Mehalick

Laxmi Mrig

Phil Pierce

Paul Pittman

Hal Post (Chairman)

Arthur Rudin

Miles C. Russell

Steve Sacco

Chad Schrock
SFRI

NASA/Lewis Research Contror

Sandia National Laboratories.

Monegon, Ltd. (formerly with TEAM, Inc.)

General Electric Company

SERI

SERI

Westinghouse Electric Corp.

Sandia National Laboratories

ARCO Solar, Ine.

MIT/LL

MIT/LL (formerly)

SERI (formerly) 
Elmer Streed

Russell S. Sugimura

Paul Sutton
NBS

JPL

JPL/Lead Center (form erly)

This task group prepared the performance criteria in Sections 2.0 and 8.0.

\section{TASK GROUP STEERING COMMITTEE}

Dick DeBlasio/Gary Nuss (Chairman,

Steering Committee)

SERI

Steve Forman (Chairman, Task Group \#2)

Steve Hogan

MIT/LL

SERI

Leonard Magid

DOE-PV Systems Branch

Robert McGinnis

Gary Nuss (Chief, Quality Assurance and Standards Branch)

Photowatt International, Inc.

SERI

Hal Post (Chairman, Task Group \# 3)

Ron Ross (Chairman, Task Group \#1)

Sandia National Laboratories

JPL

NBS

Harry Schafft

Paul Sutton

JPL/Lead Center

The Task Group Steering Committee coordinated the integration of task group activities and their products into a final document.

\section{THE TECHNICAL REVIEW AND EDITORIAL TEAM}

$\begin{array}{ll}\text { Harry Schafft (Team Leader) } & \text { NBS } \\ \text { Steve Hogan } & \text { SERI } \\ \text { Harold Lauffenburger } & \text { SERI } \\ \text { Bill Lankford } & \text { NBS }\end{array}$

With direction from the Trsk Group Steering Committee, the Technical Review and Editorial Team designed the format of the document, and reviewed and edited the criteria for technical content and consistency. Cindy Andersen, SERI, provided administrative support to the project.

\section{COORDINATING COUNCIL MEMBERS}

Charles Backus

Drew Bottaro

Ron Diamond

John J. Fayed

Steve Forman

R. G. Harris

Gary Jones

William Kaszeta

James M. Marler

William Masters

Kobert McGinnis

Michael Merchant
Arizona State University

MIT/Energy Laboratory

Applied Solàr Energy Corp

NEMA

MIT/LL

Underwriters Laboratories, Inc.

Sandia National Laboratories

SES, Inc.

General Electric Company

Acurex

Photowatt International, Inc.

MCM Enterprises 
Edward Passerini

Steve Patrick

David Redfield

Donald R. Roberts

Ron Ross

Joan Shorey

George Storti

A. M. Wilson

William Yerkes

Gene Zerlaut
University of Alabama

Wyle Laboratories

Institute of Electrical and

Electronics Engineers

Westinghouse Electric Corp.

JPL

Solar Lobby

Solarex Corporation

Electronic Industries Association

ARCO Solar, Inc.

Am erican Society for Testing and Materials (ASTM).

The Coordinating Council provided valuable support through coordination activities, guidance, recommendations, and its review of this document. 


\subsection{PHOTOVOLTAIC SYSTEM}

Page

Introduction $\ldots \ldots \ldots \ldots \ldots \ldots \ldots \ldots \ldots \ldots \ldots \ldots \ldots \ldots \ldots \ldots \ldots \ldots \ldots \ldots \ldots \ldots$

System Performance Criteria $\ldots \ldots \ldots \ldots \ldots \ldots \ldots \ldots \ldots \ldots \ldots \ldots \ldots \ldots \ldots \ldots \ldots \ldots \ldots$. $2-5$

Electrical Attributes $\ldots \ldots \ldots \ldots \ldots \ldots \ldots \ldots \ldots \ldots \ldots \ldots \ldots \ldots \ldots \ldots \ldots \ldots \ldots$

SY.E.1 System Power Performance...................... 2-5

SY.E.2 System Energy Perf ormance.$\ldots \ldots \ldots \ldots \ldots \ldots \ldots \ldots \ldots \ldots \ldots \ldots \ldots$ 2-6

SY.E.3 Economic Performance ........................... 2-8

SY.E.4 Array Capability .............................. 2-8

SY.E.5 Power Conditioning Capability ..................... 2-9

SY.E.6 Storage Capability .............................. 2-9

SY.E.7 Auxiliary Energy .............................. 2-10

SY.E.8 Lightning Protection........................... 2-10

Mechanical/Struc tural Attributes.......................... 2-11

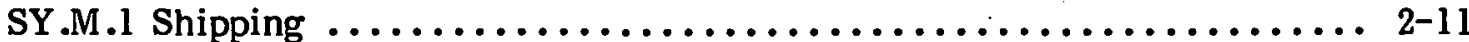

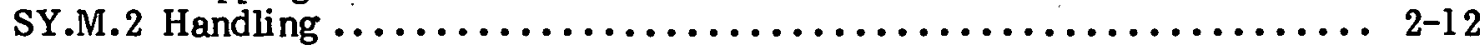

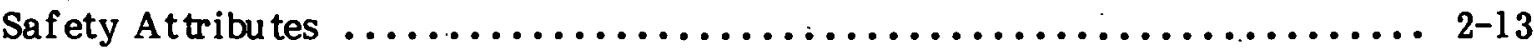

SY.S.1 System Safety ............................. 2-13

SY.S.2 System Grounding $\ldots \ldots \ldots \ldots \ldots \ldots \ldots \ldots \ldots \ldots \ldots \ldots \ldots \ldots \ldots \ldots$ 2-13

SY.S.3 Equipment Grounding .......................... 2-14

SY.S.4 Electrical Interrupts . ............................ 2-15

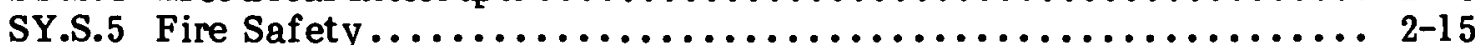

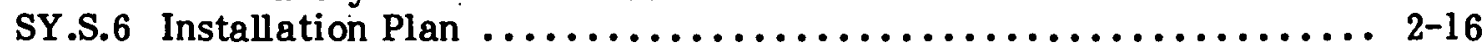

SY.S.7 Burn Hazards ................................... 2-16

Installation, Operating, and Maintenance Attributes.............. 2-17.

SY.I.1 Installation, Operation, and Maintenance Manual ........... 2-17

SY.I.2 System Maintainability............................ 2-18

SY.I.3 Access for System Maintenance ..................... 2-19

SY.I.4 Insurabtlity ................................ 2-21

SY.I.5 Regulatory Require ments $\ldots \ldots \ldots \ldots \ldots \ldots \ldots \ldots \ldots \ldots \ldots \ldots \ldots$ 2-21

Building and Site Attributes $\ldots \ldots \ldots \ldots \ldots \ldots \ldots \ldots \ldots \ldots \ldots \ldots \ldots \ldots \ldots \ldots 2-22$

SY.B.1 Shading of the Array Field....................... 2-22

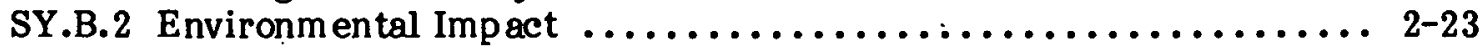

SY.B.3 Siting................................... 2-23

System Monitor and Control Performance Criteria ..................... 2-24

Elec trical Attributes $. . \ldots \ldots \ldots \ldots \ldots \ldots \ldots \ldots \ldots \ldots \ldots \ldots \ldots \ldots \ldots \ldots \ldots \ldots \ldots . \ldots 2-24$

SM.E.l System Monitor and Control Capability .................. 2-24

SM.E.2 Power Flow Control ............................... 2-24

SM.E.3 Load Managem ent ............................. 2-25

SM.E.4 System Monitor .............................. 2-25

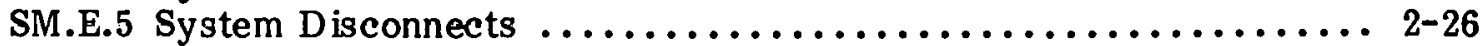




\section{THIS PAGE}

WAS INTENTIONALLY

LEFT BLANK

$2 \cdot 2$ 
SECTION 2.0

PHOTOVOLTAIC SYSTEM

\section{INTRODUCTION}

A photovoltaic (PV) power system is designed to convert solar energy into electrical energy suitable for connection to an application load. To achieve this conversion, various subsystems are required. Figure 2-1 presents an interface diagram for a generalized PV power system that shows various required component subsystems and the different interfaces that exist between them. Performance criteria for other than the system as a whole are discussed in other sections. For completeness, Fig. 2-l includes a thermal subsystem, which may be used for applications requiring combined PV/thermal modules. Energy conversion for system applications can be represented by all or only some of the subsystems noted, which are appropriately designed for the intended application. Similarly, the system design should include a set of requirements for environmental conditions applicable to the installation area, specific constraints associated with the application, nominal design operating conditions to supply the load, and specific goals.

The performance criteria identified in this section relate to the total system and of ten are general; however, more specific criteria will be available as additional information from ongoing photovoltaic system and application studies becomes available. Knowledge derived from experience with installation and operation of experimental facilities should also be included in future revisions. Many system criteria presented here (in terms of the total system) are related to and serve as lead-ins to the more specific subsystem performance criteria. The criteria pertain to the performance of a system regardless of application, unless an application dependence is noted.

Performance criteria relating directly to loads are not included. However, system design must consider potential interface problems with the load as well as possible modification of the load to achieve cost-effectiveness or satisfactory operation.

Performance criteria for the thermal subsystem are restricted to those characteristics unique to a combined PV/thermal system. As defined here, a combined collector is a single collector that provides electrical and thermal energy conversion. The basic design and operation of the thermal part of a combined system may be significantly different from those for a solar thermal system. Performance criteria for those characteristics of the thermal subsystem unaffected by these design and operational differences are identified in interim performance (IPC) documents for solar heating and cooling systems [1, 2] and will not be discussed here. Criteria for the thermal subsystem, especially as it interfaces with the array subsystem, are presently being developed for the combined PV/thermal system. These criteria will be included as they become available.

For those users desiring more information on system design and application analysis, see Refs. 3 through 12, 16, 21, and 27. These publications may be purchased from the National Technical Information Service (NTIS); 5285 Port Royal Road; Springfield, VA 22161; (703) 557-4780. 


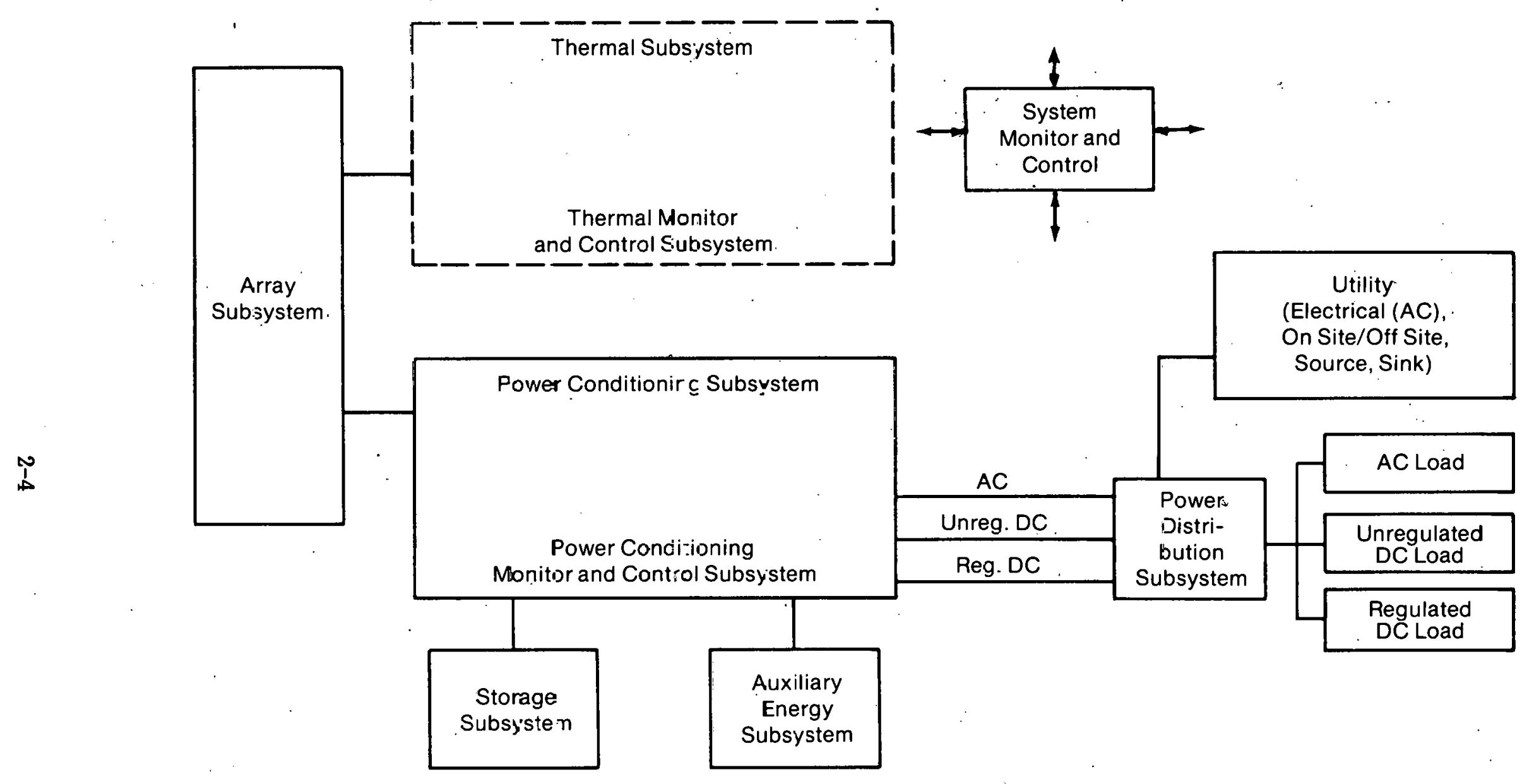

Figure 2-1. Generalized Photovoltaic Power System Interface Diagram

Note: The double-arrowed lines surrounding the System Monitor and Control Box 


\section{SYSTEM PERFORMANCE CRITERIA}

\section{Electrical Attributes}

\section{SY.E.l System Power Performance}

Criterion. The power produced by the PV system, with that available from auxiliary sources, shall be sufficient to meet the peak power needs of the application.

Evaluation. The output power capability of the system, with that available from auxiliary sources, shall be determined by analysis or by experimental measurement at the input side to the load and compared with the power requirements of the load to verify that the needs of the application are met.

Commentary. At the time of installation, system power performance should be verified by experimental measurements to include array current-voltage (I-V) characteristics for known irradiance levels and power output through the power conditioning unit (PCU) for known operating conditions. During the developmental years of photovoltaic systems, the consumer will need to know whether the system operates as the manufacturer says it will. The consumer also will want to know whether or not photovoltaic modules are damaged in shipping, handling, or installation. A current-voltage curve trace for the photovoltaic array at installation will indicate whether any modules have failed electrically. For an array with a high degree of series-paralleling in the module interconnection scheme, a failed module will show up as a "stair-step" on the I-V curve. The PV array I-V characteristic for most systems would be generated upstream of any power conditioning equipment because of the limited input voltage or voltage range of the PCU.

As the commercial PV industry matures and module prices decrease, the added time and expense of checking out a large array may not be warranted unless there is sufficient reason to believe modules have suffered damage. Experimental verification of complete system power performance before installation usually will not be practical. Therefore, analytical methods employing functionally defined subsystems should be used to calculate system power performance $[13,14,15]$. After installation, performance should be verified by operating the system during certain conditions and extrapolating the results to expected future conditions of operation.

It is extremely difficult to ascertain exact total system power performance based on one day's system measurements because of wide variations in weather conditions. As a result, photovoltaic manufacturers design their power systems using solar radiation data that have been averaged monthly and annually over many years.

System power rating is one method of specifying a system power output as well as a way of comparing various systems. The system power rating would be based on the array power characteristics at the Nominal Operating Cell Temperature (NOCT) condition and an irradiance level of $1000 \mathrm{~W} / \mathrm{m}^{2}$. System power rating would then be determined by adjusting the array power for losses associated with the cabling and power conditioning subsystems at the array power level noted above. In the case of PV systems employing an electrical storage subsystem, the system power rating becomes more difficult to define. For this reason, the system power rating will include only the effects of PV power-producing or power-conversion equipment and not of electrical storage devices. 
System power output depends on system configuration and site weather characteristics. The system power level can be determined at each calculation point of the simulation procedure described for system energy performance (see SY.E.2 commentary). A power duration curve shows the number of hours the system is operating at or below a specific power level. Similarly, a power duration curve can also show the annual system energy output at or below a given power level. Figure 2-2 presents an example of this type of curve for a simulated residential system in the Southwest. From the figure, $10 \mathrm{MWh}$ of annual energy output is generated at a power level of $3 \mathrm{~kW}$ or less. The power curve levels out at 9.8-kW peak power output but only $0.2 \mathrm{MWh}$ of energy is generated between a power output of $8.1 \mathrm{~kW}$ and $9.8 \mathrm{~kW}$. The power conditioner assumed in this simulation has an efficiency of 0.95 when operated at an input power level equal to the array NOCT peak power output. Thus, the array NOCT power output of $8.1 \mathrm{~kW}$ (at an irradiance level of $1000 \mathrm{~W} / \mathrm{m}^{2}$ ), modified by the PCU efficiency and assuming zero cabling losses, yields a reasonable system power rating of $7.7 \mathrm{~kW}$. Similar plots for system power performance in the Northeast and Southeast also indicate that the modified array peak power point at NOCT represents a reasonable system power rating.

\section{SY.E.2 System Energy Performance}

Criterion. The energy produced by the PV system, with that drawn from auxiliary sources, shall be sufficient to meet the cumulative energy needs of the application.

Evaluation. The energy output of the PV system on a daily, monthly, seasonal, or annual basis shall be determined by analysis or by experimental measurement. This energy, with that drawn from auxiliary sources, will be compared with that required by the load to verify that the needs of the application are met.

Commentary. Experimental verification of complete PV system energy performance prior to installation is usually not practical. Therefore, analytical methods using subsystems represented by empirical or experimentally determined performance characteristics are used to calculate system energy performance. Hour-by-hour simulations for representative days in each season may be sufficient to determine average monthly and total annual energy supplied by the PV system, resulting in a much lower simulation cost than that for hourly simulations over the entire year.

System energy performance for a utility-connected PV system can be determined analytically according to the following procedure:

- specify system configuration;

- specify load;

- use appropriate weather data (e.g., SOLMET data [17]);

- speclfy array I-V characteristics as functions of irradiance, ambient air temperature, and wind speed;

- specify PCU performance; and

- specify performance of any additional subsystems, as required (e.g., battery pcrformance).

From these data, PV system energy performance can be calculated using SOLCEL-II or other appropriate computer simulation programs $[13,14,15]$. Depending on the accuracy required, less sophisticated and less expensive simulation techniques may be used [16] 


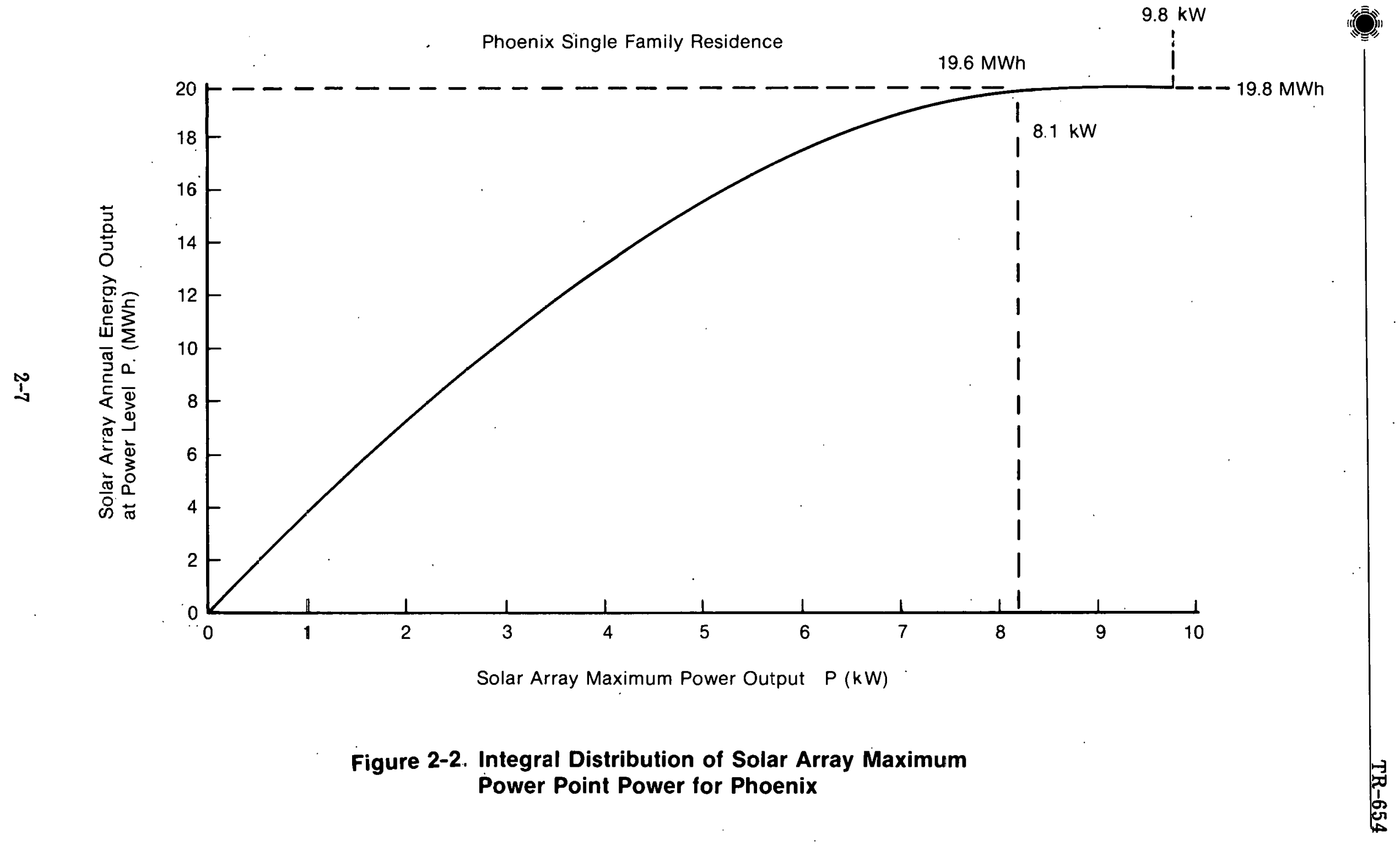


System energy rating has been proposed as one concept whereby different systems serving the same load at the same location can be compared based on a common uniform computational method. However, the specific methodology for system energy rating is still being developed and will be detailed in a future edition of this document.

\section{SY.E.3 Economic Performance}

Criterion. The economics of a PV system shall be provided in terms appropriate to the owner, the application, and the location.

Evaluation. Photovoltaic system economics shall be calculated using methods and inputs appropriate for different kinds of owners and different application characteristics. For utilities, levelized energy cost should be calculated based on revenue requirements. For other owners, net present value of the photovoltaic system is recommended.

Commentary. The use of economic analyses permits enmparisons among system dcsigns and investment opportunities. Economic parameters characteristic of the owner should be used. Utilities generally employ a revenue requirements approach like the one presented in Ref. 18. Other owners generally prefer an after-tax analysis (see Ref. 16 and 20). Values for discount rate, income tax rate, loan parameters, tax credits, electricity escalation, and depreciation parameters specific to the consumer should be used in costing. Estimates are required for PV subsystem costs, installation costs, indirect costs, and annual operation and maintenance (O\&M) costs. For grid-connected systems with nonutility owners, conventional electricity savings should be calculated including the effects of load profile/system output match, sellback rates, storage dispatch, and utility rate structures.

Many of the methods now recommended assume constant average escalation rates, tax rates, inflation rates, discount rates, and electricity rate structures over the analysis period. The uncertainty associated with estimating these parameters may not justify the requirement of more complex, time-varying procedures.

\section{SY.E.4 Array Capability}

Criterion. The capabilities of the array subsystem shall satisfy the needs of the PV system.

Evaluation. The solar energy converted by the array and the energy requirements of the system shall be reviewed and then compared with the design and specifications of the array subsystem to determine compliance.

Commentary. The evaluation of the array capabilities should be based on meeting system design functions and performance requirements using design parametric studies for the climatic region, operating conditions, and load characteristics for which the array is intended. Array performance shulild be based on module electrical performance measurements and, if appropriate, thermal performance.

The array selected depends on the design requirements. It may be selected to meet a peak system output or an annual system output. It may be limited to a maximum size because the roof area or ground area adjacent to the application site is limited. If thèse 
restrictions are not imposed, the array capability is determined from the results of system optimization studies that include performance and cost, and that use the goals established by the system purchaser.

Array orientation is an important input to system performance calculations, affecting system power and energy production. System design optimization calculations should be used to select the optimum array orientation. Arrays can be either fixed, discretely adjustable, or continuously adjustable. Fixed arrays may be limited by the building roof orientation in the case of a retrofit installation. Optimum selection of the fixed tilt angle depends on the load profile throughout the year. For instance, a summer peak demand would result in a lower optimum tilt angle than would a winter peak demand. Previous studies have shown, however, that on a yearly basis, deviations of $+15^{\circ}$ from latitude for the tilt angle and $\pm 20^{\circ}$ east or west of due south may not result in significant decreases in incident energy.

\section{SY.E.5 Power Conditioning Capability}

Criterion. The capabilities of the power conditioning subsystem shall satisfy the needs of the PV system.

Evaluation. The power conditioning requirements of the system shall be reviewed and then compared with the design and specifications of the power conditioning subsystem to determine compliance.

Commentary. The determination of the correct size of the power conditioner will be based on a number of cost/performance trade-offs that depend on the requirements of the application. For most systems, high power conditioner efficiency is of paramount importance to assure maximum system energy output. Because PCU efficiency increases with loading, the smallest power conditioner able to perform the required function should be used so that it operates at a high percentage of full-load rating most of the time.

For systems without storage, which sell back excess energy to the utility grid, the power conditioner is usually selected to have a full-load rating equal to or slightly less than the peak power rating of the array. In systems that include storage, the power conditioner size depends primarily on the application load. For example, in the case of a remote, stand-alone system, the power conditioner can be selected to have a full-load rating considerably lower than the peak array capability. On the other hand, for a PV system used for peaking service, the PCU size may be considerably greater than that of the array peak power.

Power conditioner performance requirements are based on the needs of the application. A grid-connected system may require high quality waveform and low harmonic injection current. Alternatively, a stand-alone system may have considerably less stringent requirements. These requirements and certain economic considerations should be used to select an appropriate power conditioning unit or units.

\section{SY.E.6 Storage Capability}

Criterion. The capabilities of the electrical storage subsystem, if it is included, shall satisfy the needs of the PV system. 
Evaluation. The electrical storage requirements of the system shall be reviewed and then compared with the design and specifications of the electrical storage subsystem to determine compliance.

Commentary. For most stand-alone PV systems, battery storage is included to provide power to the load for periods when the P.V array power output is insufficient to meet the load demand. For applications in which auxiliary power is provided, the question of whether electrical storage is appropriate is determined according to which designs are most effective and suitable, and how they compare economically. When auxiliary power comes from a utility grid, a cost/performance trade-off analysis determines the amount of storage, amount of power to be obtained from the grid, and amount of power to be fed back into the grid (if permitted). With battery storage, the initial capital cost, the round-trip efficiency loss, and the battery maintenance and replacement costs are significant parameters. With utility interconnection, the significant parameters are the utility cost for incoming power and the credit given or value paid by the utility for outgoing power.

\section{SY.E.7 Auxiliary Energy}

Criterion. The capabilities of the auxiliary energy subsystem, if it is included, shall satisfy the needs of the PV system.

Evaluation. The auxiliary energy requirements of the system shall be reviewed and then compared with the design and specifications of the auxiliary energy subsystem to determine compliance.

Commentary. In general, optimum systems designed for nonremote applications include no more than one day's electrical storage and two to three days' thermal storage of the energy needed to satisfy the loads. Therefore, an auxiliary source of energy must be available to satisfy the loads during several days of bad weather. In most cases, the utility serves as such a source, but a small self-contained electrical generator can also be used. The choice becomes one of performance, economics, and availability. For systems providing thermal energy, the combined solar and auxiliary energy source must meet the system thermal design requirements.

\section{SY.E.8 Lightning Protection}

Criterion. PV systems shall be able to sustain induced current surges generated by nearby lightning strikes without excessive damage or significant performance degradation.

Evaluation. Documentation of satisfactory long-term performance under in-use conditions is considered to be the best verification of the protection scheme. When adequate information is not available, appropriate engineering analysis and tests should be considered to check or verify that lightning discharge current has a low impedance path to ground in preference to all high impedance paths.

Commentary. The purpose here is to control the level of damage to minimize system degradation and to prevent premature system failure. The criterion also addresses optical flash and the energy coupled into the system by the array structure and system wiring. However, electromagnetic interference (EMI) is not addressed. 
PV systems are of ten installed on mountaintops and in other locations where the risk of lightning can be severe. It is the responsibility of the designer to determine the level of risk from lightning and the economic considerations appropriate for protection $[23,24,25]$. Primary protection for all system elements is afforded by good grounding practices and protection devices to shunt unwanted transients to ground.

PV arrays often have large surfaces, are fully exposed to lightning, and are difficult to protect by standard methods without affecting system performance. Photovoltaic modules probably will not be designed to withstand direct lightning strikes. However, the field wiring of a large system should be protected so that a lightning strike to a field cable would cause only local damage. Since one method of reducing damage is to minimize the probability of a direct strike, lightning rods or other protective devices should be specified as part of the system where they are warranted.

Array field support structures and collectors should be grounded appropriately. System grounding should be evaluated as part of the system design to assure adequate grounding. Additional information is needed on the response of arrays to lightning, and on optimum means of array protection.

Photovoltaic system power conditioning equipment is especially susceptible to damage from induced surges. Protection of these components does not appear to present problems substantially different from those of conventional electric power systems and structures and, therefore, is covered by present codes and standards. Surge protectors should be specified where required for protection against induced surges, with particular attention to isolating system controls from surge currents. Filters, cable shielding, and surge suppression devices should be used to minimize transient effects and keep those induced on long cable runs from damaging solar cells or other electronics.

These considerations make it necessary to evaluate lightning risks and include protection as an integral part of system design. This ensures that lightning protection devices do not adversely affect other aspects of system performance; e.g., array shadowing by lightning rods adjacent to the array hampers the performance of the system.

In combined PV/thermal systems, designers should always consider the possibility of lightning-induced insulation breakdown resulting in electrical voltages and currents in the thermal subsystem.

The safety of operating personnel should also be considered in the design of lightning protection and is dealt with in SY.S.1.

\section{Mechanical/Struetural Attributes}

\section{SY.M.l Shipping}

Criterion. Packaging of PV system components for shipping shall permit these components to withstand normal hazards incurred during transport without physical damage or loss of functional performance.

Evaluation. Documentation of satisfactory performance using equivalent packaging procedures for shipping PV components shall be used. When adequate information is unavailable, engineering analysis and review of carrier requirements may be used to demonstrate that the shipping container/package can withstand any dropping, loading, 
vibration, and environmental stresses. Appropriate tests may be developed and used for evaluation compliance.

Commentary. Breakage and damage resulting from shipment is a major problem. Proper package design must consider the properties (ruggedness) of the equipment being shipped. Standards exist that apply to different modes of transportation as well as different uses; i.e., domestic or export, governmental or commercial. However, in all cases, the burden for safe packaging and shipment lies primarily with the manufacturer, not with the carrier.

In general, common carriers require only that the shipping container be made of materials that afford safe handling, reasonable and proper protection of contents, and protection against damage to other freight equipment. It should be noted that the degree to which shipping and packaging do not conform to the carriers' stated and published packaging requirements can result in the carrier levying speclal rales urid cliariges.

Commercial equipment has several levels of packaging. The first or "commercial standard" is cardboard and strapping. The next level is reinforced cardboard with strapping connected through a pallet. The next level is termed export boxing and is designed to survive shipboard handling and above-deck storage. The package is typically made from marine-grade plywood into a single, palletized shipping box lined with polyethylene with glued seams. The top (also marine-grade plywood) is sealed with water-resistant glue and then nailed. In this last case, the product inside must be wrapped and protected. Dessicant is not used because in a sealed environment it quickly absorbs water. After reaching its limit, it creates rather than eliminates a moisture problem.

Photovoltaic modules are particularly vulnerable to physical damage and should be adequately protected within the shipping container by liners, partitions, wrappers, excelsior, or other packing material. Specific stresses that occur during shipment include dropping (shock), loading (containers stacked on top of it), vibration, and environmental elements.

Standardized tests for the above can be found in the literature (scc, c.g., Federal Test Method S'I' No. 101 B).

\section{SY.M.2 Handling}

Criterion. Components of PV systems shall withslund, without physical damagc or loss of functional performance, the stresses that accompany handling in accordance with the manufacturer's prescribed handling procedures and precautions.

Evaluation. Documentation of satisfactory performance is needed after in-use liutd= Iing and installation of equivulent components. When adcquale information is unnvnilable, engineering analysis and review of the mechanical design, specifications, and manufacturer's procedures relative to appropriate handling, storage, and installation of the application shall indicate conformance.

Commentary. Handling of equipment by nontèchnical personnel before und during installation must be considered during the mechanical design phase. Except for components directly exposed to the outside environment, physical stresses induced during transport and handling are generally substantially greater than will be applied during system operation. 
Equipment hardware items (components, elements of subsystems, and subsystems) must be built to meet installation stresses as well as those from shipping and handling. Ruggedness needs to be designed into the equipment. Components installed in large systems may be exposed to less stress than those installed in small systems because of higher levels of skill of installers for the former. On the other hand, equipment familiar to solar installers might be treated with less care than equipment with which they are less familiar.

\section{Safety Attributes}

\section{SY.S.I System Safety}

Criterion. The design, construction, operation, and maintenance of the PV system shall be in accordance with applicable safety codes and standards and regulatory requirem ents.

Evaluation. Review the design, the construction schedule and procedures, and the operational procedures along with system design criteria to show conformance with applicable safety codes and standards and with regulatory requirements.

Commentary. Safety reviews of system design, construction, and operating procedures is an ongoing activity. It is wise to start this practice early in the design phase so that constant review will ensure a safe system with minimal, if any, construction or operational safety problems. If the application is large enough and the construction schedule tight, it may be advisable to hire a safety consultant to independently review the safety aspects of the design, installation, and operation.

Designed-in safety involves following code requirements, using "code-approved" (by independent testing laboratories) equipment, and having "inspected" installations. The National Electrical Code is a prime example, although other National Fire Protection Association (NFPA) codes are important, particularly when considering insurance requirements and related concerns of equipment flammability and toxic gas production. Standards exist for testing building materials-UL 263 (ANSI 2.1), "Fire Tests of Building Construction and Materials," and UL 790, "Tests for Fire Resistance of Roof Covering Materials."

Personnel safety is largely dictated by the Occupational Safety and Health Administration (OSHA) regulations: These regulations apply to any construction site-residential through central station-although only commercial-industrial facilities fall under the operating personnel safety requirements; residences are exempt.

\section{SY.S.2 System Grounding}

Criterion. The maximum cell string voltage above earth ground of the PV system shall be within the voltage isolation capabilities of the PV module and other subsystem components during installation, operation, and maintenance.

Evaluation. Wiring plans, drawings, specifications, and calculations must be reviewed to determine proper placement and sizing of grounding conductors to:

- limit the voltage to ground; 
- prevent excessive voltages due to lightning, line surges, unintentional contact with higher voltage lines, or induced voltages from adjacent circuits or static charges; and

- facilitate the clearing of ground faults by circuit protective equipment.

This review shall indicate conformance to this criterion. The sizing of a grounding conductor shall be sufficient to carry the expected fault current indefinitely or until the circuit interrupting devices (if present) act to clear the circuit.

Commentary. System grounding stabilizes voltages and thereby prevents excessive stressing of insulation and facilitates the clearing of protective devices. Because of the many possible configurations of a photovoltaic system, one cannot simply require a grounded subsystem, such as the array, without complete knowledge of the grounding details assoriated with the other subsystems and their components, such as the diesel generator, the utility interface, or battery storage.

Since having more than one system ground may have detrimental effects on overall system performance and personnel safety, conformalice to this criterion must begin at the system level and encompass all subsystem components. The grounding method must be compatible with durability and reliability requirements.

\section{SY.S.3 Equipment Grounding}

Criterion. Electrical equipment structures shall be electrically connected to earth by a permanent and continuous path.

Evaluation. $\Lambda$ review of wiring plans, drawings, specifications, and calculations (beginning at the system level and continuing to the equipment level) to determine proper placement and sizing of grounding conductors shall indicate conformance to this criterion. The sizing of a grounding conductor shall be sufflcient to carry the expected fault current indefinitely or until the circuit interrupting devicus (if present) act to clear thc circuit.

Commentary. Grounding of electrical equipment structures, which includes all non-current-carrying metal frames, supports, and enclosures for circuit conductors and equipment, contributes to reliable ground fault protection by providing adequate conductors for the flow of ground fault current during line-to-ground faults. The equipment grounding conductor is separate from the system ground (return) conductor. Equipment grounding systems, consisting of interconnected networks of equipment grounding conductors, perform two basic functions:

- they limit the shock voltage on non-current-carrying metal parts and enclosures for conductors, equipment, and devices to a safe value when ground faults occur; and

- they prevent damage to the installation by conducting ground fault currents of adequate magnitude to assure fast operation of circuit protective equipment.

To ensure the continuous performance of these basic functions, each equipment grounding conductor and all connections in every ground fault current path must meet all of the following requirements: 
- Conductors and connections must have sufficiently low impedance to (1) limit the shock voltage on non-current-carrying metal parts and enclosures to a safe value during ground fault and (2) conduct adequate ground fault current to assure fast operation of circuit protective equipment.

- Conductors and connections must have adequate short-time current capacity to conduct fault currents likely to be imposed on them for the time required to open circuit protective equipment without being damaged by overheating.

- Conductors and connections must have adequate mechanical strength (or protection) to survive without becoming loose or breaking.

- Conductor and connector materials must not deteriorate by corrosion.

- Conductor connections must be tight and remain tight to ensure the integrity of equipment grounding networks throughout the life of the electrical system.

Equipment grounding connectors and connections must be arranged so that current will only flow through them during ground faults. If grounded circuit conductors are incorrectly grounded or bonded to equipment grounding conductors, there may be an excessive flow of normal load current in the equipment grounding system that could lead to unwarranted interruptions in the operation of the PV system.

\section{SY.S.4 Electrical Interrupts}

Criterion. The system shall be provided with a means to interrupt current between the subsystems.

Evaluation. Review electrical connection drawings and equipment specifications to, determine compliance with electrical code requirements.

Commentary. The electrical subsystems must be safe when personnel check and service them. The safety scheme must be able to isolate and/or interrupt the current between the subsystems in case of a fault. The National Electric Code (NEC) provides requirements for electrical systems but does not address PV systems. Since the insulation system of the PV array is considered part of the overall insulation system, it requires further evaluation and study.

\section{SY.S.5 Fire Safety}

Criterion. The materials used in electrical subsystems shall comply with applicable codes concerning flammability, flame spread, and release of excessive levels of smoke or toxic gases.

Evaluation. Review equipment specifications or test results to determine compliance with applicable codes concerning flammability, flame spread, and release of excessive smoke or toxic gases.

Commentary. Fire safety requirements and tests, such as those developed by Underwriters Laboratories (UL) and the American Society of Testing Materials (ASTM) may verify fire-safe performance. The company underwriting the insurance coverage may provide valuable assistance in ensuring that all safety requirements are met. 


\section{SY.S.6 Installation Plan}

Criterion. The system installation shall minimize safety hazards to installation personnel.

Evaluation. The installation plan shall include clear and complete specified installation procedures that identify any unusual hazards. OSHA regulations should be observed in determining acceptable procedures.

Commentary. Because most installers are unfamiliar with PV systems, the system designer has a greater responsibility to provide adequate instructions. Since the system may present hazards when only partially assembled, the designer must plan the installation activities to ensure that hazardous conditions do not exist at any time; e.g., by scheduling the installation of fault protection components as soon as possible. Specifically, the designer should remember that photovoltaic modules are energized when illuminated whether or not they are connected into the system, which may be easily forgotten by installers. Instructions should detail safe handling procedures for PV modules during installation, and modules should be designed with nonhazardous opencircuit voltage, or with integral protectlon, such us short-circuiting jumpers to he. removed only when installation is complete.

Structural hazards may exist if not all structural elements are in place before array modules are mounted. If the array module is a structural element, the designer should consider whether the array design will meet structural criteria at all assembly stages.

Lightning and other fault protection elements of the system design should be installed as early as possible, so that the other elements are fully protected when installed.

Particular hazaras exist with the installation of storage batteries, because of their high fault current capability and the possibility of chemical burns from the electrolyte that may leak from cells damaged in shipping. Existing codes and standards for large storage battery installations include provisions for protecting installers against these hazards. These provisions should be incorporated into system installation planning and instructions.

On-site work should be planned so that simultaneously occurring activities do not interfere with each other and create safety hazards. Installers' skill level requirements shoüld be specified as a part of the installation plan.

\section{SY.S.7 Burn Hazards}

Critcrion. The casing, of the system, individual subsystems, and all other exposed parts shall not become so hot as to present a burn hazard tu per'sonnel working nival the unit.

Evaluation. A review of design drawings to verify that adequate surface cooling has been provided will indicate conformance with the criterion.

Commentary. If required, the subsystems should be provided with internal cooling fans and proper cooling air flow paths in order to maintain safe surface temperatures for maintenance personnel and other workers. Where cooling may be impractical, burn hazard areas should be indicated. 


\title{
Installation, Operation, and Maintenanc. Attributes
}

\section{SY.I.1 Installation, Operation, and Maintenance Manual}

Criterion. Guidance for the safe and successful installation, operation, and maintenance of a PV system and its associated subsystems shall be provided in one or more manuals.

Evaluation. A review of the manual(s) to assure that information necessary to install, operate, and maintain the system, or subsystem, in a safe and reliable manner is provided shall indicate conformance to this criterion. The following issues should be addressed:

\author{
Unpacking Procedure \\ Site Preparation or Special Considerations \\ Safe Installation Practices \\ Specifications Sheet \\ Theory of Operation \\ Operating Procedures \\ Safe Operating Practices \\ Start-Up, Check-Out, and Shut-Down Procedures \\ Maintenance Inspections \\ Inspection Intervals \\ Maintenance/Servicing Procedures \\ Parts List Identification \\ Replacement Considerations \\ Warranty Information
}

Commentary. (See SY.S.6.) Optimum system performance and safe operation depend on the proper installation of the system. Thus, installation information is of prime.importance. Installation instructions should detail safe handling and assembly procedures for system components. Since the system may present hazards when only partially assembled, installation instructions should caution against possible hazards.

In most cases, the daily operation of the photovoltaic system will be fully automatic and require no special attention. However, start-up and shut-down procedure instructions are required for user service. Start-up and shut-down procedures should be indicated on a simple label. Indicators of correct system operation (i.e., indicator lights and operation test points) should be mentioned. Additional specification of anticipated system operating conditions at system access monitoring points are required to facilitate operational checks and troubleshooting.

Larger equipment, such as that used for intermediate load center or central power applications, shall include a minimum of two copies of current installation, operation, and maintenance manuals. Manufacturers of commercial or consumer equipment suitable for residential use shall make current operation and maintenance manuals available to qualified repair personnel.

A block diagram that indicates how the entire system functions shall be constructed with a schematic diagram of each block highlighting the main power or electrical flow. If any part of the circuit is unusual, a partial, simplified schematic should be provided to clarify the operation. Inputs, outputs, and test points should be clearly specified. 
Comprehensive maintenance instructions shall be provided to the system owner that include plans for maintaining the system for its service life. Warnings against hazards that can arise during the maintenance of the system should be highlighted along with a description of precautions to take to avoid these hazards.

The manual shall list all parts of the system by subsystem according to shape, dimension, material, weight, function, and performance characteristics. The manual shall include sequence of operation and flow and wiring diagrams. It shall include a tabulation of those performance requirements that are dependent upon specific maintenance procedures. The maintenance procedures, including ordinary, preventive, and minor repairs, shall be cross-referenced for all subsystems and organized into a maintenance schedule. The manual shall describe operation procedures for all parts of the system. Similarly, it should include an outline of troubleshooting procedures if system failure or degraded performance occur. The outline should list system failure symptoms and probable causes, along with a concise description of the troubleshooting procedure. Equipment and the number of people required for the troubleshooting should be described. How and where electrical readings are to be taken should be clearly indicated by text, photographs, and drawings. Once the failed system/component is isolated, procedures for repair or replacement should be described.

The manual shall include all ordinary maintenance, preventive maintenance and minor: repair work, and projections for equipment replacement. It should also include a format for keeping maintenance records-type of maintenance, time required to perform the maintenance, and other pertinent data.

Field inspections and maintenance operations require handling electrically active elements during daylight hours. A manual explaining special safety rules and regulations for cleaning, replacing, and inspecting equipment shall be written. It is important that field personnel understand these procedures.

The manufacturer shall state the equipment warranty periud and specify which costs are covered, such as parts, labor, and travel and per diem for service personnel. Service. availability shall be stated.

The above comments apply for all portions of the photovoltaic system and subsystems. Special considerations for each subsystem shall be detailed in their respective installation/operation/maintenance sections.

\section{SY.I.2 System Maintainability}

Criterion. A mäintenance muluul containing safc and easy methonds nf servicing system and subsystems using a minimum of special equipment should be provided. Hazard warning labels should be included on those items or areas where potential problems exist.

Evaluation. A review of the maintenance manual and applicable documents and drawings should be made. Attention should be given to maintenance intervals and procedures as well as service procedures. It also is important to verify that appropriate sensors or access for sensors have been provided for inspecting and monitoring essential parameters.

Commentary. Maintenance and servicing of the PV system is required to provide for optimum and safe system operation. Some systems contain toxic or combustible materi- 
als (e.g., lead-acid batteries), or both, that could poison or burn maintenance personnel or cause fires or explosions when repairs involve soldering or welding. Electrical isolation of the system is mandatory to minimize electrical shock to maintenance personnel.

Parts, components, and equipment required for service, repair, or replacement shall be commercially available through the manufacturer or supplier. Parts replacement may vary from discrete components to plug-in circuit boards. In many instances, modular circuit boards are offered as replacements because of the proprietary nature of circuit design, and of ten cost less than removing the module and replacing individual components. The industry does not now have a specified time period during which replacement parts are offered and, thus, should adopt a time period that will provide for system operation over its design life.

Adequately located test sensors will permit system monitoring and expedite maintenance and repair. Typical test sensors include voltage, current, power, and temperature transducers and watt-hour meters. Specific measurements include array temperatures, DC input voltage and current, DC input power, AC output voltage, inverter output in watthours and VAR-hours and transformer output in watt-hours and VAR-hours. In addition, reference cell temperature and short-circuit cell current could be measured from either an in-place reference cell or portable test instrument. A digital voltmeter and X-Y plotter combination may also be used to measure and plot the I-V characteristic of the array. The amount and requirement for system monitoring sensors and the necessity for recording equipment vary with the system size and the maturity of system design. Larger systems and initial system installations require more monitoring capability.

For ease in service, problems must be diagnosed quickly, defective parts replaced easily, and operation verified accurately. A proper manual is essential. In residential equipment, a manual should be available to qualified service personnel. In larger installations, such as intermediate load center and central station applications, a manual should be available with the equipment. It should include simplified block diagrams, complete schematic designs, and significant signal flow field test procedures.

Where possible, the unit should use plug-in modules that can be replaced without extensive readjustment. Each subassembly should be documented, test points identified and service checks defined. Substitution of parts or components should not be difficult. Repair time can be reduced if substitute boards or modules are stocked by the maintenance contractor with the number of functional boards or modules kept to a minimum, consistent with cost requirements. In cases of PV modules or batteries, it is particularly appropriate to ensure both safety and rapid interchange of the replacement parts involved. Accessibility is also an important part of maintainability and is dealt with in SY.I.3.

These comments apply for all portions of the photovoltaic system and subsystems. Special considerations for each subsystem are detailed in their respective installation/operation/maintenance sections.

\section{SY.I.3 Access for System Maintenance}

Criterion. All items of equipment and system components that may require periodic examination for adjustment, servicing, and maintenance should be accessible for inspection, service, repair, removal, and replacement. 
Evaluation. Drawings and specifications shall be reviewed and analyzed to determine if the system design will facilitate effective maintenance. The clear working space shall be checked against NEC requirements.

Commentary. Accessibility for system maintenance and servicing is required for each of the different PV subsystems. The degree of accessibility may vary from subsystem to subsystem.

For photovoltaic modules, concentrator receivers, optics, tracking controls, arrays, and their appurtenances, maintenance entails routine periodic inspection, servicing, washing, and removal or replacement. Maintenance should be performed without dismantling any adjoining major pieces of equipment or structural elements. Individual modules or panels should be replaceable or repairable with minimal disturbance of modules or panels in the array. Modules, concentrator optics, panels, und arrays should bc designed to facilitate easy cleaning of optical surfaces. (See Sec. 3, criteria MO.M.9 (Optical Surfaces Soiling) and MO.M.10 (Cleaning Tolerance).) Some equipment might be designcd so that sequential installation is necessary, which could make it very difficult to replace an individual panel without disturbing the entire array.

Access roads may be needed for the array field. The type of road needed will depend on the way in which maintenance will be performed.

For electronic components where "live" parts are exposed for servicing, inspection, removal, and replacement within the array field, the minimum clear working space shall not be less than in Table 2-1.

Table 2-1. MINIMUM CLEAR WORKING SPACE ${ }^{2}$

\begin{tabular}{ccc}
\hline \multicolumn{2}{c}{$\begin{array}{c}\text { DC Voltage to Ground } \\
\text { (Volts) }\end{array}$} & Minimum Horizontal Spacing \\
\cline { 1 - 2 } More 'Than & Up to and Including & meters (feet) \\
\hline 0 & 30 & Not specified \\
30 & 150 & $0.91(3)$ \\
150 & 600 & $1.22(4)$ \\
600 & 2500 & $1.52(5)$ \\
\hline a From NEC. &
\end{tabular}

The information in Table 2-1 may not be applicable to central station use. In an array where the contacts of the plug and receptacle are not accessible to contact, the working spacings in the table generally will not be required.

Test access should include connectors for auxiliary test equipment if the level of maintenance warrants them. In simple cases, a VOM or more complex equipment may be used to facilitate rapid service with minimal cost.

The safety of service personnel should also be considered. The use of warning labels and panel interlocks should mitigate or eliminate any dangerous conditions. See SY.S.1 (System Safety) for general system safety considerations. 


\section{SY.j.4 Insurability}

Criterion. The design, construction, and operation of the PV system shall be in accordance with applicable insurance requirements.

Evaluation. Review of the applicable insurances and the system design, construction plans and procedures, and operating procedures, shall indicate conformance to this criterion.

Commentary. Various insurance companies place requirements on system design, construction, and operation [21]. These requirements come from the individual insurance companies' risk assessment and field data. The type of insurances involved are typically construction insurance, design or "trade-off" insurance, and owner's insurance.

Construction insurance typically specifies, based on the size and type of installation, the precautions and equipment that must be provided before and during installation. Such precautions are usually access control requirements (fencing to keep out intruders but allow fire equipment in), and work control requirements (safety helmets, the buddy system, etc.). OSHA requirements also affect work control requirements.

Design or "trade-off" insurance is an option where the cost of modifying equipment to make it more rugged is traded for the cost of insuring it against the possibility of a damaging situation occurring. For example, if a photovoltaic module were.designed to survive $31 \mathrm{~mm}$ ( 1.25 in.) hail and the module were to be installed in a region where $50 \mathrm{~mm}(2$ in.) hail was prevalent, the cost of redesigning the module for $50 \mathrm{~mm}$ hail would be traded off against the present worth of insurance covering damages to the array should $50 \mathrm{~mm}$ hail occur in that region. The lower cost option would then be used in the system design.

Finally, owner's insurance covers the owner's responsibilities with the operation of the system. Installation design requirements included are particularly for a large installation. Examples of this are fire coverage, protection, access control, maintenance facility fire requirements, and operational policies.

\section{SY.I.5 Regulatory Requirements}

Criterion. The PV system and all its components and subsystems shall meet all applicable local regulatory requirements for construction, installation, and operation.

Evaluation. Review of applicable regulations and system design, construction plans and procedures, and operating procedures shall indicate conformance to this criterion.

Commentary. The major regulatory constraints on PV systems are the building codes adopted by each jurisdiction in the United States [21].

A building code is a legal document which sets forth requirements to protect the public health, safety, and general welfare as they relate to the construction and occupancy of buildings and structures. The building code development process in the United States is quite complex. Building codes are normally enacted into law by local governments exercising the authority delegated to them for this purpose by the individual states. There are about 14,000 jurisdictions that issue building permits in the United States. Thus, there is a considerable diversity of substantive provisions among the thousands of locally 
enacted codes, even though three-quarters of these codes are based on one the four model codes.

Except in some of the larger cities, drafting of building codes in the United States is generally accomplished by the Model Code Association and allied groups. Three of the model code organizations are regionally located and their membership is controlled by local governm ent code officials:

- BOCA - Building Officials and Code Administrators International, Inc. (Basic Building Code)

- ICBO - International Conference of Building Officials (Uniform Building Code)

- SBCC - Southern Building Code Congress International, Inc. (Standard Building Code).

The responsibility for the fourth model code, the National Building Code, lies with the National Conference on Building Codes and Standards (NCSBCS) for revision and update using the American National Standards Institute (ANSI) consensus procedures.

A recommended model code [22] for the use of solar heating, cooling, and hot water systems has been drafted and is currently under review. This document covers new solarrelated aspects of existing provisions pertaining primarily to structural, electrical, and fire codes.

\section{Building and Site Attributes}

\section{SY.B.I Shading of the Array Field}

Criterion. The location and orientation of the array field shall be such that the output energy loss resulting from shading-by trees, external structures or appendages, or other arrays within the field-does not exceed the amount allowed for in the system design.

Evaluation. Calculations and array installation drawings shall be reviewed to determine areas of shading by objects such as mechanical equipment, chimneys, vents, trees, buildings, or other portions of the array field. 'I'he design provisions for counteracting the effects of array shadowing should be reviewed and analyzed to determine their ability to limit localized "hot-spot" heating and optimize the annual electrical energy output.

Commentary. Data are available for calculating solar azimuth and elevation angle as a function of site latitude, longitude, and time of day $[19,26]$. In some cases, the analysis of complex shadowing patterns may require a photographic investigation of the shading through the úse of a scale model of the installation and a collimated light beam. Sophisticated computer codes are also available to analyze complex shadowing geometries.

Consideration shall be given to the site latitude, the height of nearby objects above the collector, the azimuth angle of the objects relative to the collector, and the cut-off angles at which solar energy can no longer be efficiently collected. 
Where shadowing occurs, efforts should be made to minimize this factor on the array annual energy output. The effects of localized "hot-spot" heating due to shadowing should be considered in the design.

When arrays are mounted on structures that move to track the sun, complicated arrayto-array shadowing patterns can occur that vary throughout the year. In general, detailed analyses are required to determine the shape that the shadows produce on the affected arrays, and the overall effect of the shadowing on annual system output.

\section{SY.B.2 Environmental Impact}

Criterion. The construction and operation of a PV power system shall not produce an unacceptable environmental eff ect on the immediate natural environment.

Evaluation. Plans and specifications shall be reviewed to ensure conformance with appropriate environmental regulations.

Commentary. Each PV power facility construction project requires its own set of permits, approvals, and certifications to satisfy environmental regulations [21]. Variations in these requirements occur according to differences in the types and locations of the projects. The National Environmental Policy Act (NEPA) may require that an environmental impact statement (EIS) be filed by the responsible federal agency for any project rcquiring a federal license, permit, or certification and for all controversial projects. Under NEPA, only federal agencies are required to file an EIS. However, laws similar to NEPA have been enacted in many states, so that many state, county, and city agencies have similar requirements.

The environmental assessment report, prepared by the applicant or a contractor, should address potential environmental effects that might result during the construction and operation of the facility. The report should include a discussion of the unavoidable effects as well as mitigation of impacts and should consider potential impacts on each of the following: geology and soils, surface and ground water, climate and air quality, noise, biology, land use, socioeconomics, traffic, aesthetics, cultural resources, and public acceptability.

\section{SY.B.3 Siting}

Criterion. The PV system shall be compatible with the site characteristics.

Evaluation. The PV system design, layout, and installation schedule and procedures shall be reviewed to determine conformance with the system's design criteria and environmental impast statement, assessment, or report.

Commentary. Proper design integration, considering site preparation and system requirements, can save time and money and reduce frustration through a smooth installation schedule.

Many factors affect site preparation. The first is the site (geological) survey. This survey establishes the soil conditions which, in turn, dictate the foundation design. Expansive soil, if not discovered early, could cause problems with array settling and upheaval. If a sitc has mineral springs, a dewatering system of pumps and drains may be required to 
control erosion or array settling. In conjunction with site selection, an environmental survey is also made. Depending on the application size as well as other considerations, an environmental impact report may be required (see SY.B.2). This may be a statement (if a small application), an assessment (if an environmental problem exists), or a report (if a large application and/or many problems exist).

Once the site is selected, environmental concerns established, and the system configured, the effect of site preparations on the construction schedule must be considered. This is especially true as the application sizes get bigger and require more construction labor as well as better field coordination.

One important aspect of the construction planning phase is insurance (see SY.I.4). Construction insurance and owner's insurance specify certain site requirements before construction begins (e.g., fire protection tanks, hydrants, extinguishers, etc., and access control) and af ter the system begins operation (e.g., additional fire protection equipment and operator emergency procedural controls). The system location and safety concerng for passersby and observers will dictate the level of site isolation and protection required; e.g., 2.4-m (8-ft) chain-link fence, guards, electronic surveillance, etc. An additional aspect of construction planning, especially for larger applications, involves the question of whether to use temporary buildings for construction or erect permanent buildings using them for construction purposes first and later converting them to their final use. Similarly, matters concerning services such as water, sewers, etc., must also be considered.

\section{SYSTEM MONITOR AND CONTROL PERFORMANCE CRITERIA}

\section{Electrical Attributes}

\section{SM.B.1 System Monitor and Control Capability}

Criterion. The capabilities of the system monitor and control shall satisfy the needs of the PV system.

Evaluation. The monitor and control requirements of the system shall be reviewed and then compared with the design and specifications of the system monitor and control to determine compliance.

Commentary. A PV power system can satisfy the system loads in a number of different ways. Energy collected by the solar arrays can be sent to satisfy loads directly. Loads can also be satisfied by energy supplied by a battery, or from an auxiliary energy source (utility, diesel generator, etc.). If the system includes a battery, it can be charged either by diverting some of the array energy from the loads, or it can be charged directly from the auxiliary energy source. If the system has no storage, then excess array entergy can be sent to the utility for its use. When the system is designed, the optimum use of all subsystems must be considered relative to the goals set forth for overall system performance, and the system control must be designed to implement this strategy.

\section{SM.E.2 Power Flow Control}

Criterion. The system monitor and control shall determine and effect the flow of power through the system to implement the strategy required by the system design. 
Evaluation. The required control strategy shall be compared with the drawings and specifications for the monitor and control circuitry to determine compliance.

Commentary. The energy produced at the array must be used optimally to maximize system efficiency and make the greatest use of the energy produced. Most solar energy systems include a number of options with regard to energy and power flow because of the potential interactions between energy produced at the array, energy stored, energy required by the on-site loads, and auxiliary energy available at the utility. In general, computer simulations of annual system operation are used to compare the many possible strategies and to choose the one best for the application. The system hardware-in particular, the monitor and control circuitry-must implement the strategy selected.

\section{SM.E.3 Load Management}

Criterion. If load management is used, the system monitor and control shall coordinate the level of system output and the magnitude of the loads in accordance with the system strategy chosen.

Evaluation. The system operating strategy shall be compared with the schematic drawings and specifications for the system monitor and control circuitry to determine compliance.

Commentary. For some applications, the control of on-site loads by the PV system is permissible and provides a means to effect an optimum match between system output and on-site loading on a real-time basis, minimizing the need for auxiliary energy. Where such a strategy is used, the monitor and control circuitry must sense the output capability of the system and exert control over the load so that an optimum match is maintained. When the on-site load comprises a number of diverse loads, the monitor and control circuitry must be provided with a strategy of priorities so that loads are shed and picked up in the proper order of priority as system output varies.

\section{SM.E.4 System Monitor}

Criterion. The system monitor and control shall determine the operating characteristics of the system and initiate necessary protective actions in case abnormal conditions occur.

Evaluation. Drawings and specifications for monitor and control circuitry shall be reviewed to determine that instrumentation has been provided for the measurement, indication, and recording of all system characteristics deemed necessary to monitor system operation and effect protective action under abnormal conditions.

Commentary. The PV system should be self-operating. During conditions of normal operation, the monitor and control subsystem should monitor appropriate parameters for inputs to the control circuits and display and record parameters, as necessary, to facilitate normal system operation, maintenance, and repair. The system monitor should also sense abnormal conditions and, when necessary, initiate appropriate corrective or protective actions and indicate the need for servicing. 


\section{SM.E.5 System Disconnects}

Criterion. The system monitor and control shall effect a visible (positive) disconnect between the system and its on-site loads and utility interconnection.

Evaluation. Schematic drawings and specifications shall be reviewed to verify that a positive disconnect is located at the system output and that the monitor and control circuitry can open the disconnect when necessary.

Commentary. Conditions may exist within the system, the on-site loads, or the utility grid where the PV system must be disconnected from the utility and loads. In some cases, this may be done for the protection of the system, or for the protection of the on-site loads, the utility, or its personnel. When repair or maintenance work must be done on the system, a visible (positive) disconnect must be effected to prevent utility line voltage from being present in the system. Additional disconnects may be necessary to protect. personnel from electrical hazards within the PV system (see SY.S.4). Code requirements will vary throughout the country, and some muy reyuil'e the existence of a visible (positive) disconnect between the PV system and the on-site load and utility tie. 


\section{REFERENCES}

1. U.S. National Bureau of Standards. Interim Performance Criteria for Solar Heating and Cooling Systems in Commercial Buildings. NBSIR 76-1187. Washington, DC: U.S. NBS; November 1976.

2. U.S. National Bureau of Standards. Performance Criteria for Solar Heating and Cooling Systems in Residential Buildings. NBSIR 80-2095. Washington, DC: U.S. NBS; July 1980.

3. Westinghouse Electric Corporation. Conceptual Design and System Analysis of Photovoltaic Power Systems. 3 volumes. Report No. ALO-2744-13. Westinghouse Electric Corp.; March 1977.

4. General Electric Company, Space Division. Conceptual Design and Systems Analysis of Photovoltaic Systems, Final Report. 3. volumes. Report No. ALO-3686-14. G E Company; March 1977.

5. Spectrolab, Inc. Photovoltaic Systems Concept Study, Final Report. 5 volumes. Report No. ALO-2748-12. Spectrolab, Inc.; April 1977.

6. Buerger, E. J.; et al., General Electric Space Division. Regional Conceptual Design and Analysis Studies for Residential Photovoltaic Systems; .Vols. I \& II. SAND787039. Albuquerque, NM: Sandia Laboratories; January 1979.

7. Pittman, P. F.; et al., Westinghouse R\&D Center. Regional Conceptual Design and Analysis Studies for Residential Photovoltaic Systems; Vols. I \& II. SAND78-7040. Albuquerque, NM: Sandia Laboratories; July 1979.

8. Mengel, R. W.; et al., BDM Corporation. Photovoltaic Applications Definition and Photovoltaic Systems Definition Study in the Agricultural Sector. SAND79-7018, Albuquerque, NM: Sandia Laboratories; forthcoming.

9. Whisnant, R. A.; et al., Application Analysis and Photovoltaic System Conceptual Designs for Service/Commercial/Institutional and Industrial Sectors. SAND79-7020. Albuquerque, NM: Sandia Jahnratories; Scptember 1979.

10. Ruzek, J. B.; Stolte, W. J., Bechtel National, Inc. Requirements Definition and Preliminary Design of a Photovoltaic Central Power Station Experimental Test Facility; Vols, I, II, and III. SAND79-7012. Albuquerque, NM: Sandia Laboratories; June 1979.

11. O'Brien G.; et al., General Electric Space Division. Requirements Definition and Preliminary Design of a Photovoltaic Central Power Station Experimental Test Facility; Vols. I, II, III. SAND79-7022. Albuquerque, NM: Sandia Laboratories; June 1979.

12. Bechtel National, Inc. Terrestial Central Station Array Life-Cycle Analysis Support Study. Prepared for the Jet Propulsion Laboratory under contract number 954848; August 1978. 
13. Evans, D. L.; et al., Arizona State University. Simulation and Simplified Design Studies of Photovoltaic Systems. SAND80-7013. Albuquerque, NM: Sandia Laboratories; October 1980.

14. Hoover, E. R. SOLCEL-II: An Improved Photovoltaic System Analysis Program. SAND79-1785. Albuquerque, NM: Sandia Laboratories; forthcoming.

15. Solar Energy Laboratory. TRANSYS-A Transient Simulation Program. Madison, WI: University of Wisconsin.

16. Young, S.; et al., Science Applications, Inc. Design Handbook for Photovoltaic Power Systems. Albuquerque, NM: Sandia Laboratories (forthcoming).

17. U.S. Department of Commerce. SOLMET, Vol. I-User's Manual, U.S. DOE Contract No. E(49-26)-1041. Ashville, NC; 1977.

18. Doane, J. W.; et al. The Cost of Energy from Utility-Owned Solar Electric Systems. ERDA/JPL-10 12-76/3. Washington DC: U.S. Energy Research and Development Administration; June 1976.

19. Walraven, R. "Calculating the Position of the Sun." Solar Energy. Vol. 20: pp. 393-397; 1978.

20. Perino, A. M. A Methodology for Determining the Economic Feasibility of Residential or Commercial Solar Energy Systems. SAND78-0931. Albuquerque, NM: Sandia Laboratories; January 1979.

21. Watkins, G.A.; et al., Battelle-Columbus Laboratories. Photovoltaic Institutional Issues Study. SAND79-7054. Albuquerque, NM: Sandia Laboratories; April 1980.

22. Recommended Requirements to Code Officials for Solar Heating, Cooling, and Hot Water Systems. Available from the Council of American Building Officials, Suite 560, 2233 Wisconsin Ave. NW, Washington, DC 20005.

23. World Meteorological Organization. World Distribution of Thunderstorm Days.

24. Fowles, H.; et al., Mission Research Corporation. Transient Effects from Lightning, Vols. I and II, SAND79-7051. Albuquerque, NM: Sandia Laobratories; January 1980.

25. U.S. Department of Commerce Weather Bureau, Climatological Services Division. Mean Number of Thunderstorm Days in the United States. Technical Paper No. 19; Septembar 1952.

26. Boes, E.C. Fundamentals of Solar Radiation. SAND79-0490. Albuquerque, NM: Sandia National Laboratories; December 1979.

27. Burgess, E.L.; Walker, F.A. Summary of Photovoltaic Application Experiments Designs. ALO-71. U.S. Department of Energy, Albuquerque (NM) Opcrations Office; October 1979. 


\subsection{ARRAY SUBSYSTEM}

Page

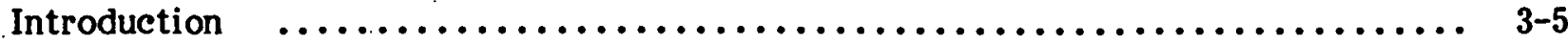

Solar Cell Performance Criteria............................... 3-5

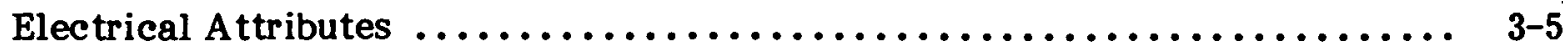

CE.E.1 Flat-Plate Solar Cell Electrical Output................ 3-5

CE.E.2 Concentrator Solar Cell Electrical Output .............. 3-7

Mechanical/Structural Attributes........................... 3-8

CE.M.l Antireflection Corting Integrity..................... 3-8

CE.M.2 Structural Loading Capability ........................ 3-8

CE.M.3 Contact Metallization Integrity $\ldots \ldots \ldots \ldots \ldots \ldots \ldots \ldots \ldots \ldots \ldots \ldots$

Durability/Reliability Attributes ............................ 3-9

CE.D.1 Temperature Cycling .......................... 3-9

CE.D.2 Humidity................................. 3-9

Module Performance Criteria $\ldots \ldots \ldots \ldots \ldots \ldots \ldots \ldots \ldots \ldots \ldots \ldots \ldots \ldots \ldots \ldots \ldots \ldots$ 3-10

Electrical Attributes $\ldots \ldots \ldots \ldots \ldots \ldots \ldots \ldots \ldots \ldots \ldots \ldots \ldots \ldots \ldots \ldots \ldots \ldots \ldots \ldots$. $\ldots \ldots 10$

MO.E.l Module Electrical Output......................... 3-10

MO.E.2 Electrical Terminals ........................... 3-11

MO.E.3 Module and Receiver Fault Tolerance ..................... 3-11

MO.E.4 Mismatch Losses in Modules and Arrays ................ 3-12

Mechanical/Structural Attributes............................ 3-12

MO.M.1 Flat-Plate Module Structural Adequacy .................. 3-12

MO.M.2 Concentrator Module Structural Adequacy ................. 3-13

MO.M.3 Shipping ................................ 3-13

MO.M.4 Handling ................................... 3-13

MO.M.5 Attachment Provisions for Flat-Plate Modules ............. 3-13

MO.M.6 Twist Capability of Flat-Plgte Modules.................... 3-14

MO.M.7 Interconnect Stress Relief ........................ 3-14

MO.M.8 Hail ...................................... 3-15

MO.M.9 Optical Surfaces Soiling ........................... 3-15

MO.M.10 Cleaning Tolerance .............................. 3-16

MO.M.11 Off-Axis Survival of Concentrator

Module and Receiver ........................ 3-16

MO.M.12 Materials Compatibility ........................ 3-17

MO.M.13 Physical Deterioration of Gaskets, Sealants, and

Polymeric Coupling Hoses ..................... 3-17

MO.M.14 Compatibility of Materials with

Heat Transfer Fluids.......................... 3-17

MO.M.15 Deterioration of Fluids or Phase-Change Materials.......... 3-17

MO.M.16 Effects of Decomposition Products ................... 3-17

MO.M.17 Corrosion by Leachable Substances .................... 3-17

MO.M.18 Cell Temperature Control for Flat-Plate Modules............ 3-18 


\subsection{ARRAY SUBSYSTEM (continued)}

Page

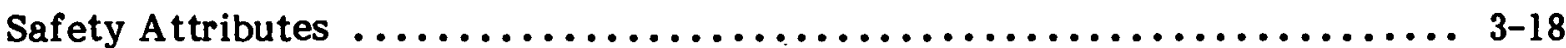

MO.S.l Electrical Voltage Isolation ...................... 3-18

MO.S.2 Flammability ............................... 3-19

Durability/Reliability Attributes $\ldots \ldots \ldots \ldots \ldots \ldots \ldots \ldots \ldots \ldots \ldots \ldots \ldots \ldots \ldots$. $\ldots \ldots 19$

MO.D.1 Temperature Cycling .......................... 3-19

MO.D.2 Solar Weathering $\ldots \ldots \ldots \ldots \ldots \ldots \ldots \ldots \ldots \ldots \ldots \ldots \ldots \ldots \ldots \ldots$ 3-20

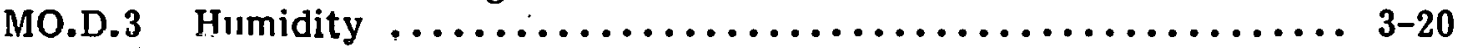

MO.D.4 Rain......................................

MO.D.5 Electrical 'l'erminals .......................... 3-21

Installation, Operation, and Maintenance Attributes................ 3-21

MO.I.1 Physical Inter changeability ..................... 3-21

MO.I.2 Access for Maintenance ...................... 3-21

MO.I.3 Field Monitoring ............................ 3-22

Concentrator Optics/Receiver Performance Criteria ................... 3-22

Electrical Attributes $\ldots \ldots \ldots \ldots \ldots \ldots \ldots \ldots \ldots \ldots \ldots \ldots \ldots \ldots \ldots \ldots \ldots \ldots \ldots, \ldots \ldots \ldots$

CR.E.1 Receiver Electrical Output ....................... 3-22

CR.E.2 Electrical Terminals ........................... 3-22

CR.E.3 Module and Receiver Fault Tolerance ................. 3-22

Mechanical/Structural Attributes............................ 3-22

CR.M.1 Attachment Provisions ......................... 3-22

CR.M.2 Off-Axis Survival of Concentrator

Module and Receiver ........................... 3-23

CR.M.3 Materials Compatibility ........................ 3-23

CR.M.4 Physical Deterioration of Gaskets,

Sealants, and Polymeric Coupling Hoses .............. 3-23

CR.M.5 Compatibility of Materials with Heat Transfer Fluids ....... 3-23

CR.M.6 Corrosion by Leachable Substances ................... 3-24

Clk.M.7 Deterioration of Fluids or Phase-Change Materials.......... 3-24

CR.M.8 Effects of Decomposition Products ................. 3-23

CR.M.9 Interconnect Stress Relief ....................... 3-25

Durability/Reliability Attributes ........................... 3-25

CR.D.1 Temperature-Humidity Cycling Stress............... 3-25

CR.D.2 Electrical Terminals ........................... $3-2 B$

CR.D.3 Solar Weathering ............................. 3-25

CR.D.4 Humidity.................................. 3-25

CR.D.5 Rain................................... 3-25

CR.D.6 Temperature Cycling ........................ 3-26

Installation, Operation, and Maintenance Attributes............... 3-26

CR.I.1 Field Monitoring ............................ 3-26 


\subsection{ARRAY SUBSYSTEM (concluded)}

Page

Array/Array Field Performance Criteria $\ldots \ldots \ldots \ldots \ldots \ldots \ldots \ldots \ldots \ldots \ldots \ldots \ldots \ldots$

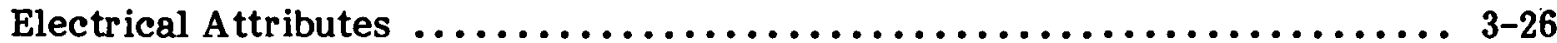

AR.E.1 Array Electrical Output ....................... 3-26

AR.E.2 Array Field Electrical Output ..................... 3-26

AR.E.3 Lightning Protection........................... 3-27

AR.E.4 Array Compatibility ........................... 3-27

AR.E.5 Mismatch Losses in Modules and Arrays ................ 3-27

Mechanical/Structural Attributes......................... 3-27

AR.M.1 Flat-Plate Array Structural Adequacy ................. 3-27

AR.M.2 Concentrator Array Structural Adequacy ............... 3-28

AR.M.3 Off-Axis Survival of Field Components ................. 3-28

Safety Attributes $\ldots \ldots \ldots \ldots \ldots \ldots \ldots \ldots \ldots \ldots \ldots \ldots \ldots \ldots \ldots \ldots \ldots \ldots \ldots \ldots$. $\ldots \ldots \ldots$

AR.S.1 Off-Axis Survival of Field Components ................ 3-28

AR.S.2 Safety Procedures ............................. 3-29

AR.S.3 Flammability ................................ 3-29

Durability/Reliability Attributes $\ldots \ldots \ldots \ldots \ldots \ldots \ldots \ldots \ldots \ldots \ldots \ldots \ldots \ldots \ldots \ldots \ldots$. . . . 29

AR.D.1 Humidity .................................. 3-29

Installation, Operation, and Maintenance Attributes.................. 3-29

AR.I.1 Access for Maintenance .......................... 3-29

AR.I.2 Array Spacing for Shadowing ......................... 3-29

AR.I.3 Installation, Operation, and Maintenance Manual .......... 3-29

AR.I.4 . Installation Plan ............................ 3-29

AR.I.5 System Maintainability ......................... 3-29

AR.I.6 Field Monitoring ............................. 3-29 


\section{THIS PAGE}

\section{WAS INTENTIONALLY \\ LEFT BLANK}

$3-4$ 


\section{SECTION 3.0}

\section{ARRAY SUBSYSTEM}

\section{INTRODUCTION}

This section provides performance criteria for elements of the array subsystem hierarchy illustrated in Fig. 3-1. This hierarchy is addressed in four subsections: for cells, modules, concentrator optics/receivers, and array/array fields. Performance criteria for component elements, such as tracking and control, are subsumed in appropriate subsections. There are other elements that are not given separate performance criteria because they do not have unique performance attributes. For example, there are no performance criteria for panels because their performance requirements are not sufficiently different from those for modules or arrays.

Essentially all field and laboratory experience to date has been with PV systems using single-crystal silicon wafer technology. This section is based on the history of that technology and, in many cases, the attributes described were chosen to minimize or remove the effect of specific failure modes of single-crystal silicon on system performance. As other photovoltaic systems become commercially available, they will either be judged by these criteria or other criteria will have to be developed. Some criteria developed for single-crystal silicon wafer technology will have to be modified before they can be applied to devices of other technologies and additional performance criteria may be needed to properly evaluate the new systems. Users of this section will have to determine whether the present criteria apply to systems or devices using other technologies or advances within the single-crystal silicon technology.

The emphasis here has been to prepare criteria and test methods that would prove useful to the photovoltaic community in the near term. A few aspects of silicon technology have not been included because of the insufficiency of present knowledge in a particular area. These include criteria and test methods for photovoltaic arrays with thermal heat output, some aspects of concentrating arrays, tracking, and control. Criteria and test methods are now being developed in these and other areas and will be incorporated into later draf ts of this document as they become available. The test methods referred to in this section with the code designation TE.AR. are located in Appendix B.

\section{SOLAR CELLL PERFORMANCE CRITERIA}

\section{Electrical Attributes}

\section{CE.E.1 Flat-Plate Solar Cell Electrical Output}

Criterion. A flat-plate solar cell shall have an electrical output under illumination that satisfies specifications.

Evaluation. The electrical output of a flat-plate solar cell is characterized by certain electrical output parameters determined from the current-voltage (I-V) characteristic curve of the cell. Test TE.AR.E.1 (Electrical Performance Test-Flat-Plate Cells, Modules, and Arrays) shall be used to determine either the entire curve or some portion of it.

Commentary. The I-V curve determines a great number of cell electrical parameters. These include the short circuit current $\left(\mathrm{I}_{\mathrm{sc}}\right)$, the open circuit voltage $\left(\mathrm{V}_{\mathrm{oc}}\right)$, the maximum 


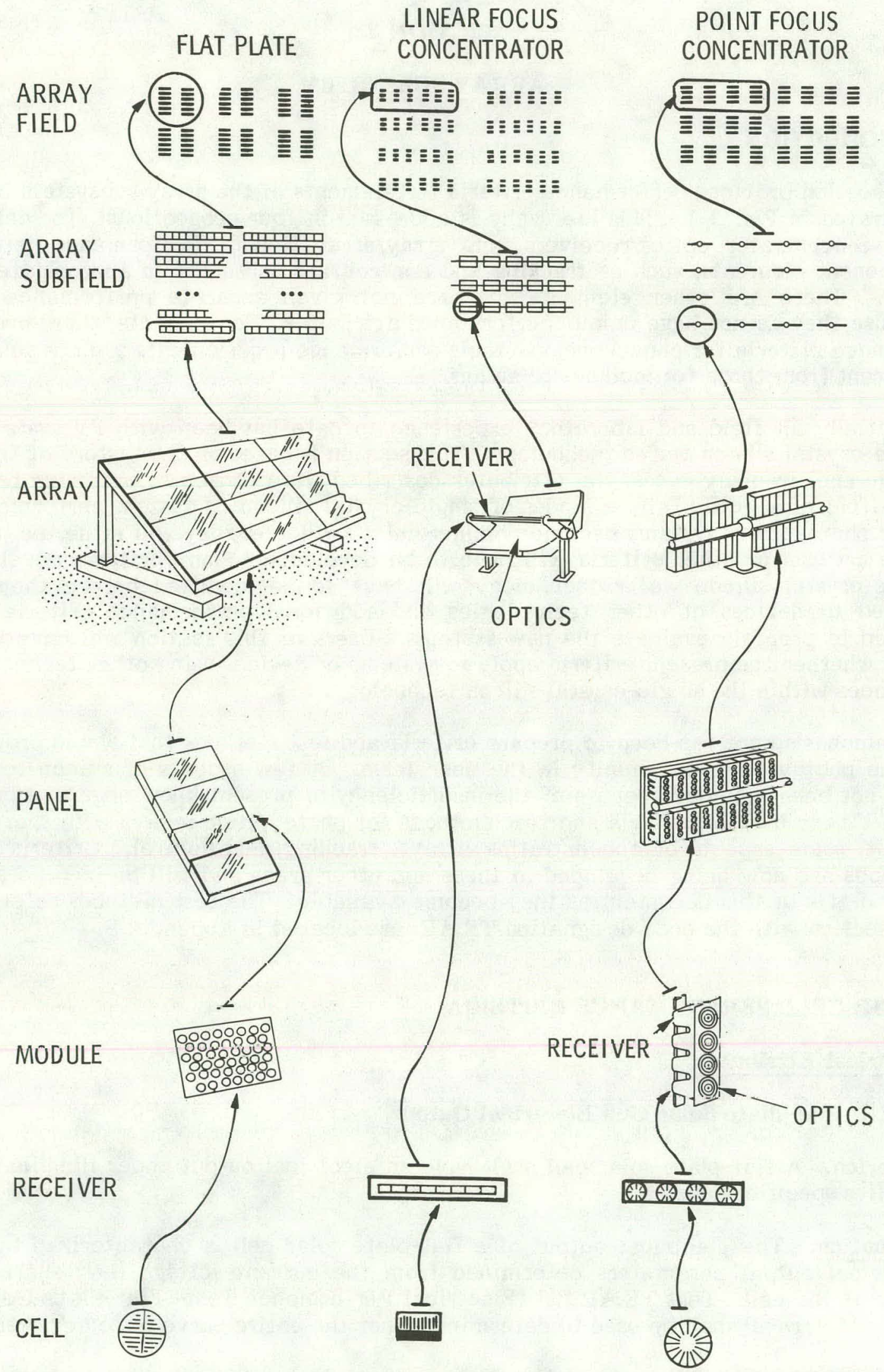

Figure 3-1. Photovoltaic Array Hierarchy 
power $\left(P_{m}\right)$, the voltage and current at maximum power $\left(V_{m}, I_{m}\right)$, the cell electrical conversion efficiency ( $\eta_{C}$ ), the curve fill factor (FF) and, for some purposes, the output current at a specified voltage $\left(\mathrm{I}_{\mathrm{V}}\right)$. The entire front area of the cell, including grids and contacts, is used in efficiency calculations.

This method may be used for determining either the encapsulated or unencapsulated cell efficiency. Encapsulated cell efficiency ( $\eta_{\mathrm{EC}}$ )is of ten used to get a measure of the cell's performance when combined with the anticipated encapsulant. It may be measured by contacting a single cell in a module that is illuminated as per Test TE.AR.E.1.

Various considerations determine whether the entire curve or some portion of it is specified. For example, in a research environment it may be desirable to specify the entire curve and associated output parameters; while in the manufacturing process environment it is common to sort cells on the assembly line by examining the current output at a single voltage level. The parameters measured also may be used in the sale or purchase of cells, the matching of cells for assembly into modules (see MO.E.4), solar cell research, and the detection of cell degradation.

Cell output parameters vary with temperature and the level and spectral content of the irradiance. For comparison purposes these are normalized to and reported at a temperature of $28^{\circ} \mathrm{C}, 1000 \mathrm{~W} / \mathrm{m}^{2}$ irradiance, and air mass 1.5 spectrum.

\section{CE.E.2 Concentrator Solar Cell Electrical Output}

Criterion. A concentrator solar cell shall have an electrical output under illumination that satisfies specifications.

Evaluation. The electrical output parameters of a concentrator solar cell are characterized by certain electrical output parameters that are determined from the current-voltage (I-V) characteristic curve of the cell. Test TE.AR.E.2 (Electrical Performance Test-Concentrator Solar Cells) shall be used to determine either the entire curve or some portion of it.

Commentary. The I-V curve determines a large number of cell electrical and performance parameters. These include the short circuit current $\left(\mathrm{I}_{3 \mathrm{c}}\right)$, the open circuit voltage $\left(V_{o c}\right)$, the maximum power $\left(P_{m}\right)$, the voltage and current at maximum power $\left(V_{m}, I_{m}\right)$, the cell electrical conversion efficiency $\left(\eta_{C}\right)$, the curve fill factor (FF) and, for some purposes, the output current at a specified voltage $\left(I_{v}\right)$. The active area of a concentrator cell for computation of efficiency is the area designed to be illuminated. This area includes interior grids and contacts. The active area may exclude the area of the cell that is covered by contacts at the outer edge of the cell provided the optical system avoids illuminating this area. Both the active area and total area of the cell should be included in the report. If deviations from these are applicable, the method of area and irradiance determination must be completely described.

Various considerations determine whether the entire curve or some portion of it is specified. For example, in a research environment it may be desirable to specify the entire curve and associated output parameters, while in the manufacturing process environment it is common to sort cells on the assembly line by examining the current output at a single voltage level. The parameters measured also may be used in the sale or purchase of cells, the matching of cells for assembly into modules, solar cell research, and the detection of cell degradation. 
Cell output parameters vary with temperature and the level and spectral content of the irradiance. For comparison purposes, the gutput parameters are adjusted to and reported at a temperature of $28^{\circ} \mathrm{C}$ and $1.000 \mathrm{~W} / \mathrm{m}^{2}$ with the reference irradiance spectrum (see glossary). Tables or plots of efficiency and fill factor as a function of incident irradiance (air mass 1.5 spectrum) should be reported for $28^{\circ} \mathrm{C}$ and for a design operating temperature and irradiance.

\section{Mechanical/Structural Attributes}

\section{CE.M.1 Antireflection Coating Integrity}

Criterion. The antireflection (AR) coatings of solar cells to be used in either flat-plate or concentrator modules shall be capable of withstanding handling and exposure to water vapor without delamination during subsequent fabrication and assembly steps.

Bvaluation. The acceptability of AR coatings on solar cells shall be evaluated using Test TE.AR.M.9 (Antireflection Coating Adhesion Test-Solar Cells). Changes in the color or delamination of the AR coating will be evaluated.

Commentary. AR coatings on solar cells must be able to withstand the cleaning and handling encountered during module manufacturing and be stable even in the presence of moisture throughout the life of the cell. Poor adhering AR coatings of ten are destroyed even on encapsulated cells because of moisture. The loss of an AR coating on a silicon solar cell can cause as much as $30 \%-40 \%$ degradation in output power.

Certain cells are constructed of materials that are not intended for any exposure to air and, therefore, are packaged to prevent such exposure. These cells are considered an integral part of the completed module and are tested on the module level.

\section{CE.M.2 Struetural Loading Capability}

Criterion. Flat-plate and concentrator solar cells shall be able to withstand steady-state and transient structural loading stresses applied during normal service for their design life.

Evaluation. Satisfactory long-term performance shall be documented under in-use conditions. When adequate information is unavailable, fracture mechanics analysis or structural loading tests (see Ref. 1) may be used to evaluate cell structural loading capability.

Commentary. Cells can encounter various steady-state and transient struct.ural lnading stresses during cell manufacture, module fabrication, shipping, handling, installation, and field use. During cell fabrication, wafers or cells with low fracture strength distribution are likely to be fractured during subsequent cell processing and handling, or in field service. To ensure the adequate strength of cells and provide a margin of safety against cracking under rapid and sustained loading, it is common practice to perform a proof test at a level somewhat higher than the expected condition. An assessment of several mechanical strength tests for silicon solar cells is given in Ref. 1 . 


\section{CE.M.3 Contact Metallization Integrity}

Criterion. Solar cell contact metallization for flat-plate or concentrator modules shall be capable of withstanding the stresses imposed by the attachment and subsequent handling of interconnects during manufacture and service use.

Evaluation. Contact metallization integrity shall be evaluated by using Test TE.AR.M.7 (Contact Pull Strength [Wire Pull Test]-Solar Cells).

Commentary. Solar cells used in flat-plate or concentrator modules must be basically capable of being linked with an interconnector without loss of integrity of cell contacts. Various interconnector attachment techniques and designs are likely to be used by the module manufacturer, but in all cases the basic integrity of the cell contact metallization is required. Since Test T.E.AR.M.7 is a destructive test, it is used as a qualification or in-process acceptance test on a sampling basis.

Certain cells are constructed of materials that are not intended to be exposed to air and are therefore packaged to prevent such exposure. The contact metallization integrity may best be determined by applying environmental stress to the completed module. In most cases, Test TE.AR.M.7, used for discrete silicon cells, will be suitable to evaluate the integrity of the provisions made for external contact (terminals).

\section{Durability/Reliability Attributes}

\section{CE.D.1 Temperature Cycling}

Criterion. Solar cells shall be capable of effectively withstanding the stresses induced by temperature cycling for their design life.

Evaluation. Satisfactory long-term performance shall be documented under in-use conditions in the field configuration; i.e., a component of a module or concentrator receiver. When adequate documentation is unavailable, the Solar Cell Temperature Cycling Test (in preparation) may be used to evaluate thermal cycling degradation.

The characteristics to be evaluated for determining temperature cycling withstanding capability include output power degradation and altered physical appearance.

Commentary. Array subsystem elements encounter temperature cycling stresses as a result of diurnal and climatic excursions. For various silicon cell types (fabricated with different metallization processes) sensitivity to temperature cycling stresses has varied widely. Some insight into the mechanisms responsible for existing results has been obtained [2].

\section{CE.D.2 Humidity}

Criterion. Solar cells used in either flat-plate or concentrator modules shall be capable of withstanding the effects of humidity.

Evaluation. To determine the acceptability of solar cell materials (i.e., contact metals and AR coatings) with respect to their stability in the presence of humidity, Test TE.AR.D.3 (Humidity Test--Solar Cells) shall be used, except for those cells packaged to 
prevent exposure to air and moisture. For the latter encapsulated cells, the entire encapsulated assembly shall be tested at the module level with Test TE.AR.D.4 (Humidity Test-Array Elements).

Commentary. Solar cells used in flat-plate or concentrator modules must be able to withstand exposure to humidity. No matter. what the encapsulation technique, short of complete hermetic sealing, moisture will be present at the solar cell surfaces and contacts. To ensure long-life operation of the module, the solar cell component must be fabricated using moisture-resistant materials and processes. Therefore, the humidity resistance requirement is placed on cells to be sealed in nonhermetic packages before encapsulation.

Certain cells are constructed of materials that should not be exposed to air and, therefore, are packaged to prevent such exposure. These cells are considered an integral part of the completed module and are tested on the module level.

\section{MODULE PERFORMANCE CRITERIA}

\section{Electrical Attributes}

\section{MO.E.l Module Electrical Output}

Criterion. A module shall have an electrical output under illumination that satisfies specifications.

Evaluation. The electrical output parameters of a module are those parameters determined from the curront-voltage (I-V) chararteristic curve of the module. Test TE.AR.E.1 (Electrical Performance Test- Flat-Plate Cells, Modules, and Arrays) shall be used to determine either the entire curve, or some portion of it, for flat-plate modules. The test method for concentrator modules is in preparation.

Commentary. The $I-V$ curve is used to determine a large number of module electrical parameters. These include the short circuit current $\left(\mathrm{I}_{s c}\right)$, the open circuit voltage $\left(\mathrm{V}_{\mathrm{oc}}\right)$, the maximum power $\left(P_{m}\right)$, the voltage and current at maximum power $\left(V_{m}, I_{m}\right)$, the module electrical conversion efficiency $\left(\eta_{C}\right)$, the curve fill factor (FF) and, for some purposes, the output current at a specified voltage $\left(I_{v}\right)$. The area used in efficiency calculations is the entire front, normally llluminuled urea of the module, including the frame.

Various considerations determine whether the entire curve or some portion of it is specified. For example, in a research environment, it may be desirable to specify the entire curve and associated output parameters, while in the mululacturing process environment, it is common to sort modules on the assembly line by examining the short-circuit current and the current output at a single voltage level. The parameters measured may also be used in the sale or purchase of modules, thè matching of modules for assembly into arrays, and the detection of module degradation.

Module output parameters vary with temperature and the level and spectral content of the irradiance. For comparing flat-plate modules the output parameters are given at the electrical performance reporting conditions specified in Table B-l of Test TE.AR.E.1. Reporting conditions are being developed for concentrator modules. 


\section{MO.E.2 Electrical Terminals}

Criterion. Electrical terminals for modules and receivers shall be designed and sized to facilitate field servicing and withstand the environmental and service stresses applied during normal service for their design life.

Evaluation. Satisfactory performance shall be documented under in-use conditions. When adequate information is unavailable, drawings, specifications, test data, and engineering analysis shall be reviewed and analyzed to verify compliance with the criterion.

Commentary. The primary requirements for electrical terminals consist of adequate current and vol tage capacity, low ohmic contact resistance, and adequate environmental qualification consistent with low cost. Selection of a specific terminal depends on both site and application. Remote applications will have lower voltage and current requirements than large industrial applications. Environmental qualification consists of the ability to withstand temperature cycling, ultraviolet exposure, humidity, corrosive atmosphere, fungus, and pull loads. More definitive performance criteria for electrical terminals will be included in subsequent revisions of this report. The information presented has been included for completeness.

\section{MO.E.3 Module and Receiver Fault Tolerance}

Criterion. Modules and receivers shall endure commonly occurring circuit faults such as cracked or mismatched cells, single-point open-circuit failures, and nonuniform illumination (partial shadowing) without catastrophic effects, such as major power loss, encapsulant deterioration, or saf ety hazards.

Evaluation. Drawings, specifications, testing, and engineering analysis shall be used to evaluate the fault tolerance of the module circuit $[3,4]$. Experimental evaluation with artificially introduced fault conditions can also be carried out. Experimental simulation is particularly effective in evaluating module resistance to hot-spot heating.

Commentary. Field experience indicates that periodic circuit faults, such as partial shadowing, cracking of cells, and interconnect open circuits, occur even in highly reliable arrays. Under these fault conditions it is desirable to limit the degree of power loss and to assure that possible hot-spot heating due to reverse biasing does not propagate the fault by such mechanisms as solder melting, encapsulant deterioration, or dielectric degradation.

Hot-spot heating is caused when operating.current levels exceed the reduced short-circuit current capability of an individual cell or group of cells in an array circuit. The reduced short-circuit current fault condition can be caused by nonuniform illumination (local shadowing), individual cell degradation due to cracking or soiling, or loss of a portion of a series-parallel circuit due to individual interconnect open circuits. Under this condition, the over-currented cells dissipate power equal to the product of the current; the reversed voltage that develops across the cells can heat them to elevated temperatures high enough to melt solder.

These problems can be alleviated by designing redundancy and over-current carrying capability into the cell circuit. Redundant cell contact attachment points and interconnects are useful in reducing the probability of a single-point circuit failure causing an opencircuit or a reduced short-circuit current condition. By-pass diodes, extensive cell 
paralleling, and a low cell shunt resistance are effective in minimizing hot-spot heating by providing over-current carrying ability $[3,4]$. Good cell heat sinking and heat resistant encapsulant materials and processes are useful in controlling the effects of hot-spot heating such as gas generation and encapsulant deterioration.

\section{MO.E.4 Mismatch Losses in Modules and Arrays}

Criterion. Electrical mismatch losses caused by combining cells into modules and modules into arrays shall not exceed acceptable leveis.

Evaluation. Engineering analysis or experimental measurement shall be used to evaluate the extent of mismatch losses [5]. Mismatch losses shall be evaluated by determining the difference between the power output of a cell or module network and the sum of the power output of the individual elements making up the network.

Commentary. Because of manufacturing process tolerances, cells and modules of the same design generally have a distribution of electrical performance current-voltuge (I-V) characteristics. When a number of cells and modules are combined in series or parallel electrical circuits or both, mismatch losses occur that reduce the overall electrical efficiency of the module/array and may lead to reverse-biasing and hot-spot heating. These mismatch losses can be controlled by limiting the variation in cell/module performance, by sorting and matching the performance of individual elements, or by using fault tolerant circuit design practices. Fault tolerant circuit design practices (performance criteria in preparation) are also desirable to control subsequent mismatch due to differential aging and other similar processes.

\section{Mechanical/structural Attributes}

\section{MO.M.1 Flat-Plate Module Structural Adequacy}

Criterion. Flat-plate PV modules shall support all loads expected during the design life of the module without structural failure or significant performance degradation.

Evaluation. The structural adequacy of flat-plate PV modules shall be demonstrated by analysis. Documentation of satisfactory long-term performance under in-use conditions shall be considered contributory evidence of structural adequacy. Additional contributory evidence of structural adequacy for modules may be obtained from the following Tests: TE.AR.M.1 (Structural Loading Test-Flat-Plate Modules [Cyclic Pressure Load Testl), TE,AR.M.2 (Temperature Cycling Test-Flat-Plate Modules), and Warped Mounting Surface (in preparation).

Commentary. The structural design of frames and structural substrates for modules depends primarily on the wind loading. Wind pressure loads on individual modules will be higher than the net average pressure acting on arrays. The structural design of glass superstrates for flat-plate modules, in many cases, will be dictated by minimum hailwithstanding requirements. For larger annealed glass superstrate modules, normal pressure loads (primarily wind) will control the structural design. Brittle materials, like glass, require design considerations because their strength is a function of surface condition (flaws and scratches), surface area of part, and time duration of loading. Some guidelines for designing glass superstrate PV modules are provided in Ref. 6. 


\section{MO.M.2 Concentrator Module Structural Adequacy}

Criterion. In any sun-tracking operating mode, the concentrator module shall support design loads (dead weight, wind, earthquake, and constraint loads) without structural failure or performance degradation. In a nonoperating mode or position, the concentrator module shall support all loads expected during the design life of the system without structural failure or subsequent significant performance degradation when the system is returned to an operating condition.

Evaluation. The structural adequacy of concentrator modules shall be demonstrated by structural analysis. Documentation of satisfactory long-term performance under in-use conditions shall be considered contributory evidence of structural adequacy.

Commentary. Wind loading is recognized as a primary structural cost driver for concentrator modules. In some applications it may be cost effective to take advantage of the reduced wind loading resulting from boundary layer effects near the ground (shielding from adjacent rows of arrays or wind shielding devices) provided that the increased cost of supporting analysis and documentation is defrayed by decreased structural costs. In connection with concentrator modules it is appropriate to distinguish between operating and nonoperating loads. The operating loads occur while the array is in a sun-tracking mode. Operating wind loads, for example, may be less than nonoperating wind loads, because studies have shown that virtually all of the sun's irradiance occurs during periods when relatively low wind speeds exist. The operating loads (dead weight-thermal and wind) will significantly influence the structural design of the receiver and concentrator module because the optical quality and alignment of the concentrator module will be affected by these loads. Nonoperating loads occur at any time during the design life of the array. Concentrator modules must withstand these loads without structural failure, and permanent deformations of the concentrator module should not excessively reduce its ability to collect solar energy.

\section{MO.M.3 Shipping (see SY.M.1)}

\section{MO.M.4 Handling (see SY.M.2)}

\section{MO.M.5 Attachment Provisions for Flat-Plate Modules}

Criterion. Attachment of flat-plate modules to their intended supporting structure shall not result in deflections, stress points, or mechanical interferences of component parts that degrade the perf ormance of the module over its design life.

Evaluation. Engineering analysis and drawings shall be reviewed to determine conformance with standardized codes and recommended practices for strengths of materials, flatness of surfaces, location, and clearances associated with mounting hardware (e.g., see ANSI - Y 14.5).

Commentary. Module mounting on support structures may use a variety of techniques ranging from aligned through-holes fasteners to adhesive bonding. To minimize problems in attaching modules to the supporting structure, the following factors affecting attachment should be reviewed: flatness of the mating interfaces of structure and modules, spacing allowances to adjacent modules, tolerances on sizes and locations of fasteners, and load-carrying capability of the fastening or attachment device. These factors should guarantee that no unacceptable deflections, stress points, or mechanical interference of 
component parts be experienced by the modules upon attachment to the intended supporting structure. An example of a standard design practice from ANSI - Y 14.5 that may be applicable is drilling holes for mounting materials. This standard practice calls for the hole to be drilled at least 1.5 diameters from the edge of the material. This practice is for single-piece materials (modules without frames) and is intended to minimize shear stress loads. For modules with metal frames around the edges (that provide more rigidity), holes can be closer to the edge.

\section{MO.M.6 Twist Capability of Plat-Plate Modules}

Criterion. Flat-plate PV modules shall be capable of withstanding small twists caused by mounting on a nonplanar surface.

Evaluation. Satisfactory performance shall be documented during normal field installation. When adequate information is unavailable, engineering analysis or the Warped Mounting Surface Test (Twist Test) (in preparation) may be used.

Commentary. The intent of this criterion is to preclude damage to a module caused by the possible twisting of the module substrate when installed on a primary structure that is not entirely planar. An alternate approach would be to specify a stringent planar requirement for the primary structure. However, when module costs are reduced, structural costs with such a requirement would be unreasonably high. Current modules show no difficulty in tolerating small amounts of twist $\left(\leq 1.25^{\circ}\right)$ when the twist test is performed.

\section{MO.M.7 Interconnect Stress Rellef}

Criterion. Electrical interconnects between cells in modules and in receivers shall be capable of withstanding environmentally induced strcsees applied during normal service f or their design life.

Evaluation. Satisf actory long-term performance shall be documented under in-use conditions. Module drawings and specifications shall be reviewed to check that materials will be thermally compatible and those used for interconnootions will last the design life. When adequate information is unavailable, Tests TE.AR.M.l (Structural Loading Test-Flat-Plate Module (Cyclic Pressure Load Test)), 'IE.AR.M.2 (Temperature Cycling Test-Flat-Plate Modules) or TE.AR.M.3 (Temperature Cycling Test-Concentrator Modules) shall be used to evaluate the effect of cyclic loading on interconnects.

Commentary. Rccciver and flat-plate module interconnections can encounter various loading stresses depending on the construction of the array in which they are installcd. The primary sources of movement due to structural deflection of the array are caused by positional changes during tracking; environmental loading due to wind, hail, and ice; and relative positional changes between the array structure and the supporting foundation. Induced fatigue is not immediate but will occur over a long period of time. Differences in thermal expansion coefficients of the solar cell, interconnects, encapsulants, and receiver supporting structure will also cause stress. Fatigue of ten occurs at the solder connection between the interconnect and the cell. Concentrator receiver interconnects differ from flat-plate interconnects in that the former are typically longer and wider for carrying higher currents. 
Techniques that are useful in improving stress include reducing interconnect thickness; increasing expansion loop height; increasing the distance (and thereby the interconnector length) between attachments to the cells by measuring across the intercell gap; selecting a material with a higher endurance limit; modifying the lateral dimension of the interconnector loop so that maximum bending no longer concentrates at a single point on the loop; and preventing solder from filling (wicking) and stiffening expansion loop radii [7].

\section{MO.M.8 Hail}

Criterion. Modules and their exposed elements shall resist the impact of hailstones expected at the site without significant damage or major impairment of the functioning of the module or its optical elements.

Evaluation. Engineering analysis, based on an assessment of the environmental conditions at the specific site of interest, a comparison with test results from proven designs, or the Tests TE.AR.M.4 (Hail Test-Flat-Plate Modules) and TE.AR.M.5 (Hail Test-Concentrator Modules) may be used to evaluate the ability of modules and concentrator optics to withstand specified levels of hailstone impact.

Commentary. The intent is to preclude damage that would result in curtailment of module electrical performance or result in premature failure. Susceptible points on a flatplate module include corners and edges, cell edges, and substrate supports; on a concentrator module, susceptible points are corners and edges of glass reflective surfaces and cover plates on receivers. The optical elements of concentrator systems may be fractured or dented by hailstones and functionally degraded.

Hailstone size depends to a great extent on site. Therefore, environmental conditions at a specific site should be assessed before the design. The methodology given in Ref. 8 can aid in that assessment. In lieu of site-determined hailstone size, Ref. 8 or 9 may be used as a guide in establishing the hailstone size for a particular application. For assessing risks to solar collectors, the U.S. Department of Housing and Urban Development (HUD) [9] has recommended using a hailstone diameter equal to $8 \mathrm{~mm}(0.3 \mathrm{in.})$ times the average number of hail days per year at the specific site.

Vulnerability to this environment may be reduced by appropriate material selection and structural design. Reference. 10 may be useful in determining the damage potential of various hailstone sizes on glass sheet.

\section{MO.M.9 Optical Surface Soiling}

Criterion. Optical elements of modules, including receivers and optics, shall not retain dirt to an extent that would significantly impair the function of the photovoltaic equipment during its design life.

Evaluation. Satisfactory long-term performance shall be documented under in-use conditions. When adequate documentation is unavailable, engineering analysis or an outdoor soiling test may be used to evaluate optical surface soiling degradation. The characteristics to be evaluated for determining soiling withstand capability include output power degradation (specifically, changes in short-circuit current) and optical obscureness. 
Commentary. The effect of retained dirt on optical surfaces of photovoltaic equipment is significant; e.g., flat-plate modules have experienced up to $60 \%$ power degradation af ter outdoor exposure. The optical loss results from absorption and scattering by particulates that collect on and may even become embedded in the surface. Particulates impinge on an optical surface through complex fluid mechanical interactions between the dust-laden atmosphere and the photovoltaic equipment. Initial particle adhesion is dominated by surface energetics. However, condensed water vapor at the particle-surface interface provides a vehicle for soluble components and dirt to form very strong chemical and physical bonds between the dirt and the surface. To keep the surface of the module free from dirt, the illuminated optical surface(s) should be smooth and generally free of projections that could promote entrapment of dust and other debris. Particular attention should be given to the selection of materials that will minimize the accumulation of nonremovable contaminants, particulates, and stains on the optical surface. Also, materials should be used that will promote self-cleaning by natural processes like wind and rain. Field experiments with modules and top cover materials in different geographical locations indicate significant time and site dependence and site of soiling characteristics. Removal mechanics (such as rain and snow melt) are the key to long-term selection of materials that will minimize the accumulation of nonremovable contaminants, particulates, and stains on the optical surface. Also, materials should be used that will promote self-cleaning by natural processes like wind and rain. Field experiments with modules and top cover materials in different geographical locations indicate significant time and site dependence and site of soiling characteristics. Removal mechanies (such as rain and snow melt) are the key to long-term soiling differences [1l]. While an acceptable laboratory test method is desirable, research work to date indicates soiling to be a very complex problem and development of a testing method in the near term is not envisioned. Side-by-side outdoor exposure testing for long periods of time at a variety of sites is currently the most effective way to evaluate soiling differences.

\section{MO.M.10 Cleaning Tolerance}

Criterion. Surfaces of modules, including receivers and concentrator optics, shall be capable of withstanding periodic cleaning during normal service for their design life.

Evaluation. Satisfactory performance under in-use conditions shall be documented. When adequate information is unavailable, drawings, specifications, engineering analyses, and the manufacturer's recommended practice shall be reviewed and analyzed.

Commentary. Cleaning of optical surfaces can cause marring and scratching of those surfaces to the extent that the electrical performance of the module is significantly affected. Optical surface materials should be selected that tolerate physical and chemical (e.g., solvents and detergents) cleaning techniques. Generally, manufacturers are expected to supply cleaning instructions for the optical surfaces of their products. Along with the cleaning instructions, the manufacturer should indicate any precautions necessary to take with either cleaning fluids or cleaning procedures.

\section{MO.M.11 Off-Axis Survival of Concentrator Module and Receiver}

Criterion. The concentrator module and receiver shall not be damaged due to concentrated sunlight traversing off the normally illuminated receiver during normal operating conditions (e.g., sun acquisition or desteering operations) or abnormal operating conditions (e.g., tracking motor power failure). 
Evaluation. Documentation of satisfactory long-term performance under in-use conditions or engineering analysis shall be used to evaluate potential degradation. The characteristics to be evaluated are the use of materials that may be combustible and ignite, or soften or melt, thus impairing the mechanical integrity of the module.

Commentary. Concentrator modules and receivers can encounter complex steady-state and transient thermal loading during off-axis pointing. Depending on the specific concentrator optics chosen, the energy distribution can be highly nonuniform and may reach very high levels of concentration in localized areas. Depending on the nature of the off-axis condition (i.e., whether the array is moving or stopped) the module may be exposed to intense energy concentrations for extended periods of time.

\section{MO.M.12 Materials Compatibility}

Criterion. Materials used in modules, receivers, and concentrator optics and the building elements with which they interact shall have sufficient chemical compatibility to prevent corrosive wear and deterioration that would significantly shorten their intended service life.

Evaluation. Documentation of satisfactory long-term performance under in-use conditions or engineering analysis shall be used. When adequate information is unavailable, tests shall be performed.

Commentary. Dissimilar materials used in modules, concentrator receivers and optics can be incompatible when exposed to thermal extremes and the humidity of the environment, or when they come in contact with corrosive chemicals such as heat transfer and other fluids. When several different materials come in contact in an outside environment, a corrosive electrochemical couple can destroy the components quite rapidly if the proper selection of materials is not made. When dissimilar materials are used in contact with heat transfer or other fluids, testing to evaluate compatibility is suggested.

The use of protective finishes, corrosion inhibitors, or dielectric fittings that electrically isolate dissimilar materials may be desirable. For plastics, plasticizer migration may be a concern. The presence of pinholes in protective coatings may drastically accelerate corrosive action. In considering the compatibility of dissimilar materials, all elements of a. solar system should be evaluated-including the energy transport system, structural support and connections, fabricated parts, and roofing materials.

MO.M.13 Physical Deterioration of Gaskets, Sealants, and Polymeric Coupling Hoses (See CR.M.4)

MO.M.14 Compatibility of Materials with Heat Transfer Fluids (See CR.M.5)

MO.M.15 Deterioration of Fluids or Phase-Change Materials (See CR.M.7)

MO.M.16 Effects of Decomposition Products (See CR.M.8)

MO.M.17 Corrosion by Leachable Substances (See CR.M.6) 


\section{MO.M.18 Cell Temperature Control for Flat-Plate Modules}

Criterion. Modules shall be capable of controlling electrical power loss and accelerated encapsulant aging caused by high cell operating temperatures.

Evaluation. Test TE.AR.M.1 (Nominal Operating Cell Temperature Determination-FlatPlate) shall be used to measure the NOCT of a flat-plate module. Module drawings and specifications shall be reviewed to check that encapsulant materials used will perform for the expected design life. (See Durability/Reliability Attribute MO.D.2, Solar Weathering).

Commentary. Electrical power output of solar cell modules decreases as temperatures increase (e.g., silicon at a rate of approximately $0.5 \%$ per ${ }^{\circ} \mathrm{C}$ ). Also, higher temperatures will accelerate physical and chemical degradation of the module (e.g., corrosion). These power reductions can be minimized by controlling the cell operating temperature using techniques such as a substrate with high infrared emission, high thermal conductance, and low solar absorption; front cover/encapsulants with thin transparent materials and relatively high thermal conductivity; and avoiding an air gap between the front cover/encapsulant and the cells (i.e., avoid a greenhouse effect) [12-14].

Fins give a slight advantage (less than $5^{\circ} \mathrm{C}$ temperature reduction), but generally are not cost-effective. The effectiveness of fins for roof mounting applications depends strongly on the backside air infiltration level. Transparent substrates offer a negligible advantage in open-frame mounting and can be a definite handicap for roof applications due to greenhouse effects. Water cooling offers significant improvement in module performance. However, it is not expected to be cost-effective unless the application already involves heating or pumping water, or unless a gravity water system is feasible. At present, care in thermal design and cost considerations result in a NOCT of $43^{\circ} \mathrm{C}$ to $48^{\circ} \mathrm{C}$ for open back flat-plate modules.

\section{Safety Attributes}

\section{MOS.l Electrical Voltage Isolation}

Criterion. PV modules shall provide an electrical insulation system to isolate live circuit elements and protect against human injury or performance degradation due to electrical shock or short circuits to the module mounting structure.

Evaluation. Review of model drawings and specifications shall indicate conformance with the system voltage level and with the electrical safety protection system of the intended class or range of applications. To verify adequacy of the insulation systems, Test TE.AR.M.10 (Dielectric Voltage Withstand Test), leakage current tests (in preparation), and insulation resistance tests (in preparation) shall be conducted on representative samples both before and after environmental exposurès.

Commentary. The insulation system shall be compatible with the intended class or range of applications of the module (including system safety provisions such as array grounding, lightning protection, and ground fault detection/interrupters) and with its installation, operation, and maintenance procedures. A fundamental requirement of the encapsulation and insulation system of photovoltaic devices is that it withstand the voltage imposed on it in service throughout its design life. To ensure the adequacy of the insulation system 
and provide a margin for degradation from aging, it is common practice to select a test voltage level for the Dielectric Voltage Withstand Test that is somewhat higher than the expected service condition. Test levels commonly used by institutions such as Underwriters Laboratories (UL) are:

- $1000 \mathrm{~V}$ plus twice the maximum rated voltage of the insulation system for systems with rated voltage levels above $50 \mathrm{~V}$; and

- $500 \mathrm{~V}$ for insulation systems with rated voltage levels below $50 \mathrm{~V}$.

As a measure of the extent to which the Dielectric Voltage Withstand Test has stressed the insulation system, a maximum allowable leakage current of $50 \mu \mathrm{A}$ during the test is usually specified.

Insulation resistance tests are typically conducted with the module insulation system subjected to a test voltage equivalent to the system operating voltage. The required minimum insulation resistance of $50 \mathrm{k} \Omega$ is consistent with UL recommendations for keeping shock sensation below "let-go" current levels.

\section{MOS.2 Flammability}

Criterion. Modules and arrays forming or attached to roofs shall not reduce the required fire resistance of roof covering materials.

Evaluation. UL Standard 790, Tests for Fire Resistance of Roof Covering Materials, shall form the basic test procedure.

Commcntary. UL 790 does not specifically detail the testing of a photovoltaic array as part of the roof covering, although the types and methods of fire exposure and the conditions of acceptance for classification may be applied to a particular PV assembly. A proposed UL Standard 1279, Standard for Solar Collectors, will contain information on testing solar collectors that may be applicable to photovoltaic arrays.

\section{Durability/Reliability Attributes}

\section{MO.D.1 Temperature Cycling}

Criterion. Modules shall be capable of withstanding the stresses induced by temperature cycling for their design life without significant degradation of module performance.

Evaluation. Satisfactory long-term performance under in-use coriditions shall be documented. When adequate information is unavailable, engineering analysis or the Tests TE.AR.M.2 (Temperature Cycling Test-Flat-Plate Modules) or TE.AR.M.3 (Temperature Cycling Test-Concentrator Modules) shall be used to evaluate thermal cycling degradation. The characteristics to be evaluated for determining temperature cycling withstand capability include output power degradation and altered physical appearance.

Commentary. Modules encounter temperature cycling stresses as a result of diurnal and climatic excursions. Susceptible parts of the module include the encapsulant system, cells, interconnects, und bonding materials. 


\section{MO.D.2 Solar Weathering}

Criterion. Modules, receivers, concentrator optics, their components and materials shall not be affected by exposure to solar irradiance in service to an extent that will significantly impair their function during their design life.

Evaluation. Documentation of satisfactory long-term performance under in-use conditions, acceptable test results, or engineering analysis shall be required. Where adequate docum entation is unavailable, Tests TE.AR.D.1 (Solar Radiation Weathering Tests-Materials and Components), and TE.AR.D.2 (Solar Radiation Weathering Tests-Modules and Minimodules) may be used. The characteristics to be evaluated for determining solar weathering capability include output power degradation and physical appearance alteration. A test method is being developed for concentrator receivers and optics.

Commentary. Conformal polymeric encapsulants, organic potting materials, adhesives, and organic adhesion-promoting treated materials are particularly susceptible to solar ultraviolet-induced weathering under prolonged exposure. Field observations have shown the occurrence of delamination of cell-encapsulants substrate-superstrate, encapsulantsubstrate and encapsulant-cover interfaces, carbonation, cell-cracking, encapsulant discoloration, and contact corrosion.

Moist ure (dust, rain, dew, high humidity, condensation), in combination with solar ultraviolet radiation, is a principal agent in producing adverse synergistic degrading effects in materials. This has led to the inclusion of water spray and moisture cycles in accelerated and simulated exposure test methods.

The use of diagnostic tests, including baseline photographs, transmittance data of cover materials, and electrical performance characteristics $\left(\mathrm{I}_{\mathrm{s} .}, \mathrm{V}_{\mathrm{oc}}, \mathrm{I}-\mathrm{V}\right.$ curves, $\mathrm{P}_{\mathrm{m}}$, etc.), are usually required to estimate the effects of exposure-induced degradation in reducing mondule efficiency and operating characteristics.

\section{MO.D.3 Humidity}

Criterion. Modules, receivers, concentrator optics, and tracking controls shall be capable of withstanding the stresses induced by humidity for their design life without significant performance degradation.

Evaluation. Documentation of satisfactory long-term performance under in-use conditions shall be required. When adequate docum entation is unavailable, engineering analysis or Test TE.AR.D.5 (Humidity Test-Array Elements) shall be used to evaluate humidity degradation. The characteristics to be evaluated for determining humidity withstand capability include output power degrudation and physical appearance alteration for modules and receivers, optics obscureness or altered alignment for concentrator optics, and functional performance degradation for tracking control.

Commentary. Humidity, which is one form of atmospheric water vapor, can significantly degrade the performance of photovoltaic equipment as a result of moisture migration and penetration. High relative humidity at elevated temperature can be especially stressful. 
Corrosion can be accelerated by humidity. Hygroscopic materials are sensitive to moisture and may deteriorate rapidly under humid conditions. Absorption of moisture by many materials results in swelling that destroys their function and causes loss of physical strength and changes in other important mechanical properties. Insulating materials that absorb moisture may suffer degradation of their electrical and thermal properties. Cycling temperature and humidity may cause condensation of moisture inside the equipment that could cause malfunctions resulting from electrical shorts. Such cycling may cause dulling or obscuring of reflecting or transmitting optics, terminal corrosion, and cell metallization.

\section{MO.D.4 Rain}

Criterion. Modules, receivers, and concentrator optics shall be capable of withstanding exposure to rain for their design life without significant performance degradation.

Evaluation. Documentation of satisfactory long-term performance under in-use conditions shall be required. When adequate documentation is unavailable, engineering analysis or the Rain Test (in preparation) shall be used to evaluate rain tolerance. The characteristics to be evaluated for determining rain withstand capability include output power degradation and altered physical appearance.

Commentary. Rain can degrade the performance of modules and receivers because of moisture penetration. Absorption by many materials results in swelling, which may degrade performance, cause loss of physical strength, and affect other important mechanical properties. Insulating materials that absorb moisture may suffer degradation of their electrical and thermal properties.

MO.D.5 Electrical Terminals (See MO.E.2)

Installation, Operation, and Maintenance Attributes

\section{MO.I.1 Physical Interchangeability}

Criterion. Modules of the same model by the same manufacturer shall be physically interchangeable.

Evaluation. Drawings and specifications of the module shall be reviewed to see that modules are interchangeable.

Commentary. The intent of this criterion is to provide reasonable assurance that modules placed in the field can be installed; replaced, and operated with a minimum amount of handling by field personnel. Tolerance on all external module dimensions shall be maintained at a level consistent with module interchangeability. Surfaces, mounting holes, and any attachment interfaces shall be maintained within the tolerance specified in the interface control drawings.

MO.I.2 Access for Maintenance (See SY.I.3) 
MOI.3 Field Monitoring (See AR.I.6 and SY.I.2)

\section{CONCENTRATOR OPTICS/RECEIVER PERFORMANCE CRITERIA}

\section{Electrical Attributes}

\section{CR.E.1 Receiver Rlectrical Output}

Criterion. A receiver shall have an electrical output under illumination that satisfies specifications.

Evaluation. The electrical output of a receiver is characterized by certain electrical output parameters determined from the current-voltage (I-V) characteristic curve of the receiver. Test TE.AR.E.2 (Electrical Performance Test-Concentrator Solar Cells) shall be used to determine either the entire curve or some portion thereof.

Commentary. The electrical output parameters of a receiver include the short-circuit current ( $\left.\mathrm{I}_{s c}\right)$, the open-circuit voltage $\left(\mathrm{V}_{\mathrm{oc}}\right)$, the maximum power $\left(\mathrm{P}_{\mathrm{p}}\right)$, the voltage and current at maximum power $\left(V_{m}, I_{m}\right)$, the cell electrical conversion efficiency $\left(\eta_{C}\right)$, the curve fill factor (FF) and, for some purposes, the output current at a specified voltage $\left(I_{v}\right)$.

The active area of a receiver for computation of efficiency is the area designed to be illuminated. This includes interior grids and contacts and gaps between cells. The active area may exclude the area of the cells that are covered by contacts at the outer edges of the receiver, provided that it is reasonable to expect the optical system to avoid illuminating these areas. Both the active area and the total area of the receiver should be included in the report.

Receiver output parameters vary with temperature and with the intensity and the spectrum of the irradiance. Receiver electrical performance reporting conditions arc being developed.

\section{CR.E.2 Electrical Terminals (See MO.E.2)}

\section{CK.E.3 Module and Receiver Fault Tolerance (See MO.B.3)}

\section{Mechanical/Structural Attributes}

\section{CR.M.1 Attachment Provisions}

Criterion. The provisions for attaching a replaceable receiver to the support structure shall not cause significant out-of-focus distortions of the receiver when it is subjected to the operating mode structural load.

Evaluation. Documentation of satisfactory long-term experience under in-use conditions shall serve as the primary evaluation method. When adequate information is unavailable, design drawings, specifications, and engineering analyses shall be used to evaluate the receiver attachment provisions with respect to the aforementioned criteria. 
Commentary. Receiver attachment provisions must accommodate the various structural specified loading conditions. In particular, these attachment provisions shall minimize the constraint forces acting on the receiver because of temperature changes and any other differential movement between the receiver and the support structure. Since the field removal and replacement of a defective receiver can be anticipated at some time during the life of the system, these attachment provisions shall be designed to permit expeditious replacements, without disturbing the operation of other modules in the field.

\section{CR.M.2 Off-Axis Survival of Concentrator Module and Receiver (See MO.M.11)}

\section{CR.M.3 Materials Compatibility (See MO.M.12)}

\section{CR.M.4 Physical Deterioration of Gaskets, Sealants, and Polymeric Coupling Hoses}

Criterion. Gaskets, sealants, and polymeric coupling hoses, whether dry or in direct contact with heat transfer fluids, shall not have their physical properties adversely affected by contact with these fluids to the extent that their functioning is significantly impaired during their design life.

Evaluation. Documentation of satisfactory long-term performance under in-use conditions or engineering analysis shall be required. Acceptability of gaskets and sealants shall be determined by the methods outlined in ASTM D 3667-78 and in Appendices B and $C$ of NBSIR 77-1437. Where adequate information is unavailable, coupling hoses may be tested using methods that meet the criterion.

Commentary. Gaskets, sealants, polymeric coupling hoses, and similar organic materials frequently swell when exposed to liquids and, thus, may lose their ability to function.

The joints near coupling hoses are a potential source of leakage; therefore, the selection of coupling hoses and clamps is quite critical. Many failures have been noted with clamping hoses having screw or spring-type clamps. The hose tends to harden beneath the clamp when the hose is exposed to high temperatures, causing it to lose resiliency and leak. Further tightening of the clamps temporarily stops leakage but aggravates hardening. This results in a hard, nonresilient ring under the clamp that can no longer be tightened. Silicone íubluer liuses and EPDMs (Ethylene-Propylene-Diene Monomers), if properly vulcanized, tend to maintain their resiliency. The silicone rubber hoses, however, tend to be so pliable that if screw-type clamps with perforated bands are used the material is extruded through the perforations in the band. If this material is used, smooth band clamps also should be used.

\section{CR.M.5 Compatibillty of Materials with Heat Transfer Fluids}

Criterion. Materials designed to be used in contact with heat transfer fluids shall not be corroded or otherwise adversely affected by these fluids to the extent that their function will be significantly impaired under in-use conditions during their design life.

Evaluation. Documentation of satisfactory long-term performance under in-use conditions or engineering analysis shall be required. Acceptability of gaskets and sealants shall be determined by the methods outlined in Appendix B of NBSIR 77-1437. Where adequate information is unavailable, materials may be tested using methods that meet the criterion. 
Commentary. Corrosion of metals by heat transfer fluids could be a serious problem in solar energy systems. The Society of Automotive Engineers (SAE) Standard J447, "Prevention of Corrosion of Metals," provides guidance in preventing corrosion. Experience indicates that tight closed-loop systems help.

Any use of inhibitors should be keyed to the characteristics of all elements of the energy transport system to which it is exposed, including collectors, piping, connectors, tanks, pumps, valves, and heat exchangers. With nontoxic heat transfer fluids, any inhibitors should be selected to maintain desired fluid properties. (See CR.M.6.)

\section{CR.M.6 Corrosion by Leachable Substances}

Criterion. Chemical substances that can be leached by moisture from any of the materials within the system shall not cause corrosive deterioration of solar components or building elements that would significantly impair their function over their design life.

Evaluation. Documentation of satisfactory long-term performance under in-use conditions or engineering analysis shall be required. Where adequate information is unavailable, testing methods that meet the criterion shall be used.

Commentary. Salts that can be leached by moisture from some types of glass fiber and mineral wool insulation or from organic components may cause corrosion of nearby system components. Chlorides or sulfates are of particular concern in regard to metallic corrosion. Corrosion of solar components can also be caused by substances leached from roofing materials.

\section{CR.M.7 Deterioration of Fluids or Phase-Change Materials}

Criterion. Fluids or phase change materials shall not freeze, give rise to excessive precipitation, lose their homogeneity, boil, change absorptivity, or change $\mathrm{pH}$ or viscosity beyond design ranges when exposed to their maximum and minimum service temperatures and pressures during design life.

Evaluation. Documentation of satisfactory long-term performance under in-use conditions or engineering analysis shall be required. Where adequate information is unavailable, testing methods that m eet the criterion shall be used.

Commentary. Although boiling can be prevented by pressurization, excessive temperature can break down some constituents of the fluid to form organic acids. Buffers can counter the $\mathrm{pH}$ balance but only until they are exhausted. Some changes in $\mathrm{pH}$ are acceptable, but when the allowable range is exceeded, the transfer fluid or the buffers must be renewed. This can be an acceptable maintenance requirement.

Thermal cycling may cause precipitation to occur that may lead to a buildup of solids in pump seals and valve seats and cause a malfunction.

If they are taken into consideration in the design, viscosity changes may lead to pumping problems (such as excessive pumping power requirements or overheating). 


\section{CR.M.8 Effects of Decomposition Products}

Criterion. Chemical decomposition products that are expelled from solar components or building elements under in-use conditions shall not cause the degradation of solar components or building elements to an extent that would significantly impair their function over their design life.

Evaluation. Documentation of satisfactory long-term performance under in-use conditions shall be required. Where adequate information is unavailable, engineering analysis or testing methods that meet the criterion shall be used.

Commentary. Although components and materials, such as gaskets, sealants, and coatings, may yield degradation products during their service life without impairing their function or aesthetic properties, these degradation products could significantly impair the performance of other components in the system.

Heat transfer fluids, including inhibited water, may decompose and cause scale buildup that may cause deterioration. This is particularly true of hot water heaters where supply water is heated directly in the collector and dissolved solids (calcium salts) precipitate.

\section{CR.M.9 Interconnect Stress Relief (See MO.M.7)}

\section{Durability/Reliability Attributes}

\section{CR.D.I Temperature-Humidity Cycling Stresses}

Criterion. Receivers shall be capable of withstanding the stresses induced by temperature-humidity cycling for their design life without significant performance degradation.

Evaluation. Documentation of satisfactory long-term performance under in-use conditions shall be required. When such documentation is unavailable, the Test TE.AR.M.6 (Temperature/Humidity Cycling Test-Concentrator Receiver) shall be used to evaluate receivers. The characteristics to be evaluated shall include output power degradation and altered physical appearance.

Commentary. Receivers will encounter the combined effects of temperature-humidity cycling stresses as a result of diurnal and climatic excursions. 'Temperature and humidity may combine to produce effects that could not be caused by either one alone. These include temperature- and moisture-induced expansion of plastics and freeze-thaw effects. Susceptible parts of the receivers include cells, interconnects, encapsulant systems, and bonding materials. To determine satisfactory long-term performance under inuse conditions, a five-year minimum of actual environmental evaluation is suggested.

CR.D.2 Electrical Terminals (See MO.E.2)

CR.D.3 Solar Weathering (See MO.D.2)

CR.D.4 Humidity (See MO.D.3)

CR.D.5 Rain (See MO.D.4) 
CR.D.6 Temperature Cycling (See MO.D.1)

Installation, Operation, and Maintenance Attributes

CR.I.l Field Monitoring (See AR.I.6)

\section{ARRAY/ARRAY FIELD PERFORMANCE CRITERIA}

\section{Electrical Attributes}

\section{AR.B.1 Array Blectrical Output}

Criterion. An array shall have an electrical output under illumination that satisfies specificatons.

Evaluation. The electrical output of an array is characterized by certain electrical output parameters that are determined from the current-voltage (I-V) characteristic curve of the array. Test TE.AR.E.l (Electrical Performance Test-Flat-Plate Cells, Modules, and Arrays) shall be used to determine either the entire curve or some portion thereof.

Commentary. The I- $\mathrm{V}$ curve is used to determine a large number of array electrical parameters. These include the short-circuit current $\left(\mathrm{I}_{s c}\right)$, the open-circuit voltage $\left(\mathrm{V}_{\mathrm{oc}}\right)$, the maximum power $\left(P_{m}\right)$, the voltage and current at maximum power $\left(V_{m}, I_{m}\right)$, the array electrical conversion efficiency $\left(\eta_{c}\right)$, the curve fill factor (FF) and, for some purposes, the output current at a specified voltage $\left(I_{w}\right)$. The entire front area of the array, including the frame, is used in efficiency calculations.

'The parameters measured also may be used in the sale or purchase of arrays, the matching of arrays for assembly into array fields, and the detection of array degradation. The array may represent a source of high power output, and, as such, it may be impractical to measure a complete I-V curve. To interconnect arrays and match them to a given load it is of ten desirable to determine the current at a single voltage level.

The values of the array output parameters vary with the temperature and irradiance conditions. For comparison of flat-plate arrays output parameter values are normalized to and reported at the electrical performance reporting conditions specified in Table B-1 of Test TE.AR.E.1. Reporting conditions are being developed for concentrator arrays. The physical size of many arrays precludes indoor measurement of the output parameters and, hence, these parameters are of ten determined under outdoor illumination.

\section{AR.B.2 Array Field Electrical Output}

Criterion. An array field shall have an electrical output. under illumination that satisfies specifications.

Evaluation. The electrical output of an array field is characterized by certain electrical output parameters that are determined from the current-voltage (I-V) characteristic curve of the array field. This curve, or some portion of it, may be determined from a direct measurement of the array field according to Test TE.AR.E.l (Electrical Perfor- 
mance Test-Flat-Plate Cells, Modules, and Arrays) or from engineering analyses of the $\mathrm{I}-\mathrm{V}$ curves of measurable portions of the array field. The test method for determining current-voltage characteristics of concentrators is in preparation.

Commentary. The electrical output parameters of an array field include the short-circuit current $\left(\mathrm{I}_{\mathrm{sc}}\right)$, the open-circuit voltage $\left(\mathrm{V}_{\mathrm{oc}}\right)$, the output current at a specified voltage $\left(I_{v},\right)$ the maximum power $\left(P_{m}\right)$, the voltage and current at maximum power $\left(I_{m}, V_{m}\right)$, and the electrical conversion efficiency $\left(\eta_{\mathrm{C}}\right)$. The area used in conversion efficiency calculations, to reflect land utilization, is defined by the line connecting the outer bounds of the arrays in the array field projected on the horizontal.

These electrical output parameters may be used to monitor performance, detect any degradation of the array field, and compare performance with other array fields. Because the array field represents a source of high power output, it may be impractical to measure a complete I-V curve. In this case, an I-V curve may be determined from measurements or data from individual branch circuits or other measurable parts of the array field.

The values of the electrical output parameters of an array field vary with temperature and irradiance. For comparison of flat-plate arrays, output parameter values may be normalized to and reported at the electrical performance reporting conditions specified in Table B-1 of Test TE.AR.E.l. The physical size of the array field requires the electrical parameters to be measured outdoors. The methods presently available to normalize the measured or determined parameters to the standard reporting conditions are such that they may not be accurate.

\section{AR.E.3 Lightning Protection (See SY.E.8)}

\section{AR.E.4 Array Capability (See SY.E.4)}

\section{AR.E.5 Mismatch Losses in Modules and Arrays (See MO.E.4)}

\section{Mechanical/Structural Attributes}

\section{AR.M.1 Flat-Plate Array Structural Adequacy}

Criterion. Flat-plate arrays shall support all loads expected during the design life of the system without structural failure or significant performance degradation.

Evaluation. The structural adequacy of the array structure for a given application shall be demonstrated by structural analysis. Documentation of satisfactory long-term performance under in-use conditions shall be considered contributory evidence of structural adequacy.

Commentary. The loading criteria to be used in evaluating the array structure are primarily dependent on geography, use, and construction. Wind loading is recognized as a primary structure cost driver for photovoltaic arrays. In some applications it may be cost-effective to take advantage of the reduced wind loading due to boundary layer effects near the ground, shielding from adjacent rows or arrays, or wind shielding devices, provided that the increased cost of supporting analysis and documentation is defrayed by decreased structural costs. 


\section{AR.M.2 Concentrator Array Structural Adequacy}

Criterion. In any sun-tracking operating mode, the PV concentrator array shall safely support operating design loads (dead weight, wind, and constraint loads) without structural failure or performance degradation beyond that accounted for in the energy loss budget for the system. When in a nonoperating mode or position, the concentrator array shall support all loads expected during the design life of the system without structural failure or subsequent performance degradation when the system is returned to an operating condition.

Evaluation. The structural adequacy of the array structure for a given application shall be demonstrated by structural analysis. Documentation of satisfactory long-term performance under in-use conditions shall be considered contributory evidence of structural adequacy.

Commentary. The loading criteria to be used in evaluating the array structure are primarily dependent on geography, use, and construction. Wind loading is recognized as a primary structural cost driver for photovoltaic arrays. In some applications it may be cost-effective to take advantage of the reduced wind loading caused by boundary layer effects near the ground, shielding from adjacent rows of arrays, or wind shielding devices, provided that the increased cost of supporting analysis and documentation is defrayed by decreased structural costs. In connection with concentrator arrays, it is appropriate to distinguish between operating and nonoperating loads. The operating loads are those that occur while the array is in a sun-tracking operating mode. Operating loads cause structural deformations which affect the ability of the concentrator array to accurately track the sun. Operating wind loads might be significantly lower than nonoperating wind loads because studies have shown that virtually all of the sun's insolation occurs at relatively low wind speeds. Nonoperating loads occur at any time during the design life of the array. In addition to withstanding these loads without structural failure, permanent deformations of concentrator array structures should not reduce excessively the ability of the array to collect solar energy.

\section{AR.M.3 Off-Axis Survival of Field Components (See AR.S.1)}

\section{Safety Attributes}

\section{AR.S.l Off-Axis Survival of Field Components}

Criterion. Field components shall be capable of tolerating concentrated sunlight traversing off the normally illuminated area during normal operating conditions (e.g., surı acyuisition or steering operations) or abnormal operating conditions (e.g., power failure of tracking motors) without significant degradation.

Evaluation. Off-axis survival shall be demonstrated by engineering and safety analyses during field layout and design. The characteristics to be evaluated are adequate spacing of components and use of shielas or barriers, any redundancy in coinponent design, use of noncombustible materials, and use of materials that will not sof ten or melt.

Commentary. Concentrators can impose complex steady-state and transient thermal loads on adjacent structures during off-axis pointing. Depending on the specific concentrator, optics chosen, and the field layout, the energy distribution on adjacent structures 
can be highly nonuniform and may reach very high levels of concentration in localized areas. The nature of the off-axis condition-that is, whether the array is moving or stopped-determines the extent to which adjacent structures may be exposed to intense energy concentrations for extended periods of time.

Linear focusing concentrators inherently concentrate light off the receiver at the ends of the trough during normal operation while tracking and the effect of this concentrated light must be accounted for in field layout.

\section{AR.S.2 Safety Procedures (See SY.S.1)}

\section{AR.S.3 Flammability (See MO.S.5)}

\section{Durability/Reliability Attributes}

AR.D.1 Humidity (See MO.D.3)

Installation, Operation, and Maintenance Attributes

AR.I.1 Access for Maintenance (See SY.I.3)

AR.I.2 Array Spacing for Shadowing (See SY.B.1)

AR.I.3 Installation, Operation, and Maintenance Manual (See SY.I.2)

AR.I.4 Installation Plan (See SY.S.6)

AR.I.5 System Maintainability (See SY.I.2)

\section{AR.I.6 Field Monitoring}

Criterion. Modules, receivers, tracking and control apparatus, and arrays shall provide monitoring capability for evaluating clcctrical and thermal performance.

Evaluation. Drawings, specifications, and the operating/maintenance manuals shall be reviewed to determine that appropriate accessible and monitoring points (e.g., electrical terminals) have been incorporated.

Commentary. The location of accessible and appropriate sensors will permit arrayrelated parameter monitoring and expedite the maintenance and repair of equipment. Periodic monitoring of modules (arrays, concentrators, etc.) is sometimes necessary to check for hot-spot heating, power degradation, etc. Test points at the appropriate element are useful for monitoring the above conditions. 


\section{REFERENCES}

1. Chen, C. P. Fracture Strength of Silicon Solar Cells. DOE/JPL-1012-32. Pasadena, CA: Jet Propulsion Laboratory; October 1979.

2. Prince, J. L.; Lathrop, J. W. Investigation of Reliability Attributes and Accelerated Stress Factors on Terrestrial Solar Cells. DOE/JPL-954929-79/4. Pasadena; CA: Jet Propulsion Laboratory; May 1979.

3. Ross, R. G., Jr. Interface Design Considerations for Terrestrial Solar Cell Modules. Proceedings of the 12th IEEE Photovoltaics Specialists Conference, Baton Rouge, Louisiana; December 1976; pp. 801-806.

4. Gonzalez, C.; Weaver, R. Circuit Design Considerations for Photovoltaic M̃odules and Systems. Presented at the 14th IEEE Photovoltaics Specialists Conference, San Diego, California, 7-10 January 1980.

5. Bucciarelli, L. I., Jr. "Power Loss in Photovoltaic Arrays Due to Mismatch in Cell Characteristics." Solar Energy. Vol. 23; 1979; pp. 277-288.

6. Moore, D. Proposed Method for Determining the Thickness of Rectangular Glass Solar Collector Panels. DOE/JPL 1012-41. Pasadena, CA: Jet Propulsion Laboratory; March 1980.

7. Jet Propulsion Laboratory. "Solar Cell Interconnector Design Problems." Solar Cell Array Design Handbook. Pasadena, CA: JPL; October 1976.

8. Gonzalez, C. Environmental Hail Model for Assessing Risk to Solar Collectors. LSA Project Task Report 5101-45 (JPL Internal Document), Pasadena, CA: Jet Propulsion Laboratory; December 1977.

9. U.S. Department of Housing and Urban Development. HUD Intermediate Minimum Property Standard Supplement for Solar Heating and Domestíc Hot Water Systems. Document 4930.2, Vol. 5. Washington, DC.; 1977.

10. Moore, D.; Wilson, A. Photovoltaic Solar Panel Resistance to Simulated Hail. DOE/JPL 1012-78/6. Pasadena, CA: Jet Propulsion Laboratory; October 1978.

11. Hoffman, A.; Magg, C. Airborne Particulates Soiling of Terrestrial Photovoltaic Modules and Cover Materials. Presented at the Institute of Environmental Sciences Annual Meeting, Philadelphia, PA. 11-14 May 1980.

12. Stultz, J.; Wen, L. C. Thermal Performance Testing and Analysis of Photovoltaic Modules in Natural Sunlight. LSSA Project Task Report 5101-31 (JPL Internal Document). Pasadena, CA: Jet Propulsion Laboratory; July 1977.

13. Stultz, J. Thermal and Other Tests of Photovoltaic Modules Performed in Natural Sunlight. DOE/JPL 1012-78/9. Pasadena, CA: Jet Propulsion Laboratory; July 1978.

14. Stultz, J. "Thermal and Other Tests of Photovoltaic Modules Performed in Natural Sunlight." Journal of Energy. Vol. 3 (No. 6): November-December 1979; pp. 363372. 


\subsection{POWER CONDITIONING SUBSYSTEM}

Page

Introduction $\ldots \ldots \ldots \ldots \ldots \ldots \ldots \ldots \ldots \ldots \ldots \ldots \ldots \ldots \ldots \ldots \ldots \ldots \ldots \ldots \ldots$

Performance Criteria $. \ldots \ldots \ldots \ldots \ldots \ldots \ldots \ldots \ldots \ldots \ldots \ldots \ldots \ldots \ldots \ldots \ldots \ldots \ldots \ldots . \ldots . \ldots$

Electrical Attributes $\ldots \ldots \ldots \ldots \ldots \ldots \ldots \ldots \ldots \ldots \ldots \ldots \ldots \ldots \ldots \ldots \ldots \ldots \ldots$ 4-4

PC.E.1 Input Voltage Specification ..................... 4 4-4

PC.E.2 Input Ripple Current Ratio .................... 4-4

PC.E.3 Input Current-Voltage Characteristics ............... 4-5

PC.E.4 . Output Voltage for Stand-Alone Inverter .............. 4-5

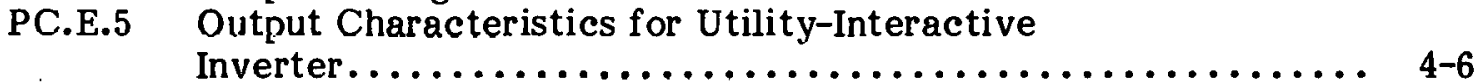

PC.E.6 Unbalanced Load for Stand-Alone Inverter ............. 4-6

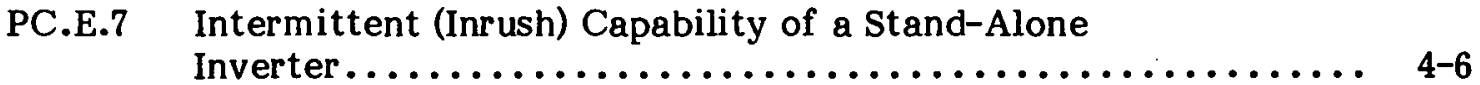

P.C.E.8 Load Power Factor for Stand-Alone Inverters . . . . . . . . . 4-7

PC.E.9 Output Power Factor or VARS for Utility-Interactive

Inverter............................... 4-7

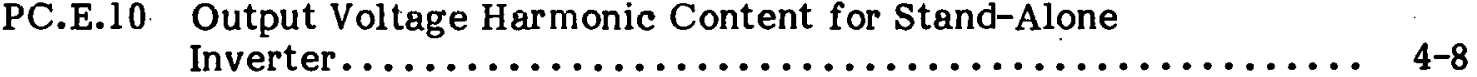

PC.E.11 Output Current Harmonic Content for Utility-

Interactive Inverter ........................ 4-8

PC.E.1 2 Output Frequency of Stand-Alone Inverter ............ 4-9

PC.E.13 Turn-on Characteristics ....................... 4-9

PC.E.14 Efficiency............................... 4-10

PC.E.15 Input Undervoltage/Overvoltage Survival Capability ........ 4-10

PC.E.16 Output Undervoltage/Overvoltage .................. 4-11

PC.E.17 Output Underfrequency/Overfrequency................ 4-12

Thermal Attributes $\ldots \ldots \ldots \ldots \ldots \ldots \ldots \ldots \ldots \ldots \ldots \ldots \ldots \ldots \ldots \ldots \ldots \ldots . \ldots \ldots \ldots$

PC.T.1 Overtemperature.......................... 4-12

Mechanical/structural Attributes......................... 4-12

PC.M.l Operational Temperature, Pressure, and Humidity ......... 4-12

Safety Attributes $\ldots \ldots \ldots \ldots \ldots \ldots \ldots \ldots \ldots \ldots \ldots \ldots \ldots \ldots \ldots \ldots \ldots \ldots \ldots$

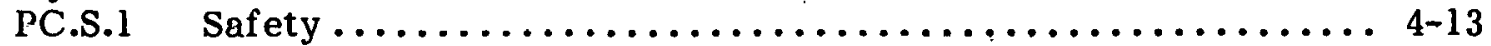

PC.S.2 Burn Hazard............................. 4-14

PC.S.3 Fire Safety ............................... 4-14

PC.S.4 Electrical Isolation and Insulation ................. 4-14

Installation, Operation, and Maintenance Attributes.............. 4-16

PC.I.1 Installation, Operation, and Maintenance Manual .......... 4-16

PC.I.2 Maintainability ........................... 4-16

PC.I.3 Accessibility ........................... 4-16

PC.I.4 Local Monitoring............................ 4-16

PC.I.5 Local/Remote Controls ........................ 4-17

PC.I.6 Local/Remote Monitoring ...................... 4-17 


\section{THIS PAGE}

\section{WAS INTENTIONALLY LEFT BLANK}




\section{SECTION 4.0}

\section{POWER CONDITIONING SUBSYSTEM}

\section{INTRODUCTION}

The power conditioning subsystem comprises the power conditioning units (PCU) and power routing switches required to link one or more power sources to one or more loads. It also provides necessary subsystem supervisory functions and signal wiring. The power conditioning subsystem may be controlled by the system monitor and control unit through the power conditioning monitor and control subsystem, which responds to both internal and external signals for supervision of PCU operation. To avoid conflicts, all signals to and from PCUs and power routing switches should be routed through the power conditioning monitor and control subsystem. The system monitor and control unit is described in Section 2.0; the power conditioning monitor and control subsystem is described in Section 5.0.

An inverter is a PCU which changes a DC input to an AC output, and may be used in two types of systems: stand-alone (SA) and utility interactive (UI) systems.

An SA system is one in which the inverter operates independently of a utility line; it never operates in parallel with the utility line. The output voltage of an SA inverter is fixed; the output current drawn is determined by the loads. Generally, all load requirements (real, reactive, transient) must be supplied by the inverter. It is possible to draw supplementary power, if needed, by disconnecting the load from the inverter and connecting the load to the utility (if available) by electronic or mechanical switching. A DC power supply can be used to provide supplementary power to the DC input of the inverter. A diesel generator or other supplementary energy source can be used in a stand-alone system.

A UI system is one in which the inverter or system operates in parallel with a utility line to supply a common load and may supply power to that line. The output voltage of the UI inverter is set by the utility line; the inverter controls the output current. Contrast this capability with that of the SA inverter described previously. The power supplied by or to the utility is the difference between that supplied by the PV system and that used by the load. Transient overloads, such as those required for starting a motor, would normally be supplied by the utility. Proper function of the inverter may or may not be dependent on the connection to the utility line.

A UI system could be designed so that power is never delivered to the utility. In this case, the PV power system must operate in a load-following mode whenever array capability is greater than the load, thus not using all available energy. Alternatively, another discretionary load (battery charger/battery or water heater, for instance) may accept excess PV power available. A UI system may also employ equipment to operate the array at the maximum power point (see glossary). In this case, a sufficient load must always be available to absorb all available array power.

Both stand-alone and UI systems may include an energy storage device to store PV and/or off-peak utility energy for use at night or when load demand exceeds available PV power.

Performance criteria in this section are applicable to both SA and UI applications unless otherwise indicated. In some cases, specific comments relative to one or the other 
application are made in the commentary statements, as appropriate. Later editions of this document will include performance criteria for other types of power conditioning units, as described in the glossary. Test methods referred to in this section with the code designation TE.PC. are located in Appendix B.

\section{PERFORMANCE CRITERIA}

\section{Electrical Attributes}

\section{PC.E.1 Input Voltage Specification}

Criterion. The PCU shall perform as specified for any applied DC input voltage within the input voltage and environment operating range specified.

Evaluation. Test TE.PC.E.l (Power Conditioning Unified Test Procedure for Solid-State Inverters).

Commentary. It is recommended that PV array voltage ranges be standardized so that PCUs need not be custom designed for each application. For SA and transformer-isolated UI units, $100 \mathrm{~V}$ to $300 \mathrm{~V}$ have been used for up to $50-\mathrm{kW}$ ratings in both single and three-phase systems. Other voltages may become desirable as new power switching devices are developed. Recently, UI inverters for up to $10 \mathrm{~kW}$ have been designed for the $160 \mathrm{~V}$ to $240 \mathrm{~V}$ input voltage range. If line-commutated UI inverters are to be used without transformer isolation, the input voltage range should be consistent with restrictions on maximum DC input voltage; e.g., 90\% of the RMS AC utility voltage for single-phase units and 135\% (6 pulse) and $141 \%$ (12 pulse) of the RMS AC line-to-line utility voltage for three-phase units. Similar restrictions apply to self-commutated inverters without transf orm er isolation.

\section{P.C.E.2 Input Ripple Current Ratio}

Criterion. The input ripple current ratio for the PCU shall be less than that value specified for the unit for a specified range of input impedances.

Evaluation. Test TE.PC.E.1 (Power Conditioning Unified Test Procedure for Solid-State Inverters).

Commentary. Measurement system bandwidth is restricted so that switching transients that have little practical effect on loads (other than EMI considerations) will not produce misleading measurements.

Ripple superimposed on the average current drawn from the PV array can reduce average array output power and, if excessive, can cause the inverter to malfunction. At the maximum power point the PV array impedance (for small changes) can be approximated by a resistor numerically equal to the voltage divided by the current. Generally this incremental resistance is minimum when the array maximum power point voltage is lowest (either by design or because of high-temperature operation), leading to the worst ripple currents for a given PCU. The effects on a PV array of ripple current drawn by a connected load is discussed in Ref. 1 . In systems with storage, the effects of ripple current are still under investigation. 
An analysis of how the inverter input ripple current is affected by the instantaneous power balance and the input filter circuitry is shown in Ref. 2. As described in this reference, the input filter strongly affects the amount of ripple fed back to the source. Array nonlinearity can also introduce additional harmonics. Filters, if required, should be placed at the input to the PCU to prevent conduction of internally generated signals to the PV array, from which they could be radiated to cause electromagnetic interference (EMI).

\section{PC.E.3 Input Current-Voltage Characteristics}

Criterion. The input current drawn by the inverter as a function of applied input voltage shall satisfy the input current-voltage characteristics as specified for a given set of output load and voltage conditions.

Evaluation. Test TE.PC.E.1 (Power Conditioning Unified Test Procedure for Solid-State Inverters).

Commentary. The current-voltage input characteristics of the inverter are important because they provide insight into system performance under variable conditions of PV array output and system load.

If a closed-loop maximum power point tracker is included in the PCU package, it must temporarily be overridden in order to measure input characteristics.

\section{PC.E.4 Output Voltage for Stand-Alone Inverter}

Criterion. The output voltage of an SA inverter shall satisfy specifications for amplitude adjustment range and response speed.

Evaluation. To be prepared for a future edition.

Commentary. Inverters designed for SA systems applications should provide a nominal AC output voltage at one of the electric utility standards, such as $120 / 240 \mathrm{~V}$ single-phase or $120 / 208 \mathrm{~V}$ three-phase. It will usually not be necessary or desirable to adjust the output voltage by means of front panel controls, because most loads are able to operate within nominal utility tolerances. An internal adjustment range of $\pm 10 \%$ of nominal is common.

Since most loads that would be connected to the inverter can operate with utility power, they will tolerate the normal fluctuations found on a utility line. This level of regulation should, therefore, be sufficient except for special cases. Voltage regulation aspects are the static and dynamic response characteristics of the inverter.

If the inverter can handle momentary overloads, such as motor starts, the manufacturer should specify its regulation characteristics under such conditions, if they differ from normal operations. Some inverters, such as those used for variable-speed AC motor drives will require additional specifications. 


\section{PC.E.5 Output Characteristics for Utility-Interactive Inverter}

Criterion. The UI inverter shall be capable of operating with specified output characteristics when connected to a utility line of specified characteristics which constrains the inverter-output voltage and frequency and presents a specified impedance to the inverter.

Evaluation. Test TE.PC.E.1 (Power Conditioning Unified Test Procedure for Solid-State Inverters).

Commentary. In a UI system, the output of the inverter is connected directly to the utility line; therefore, output voltage and frequency are fixed. The inverter should be capable of operating over a range of output voltages and frequencies that are compatible with the utility line characteristics. The nominal output voltage, frequency, and operational range, expressed as a percentage of nominal, shall be specified.

For UI inverters operating in parallel with utility sources of comparable capacity, as in small diesel-powered systems, protective measures and a description of adjustments (if applicable) should be provided to prevent the voltage or frequency of the combined power system from exceeding safe levels.

For inverters using a three-phase utility. connection, the manufacturer should state the allowable phase voltage imbalance and phase deviation from nominal.

A standard U.S. test line impedance for single-phase residential UI inverters will be determined. Line impedances substantially different from the standard test impedance may affect inverter specifications, such as harmonic current injection and device stability. A range of line impedances should be considered in the design of the equipment. Line commutated inverters rely on the utility line to supply commutation energy for proper circuit operation, if no filter is present.

\section{PC.E.6 Unbalanced Load for Stand-Alone Inverter}

Criterion. The inverter shall be able to sustain an unbalanced load equal to a maximum stated level.

Evaluation. Test TE.PC.E.l (Power Conditioning Unified Test Procedure for Solid-State Inverters).

Commentary. In a three-phase system, modern utility-supplied loads usually exhibit some imbalance among phase loads. The same is true for two sides of a $240-\mathrm{V}$ singlephase center tap system. A $\mathrm{r} \cdot \mathrm{CU}$ should be capable of operation in these unbalanced loads and should protect itself and the load if the limits of load imbalance are exceeded.

\section{PC.E.7 Intermittent (Inrush) Capability of a Stand-Alone Inverter}

Criterion. The inverter shall be capable of providing reactive and real power output in excess of its rated output power consistent with its overload specification.

Evaluation. Test TE.PC.E.l (Power Conditioning Unified Test Procedure for Solid-State Inverters). 
Commentary. Overload capability is the ability of the PCU to provide output in excess of specified ratings. This may be required in order to put high inrush current loads into operation. Overload capability may be a necessary performance requirement. Application of a load within the specified overload rating of the PCU shall not activate protective devices, turn off the PCU, or damage internal components.

Where necessary, SA systems should be specified to supply sufficient rated or overload capacity (including reactive currents) to provide inrush currents to start equipment such as compressors, motors, and tungsten-type loads. If the power system does not include storage, then the real (nonreactive) portion of the overload capability may be limited by the PV array. If storage is provided, then real power will likely be limited by the overload rating of the PCU. These overload ratings may permit high inrush currents for short times and a longer time for overload capability (e.g., for motor starting and inertial loads). Note that higher-than-necessary overload capability may unnecessarily decrease efficiency and increase the cost of the PCU. Overload capability is part of a complex trade-off against such things as efficiency and cost; therefore, increased overload capability is not necessarily a benefit.

\section{PC.E.8 Load Power Factor for Stand-Alone Inverters}

Criterion. All inverter output specifications shall be met when the load displacement power factor is within its specified maximum allowable limit.

Evaluation. Test TE.PC.E.l (Power Conditioning Unified Test Procedure for Solid-State Inverters).

Commentary. Displacement or fundamental power factor has traditionally been the loading used to specify inverter capability. As the use of nonlinear loads increases, such as AC-powered switching power supplies, the effects of harmonic currents drawn from inverters have become more important. The effects of nonlinear loads and limitations on them shall be stated.

A power transfer map (as defined in the glossary) may be used to specify the allowable load power factor.

\section{PC.E.9 Output Power Factor or VARs for Utility-Interactive Inverter}

Criterion. Output total power factor or VARs shall be within specifications over the full rated range of operation of the inverter.

Evaluation. Test TE.PC.E.1 (Power Conditioning Unified Test Procedure for Solid-State Inverters).

Commentary. When an inductive load is connected to a utility line, the current (defined into the load) lags the voltage. This condition is a lagging power factor or a consumer of reactive volt-amps as defined in utility terminology.

Conversely, a capacitive load presents a leading power factor which supplies reactive volt-amps. To prevent confusion, the UI inverter should be treated as any other utility load and the direction of the current reference should be toward the inverter. If the power factor is adjustable, its range should be specified. 


\section{PC.E.10 Output Voltage Harmonic Content for Stand-Alone Inverter}

Criterion. The output voltage harmonic content shall be equal to or less than that specified over the full rated range of operation of the inverter.

Evaluation. Test TE.PC.E.I (Power Conditioning Unified Test Procedure for Solid-State Inverters).

Commentary. The amount of voltage distortion that can be tolerated depends on the equipment connected to the inverter and the susceptibility of this equipment to nonsinusoidal waveshapes. Most loads have been designed to operate from utility lines that have a low harmonic content. Some loads are sensitive to waveform distortion. The total harmonic voltage distortion accepted for powering critical computer loads is 5\%; no more than $3 \%$ is in any one harmonic.

Allowance of higher distortion may permit the design of higher efficiency or lower cost equipment or both. The PCU output waveform may be purposely nonsinusoidal (such as a square wave) in some specialized applications. See Ref. 3 for additional information.

\section{PC.E.11 Output Current Harmonic Content for Utility-Interactive Inverter}

Criterion. Output current harmonic content shall be equal to or less than that specified over the full range of operation of the inverter while operated into a utility line of specified characteristics.

Evaluation. Test TE.PC.E.1 (Power Conditioning Unified Test Procedure for Solid-State Inverters).

Commentary. The amount of voltage distortion that can be tolerated on the utility lines depends on the susceptibility of the equipment connected to it. The measirement and specification of voltage harmonic content is therefore preferred at the utility system level. The UI inverter can be modeled as a generator of harmonic currents. Measurements of these harmonic currents are required to calculate the effects of the inverter on the distribution system. Measurements of the individual harmonics are desirable to help select suppression techniques, because the amplitudes actually generated frequently differ from those indicated by simplified theory. The resultant voltage harmonics at the point of equipment connection, and at other points in the utility distribution system, will depend on system impedances at harmonics and inverter harmonic current content. Care should be taken to avoid resonances. The ability of the utility to absorb these harmonic currents without damage and with acceptable resultant voltage harmonics may be specific to the site. Adequate information about the line impedances at harmonics at residential and nther locations on low voltagc distribution lines is not yet avuiluble, but relatively large amounts of harmonic current may be acceptable for the near term. As the number of UI inverters in a particular residential distribution area increases, a more restrictive inverter specification (or distribution systems modification) could become necessary, consistent with utility standards which may be developed. A standard U.S. test line impedance for single-phase residential UI inverters will be determined.

Intermediate PV power systems may be large enough to make custom filters economically feasible. Measurements made on an individual installation will determine the filter required. Similar comments apply to central power applications, which use custom designed filters. 


\section{PC.E.12 Output Frequeney of a Stand-Alone Inverter}

Criterion. The output frequency of an SA inverter shall satisfy specifications for nominal value and stability.

Evaluation. A frequency measuring instrument with an accuracy and readability of $0.1 \mathrm{~Hz}$ shall be used. The frequency adjustment range (if adjustable) shall be checked at nominal input voltage and full rated load. The frequency shall then be set at the nominal operating frequency and the unit allowed to temperature stabilize.

Any frequency change shall be noted and then the frequency shall again be set to its nominal value. The input voltage and load shall be varied over the full specified operating range and the frequency shall be recorded. If required, the frequency shall be measured at environmental extremes. If it can be shown that the frequency is independent of output load, testing may be confined to the individual circuit or card that contains the elements determining frequency.

If the inverter contains provisions for phase lock to an external reference, phase error shall be recorded as the external reference frequency is varied between specified limits. The locking range is defined as the range of reference frequencies within which the inverter can achieve phase lock.

If the specification includes a requirement for a maximum rate of phase change, this shall be measured by using instrumentation which provides an abrupt change of phase into the reference frequency terminals.

Commentary. Most loads to be used with an SA inverter have been designed for operation at either 50,60 , or $400 \mathrm{~Hz}$. A majority of these loads can tolerate at least a $5 \%$ deviation from nominal, but some loads, such as clocks, require long-term frequency accuracy.

\section{PC.E.13 Turn-on Characteristics}

Criterion. The inverter shall be capable of satisfying the specified turn-on characteristics of input or output voltage, current, or power, af ter input power has been applied to the inverter, or when the inverter is recovering from a load or source fault condition.

Evaluation. The turn-on input or output transients shall be recorded by an oscilloscope equipped with a camera or a suitable chart recorder. Turn-on shall be checked at several combinations of low and high input voltage and no load to full load as specified in Test TE.PC.E.l (Power Conditioning. Unified Test Procedure for Solid-State Inverters). If applicable, short circuits (or overloads) shall be applied to the inverter and photographs taken of the recovery transient.

Commentary. Power system equipment is usually designed to turn on gradually, or "walk in." This is done to minimize transients in the AC or DC side of the power system by allowing power flow to change slowly. This walk-in capability should also operate in remote-controlled units when switching from the standby mode to the operate mode. Walk-in capabilities are especially important in UI PV applications because of the limited power available during morning turn-on procedures. 
If an inverter requires a power surge when it is turned on, or when it is connected to the utility, then this transient power requirement limits the system's useful power range.

\section{PC.E.14 Efficiency}

Criterion. The conversion efficiency shall be no lower than the values specified over the stated range of electrical and environmental conditions.

Evaluation. Test TE.PC.E.1 (Power Conditioning Unified Test Procedure for Solid-State Inverters).

Commentary. Efficiency is the fraction of input power converted into useful output power. Two efficiency definitions have been established by the Institute of Electrical and Electronics Engineers (IEEE) Industrial Application Society (IAS) and are as follows:

- P428-D 1 2.3.11 Total Efficiency. The ratio of the total output power to the total input pow er including the contribution of all harmonics.

- P428-D1 2.3.12 Fundamental Efficiency. The ratio of the fundamental output power to the fundamental input power.

Generally, harmonics of the fundamental frequency do not contribute useful power to a load and may cause undesirable heating effects in load equipment such as motors and transformers. However, for loads such as incandescent lights and resistance heating elements, harmonics can contribute useful power.

Electrodynamometer power meters will measure total power to at least $1 \mathrm{kHz}$. The same measurement can be made with Hall effect multipliers or electronic analog multipliers. The derivation of the fundamental component of voltage and current prior to multiplication would unnecessarily complicate efficiency measurements. It is therefore recommended that the total efficiency shall be measured since suitable equipment is generally available. If total harmonic distortion is low, the differences are negligible.

The system designer should bear in mind that, in general, the inverter will not operate at maximum rated output. If an oversized inverter was chosen to accommodate transient loads, but it will normally operate at partial load, then the specification should cover the partial load efficiency and not the full load efficiency.

\section{PC.E.15 Input Undervoltage/Overvoltage Survival Capability}

Criterion. The PCU shall survive specified overvoltage and undervoltage conditions at its input without damage.

Evaluation. Satisfactory performance of a reference unit shall be determined in a qualification test which subjects the unit to undervoltage and overvoltage. The unit shall automatically disconnect from the input source, or otherwise take protective action, when input voltage falls outside the design range. Restart of the inverter shall provide operation within specifications.

Commentary. When a PCU is operated directly from a PV array, an undervoltage condition will occur when more power is demanded from the array than is available at the 
maximum power point. An overvoltage may occur in cold weather when insufficient power is drawn from the PV array.

Input overvoltage may damage an inverter; thus, a disconnection or short-circuit (crowbar) between the PV source and the inverter may be necessary. With an undervoltage condition present, the inverter may not provide the specified output power quality and the inverter must be safely turned off or the load disconnected. The inverter should be capable of surviving any input undervoltage condition without damage to itself or the load.

The input voltage design range requires a complex trade-off against such items as efficiency and cost. Inverters of various designs will have different short- and long-term capabilities regarding input under- and overvoltage. The manufacturer should supply applicable information.

If the under/overvoltage circuitry acts to trip an input circuit breaker, and if such circuitry senses input voltage after the circuit breaker, some additional circuitry (such as time delays) must be provided to permit reliable turn-on of the unit.

For unattended operation, an inverter in a system without energy storage should be capable of automatic turn-on or turn-off at sunrise and sunset. In addition, large power fluctuations, such as those caused by transient cloud cover, should not cause system malfunction.

\section{PC.E.16 Output Undervoltage/Overvoltage}

Criterion. An SA inverter shall disconnect, or otherwise protect the inverter or load, or activate an alarm (or both) when the output voltage is beyond specified limits.

A UI inverter must disconnect from the utility line as specified when the utility voltage is beyond specified limits.

Evaluation. A recommended test procedure will be prepared for a future edition.

Conimentary. This performance criterion may not be required for all SA applications. Output undervoltage could be caused by inverter malfunction or output overload. Output overvoltage in SA inverters is usually the result of inverter malfunction.

Since overvoltage to the load is potentially harmful to that load, some protection may be afforded by an automatic load disconnect. While failure in the overvoltage mode is common in DC power supplies, it is uncommon for AC inverters; therefore, the need for protection must be weighed for each type of inverter design and application.

For UI inverters, the output voltage of the inverter when it is connected to the utility line is determined solely by the utility since the utility power capability will usually far exceed that of the inverter. An undervoltage or overvoltage condition from the utility indicates a serious utility problem. A UI inverter must be disconnected from the utility to protect the inverter and utility personnel when an out-of-specification condition exists. The undervoltage/overvoltage sensing may also be an inherent part of an inverter's protective design in sensing that the utility voltage has disappeared. System restart, after shutdown due to utility removal, can be manual, or if restart is automatic, the utility power first must be restored and stable. 
Many options exist for residential and intermediate load center power systems. The system could be designed so that, should utility failure occur, the system disconnects from the utility and reverts to SA operation to supply local loads as much as possible. Loss of utility in central power applications precludes further operation, and manual restart will probably be required.

\section{PC.E.17 Output Underfrequency/Overfrequency}

Criterion. The inverter shall provide an alarm or automatically disconnect to protect the load or inverter in the event of output under- or overfrequency.

Evaluation. An evaluation procedure shall be performed if the inverter contains an outof-frequency alarm/shutdown circuit. Inverter frequency may be varied or an external variable signal may be applied to the frequency detecting circuitry (whichever is appropriate). Trip/alarm frequencies shall be compared to specifications.

Commentary. In a SA application, an under- or overfrequency output indicates failure within the inverter. Such failure, if severe, can cause damage to the inverter or the connected load. In most inverter designs, failure in frequency regulation is unlikely; therefore, this protection may not be required.

For UI applications, the output frequency (when the inverter is connected to the utility) is determined solely by the utility since the utility power capability will far exceed that of the inverter. Any under- or overfrequency condition indicates a serious utility problem.

\section{Thermal Attributes}

\section{PC.T.1 Overtempcrature}

Criterion. If the equipment is provided with such protective devices, automatic shutdown shall occur or remote alarms shall become operative when the unit operating temperature is beyond its specified range.

Evaluation. The temperature sensors shall be heated or cooled with a suitable source and monitored while temperature and shutdown/alarm signals are monitored.

Commentary. Electronic equipment is designed to operate within specified temperature ranges. Critical components, usually semiconductors, are provided with minimum cooling, consistent with long-term reliability and economic considerations. An overtemperature condition may be the result of blockage of air passages or loss of forced air.

\section{Mechanical/Structural Attributes}

\section{PC.M.l Operational Temperature, Pressure, and Humidity}

Criterion. PV inverters shall be capable of operating over the specified range of ambient temperatures, pressures, and humidity conditions. 
Evaluation. Satisfactory thermal performance of a representative complete unit shall be determined in a qualification test capable of producing the range of specified temperatures for the unit. Pressure and humidity specification conformance shall be determined by test or experience and design analysis.

Commentary. Like any piece of electrical equipment, the inverter must perform satisfactorily over the ranges of temperature, humidity, and pressure to which it will be subjected in operation. The pressure range should include the barometric pressures at all locations at which the unit might be installed.

Special consideration is necessary if unit operation below $0^{\circ} \mathrm{C}$ is required, because components may be affected by these temperatures.

Although the unit may be installed in a temperature- and humidity-controlled room, unit failure should be avoided if the building HVAC system should fail. One possible set of operating conditions might be:

- Ambient temperature

- Relative humidity:

- Barometric pressure: $0^{\circ} \mathrm{C}$ to $40^{\circ} \mathrm{C}$

up to $96 \%$, noncondensing

$69.3 \mathrm{kPa}$ to $101.3 \mathrm{kPa}(520$ to $760 \mathrm{~mm} \mathrm{Hg}$ )

If required, the inverter should be provided with internal cooling fans and proper cooling air flow paths to maintain satisfactory performance over the specified temperature, pressure, and humidity ranges.

\section{Safety Attributes}

\section{PC.S.1 Safety}

Refer to performance criterion SY.S.1. See below for additional commentary warranting particular attention.

Commentary. In addition to the issues mentioned in SY.S.1, the following characteristic should be considered.

Charged capacitors represent a safety hazard to service personnel. Permanently connected bleeder resistors will discharge the capacitors, but they lower system efficiency; therefore, a trade-off must be made, balancing safety against efficiency. Another method of discharging capacitors is by using a discharge button and a voltage indicator, or a safety interlock system. These methods, although somewhat more costly, optimize both safety and efficiency.

The system generally should be designed so that the voltage across the input capacitors falls to below $30 \mathrm{VDC}$ within one minute after power is removed from the inverter, or upon access to the inverter for servicing.

See also SY.I.1, Installation, Operation, and Maintenance Manual, for futher information. 


\section{PC.S.2 Bum Hazard (see SY.S.7)}

\section{PC.S.3 Fire Safety (see SY.S.5)}

\section{PC.S.4 Electrical Isolation and Insulation}

Criterion. Input and output power connections shall meet the specifications for electrical isolation from equipment ground. If the input and output power leads are stated to be electrically isolated from each other, the isolation shall meet its specifications.

Evaluation. The dielectric withstand voltage shall be tested in accordance with Method 301 of MIL-STD-202.

- The magnitude of the test voltage should be as specified in Table 4-1. The peak voltage that may be present between conductors shall be considered when computing test voltages. Test voltages greater than $1000 \mathrm{~V}$ RMS shall be applied gradually at a rate not exceeding $500 \mathrm{~V} \mathrm{RMS} / \mathrm{s}$.

Table 4-1. DIELECTRIC WTHSTAND VOLTAGES AT ATMOSPHERIC PRESSURE

\begin{tabular}{|c|c|}
\hline Working Voltage $\mathrm{e}^{\mathrm{a}}(\mathrm{V})$ & $\begin{array}{c}\text { RMS Test Voltage (V) } \\
94.8-108 \mathrm{kPa}(711-813 \mathrm{~mm} \mathrm{Hg})\end{array}$ \\
\hline $\begin{array}{l}\text { Less than } 25 \\
\text { Greater than } 25-50 \text { incl. } \\
\text { Greater than } 50-100 \text { incl. } \\
\text { Greater than } 100-175 \text { incl. } \\
\text { Freater than } 175-700 \text { incl. } \\
\text { Greater than } 700\end{array}$ & $\begin{array}{c}50 \\
100 \\
300 \\
1000 \\
2.8 \times \text { working voitàge } \\
1.4 \times \text { working voltage }+1000\end{array}$ \\
\hline
\end{tabular}

- The nature of the potential is $\mathrm{AC}$.

- The duration of the application of the test voltage is a minimum of $5 \mathrm{~s}$.

- The points of application of the test voltage is as stipulated below:

(a) The DC input leads are tied to chassis, and the test voltage should be applied between the AC output leads and the chassis. The transformer core should be connected to chassis and all means of disconnection activated.

(b) The AC output leads are tied to the chassis, and the test voltage should be applied between the DC input leads and the chassis. 
(c) If it is proposed to apply the test voltage between the DC input leads and the AC output leads, these tests need not be made if the test voltages in (a) and (b) are greater than that proposed for (c). Two sources of test voltage shall be used, proportioned and phased so that the input-to-output test voltage satisfies Table 4-1, but the input-and-output-to-chassis voltage does not exceed that used in (a) and (b).

- The high voltage source shall have a minimum of $0.5 \mathrm{kVA}$ for voltages over $1 \mathrm{kV}$.

- Examination during and after the test shall determine evidence of arcing, flashover, breakdown of insulation, and other damage.

The insulation resistance of the inverters shall be tested in accordance with Method 302 of MIL-STD-202.

- The test condition Letter B, $500 \mathrm{~V}$.

- The points of measurement shall be as in the withstand voltage test described above.

- The electrification time shall be $1 \mathrm{~min}$.

Note: The measurements may be made at any temperature above $20^{\circ} \mathrm{C}$ and at ambient room humidity, but rejections shall be based on measurements made at $25^{\circ} \mathrm{C},\left(+10^{\circ} \mathrm{C},-5^{\circ} \mathrm{C}\right)$ and at a relative humidity not greater than $80 \%$. The insulation resistance shall be a minimum of $10 \mathrm{M} \Omega$.

Commentary. Ungrounded power systems can be a safety hazard, and for that reason it may be desirable to provide both $\mathrm{AC}$ and $\mathrm{DC}$ grounds. A decision must be made as to whether to ground the electrical system, and if the decision is positive, then the inverter $\mathrm{AC}$ and $\mathrm{DC}$ connections must be electrically isolated from each other, usually by a transformer, which may increase costs and power losses. If the input and output are not electrically isolated from each other, then either the DC or the AC side must be ungrounded.

Equipment grounding, in contrast with system grounding, relates to the manner in which nonelectrical conductive material, which encloses electrical equipment, is to be interconnected and grounded. The inverter should have no connection between the power connections and the equipment chassis or case (see $\mathrm{NEC}$ ).

The dielectric withstand and insulation resistance tests are used to prove the integrity of the insulation on all transformers that interface the DC and AC circuits, as well as the insulation of heatsinks and other components.

The withstand voltage test is a go/no-go type of test. Successful completion of the test gives some assurance that no gross defect is present in the insulation strùcture. The ability of a withstand test to expose incipient faults is less certain, therefore this test is of ten supplemented by the measurement of insulation characteristics such as insulation resistance.

This test was written with reference to MIL-STD-202 because it was available, not because of a requirement for a highly reliable military type of construction.

IEEE STD 62-1978 provides a good discussion of the subject. It refers to the following standards, which may be more suitable for these criteria. Refer also to Test TE.AR.M.10. 
- IEEE STD 4-1978, Standard for High Voltage Testing Techniques.

- ANSI/IEE STD 43-1974, Recommended Practice for Testing Insulation Resistance of Rotating Machinery.

- ANSI/IEEE STD 95-1977, Recommended Practice for Insulation Testing of Large AC Rotating Machinery with High Direct Voltage.

Whenever ungrounded lines are connected to an exterior element, such as a solar array, a voltage limiting device should be connected from each line to ground to prevent possible static charge buildup or lightning-induced voltages in excess of the capabilities of the insulation. In addition, refer to SY.S.1, SY.S.2, and SY.S.3.

A good discussion of these subjects can be found in IEEE Std. 142-1972, Recommended Practice for Grounding of Industrial and Commercial Power Systems.

Installation, Operation, and Maintenance Attributes

\section{PC.I.1 Installation, Operation, and Maintenance Manual}

Refer to performance criteria SY.I.l. See below for additional commentary warranting particular attention.

Commentary. The service manual shall provide detailed directions for discharging capacitors, and applicable warning notices shall be displayed on the equipment chassis.

PC.I.2 Maintainability (see SY.I.2)

PC.I.3 Accessibility (see SY.I.3)

\section{PC.I.4 Local Monitoring}

Criterion. Malfunction and alarm conditions shall be suitably displayed as specified. Indicators or test points shall be available as specified to enable maintenance personnel to verify equipm ent operation and facilitate corrective procedures.

Evaluation. Review of drawings and equipment to determine conformance with criterion.

Commentary. Proper equipment operation can be displayed with the use of status lights or meters that display input and output voltage, current, and power. Alarm display lights can indicate impending failure and failure display lights can indicate the cause of equipment shutdown/disconnect. As equipment reliability is demonstrated in the field or as installation circumstances warrant, local monitoring devices may be removed for economic reasons in small installations. Larger systems may retain extensive instrumentation where operating personnel are on duty. 


\section{PC.J.5 Local/Remote Controls}

Criterion. Adjustments and controls located on or inside the equipment shall be marked as to their function as specified. If remote control can be exercised, then switches and indicators shall be available to disable such remote operations.

Evaluation. Local controls and adjustments shall be exercised to verify their operation. The remote control operation shall be similarly exercised and it shall be verified that the disable function removes the remote control capability. Repeat the procedures af ter the equipment is installed.

Commentary. Some examples of functions which may be remotely controlled are UNIT ON/OFF, OUTPUT VOLTAGE, and OUTPUT POWER. Even though normal system operation includes the capability for remote control, it is desirable to provide means for local control to facilitate troubleshooting and service. To protect service personnel, the remote control function must be locked out or otherwise disabled.

The remote control interface should be standardized as soon as possible. A suggested interface is an external contact closure in Class 2 control circuits. Optoisolated digital inputs may also be used.

\section{PC.I.6 Local/Remote Monitoring}

Criterion. Local and remote status monitoring shall be as specified.

Evaluation. Review of drawings and equipment. Remote indicators that are compatible with the specified interface shall be connected; operation, including alarms, shall be verified. Repeat the procedures af ter the equipment is installed.

Commentary. The remote monitor interface should be standardized as early as passible. 


\section{REPERENCES}

1. Landsman, E. E. Effects on Solar Array of Ripple Drawn by Connected Load. (Forthcoming from MIT/LL; Lexington, Mass.)

2. Landsman, E. E. Effects on Inverter Input Current Ripple by Instantaneous Power Balance and Input Filter Circuitry. (Fortheoming from MIT/LL; Lexington, Mass.)

3. Institute of Electrical and Electronics Engineers. IEEE Guide for Harmonic Control and Reactive Compensation of Static Power Converters. (Forthcoming.) 


\subsection{POWER CONDITIONING MONITOR AND CONTROL SUBSYSTEM}

Page.

Introduction $\ldots \ldots \ldots \ldots \ldots \ldots \ldots \ldots \ldots \ldots \ldots \ldots \ldots \ldots \ldots \ldots \ldots \ldots \ldots \ldots \ldots \ldots \ldots$

Performance Criteria..$\ldots \ldots \ldots \ldots \ldots \ldots \ldots \ldots \ldots \ldots \ldots \ldots \ldots \ldots \ldots \ldots \ldots \ldots \ldots$

Electrical Attributes $\ldots \ldots \ldots \ldots \ldots \ldots \ldots \ldots \ldots \ldots \ldots \ldots \ldots \ldots \ldots \ldots \ldots \ldots \ldots \ldots, 5-4$

MC.E.1 Pre-Startup Conditions.......................... 5-4

MC.E.2 Startup (Automatic or Manual) ..................... 5 5

MC.E.3 Manual Shutdown............................... 5-5

MC.E.4 Automatic Shutdown........................... 5-5

MC.E.5 Power Supply Voltage Level and Range ................. 5-6

MC.E.6 Power Consumption ............................. 5-6

MC.E.7 Interference Susceptibility $\ldots \ldots \ldots \ldots \ldots \ldots \ldots \ldots \ldots \ldots \ldots \ldots \ldots$ 5-7

Safety Attributes $\ldots \ldots \ldots \ldots \ldots \ldots \ldots \ldots \ldots \ldots \ldots \ldots \ldots \ldots \ldots \ldots \ldots \ldots \ldots \ldots . \ldots$

MC.S.1 Safety Control............................. 5-7

Durability/Reliability Attributes $\ldots \ldots \ldots \ldots \ldots \ldots \ldots \ldots \ldots \ldots \ldots \ldots \ldots \ldots \ldots \ldots$ 5-8

MC.D.1 Cabling and Connectors ............................ 5-8

Installation, Operation, and Maintenance Attributes................. 5-8

MC.I.1 Installation, Operation, and Maintenance Manual .......... 5-8

MC.I.2 Manual Control Panels ........................... 5-8

MC.I.3 Maintainability ............................... 5-9

MC.I.4 Accessibility ............................... 5-9

MC.I.5 Environment................................ 5-9 


\section{THIS PAGE}

\section{WAS INTENTIONALLY \\ LEFT BLANK}




\section{SECTION 5.0}

\section{POWER CONDITONING MONITOR AND CONTROL SUBSYSTEM}

\section{INTRODUCTION}

The power conditioning monitor and control subsystem supervises proper power conditioning subsystem operation in response to internal and external signals. Such a subsystem may be described by levels, types, and functions. Because of the large number of possible combinations of monitor and control configurations, the scope of this section encompasses designs ranging from simple switch-operated subsystems to highly complex minicomputer-operated subsystems. The following paragraphs describe several facets of control systems including levels, types, and functions of control, and other considerations.

There are two monitor and control levels in a typical PV power system. The highest level is the photovoltaic. power system monitor and control unit, which receives information from and sends information to the thermal and power conditioning subsystems through their monitor and control units; typically, the operator interacts with this unit. Performance criteria for this unit are located in Section 2.0.

At the next lower level is the power conditioning monitor and control subsystem. This subsystem monitors the operation of the power conditioning subsystem, controls the subsystem directly, receives and carries out commands from the system monitor and control unit (if there is one), and ensures the safe operation of the subsystem. The subsystem elements may be distributed among various PV components instead of being a discrete unit.

Types of control may be categorized as switch-activated, electromechanical, and eleq tronic. A switch-activated control, typically manual, is the most basic type. It connects various components within the power conditioning subsystem or connects subsystems, such as battery storage, to the power conditioning subsystem. Electromechanical control is typified by relays-electrical and mechanical couplings-that open or close. Electronic control includes microprocessors or equivalents that use analog or digital signals for use in start up, shutdown, and optimization of the power conditioning subsystem.

Control functions can be divided into three broad categories: operating mode selection, startup, and shutdown. The control signals from the monitor and control system to the equipment and devices controlled indicate the type of control action to be taken. The signals may be either digital or analog; analog outputs may be provided for continuous control. Voltage, current, and bandwidth ratings of the control elements must be compatible with signal and termination requirements.

To operste the monitor and control subsystem properly, interface signalling must provide accurate and reliable transfer of information. Consideration should be given to the operator interface, to ensure effective communication between operator and subsystem. An acceptable interface must perform satisfactorily in the presence of electrical noise and other adverse environmental conditions. Default operation created by interface failure should be recognized and defined. Standardization of control interfaces is important for compatibility. 
Electrical interference may be a problem wherever there is close coupling between power conditioning and control systems. Electrical interference is any spurious voltage or current arising from external or internal sources that appears in a circuit. When these voltages or currents become too large, the system is adversely affected and malfunctions. Circuits can be separately characterized by their susceptibility to such interference and by their generation of such interference.

Sof tware is a very important part of any design utilizing processor control. With availability of low-cost microprocessors increasing, the inclusion of software control can be expected to increase correspondingly. Just as any system is only as good as its weakest link, so any monitor and control system is as weak as its algorithm. It is important to outline the crucial interaction between hardware and software considerations in a system. Much effort should be spent in selection of a system, its components, and analysis of system algorithms to ensure that the system operates efficiently, safely, and with only the amount of operator involvement intended.

Computers, including microprocessor-based systems, are normally susceptible to "crashing" where electrical transients, lightning, induced surges, or RF noise can force an address or instruction error that will cause the program to falsely jump into an unallowed and of ten repetitive routine. Under such a condition anything can happen, and is usually manifested in a hard or soft system failure. Until the system is reset (reinitialized) or the program is reloaded, malfunctioning will continue. Adequate safeguards (usually both hardware and software) must be included to ensure maximum "up time" on the system. Crash-proof systems are usually designed for a specific application with a fixed amount of code.

Testing residential PV equipment is important because it must often be maintained by persons with backgrounds in heating, ventilation, and air conditioning or by electricians who work with conventional systems.

A prospective manufacturer should evaluate the cost of appropriate test equipment versus the amount of time saved by service personnel in ease of repair and the increased need for service. Because of the cost of service to the residential customer, servicc test procedures should be streamlined to eliminate field repairs as much as possible. Test procedures should be comprehensive to ensure safety.

Monitor and control provide a central means for running special tests on other parts of the power conditioning and associated subsystems, such as the electrical storage element and the array. Such tests could be used to vary operating conditions to reveal problems not otherwise apparent, and could be undertaken in conjunction with direct access to appropriate parts of the subsystem (or self-testing capabilities could be included).

\section{PERFORMANCE CRITERIA}

\section{Electrical Attributes}

\section{MC.E.1 Pre-Startup Conditions}

Criterion. The monitor and control subsystem should provide for proper startup of the system af ter all pre-startup conditions have been met. 
Evaluation. Monitoring of signals to and from the monitor and control unit should demonstrate the sequence and type of signals to be consistent with the designed startup procedure.

Commentary. There exist circumstances (failure of a component, overheating of part of the system, no voltage being supplied by the array, etc.) under which startup should not be initiated because of system and personnel safety considerations. In a manually operated system, the operator may have a checklist to go through before operating the switch that turns on the system. In an automated system, the monitor and control unit may have built-in precautions that prevent initiation of startup until all necessary conditions are met. Once the necessary conditions are met, either manual or automatic startup initiation should result in a sequence of events that results in a properly functioning system.

\section{MC.E.2 Startup (Automatic or Manual)}

Criterion. When startup is properly initiated, the electrical parameter levels between subsystems should fall within the specified limits.

Evaluation. A check for compatibility of equipment specifications should be done. Anywhere a transient signal caused by startup might interfere with the operation of a component or subsystem, monitoring of electrical levels may also be a necessary test.

Commentary. All startup modes should satisfy voltage and current constraints imposed by the components involved. Startup is a control action that allows energy to flow in the power conditioning unit(s). All configurations of any power conditioning unit should be tested for the following:

- Possible failure of each component and whether startup is inhibited;

- Compliance with specified electrical constraints for each component involved in startup; and

- Possible effects on other interconnected components or subsystems to determine safe operation.

\section{MC.B.3 Manual Shutdown}

Criterion. Manual shutdown shall be possible.

Evaluation. System shall be inactivated when manual shutdown procedure is followed.

Commentary. Some means of manually shutting down the monitor and control subsystem is important for all systems. This may extend from simple switch shutdown or other power disconnection for small systems to more elaborate master shutdown provisions in large systems.

\section{MC.E.4 Automatic Shutdown}

Criterion. If automatic shutdown is included, it shall occur if operation is attempted outside specified levels on either the system or the subsystem lcvel. 
Evaluation. Analysis of possible failure modes of each component shall demonstrate that any abnormal operating mode can safely achieve shutdown. Failure-free analysis and operational testing are applicable.

Commentary. Protective control actions operate to shut down the unit automatically upon detection of abnormal operating conditions, such as high temperature, unbalanced operation (for three-phase systems), overvoltage or undervoltage, overcurrent, and loss, of synchronism.

This criterion may not be required on small systems. Many control configurations are possible for specific modes of operation. Failure of any one or more of the components may result in safe shutdown of the unit, or an appropriate part of it.

Failure of systems interconnected with the unit shall result in shutdown of the unit if unsafe operation is possible. If shutdown is not required for transients, such as voltage dips on the utility line, it shall be shown to cause no damage to equipment or operators. If automatic restarting is included, then it must pass the same tests applied to the startup function.

\section{MC.E.5 Power Supply Voltage Level and Range}

Criterion. The monitor and control subsystem shall operate in the manner specified when connected to a power source whose supply voltage is within the specified range of input voltages for the subsystem.

Evaluation. The subsystem must operate properly at maximum and minimum power supply output voltages and frequencies.

Commentary. Power supply inputs should be compatible with available sources. Standard input voltages are dictated by the location of the system. In the United States, the commonly available residential voltages are $120 \mathrm{VAC}$ or $240 \mathrm{VAC}$ single-phase, or $208 \mathrm{VAC}$ three-phase, $60 \mathrm{~Hz}$. It is also desirahle that outputs of oontrol eyetcm powcr supplies be compatible with present industrial practice, (e.g., \pm 5 VDC, \pm 12 VDC, $\pm 15 \mathrm{VDC}$, and \pm 24 to $+28 \mathrm{VDC}$ ). In some cases (e.g., stand-alone applications); power supplies may not be required if the appropriate DC levels are available for logic and controls.

\section{MC.E.6 Power Consumption}

Criterion. Power consumption of the monitor and control subsystem shall not exceed its specified limit.

Evaluation. Power consumption should be measured over the full specified operating range.

Commentary. The supply's power consumption should be specified so that it can be properly wired into the system and its effect on system efficiency can be determined. The consumption of this power supply should be minimized to keep overall system efficiency high. Many DC supplies operate most efficiently at full load; therefore, if the supply rating is not much greater than the system requirement, the power supply losses will be minimal. However, reliability considerations might dictate a specification of a power 
supply with a considerably higher rating, causing a trade-off between conflicting reliability and efficiency requirements. Because the monitor and control power supply requirements are likely to be relatively small compared to the system output power, the supply efficiency will probably be a minor concern.

\section{MC.E.7 Interference Susceptibility}

Criterion. Within the interference levels specified, the monitor and control operation shall not be affected adversely by electrical interference.

Evaluation. The monitor and control subsystem shall be subjected to electrical interference to ascertain proper operation under the influence of the specified limits of interference.

Commentary. For interference to affect performance, its source must be electrically coupled to the instruments' circuits magnetically, capacitively, conductively, or by a combination of these.

Unwanted voltages enter an electrical signal transmission system by:

- inductive pickup for AC fields electromagnetic coupling;

- electrostatic or capacitive coupling with other circuits;

- direct coupling with other circuits by ground current loops, a common return lead for more than one circuit, or leakage current paths; or

- thermoelectric and corrosion voltages generated by dissimilar material combinations.

These conditions should be considered in the design (refer to IEEE or FCC standards for futher information).

\section{Safety Attributes}

\section{MC.S.I Safety Control}

Criterion. Control equipment shall allow for manual and/or automatic shutdown in the event of an emergency.

Evaluation. System plans and schematics should show conformance with this provision.

Commentary. One of the prime reasons for having control equipment is safety; this equipment should be capable of shutting down the system to avoid damage to equipment and injury to personnel. Where applicable, indications of unsafe operation should be provided. A safety control can be implemented directly from a central unit or in a distributed manner by interlocks and disconnects. As the size of the system increases, it is desirable to increase the number of emergency shutdown locations. In some cases, the safety control equipment can provide additional hazards that would not exist if it were omitted. For example, lower voltage ranges are desirable in safety control lines and are less hazardous. Therefore, the safety control equipment and control algorithms should be designed carefully for both adequate performance and reduced risk. 


\section{Durability/Reliability Attributes}

MC.D.1 Cabling and Connectors (see CA.D.1)

Installation, Operation and Maintenance Attributes

\section{MC.I.1 Installation, Operation and Maintenance Manual}

Refer to performance criterion SY.I.l. See below for additional commentary warranting particular attention.

Commentary. The following additional items should be included in the manual where àpplicáble:

- Software program instructions should be listed in tabular form and be complete, accurate, and clear.

- All programs should be represented diagrammatically in standard flow-chart symbology to depict sequential program operation.

- Software should be divided into functional elements or modules. Programs generally can be modularized into functional elements useful in both their development and usage. Proper modularization is an asset in troubleshooting and modification and a very important consideration in large programming structures.

- Programs should be written in an acceptable programming language.

- Calibration requirements should be identified and minimized as much as possible. The stability of equipment should ensure that system calibration is seldom (and preferably never) required under normal conditions and operations. Ideally, customer service organizations should not be required to maintain special calibration facilities (except those of a minimal nature) to check test instrument calibration. However, where calibration is necessary, facilities should be provided for such calibration.

\section{M.C.I.2 Manurl Control Panels}

Criterion. Control panels included in the system should present information explicitly and provide control in a manner easily comprehended by the operator.

Evaluation. Design review and visual inspection.

Commentary. Since the control panel of any photovoltaic system is the interface between the machine and the operator, it is important that in all control panels (including master control panels and subsystem control panels such as monitor and control) display and control functions be legible. A control panel should also provide explicit indication of both normal operating and emergency or failure conditions and present system operating information in a manner easily comprehensible to the operator. An entire body of design information on human factors has been developed over a period of many years, and all control panels and other human-machine interfaces should be developed by personnel whose knowledge of human-factor design criteria is sufficient to provide a control 
panel easily read by persons with minimum training. This is particularly crucial in residential and small-scale operations. Proper attention should be paid to the use of standard colors for standard functions, such as red for danger, etc. It is desirable that all control panels appropriately announce failure or impending failure, both visually and audibly (signaling), and warn of dangerous situations such as equipment overheating, fire, and other conditions that may jeopardize system integrity. To keep costs of residential units low, attention should be given to using standard enclosures; the importance of ease in servicing cannot be overstated.

\section{MC.I.3 Maintainability}

Refer to performance criteria SY.I.2. See below for additional commentary warranting particular attention.

Commentary. The following items should also be considered for ease of maintenance:

- Built-In Test Equipment (BITE) may be used wherever justified by cost, ease of service, or other conditions.

- The level of technical analysis required by service personnel should be identified as a significant part of test procedures. BITE equipment should be used wherever justified since extensive on-site analysis requirements can be expensive. The manufacturer may provide service personnel with test boxes to locate failures. Use of these test boxes should provide positive results, eliminating any ambiguities in equipment servicing. It is of ten less costly to replace a more expensive module than to analyze and locate ambiguous problems. A well-designed control system for some applications may include an internal microprocessor to perform continual analysis, provide normal control functions, and indicate any problems that may arise.

- If desired, an internal test by manual initiation may provide system operation information.

MC.1.4 Accessibility (see SY.I.3)

\section{MC.I.5 Environment}

Criterion. All equipment must operate in and withstand expected environmental conditions.

Evaluation. Appropriate test procedures shall confirm operation and tolerance to specified environmental conditions.

Commentary. For each application, a corresponding set of environmental requirements must be sattsfled to assure reliable operation. Even where installations are made in relatively benign environments, tolerance must be provided for vibration and shock encountered in shipping and handling. Operation must tolerate temperature ranges which may be broadened by installations away from human habitation or in enclosed, nonventilated areas where unexpectedly high temperatures can occur. For monitor and control systems, humidity is primarily pertinent with respect to corrosion and can cause premature system failure if not given adequate consideration. Cellar installations could be particularly vulnerable. Salt-air coastal environments also could increase vulnerability. 
Elevation is a factor primarily related to air cooling. Equipment designed for sea level operation is generally designed for operation to $1500 \mathrm{~m}$, and higher environmental conditions must be accounted for accordingly or excessive heating may result. For low power control systems, this should be less significant than for associated power conditioning equipment. Conversely, cleanliness may be a more important factor with regard to monitor and control systems where low-level, high-impedance signaling is involved, and they may depend on many plug-in, low-current contacts that cannot tolerate dirt. 


\subsection{STORAGE SUBSYSTEM}

$\underline{\text { Page }}$

Introduction $\ldots \ldots \ldots \ldots \ldots \ldots \ldots \ldots \ldots \ldots \ldots \ldots \ldots \ldots \ldots \ldots \ldots \ldots \ldots \ldots \ldots$

Performance Criteria $\ldots \ldots \ldots \ldots \ldots \ldots \ldots \ldots \ldots \ldots \ldots \ldots \ldots \ldots \ldots \ldots \ldots \ldots \ldots \ldots . \ldots$ 6-4

Electrical Attributes $\ldots \ldots \ldots \ldots \ldots \ldots \ldots \ldots \ldots \ldots \ldots \ldots \ldots \ldots \ldots \ldots \ldots \ldots \ldots \ldots, 6$

ST.E.1 Battery Capacity............................ 6-4

ST.E.2 Battery Efficiency $\ldots \ldots \ldots \ldots \ldots \ldots \ldots \ldots \ldots \ldots \ldots \ldots \ldots \ldots \ldots$ 6-5

ST.E.3 Voltage Window ............................. 6-6

ST.E.4 Discharge Rates .......................... 6-6

ST.E.5 Equalizing Charge $\ldots \ldots \ldots \ldots \ldots \ldots \ldots \ldots \ldots \ldots \ldots \ldots \ldots \ldots$ 6-6

Thermal Attributes ................................ 6 6-7

ST.T.l Battery Operating Temperature $\ldots \ldots \ldots \ldots \ldots \ldots \ldots \ldots \ldots \ldots \ldots$ 6-7

Mechanical/Structural Attributes .......................... 6-8

ST.M.1 Battery Structural Adequacy $\ldots \ldots \ldots \ldots \ldots \ldots \ldots \ldots \ldots \ldots \ldots \ldots \ldots$ 6-8

Safety Attributes $\ldots \ldots \ldots \ldots \ldots \ldots \ldots \ldots \ldots \ldots \ldots \ldots \ldots \ldots \ldots \ldots \ldots \ldots \ldots \ldots 6$

ST.S.1 Battery Electrolyte............................ 6-8

ST.S.2 Battery Voltage and Current ....................... 6-9

ST.S.3 Hazardous Gas Concentration ...................... 6-10

ST.S.4 Fire Protection ............................ 6-11

ST.S.5 Battery Shelter ............................ 6-11

Durability/Reliability Attributes $\ldots \ldots \ldots \ldots \ldots \ldots \ldots \ldots \ldots \ldots \ldots \ldots \ldots \ldots \ldots \ldots \ldots 6$ 6.12

ST.D.l Battery Life............................... 6-12

Installation, Operation, and Maintenance Attributes...............6-12

ST.I.l Installation, Operation, and Maintenance Manual .......... 6-12

ST.I.2 Maintainability .............................. 6-13

Building/Site $\Lambda$ ttributes $\ldots \ldots \ldots \ldots \ldots \ldots \ldots \ldots \ldots \ldots \ldots \ldots \ldots \ldots \ldots \ldots \ldots \ldots \ldots$

ST.B.l Plumbing ................................ 6-14 
THIS PAGE

\section{WAS INTENTIONALLY \\ LEFT BLANK}

$6-2$ 


\section{SECTION 6.0}

\section{STORAGE SUBSYSTEM}

\section{INTRODUCTION}

Without storage, solar energy must be used when it is received. However, many power requirements are not coincidental with available sunlight. To sat isfy such loads, solar energy must be stored. With storage, solar energy can provide power to system loads, regardless of time and weather.

The wide range of solar photovoltaic (PV) energy applications for energy storage requires that different types and amounts of energy be stored for varying lengths of time. Energy storage requirements are associated with basic differences in energy storage subsystem sizes, applications, regional variations, and time frames for implementation of such subsystems. At present, commercially available batteries, such as lead-acid and nickelcadmium, are used to provide storage in PV applications. Programs are being conducted to develop other storage devices; e.g., advanced batteries and electrochemical systems, chemical and thermal systems, and magnetic and mechanical systems (flywheels). For further information on long-term development programs, see Refs. 1, 2, and 5.

The typical storage battery is an electrochemical apparatus comprising one or more connected cells that convert chemical energy into electrical energy. The cell is the smallest unit of a battery system. Cells are connected in series and/or parallel to obtain a desired battery voltage, power, and capacity. The essential parts of a cell are two dissimilar electrodes (anode and cathode) immersed in an ionic conductor called an electrolyte. The cells are enclosed in a leak-proof jar, or container, provided with binding posts to which electrical connections are made. Detailed information on the specific chemistry and chemical action of the storage battery can be found in Refs. 3, 4, 5 and 7.

The battery energy storage subsystem is used to store electrical energy collected by the PV array and to supply energy to the load during periods when the PV array is not producing enough power. In certain system designs, the battery storage subsystem may also be used to store energy supplied by an electric utility or other supplemental energy systems, such as a diesel genera tor. Two recent works (Refs. 5 and 6 ) should be useful in selecting the appropriate battery.

Battery characteristics are governed by the type of cell selected (e.g., lead-acid, nickelcadmium). However, many design variations are commercially available for each battery type. This must be considered in selecting an appropriate battery. For example, a charge-retaining lead-acid battery designed for low-rate discharge would be destroyed by the duty cycle typical of residential systems. Thus, it is essential that the system designer be familiar with battery characteristics or solicit the aid of a battery manufaclurer in specifying the optimum battery for a given PV system design.

Key characteristics useful in gauging battery performance include capacity, efficiency, and expected (or warranted) life. However, these characteristies are functions of operating parameters such as temperature, voltage range, and charge and discharge rate. Meaningful specification of key battery characteristics must include a delineation of operating or test conditions. 
Battery characteristics such as physical size (dimensions) and weight can be specified and checked by conventional methods. Certain other characteristics (e.g., gas emission) require equipment that is available but generally not used except by the battery manufacturer in its design process. At this time, there are no tests for battery life except destructive testing of the cell. Thus, type qualifying or random testing may be used where cell life is to be verified.

The performance criteria in this section are intended to point out information that must be provided to allow proper battery selection and utilization. Included in some of the commentaries are applications to remote-site, intermediate load centers and central generating stations. Battery design f or PV applications is a unique branch within battery development programs, and many design criteria are yet to be developed. While the performunce criteria addressed in this section refer, for the most part, to lead-acid and nickel-cadmium batteries for residential PV systems, it is not intended that development and use of new cell types in PV systems be constrained. Test mothode roferred to in this section with the code designation TE.ST. are located in Appendix B.

\section{PERFORMANCE CRITERIA}

\section{Electrical Attributes}

\section{ST.E.1 Battery Capacity}

Criterion. After complete formation cycles, the capacity of the battery storage subsystem shall be equal to or greater than the capacity specified for given test conditions.

Evaluation. For motive power, lead-acid batteries, NEMA STDs Pub. No. IB 2-1974, Sec. 1.0̄3-1.04, may be used when appropriate.

F or large, lead-acid storage batteries, as used in generating stations and substations, IEEE STD 450-1975, Sec. 5.1-5.5 may be used when appropriate.

Test TE.ST.E.1 (Test Procedure for Measuring Battery Capacity and Round-Trip Efficiency) may be used for determining the capacity of lead-ncir n nickel-cadmium battcries.

In cases where the above circumstances do not apply, refer to the manufacturer's instruxtions.

Commentary. The capacity of a battery storage subsystem can be expressed in amperehours (coulombic capacity), or watt-hours (energy capacity), or both, at a specific discharge rate.

A test of capacity may be made prior to installation in the form of an acceptance test and af ter installation in the form of a service or performance test. Tests may then be periodically repeated according to the requirements of the user. When the battery begins to deteriorate, testing will indicate whether the battery has failed. Usually, the industry defines battery failure as a capacity below $80 \%$ of the rated capacity value. Implicit in this is a need to be absolutely sure that all parties concerned are referring to the same capacity; i.e., new or end-of-life. 
A new battery may require several charge/discharge cycles to attain its full capacity (cycling up) if formation is incomplete.

The capacity of any battery is a function of discharge rate, final discharge voltage, and temperature. Capacity decreases with inereasing final discharge voltage and discharge rate, and increases with temperature. Thus, these operating parameters must be included in capacity specifications.

Tests may be conducted under standard operating conditions, under conditions typical of the application, under expected extreme operating conditions, or all of these. The essential element is that there be agreement between the vendor, the purchaser, and the end user about the appropriate test method and operating conditions.

Tests of capacity do not relate to safety; therefore, they generally should be conducted at the discretion of the purchaser or end user to verify specified performance, as desired. Questions of warranty may also require battery capacity tests. At present many capacity tests are conducted as part of experimental or demonstration projects to provide data for future designs. This latter situation is different from a purely commercial installation and generally warrants more testing in all areas.

\section{ST.E.2 Battery Efficiency}

Criterion. The efficiency of a new battery storage subsystem shall be equal to or greater than the efficiency specified for given test conditions.

Evaluation. For round-trip efficiency, use TE.ST.E.l (Test Procedure for Measuring Battery Capacity and Round-Trip Efficiency). For total in/out efficiency, use TE.ST.E.2 (Test Procedure for Measuring Total Battery In/Out Efficiency).

Commentary. Efficiency may be measured in terms of ampere-hour (coulombic) efficiency, watt-hour (energy) efficiency, or voltage efficiency. Generally, the watt-hour efficiency is more useful for purposes of system design, whereas the ampere-hour efficiency is more common in battery design terminology. Voltage efficiency is rarely used.

As with capacity, efficiency is a function of the battery operating parameters. Thus, specification of efficiency should include the operating parameters under which the test is conducted. The energy efficiency is lower at high rates of discharge. It is also a function of cell temperature, which must be considered during the design of the battery storage subsystem. Efficiency may decrease as the cell ages. Generally, efficiency is specified only for new cells.

Note the difference between round-trip and total in/out efficiency. The round-trip or cycle efficiency is useful for comparisons among batteries, and the total in/out efficiency is useful when examining a battery's performance within a PV system. The in/out efficiency will most likely not be measured once commercialization begins; however, for designer evaluating purposes, this test evaluation has been included.

From a system point of view, it is of ten desirable to have a battery efficiency that reflects the fraction of input energy available to the load over long periods of time. Parasitic losses within a PV system would not necessarily show up in a simple round-trip efficiency test. Parasitic losses can include the energy used to operate a battery ventilating system and air-lift pumps, the energy lost through self-discharge, or through 
equalization. The in/out efficiency test method takes into account these parasitic losses by calculating the efficiency over numerous battery discharge/charge cycles.

\section{ST.E.3 Voltage Window}

Criterion. The battery shall provide the specified capacity when operated within the specified PV system's voltage window.

Evaluation. Compliance of this criteria with specifications can be evaluated by use of Test TE.ST.E.l (Test Procedure for Measuring Battery Capacity and Round-Trip Efficiency).

Commentary. The voltage window is the range of voltages over which the battery is to be operated within the PV system. This window will usually be limited by the system's inverter; therefore, the battery manufacturer must be aware of the limitations so that the most suitable voltage window may be determined. The decision should be made only after consultations are completed between the battery and inverter manufacturers and the PV system designer.

The battery voltage is affected by the state-of-charge, charge/discharge rate, and temperature. The PV system designer must make certain that the battery will perform as desired, within the specified voltage window, under the full range of operating conditions. The PV system's voltage window should be chosen such that at low discharge rates, the battery will not be overdischarged, and at high discharge rates, a usable capacity (amount of energy) can be supplied to the loads.

\section{ST.E.4 Discharge Rates}

Criterion. The battery shall perform as specified when operated over the specified range of discharge rates.

Evaluation. This criterion's compliance with specifications can be evaluated by use of TE.ST.E.1 (Test Procedure for Measuring Battery Capacity and Round-Trip Efficiency). This test may be repeated at both the highest and the lowest discharge rates.

Commentary. If the PV system is to be used over a wide range of discharge rates (i.e., the application has a wide range of loads), a capacity test may be desirable at both the high and the low rate to cover both "worst case" conditions.

Normally, the high discharge rate is used to determine the final discharge voltage. However, if the lead-acid battery is operated at very low discharge rates, it is possible to over-discharge the battery to the extent that the specific gravity of the electrolyte is converted to a level well below the recommended limit, making it extremely difficult to recharge. Therefore, the discharge rate must not be overlooked when designing the PV system.

\section{ST.E.5 Equalizing Charge}

Criterion. The capacity of the battery shall be restored to its specified value after completion of the specified equalizing charge procedures. 
Evaluation. The battery shall be equalized as specified by the manufacturer. Battery current and terminal voltage shall be recorded throughout the equalizing charge. In the last hour of the equalizing period, each cell voltage shall be taken and recorded. At the end of the equalizing charge, each cell's specific gravity and cell temperature shall be read and recorded. Readings shall be checked for any large variations in specifig gravities and voltages; i.e., if the specific gravity variation is greater than $0.020 \mathrm{~g} / \mathrm{cm}^{3}$ or the voltage variation is greater than $0.100 \mathrm{~V} / \mathrm{cell}$, then the battery manufacturer should be notified, further checks or tests should be made on the suspect cell, and the equalizing period might have to be performed more of ten or for longer periods of time.

Commentary. Individual cells in a lead-acid battery of ten exhibit different self-discharge rates, capacities, and efficiencies. The purpose of the equalizing charge is periodically to bring all cells to a common state of charge and thereby minimize deterioration of certain cells. This is most important at the beginning of battery life in order to fully form the cells.

A second purpose of equalization in lead-acid batteries is to mix the electrolyte in the cells by generating gas bubbles. This eliminates stratification, which otherwise occurs during charging. Batteries with other mixing methods (such as mechanical stirring or airlif $t$ ) do not need this aspect of equalization.

The lead-acid battery manufacturer normally specifies a voltage, higher than that used for normal charging, of 2.60-2.75 V/cell for 5-10 V/cell hours. The equalizing charge may be carried out weekly, biweekly, or less of ten depending upon the particular application and use of the battery.

Not all batteries require an equalizing charge. For example, those that are on a float charge rarely need to be equalized. Nickel-cadmium batteries also rarely need to be equalized. If the battery's cells have a wide variation of capacities, then a normalization* may be desirable. This can be accomplished by a complete discharge to $1.0 \mathrm{~V} / \mathrm{cell}$ followed by an overcharge, returning to the battery approximately $140 \%$ of its capacity.

\section{Thermal Attributes}

\section{ST.T.1 Battery Uperating Temperature}

Criterion. The battery shall provide the specified capacity when operated within the specified cell temperature range.

Evaluation. This criterion's compliance with specifications can be evaluated by the use of TE.ST.E.1. (Test Procedure for Measuring Battery Capacity and Round-Trip Efficiency). This test should be performed at the expected temperature extremes with the manufacturer's recommended cell modifications (larger case, modified specific gravity, etc.). A table of "Cell Size Correction Factors for "Temperature" can be found in ANSI/IEEE STD 485-1978, Table 1 .

* Normalization is the terin generally used by the nickel-cadmium industry for equalization. 
Commentary: The charge/discharge characteristics as well as efficiency, capacity, lifetime, and final discharge voltage are functions of battery or cell temperature. Thermal managem ent of the battery storage subsystem in the form of adequate heating and cooling must be provided to avoid excessively low and high temperatures, respectively (see also IEEE STD 484-1975, Sec. 4.1.1(4)). The battery electrolyte can be tailored to suit the temperature environment; however, lifetime and capacity are of ten reduced.

As the electroly te temperature decreases, the battery's capacity falls off. Below $0^{\circ} \mathrm{C}$ $\left(32^{\circ} \mathrm{F}\right)$ the reduction in capacity is somewhat greater per degree than that between $25^{\circ} \mathrm{C}$ and $0^{\circ} \mathrm{C}$. At very low temperatures, a lead-acid battery is susceptible to damage by freezing electrolyte, especially at low states of charge. Nickel-cadmium batteries are not aff ected by freezing.

As the electrolyte temperature increases above $25^{\circ} \mathrm{C}$, the battery's capacity increases, within certain limits. High temperatures also increase the general rate of deterioration in a battery. Electrolyte temperatures up to $52^{\circ} \mathrm{C}\left(125^{\circ} \mathrm{F}\right)$ cun be compensated by decreasing the cell's specific gravity without serious reduction in the useful life of the battery.

\section{Mechanical/Strux tural Attributes}

\section{ST.M.1 Battery Structural Adequacy}

Criterion. The batteries shall be supported throughout the design life of the system without struc tural failure (including those subsystems subject to se is mic dist urbances).

Bvaluation. The struc tural adequacy of the battery supports shall be demonstrated by struc tural analysis.

Commentary. Battery supports are generally found in the form of "racks" or "feet" by which the batteries are slightly elevated to provide insulution, to allow access for the forks of a lift truck or lifting device, or to provide air circulation for ventilation and cooling. In some cases, the battery may be designed to sit directly on the floor.

Refer also to IEEE STD 484-1975, Secs. 4.1.3 and 4.2.1.

\section{Bafety Attributes}

\section{ST.S.l Battery Electrolyte}

Criterion. Provisions for personnel safety in the event of an electrolyte spill shall be located in or next to the battery area.

Evaluation. Review of the battery design and battery equipment list or malntenunce manual.

Commentary. Exposure to the sulfuric acid electrolyte of a lead-acid battery or the potassium hydroxide in a nickel-cadmium battery must be considered in the design. Standard techniques for protection of personnel and administrative procedures must be 
followed to comply with the minimum requirements of OSHA. This is not required for residential applications. For lead-acid batteries, these are outlined in Title 29, Part 1910, Subpart 1: Personal Protective Equipment and in Subpart G: Occupational Health and Environment Control.

Recommended protective measures include respiratory and eye and face protection as primary measures, and electrolyte handling gloves (rubber) and other clothing for protection of the body. The installation of electrolyte-resistant flooring in the vicinity of the batteries might be considered. To augment these protective measures, see also ST.B.1.

Burns caused by lead-acid battery electrolyte should be treated as per NAVSHIPS Manual 9623-907. Safety precautions to be followed while designing and installing lead-acid battery facilities are described in IEEE STD 484-1975, Sec. 3.0 and 4.1.1.

Residential systems must be constructed to keep children and unauthorized personnel. safely away from electrolyte and high-voltage areas.

\section{ST.S.2 Battery Voltage and Current}

Criterion. The battery shall be provided with adequate protection against high battery voltage and current.

Evaluation. Review of the battery design and electrical connections for adequate provisions of insulation, current interrupting devices, and grounding. (See also SY.S.3 and SY.S.4).

Commentary. IEEE STD 484-1975 provides information on protective equipment and prof cedures for safe handling of the battery (Sec. 3.0), mounting of the battery and grounding the racks (Sec. 4.1.2), and alarms recommended for generating stations (Sec. 4.1.5).

All terminals and intercell connectors in PV battery systems over $60 \mathrm{~V}$ should be covered with a nonconducting material to avoid accidental contact (dead top). For residential systems, it may be prudent to configure designs that permit minimal contact by the homeowner with any electrical portions of these systems. For large systems, access is likely to be restricted to knowledgeable technicians. However, this does not reduce the need to design a safe system.

Further protective measures include:

- Maintenance on batteries should be performed with the batteries open-circuited and isolated from ground. Such isolation should be tested before any maintenance is performed that requires electrical contact with a battery terminal. Personnel may be insulated from ground by using protective clothing, or a rubber sheet over parts of the floor and walls with which contact might be made, or both.

- Battery terminal covers not interfering with the work immediately in progress should be in place. Care should be taken to avoid dangling conductive test items or other material which could cause a short circuit.

- Electrical shock hazard may be reduced by arranging the cell layout so that voltage differences between adjacent cells or rows of cells are minimal. Also, the battery may be separated into individual groups by disconnect switches (National Electric Code, Article 480-6). 
- Only qualified personnel should be allowed into the battery room, and the battery terminals should be designed for safety or to prevent contact by personnel.

- Only insulated tools and nonm etallic flashlights should be used near a battery or bus system. Extreme care should be taken never to short circuit any part of the battery since there are no circuit breakers in the cells to open a short, and no swit ches that can be thrown to deenergize the battery terminals.

- Rings, metallic watch bands, etc., should be removed when working near bus bars or batteries.

- Conductive support structures (racks) shall be insulated from cell and battery terminals with insulators rated for the full system voltage. Such structures shall be electrically grounded, as should conductive battery cases, for systems above $60 \mathrm{~V}$.

\section{STS.3 Hazardous Gas Concentration}

Criterion. The battery area shall be provided with adequate protection against hazardous concentrations of flammable or toxic gases of any kind.

Evaluation. Analysis of the battery chemistry, system ventilation, and nearby environment.

The concentration of hydrogen in the battery area shall not exceed the flammability point of hydrogen ( $4 \%$ by volume). The minimum ventilation required is obtained by

$$
Q=\frac{0.027}{C}(I)(n),
$$

where: $Q$ is the ventilation rate required in $\mathrm{cf} m$;

$\mathrm{C}$ is the inaximum allowablc hydrogen concentration expressed as a percentage;

$I$ is that portion of the charging current passing through the cells which generates free hydrogen; and

$\mathrm{n}$ is the number of cells in the battery.

Generally, the concentration used in that calculation is taken to be $2 \%$ to provide a margin of saf ety. See IEEE STD 484-1975, Sec. 4.1.4.

Commentary. The battery area must be designed to preclude any build-up of flammable or toxic gases. This is accomplished malnly by ventilation, either natural or forced. Batteries designed for low gassing levels over the operating voltage range of ten need not have active ventilation provisions where normal room air infiltration is adequate, while those designed for other criteria may require forced ventilation.

The possible effect that additional air circulation may have on the thermal management of the batteries should also be carefully reviewed. Where this could impede the battery's performance, it may be necessary to precondition the air, or to limit the ventilation to only the charging cycle.

Another consideration to be made is the possibility of a gas build-up in a dead air space (such as a false ceiling). Although it is nearly impossible to contain hydrogen, it may be possible for a temporary accumulation to occur that would exceed its flammability level, especially during a heavy gassing period. 
Where practical, hydrogen recombiners can be used to reduce hydrogen build-up. They also help reduce the need for watering since most of the electrolyzed water is reclaimed. However, they do add to the cost of a system. Lead antimony batteries cannot use. recombiners economically as they become poisoned by the antimony's gases. Progress is being made on filters for these batteries.

Flame arresters should also be considered as an additional safety feature on any battery system. These devices prevent any flames that might exist outside of the battery from getting inside the battery, causing it to explode. However, a wise safety precaution is to never permit smoking, arcing, or open flames near the batteries or the battery area. (Refer to IEEE STD 484-1975, Secs. 3.2(4) and 4.1.1(8).)

The use of antimony in the plates of a lead-antimony battery increases the hydrogen evolution because of higher charging currents. They also produce trace quantities of the toxic gases arsine and stibine, the levels of which are set by OSHA. However, these gases should easily be within acceptable limits if sufficient ventilation for hydrogen is provided and prolonged high charging rates are avoided. The battery manufacturer should be consulted regarding gassing rates and optimum charging voltages for specific cell designs.

\section{ST.S.4 Fire Protection}

Refer to performance criterion SY.S.5. See below for additional commentary warranting particular attention.

Commentary. Establish firefighting procedures and use extinguishers suitable for electrical fires. Pouring water on a battery fire may cause currents to flow. Hydrogen and oxygen may be released, which could lead to an explosion.

Ensure unobstructed aisles for quick exit from battery area in emergencies.

\section{ST.S.5 Battery Shelter}

Criterion. Adequate shelter shall be provided to protect the battery from harmful environments.

Evaluation. Review of the battery shelter (building) and location. The shelter shall conform with state and local building codes.

Commentary. Battery shelters shall protect the battery from the environment to conform with the operating environment specified by the manufacturers. This includes limiting the battery's ambient temperature to a specified range while maintaining adequate ventilation.

A residential battery enclosure might be indoors in a harsh climate, perhaps in a dry garage or basement area with suitable ventilation and thermal provisions. It might be a simple rain shelter or enclosure in a mild climate. Battery racks are optional and generally are used only to minimize space requirements. Many batteries are designed to sit directly on the floor in insulated cases. 


\section{Durability/Reliability Attributes}

\section{ST.D.l Battery Life}

Criterion. The battery capacity shall remain above the specified value for the stated life when it is operated within its specified operating conditions.

Evaluation. Battery life cannot be evaluated without destroying the battery. Therefore, it is only practical to perform accelerated testing of the particular battery types and lots, and to evaluate in-field usage experiences. There is no agreed-on manner or procedure for life testing.

Commentary. The life of a battery is determined hy its ennstrurtion and its operating conditions. The dominant effects and predicted change in battery capacity should be specified by the vendor for an appropriate range of operating conditions.

Lead-acid batteries often show a small initial increase in capacity with cycling, followed by a long period of nearly constant capacity, followed by a final decrease. Different mechanisms operate in the cell to affect its life. Some forms of battery abuse and misuse are listed:

- Undercharging lead-acid cyclic batteries over a considerable period is one of the most common and most destructive forms of misuse. Owing to the formation of excessive amounts of lead sulfate, the positive plates tend to expand and break up, and the negative active material hardens and loses capacity.

- Overcharging lead-acid cyclic batteries is another form of abuse that can have a serious effect on battery life; however, its effects are not as immediately obvious as those of undercharging.

- Overdischarging degrades battery life, and, if combined with undercharging, the effects are intensified. Strictly speaking, a battery is not overdischarged at any particular rate unless more than its capacity at that rate (the total charge in coulombs) has been taken out. For example, with deep discharge lead-acid batteries, it is highly undesirable and uneconomical to take out more than $80 \%$ of its rated capacity as a daily routine.

- A lead-acid battery left for a considerable period at a low state of charge will also have a reduced lifetime. The causes are the same as those that cause undercharging.

- High-temperature operation will increase the general rate of deterioration in a cell because of higher rates of undesirable chemical actions. This is due to an intensified interaction between the electrolyte and the active material.

\section{Installation, Operation and Maintenance Attributes}

\section{ST.I.I Installation, Operation, and Maintenance Manual}

Refer to performance criterion SY.I.1. See below for additional commentary warranting particular attention. 
Commentary. In addition to the issues mentioned in performance criterion SY.I.l, the following procedures specifically pertaining to storage should be included in the manual:

(1) Installation: Although specifically directed toward large lead storage batteries, IEEE STD 484-1975, Secs. 5.1 and 5.2 provide a wide coverage of receiving, storage, and assembly procedures that can be applied to any battery. The battery manufacturer should be consulted if there is doubt about the applicability of any parts.

(2) Maintenance: Although specifically directed toward large lead storage batteries, ANSI/IEEE STD 450-1975 covers a wide range of maintenance, testing, and replacement procedures that can be applied to most batteries. The battery manufacturer should be consulted if there is doubt about the applicability of any parts. Additional comments on maintenance procedures are listed below:

- Access to battery areas should be restricted either by room enclosure or electrical package enclosures. Normal maintenance procedures should not be dangerous if carried out by the appropriate personnel using specified procedures for the intended application. The design of the facility should reflect the expected levels of training of maintenance personnel. Installation qualifications shall be specified by the vendor in accordance with local building codes.

- Always exercise care when working around open cells to keep foreign material of any nature from falling into the cells.

- When frequent performance inspections are made, it is common practice to use pilot cells. Pilot cells are randomly selected (usually one in six); their performance is assumed to be representative of the battery's performance. If this technique is used, complete inspections should still be performed occasionally. (If any adverse conditions are found, a complete inspection should be considered prudent.)

- Normal usage of most batteries requires periodic addition of water to replace losses due to gassing and evaporation. Permanently sealed cells are exempt from this requirement. Water addition is necessary to maintain proper electrolyte specific gravity and to ensure that all plates are completely immersed. The interval for water addition depends on duty cycle, site environment, and battery. type. The water added should meet or exceed purity requirements specified by the battery manufacturer (otherwise the battery may be damaged, have its life shortened, or the warranty may be voided). Low humidity may require more frequent watering and hence increase the maintenance requirements. This could be significant in increasing the life-cycle costs at remote sites.

(3) Disposal, Refund, and Return: Disposal of batteries represents a logistics and environmental problem unless properly done. Since battery metal has significant salvage value, return to the metal scrap salvage dealer is a reasonable alternative. Refund policies (if any) must then be stated, and a return method described.

(4) Warranty: To establish that a warranteed battery fails to perform, it may be necessary to measure its capacity. Refer to Sec. ST.E.l.

\section{ST.I.2 Maintainability}

Refer to performance criterion SY.I.2. See below for additional commentary warranting particular attention. 
Commentary. In addition to the issues mentioned in performance criterion SY.I.2, the following storage-specific comments should be considered.

- Batteries can be both heavy and filled with corrosive electrolytes; therefore, they require appropriate equipment for installation and maintenance. Before installation, the handling equipment shall be inspected for its handling capacity. Repair and/or replacement of deficient equipment is mandatory to assure handling safety.

- In any installation where the weight of a battery exceeds that which an installer can easily lift, $23 \mathrm{~kg}(50 \mathrm{lb})$, slings and lifting equipment are required. The slings (as well as the lifting equipment) shall be sufficient in size and capacity so that the procedure can be safely undertaken. Sling spreaders may also be necessary.

- There shall be sufficient operating space around the battery supports (racks, trays or platforms) to permit safe movement of the lifting equipment (and the personnel necessary to operate it) without worry of damaging other batteries. The personnel involved in the installation shall be protected from possible electrolyte spills by goggles, gloves, aprons, etc., as appropriate to the facility. See manufacturers' recommendations and existing standards (IEEE 484-1975, for example).

\section{Building/Site Attribute's}

\section{ST.B.1 Plumbing}

Criterion. Appropriate plumbing and drainage for personnel safety shall be located in the battery area.

B̈valuation. Review of the building design and installation drawings.

Commentary: Special safety showers and/or eyewash fountains may be provided in the battery room for use by personnel in the event of an electrolyte spill. Portable units may be preferable in small installations. If a shower is provided, care must be taken so the water from the shower does not splash onto the batteries.

A floor drain in the battery area may be provided, especially if the area contains a shower (in case of an electrolyte spill). The drain must not be connected to the normal plumbing but have a separate flow and containment.

An amount of neutralizing chemical sufficient to deal with any electrolyte spillage should be provided. In addition, electrolyte-resistant flooring in the battery area should be installed. 


\section{REPERENCES}

1. MITRE Corp. Battery and Electrochemical Systems Program Summary. Prepared for the U.S. Department of Energy; November 1979.

2. DOE Battery and Electrochemical Contractors' Conference Vol. I and II. Arlington, VA: December 1979.

3. Smith, G. Storage Batteries. 2nd Ed. London: Pitman Publishing Ltd.; 1971.

4. Vinal, G. Storage Batteries. 4th Ed. New York: John Wiley \& Sons, Inc; 1951.

5. Bechtel National, Inc. Handbook for Battery Energy Storage in Photovoltaic Power Systems. Prepared for Sandia National Laboratories; SAND80-7022; February 1980.

6. Hittman Associates. Data Base for Photovoltaic System Components. Prepared for Sandia National Laboratories (in preparation).

7. Falk and Salkind. Alkaline Storage Batteries. New York: John Wiley \& Sons, Inc.; (n.d.). 


\subsection{CABLING}

$\underline{\text { Page }}$

Introduction $\quad \ldots \ldots \ldots \ldots \ldots \ldots \ldots \ldots \ldots \ldots \ldots \ldots \ldots \ldots \ldots \ldots \ldots \ldots \ldots \ldots \ldots \ldots \ldots \ldots$

Performance Criteria $\ldots \ldots \ldots \ldots \ldots \ldots \ldots \ldots \ldots \ldots \ldots \ldots \ldots \ldots \ldots \ldots \ldots \ldots \ldots \ldots \ldots$

Electrical Attributes $\ldots \ldots \ldots \ldots \ldots \ldots \ldots \ldots \ldots \ldots \ldots \ldots \ldots \ldots \ldots \ldots \ldots \ldots$

CA.E.1 Cable Conductor Sizing ....................... 7-3

Safety Attributes $\ldots \ldots \ldots \ldots \ldots \ldots \ldots \ldots \ldots \ldots \ldots \ldots \ldots \ldots \ldots \ldots \ldots \ldots \ldots \ldots, \ldots \ldots$

CA.S.1 Cable Flammability $\ldots \ldots \ldots \ldots \ldots \ldots \ldots \ldots \ldots \ldots \ldots \ldots \ldots$ 7-4

CA.S.2 Clearances ............................ 7-4

CA.S.3 Fire Codes and Standards..................... $7-4$

Durability/Reliability Attributes ........................ 7-5

CA.D.1 Cabling and Connectors ..................... 7-5

CA.D.2 Cable Loading Requirements................... 7-5

CA.D.3 Solar Degradation ........................... 7-5

CA.D.4 Moisture Resistance ....................... 7-5

Installation, Operation, and Maintenance Attributes.............. 7-6

CA.I.1 Installation, Operation, and Maintenance Manual ........ 7-6

CA.I.2 Cabling Installation......................... 7-6

CA.I.3 Cable Maintenance ......................... 7-7 
THIS PAGE

\section{WAS INTENTIONALLY \\ LEFT BLANK}




\section{SECTION 7.0}

\section{CABLING}

\section{INTRODUCTION}

Photovoltaic applications pose no different selection requirements on cabling than any other power source. Technical requirements such as voltage, current to be carried, external thermal conditions, voltage regulation, and other special requirements need to be considered. A study of the conditions that the cable will have to meet, and a study of cable types available and their recommended applications, may determine a sole candidate. If several types are suitable, however, then usually the most economical one is chosen.

After the appropriate type of cable is chosen, the conductor size can be determined. The information needed to determine proper size includes four criteria:

- the current required by the intended load;

- the maximum ambient air temperature;

- the distance from the source of supply to the intended load; and

- the voltage drop desired.

Because of the wealth of information that already exists on cabling practices for other power system types, which will not have to be amended for PV installations, this section is relatively brief, but further information may be obtained from Refs. 1 and 2 .

\section{PERFORMANCE CRITERIA}

\section{Electrical Attributes}

\section{CA.E.1. Cable Conductor Sizing}

Criterion. The cable conductor size shall be such that electrical losses resulting from cabling shall be within the specified energy loss budget of the system.

Evaluation. Cabling design shall be analyzed to determine that wire sizing satisfies the energy budget of the system. This procedure generally will satisfy any National Electrical Code (NEC) requirements that consider wire heating rather than efficiency. Nevertheless, compliance with the provisions of Article 310 of the NEC shall be assured. Maximum current of modules for this analysis shall be short-circuit current.

Commentary. Wires have a finite resistance corresponding to the length, size (radius), and material of the wire. Power losses may be expected because of this resistance, and these losses should be kept within the system energy budget. (It may be necessary to balance the economics of wire size costs against the gains in power output of larger cables.) In addition, the NEC has defined acceptable current-carrying capacities for wires of different sizes and materials. These represent a safety feature and should be examined to ensure operation within acceptable limits, including short-circuit conditions if no over current protective devices are provided. In no case shall the wires be continu- 
ously loaded under normal or fault conditions beyond NEC stipulations that describe acceptable current loading as a function of wire size, ambient temperature, and temperature rating of the wire for three conductors. in a raceway, or cable, direct-earth burial.

In choosing a cable for an intended load, its environment should not cause it to exceed its temperature-to-voltage limits as specified by the Insulated Power Cable Engineers Association (IPCEA). Tables of current-carrying capacities based on heating for various sizes and types of cable have been issued by IPCEA and the NEC.

\section{Safety Attributes}

\section{CA.S.1. Cable Flammability}

Criterion. The cabling used in photovoltaic systems shall not propagate flames beyond their area of original occurrence.

Rvaluation. The cubling used shall be rated VW-1 per UL 44 Rubber Insulated Wire, et al.

Commentary: If flaming of a segment of a photovoltaic array does occur, all attempts should be made to confine it to the area of original occurrence. The use of wiring rated as described above will help accomplish that result.

\section{CA.S.2. Clearances}

Criterion. Clearances between overhead supply cables and all other eubles and structures should conform to Scc. 23 of ANSI C2.

Evaluation. Conformity to instructions contained in ANS1 C2. Review of installation drawings and specifications.

Commentary. It is important to maintain safe distances between operating cables.

\section{CA.S.3. Fire Codes and Standards}

Criterion. Cable assemblies and their installations shall comply with local and nationally recognized codes and staniards for fire sufety.

Evaluation. Drawings and specifications sliull be reviewed for conformity to locnl and nativilully recognized codes and standarde for fir $\theta$ vafety, including but not limited to applicable scetions of NFPA 89M, FFPA 90A and 90B, NFPA 211, NFPA 54, NFPA 30, NFPA 31, NFPA 256, the NEC and HUD standards. In cases where sufficient engineering information is not available, testing to show compliance may be required. Potential heat, rate of heat release, ease of ignition, and smoke generation will be considered in assessing potential fire hazards. 


\section{Durability/Reliability Attributes}

\section{CA.D.1. Cabling and Connectors}

Criterion. Cabling and connectors shall be sufficiently rugged and long-lived to withstand all system operating conditions for the expected life of the system.

Evaluation. Specifications review, visual inspection, and high potential (hi-pot) testing, where applicable, shall verify conformance to this criterion.

Commentary. Cables must provide: adequate electrical isolation under all expected environmental conditions, long-term insulation integrity, and sufficient physical strength to allow installation under difficult conditions of bending and flexing. Attention must also be given to providing freedom from cable cross talk within cable wiring, and prevention of excessive electromagnetic interference radiating from the cable system. Cables should be protected from damage by animals or vermin. Appropriate NEMA or IEEE standards should be consulted.

\section{CA.D.2. Cable Loading Requirements}

Criterion. The cabling shall not be damaged by expected in-field ice and wind loading.

Evaluation. Drawings and specifications shall be reviewed in conjunction with weather data for the intended application site to determine adequate load capabilities.

Commentary. ANSI C2 governs the approved criteria for assuring that cable systems maintain their structured integrity under in-service conditions. The strength requirements of cable support structures (if any) should be calculated using the data provided in Sec. 26 of the National Electric Safety Code, ANSI C2.

\section{CA.D.3. Solar Degradation}

Criterion. Cable components or materials shall not be adversely affected by in-service exposure to sunlight to an extent that their life-cycle function is impaired significantly.

Evaluation. Evaluation includes documentation of satisfactory long-term performance under certain use conditions, or engineering analysis.

Commentary. Some organic materials used in cabling may be particularly susceptible to solar degradation under prolonged exposure. When cable components or materials are exposed to UV radiation with or without an intermittent water spray at their maximum service temperature, there should be no signs of excessive deterioration such as cracking, crazing, embrittlement, loss in flexural strength, or any other changes that would significantly affect performance.

\section{CA.D.4. Moisture Resistance}

Criterion. Cable chosen for a speclfic apjlication shall not be adversely affected by exposure to moisture to an extent that its function during its lifetime is impaired significantly. 
Evaluation. This includes documentation of satisfactory long-term performance under usage conditions, or engineering analysis. Where adequate information is unavailable, methods that demonstrably meet the intent of the criterion should be used.

Commentary. Moist ure is exhibited in several for ms; e.g., rainfall, melting snow and ice, ar condensation. The intent of this criterion is to ensure adequate performance of cable components or materials that probably will be exposed to moisture.

Installation, Operation, and Maintenance Attributes

CA.I.1. Installation, Operation, and Maintenance Manual (see SY.I.1)

\section{CA.I.2. Cabling Installation}

Criterion. Cable shall be installed according to accepted cabling installation practices, consistent with the level of complexity of the photovoltaic system.

Evaluation. Installation shall be evaluated by determining conformity to plans and specifications developed from accepted industrial practices.

Commentary. Because of the diverse applications for cable installation, it is not possible to specify every contingency. One excellent overall source, especially applicable to interm edia te load center and central station applications, is provided in Ref. 1. (See particularly Chapter 8, Cable Installation, and Chapter 9, Cable Joints and Terminations).

The complexity of any kind of cable installation and the way it is done depend on its particular application. Remote applications might require a solitary cable buried in a shallow ditch, while central station applications would involve many diverse installation practices. As the size and cumplexity of the intended application increasc, so do established standards and practices. For central station applications, the utility will issue standards to guide the installer, operator, or maintenance person in each specific task.

In utility interactive solar applications, the architect and engineer should discuss the primary needs of voltage and capacity with utility representatives, and from that discussion the utility will determine what type of cabling it needs to furnish to the work site. Also, depending on power requirements, it will speoify to the archltect and engineer the typc of metering needed and whether a vault would be needed as well. The utility will furn ish its cabling and ancillary equipment-without the meter in residential applications, and without the utilization transformer or vault in intermediats load uentcr applicutions. The utility will also be available to advise the architect and engineer on matters pertaining to cabling and concomitant equipment that connect to the utility lines, within the confines of the intended application. In stand-alone solar applications, the architect and engineer should devise installation procedures according to the complexity of the intended application. Various standards and standard operating procedures exist, and help is available from the distribution division of the nearest utility. Another source of assistance is the field service personnel of the cable manufacturer. 


\section{CA.I.3. Cable Maintenance}

Criterion. The maintenance manual for the system shall specify inspection intervals for system cabling. (See also SY.I.1.)

Evaluation. Evaluation will determine conformity to inspection and maintenance procedures developed from accepted industrial practices:

Commentary. The frequency of inspections and maintenance varies according to the complexity of the intended application, and is usually determined locally from operating experience. Refer to Ref. 1, Chapter 11, Cable Testing, Fault Location and Cable Identification, and Chapter 12, Records, Repairs and Maintenance.

Cables are tested at the factory, but many things can happen to damage the cable before it is put in service, and many things can happen in service that will shorten its life expectancy. Cables interconnect various apparatus that are of ten great distances apart, which subjects them to many hazards. Cables may be installed in hard-to-reach locations such as underground, under floors, under water, on poles, or in conduits; therefore, they are not readily accessible for periodic inspection. They are frequently installed and forgotten until something goes wrong. 
$\lim ^{2}=$

\section{REPERBNCES}

1. Edison Electric Institute. Underground Systems Reference Book. 1957.

2. Klein, D. M. Handbook for Photovoltaic Cabling. COO-4094-90. Lexington, MA: MIT/Lincoln Laboratory; August 1980. 


\subsection{POWER DISTRIBUTION SUBSYSTEM}

Page

Introduction $\ldots \ldots \ldots \ldots \ldots \ldots \ldots \ldots \ldots \ldots \ldots \ldots \ldots \ldots \ldots \ldots \ldots \ldots \ldots \ldots \ldots \ldots . . . .6$

Performance Criteria $\ldots \ldots \ldots \ldots \ldots \ldots \ldots \ldots \ldots \ldots \ldots \ldots \ldots \ldots \ldots \ldots \ldots \ldots \ldots$

Electrical At tributes $\ldots \ldots \ldots \ldots \ldots \ldots \ldots \ldots \ldots \ldots \ldots \ldots \ldots \ldots \ldots \ldots$

PD.E.1 Power Distribution Power and Voltage Capability .......... 8-3

PD.E.2 Utility Interf ace Design ...................... 8-4

Safety Attributes $\ldots \ldots \ldots \ldots \ldots \ldots \ldots \ldots \ldots \ldots \ldots \ldots \ldots \ldots \ldots \ldots \ldots \ldots \ldots$. 8.4

PD.S.1 Power Distribution Saf ety ...................... 8-4

PD.S.2 Load Disconnect Capability..................... 8-5

PD.S.3 Utility Interf ace Design ....................... 8-5 


\section{THIS PAGE \\ WAS INTENTIONALLY \\ LEFT BLANK}

$8-2$ 


\section{SECTION 8.0}

\section{POWER DISTRIBUTION SUBSYSTEM}

\section{INTRODUCTION}

The power distribution subsystem is the electrical and physical interface between a power conditioning subsystem and electrical loads. It also contains the interface between a utility power source and the electrical loads and power conditioning subsystem. The function of this interface junction is to provide:

- the electrical connection between a power source and loads;

- system overload and short-circuit protection; and

- manual circuit disconnect capability.

Power in the subsystem may be of three types: AC, regulated DC, and unregulated DC. Unregulated DC power is power delivered to a load at a variable voltage; for example, the power supplied directly from a bank of batteries. Regulated DC power is power delivered at a fixed voltage.

A power distribution subsystem consists of a protective cabinet containing breakers or relays for each separate load circuit and a main breaker for input conductor overcurrent protection. Manual disconnect capability is essential to provide safe conditions for servicing system components. The power distribution subsystem may be designed to contain electronic relays that accept control signals from a system monitor and control unit.

A residential power distribution subsystem may simply be the "fuse box" that currently exists in a residence. Additional control relays will be used in those systems utilizing load shedding or load switching as dictated by a system monitor and control unit. For all systems, the power distribution subsystem provides the access location for the physical interconnection to and control of the various load circuits. The power distribution subsystem may be designed to contain electronic relays that accept control signals from a system monitor and control unit.

\section{PERFORMANCE CRITERIA}

\section{Electrical Attributes}

\section{PD.E.1. Power Distribution Power and Voltage Capability}

Criterion. The electrical components of the power distribution subsystem shall be appropriate for the power type and load voltage level requirements.

Evaluation. Satisfactory review of electrical system drawings and component specifications shall indicate conf ormance. 


\section{PD.E.2. Utility Interface Design}

Criterion. The power distribution subsystem to utility power interface shall be designed to conform with applicable codes and practices regarding safety and design considerations.

Evaluation. Review of the electrical connection drawings shall indicate conformity to the applicable portions of the National Electrical Code (NEC) and applicable practices of the local utility.

Commentary. The NEC contains the requirements for designing and installing the electrical interface between the utility and the appllcation. These requirements, liuwevei', apply to receiving energy from, rather than sending it to, the utility (as would occur in a utility sell-back arrangement).

The portions of the NEC that apply to receiving energy from the utility are:

- Article 220 - sizing for the feeder (load) of the application;

- Article 230 - requirements for the electrical service (utility) connection and equipment for control and protection of the electrical service and installation requirements;

- Article 240 - overcurrent (circuit breaker) protection; and

- Article 250 - grounding.

If the application is a residence, NFPA No. $701 \mathrm{~A}$, an excerpted version of the electrical code, is available.

While it may be desirable to sell back the energy generated by the photovoltaic energy source to the utility, NEC requirements for that interface do not presently exist. If the existing service conductors are used, the current returned to the utility cannot exceed their capacity. Until national guidelines and requirem ents are established, users desiring to feed energy back to the utility should consult their local utility for an acceptable method.

\section{Safety Attributes}

\section{PD.S.1. Power Distribution Safety.}

Criterion. Power distribution shall comply with existing codes or established procedures governing the installation, operation, and maintenance safety requirements of junction boxes, circuit breakers, and $\mathrm{DC}$ and $\mathrm{AC}$ circuits.

Evaluation. Code conformity shall be verified by review of drawings and component specifications.

Commentary. The power distribution subsystem typically consists of a corrosion-proof metal cabinet housing the circuit breakers, and/or relay switches, load busbars, and associated wiring. All wiring must be accessible for inspection. The cabinet must be covered and so placed as to prevent moisture or water accumulation. There should be no combustible material immediately adjacent to the distribution panel. 
The circuit breaker status (on/off) should be clearly marked for both switch positions and the current and voltage rating should be indicated. Once a trip point has been set, the breakers should be tamperproof.

The distribution panel must be sized according to the number of electrical connections it will house, and breakers sized in accordance with the current capacity of the conductors.

National Electrical Code requirements that may be applicable to the power distribution subsystem are contained in Articles 370, 240, and 250. Similarly, Underwriters Laboratories Standard for Molded Case Circuit Breakers and Circuit Breaker Enclosures, UL 489-1972, may also be applicable. Because of the possibility of reverse power flow, the circuit breaker may need to be suitable for use with a reversed line-load connection.

\section{PD.S.2. Load Disconnect Capability}

Criterion. The power distribution shall have the capability of manually disconnecting the power source from the load.

Evaluation. Satisfactory review of electrical system drawings and component specifications shall indicate conf or mance.

Commentary. Manual disconnect capability is essential to provide safe conditions for servicing system components. The power distribution center may be designed to contain electronic relays that accept control signals from the system monitor and control.

\section{PD.S.3. Utility Interface Design (See PD.E.2)}


APPENDIX A

GLOSSARY

A-1 
THIS PAGE

\section{WAS INTENTIONALLY LEFT BLANK}




\section{GLOSSARY}

$\underline{\text { Page }}$

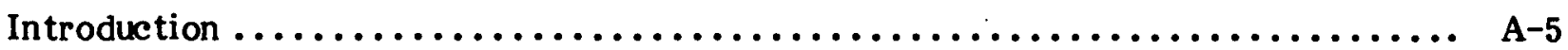

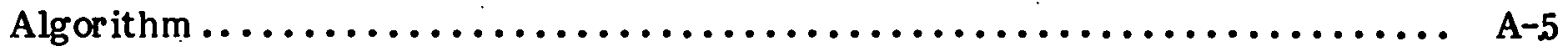

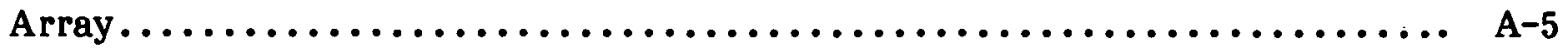

Array Field.................................... A-5

Array Subfield $\ldots \ldots \ldots \ldots \ldots \ldots \ldots \ldots \ldots \ldots \ldots \ldots \ldots \ldots \ldots \ldots \ldots \ldots \ldots \ldots \ldots \ldots$ A $\ldots \ldots \ldots$

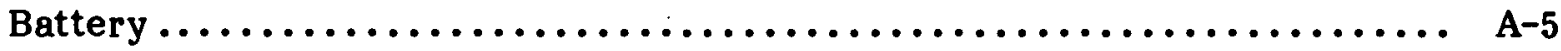

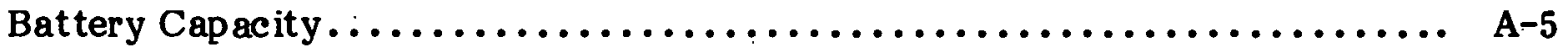

Ampere-Hour Capacity (Coulombic) ..................... A-5

Available Capacity ................................ A-5

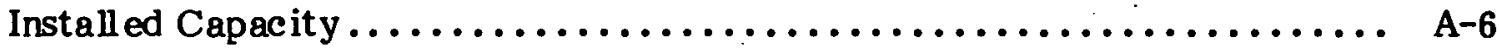

Rated Capacity .................................. A-6

Watt-Hours (Energy) Capacity $\ldots \ldots \ldots \ldots \ldots \ldots \ldots \ldots \ldots \ldots \ldots \ldots \ldots \ldots$ A $\ldots \ldots$

Capacity Tests................................. A-6

Battery Cell ...................................... A-6

Battery Cycle Life . . ............................... A-6

Battery Final Cutoff Voltage $\ldots \ldots \ldots \ldots \ldots \ldots \ldots \ldots \ldots \ldots \ldots \ldots \ldots \ldots \ldots \ldots \ldots$ A-6

Battery Ef ficiency $\ldots \ldots \ldots \ldots \ldots \ldots \ldots \ldots \ldots \ldots \ldots \ldots \ldots \ldots \ldots \ldots \ldots \ldots \ldots \ldots \ldots$

Ampere-Hour (Coulombic) Effi ciency $\ldots \ldots \ldots \ldots \ldots \ldots \ldots \ldots \ldots \ldots \ldots$ A

Voltage Efficiency $\ldots \ldots \ldots \ldots \ldots \ldots \ldots \ldots \ldots \ldots \ldots \ldots \ldots \ldots \ldots \ldots \ldots \ldots \ldots$

Watt-Hour Energy Efficiency $\ldots \ldots \ldots \ldots \ldots \ldots \ldots \ldots \ldots \ldots \ldots \ldots \ldots \ldots$ A-7

Battery Self-D is charge (Local Action) $\ldots \ldots \ldots \ldots \ldots \ldots \ldots \ldots \ldots \ldots \ldots \ldots \ldots$

Branch Circuit .................................... A-8

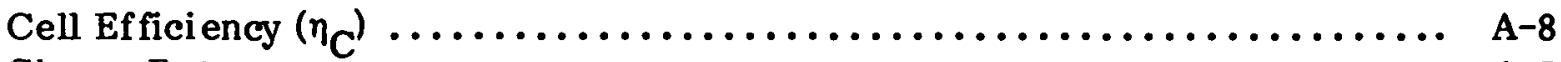

Charge Rate....................................... A-8

Collector Efficiency $\left(\eta_{C L}\right) \ldots \ldots \ldots \ldots \ldots \ldots \ldots \ldots \ldots \ldots \ldots \ldots \ldots \ldots \ldots \ldots$ A-9

Commutation ...................................... A-9

Concentrator Optics ................................. A-9

Concentrator Cell Assembly .............................. A-9

Control Functions . . . . . . . . . . . . . . . . . . . . . . . . . . . A

Depth of Discharge (DOD) .............................. A-9

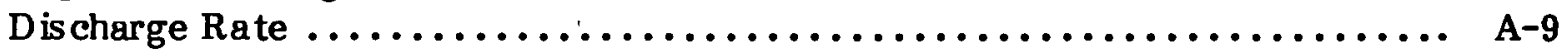

Elec trolyte ........................................ A-10

Encapsulated Solar Cell Efficiency $\left(\eta_{E C}\right) \ldots \ldots \ldots \ldots \ldots \ldots \ldots \ldots \ldots \ldots \ldots$ A $\ldots \ldots$

End-of-Charge-Voltage ............................... A-10

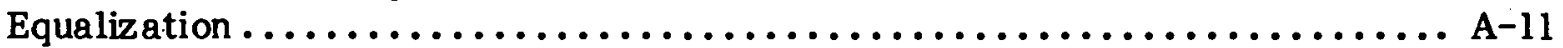

Equalizing Charge $\ldots \ldots \ldots \ldots \ldots \ldots \ldots \ldots \ldots \ldots \ldots \ldots \ldots \ldots \ldots \ldots \ldots \ldots \ldots \ldots$

Finishing Rate ..................................... A-11

Formation..................................... A

Gassing $\ldots \ldots \ldots \ldots \ldots \ldots \ldots \ldots \ldots \ldots \ldots \ldots \ldots \ldots \ldots \ldots \ldots \ldots \ldots \ldots \ldots \ldots \ldots \ldots$

Geometric Concentration Ratio (R) ........................ A-11

Illuminated Cell Area $\left(A_{C}\right) \ldots \ldots \ldots \ldots \ldots \ldots \ldots \ldots \ldots \ldots \ldots \ldots \ldots \ldots \ldots . \ldots \ldots$ 
Illumination Mismatch Ef ficiency $\left(\eta_{I M}\right) \ldots \ldots \ldots \ldots \ldots \ldots \ldots \ldots \ldots \ldots \ldots, \ldots \ldots \ldots$

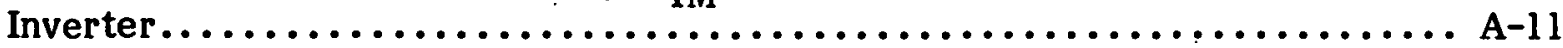

Leveliz ed Energy Cost .....................................A-11

Maximum Power Point .................................. A-12

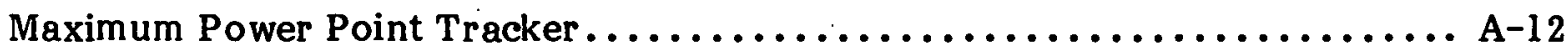

Mismatch Efficiency $\left(\eta_{\text {MIS }}\right) \ldots \ldots \ldots \ldots \ldots \ldots \ldots \ldots \ldots \ldots \ldots \ldots \ldots \ldots \ldots \ldots \ldots \ldots \ldots \ldots \ldots, 12$

M odule $\ldots \ldots \ldots \ldots \ldots \ldots \ldots \ldots \ldots \ldots \ldots \ldots \ldots \ldots \ldots \ldots \ldots \ldots \ldots \ldots \ldots \ldots$ A-12

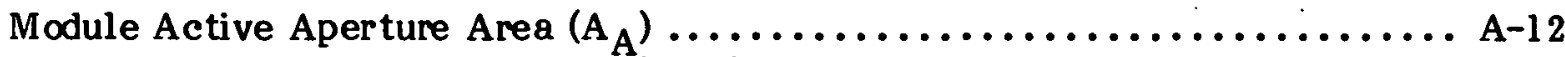

Module Aperture Area Ef ficiency $\left(\eta_{A A}\right) \ldots \ldots \ldots \ldots \ldots \ldots \ldots \ldots \ldots \ldots \ldots$ A-12

Module Packing Efficiency $\left(\eta_{p}\right) \ldots \ldots \ldots \ldots \ldots \ldots \ldots \ldots \ldots \ldots \ldots \ldots \ldots \ldots \ldots \ldots \ldots \ldots \ldots \ldots \ldots, 12$

Module Total Aperture Area $\left(\mathrm{A}_{\mathrm{TA}}\right) \ldots \ldots \ldots \ldots \ldots \ldots \ldots \ldots \ldots \ldots \ldots \ldots \ldots \ldots \ldots \ldots \ldots \ldots \ldots, 12$

Motive Power (Traction Battery) $\ldots \ldots \ldots \ldots \ldots \ldots \ldots \ldots \ldots \ldots \ldots \ldots \ldots \ldots \ldots \ldots \ldots \ldots \ldots \ldots \ldots, 12$

Net Present Value ..................................... A-12

Nominal Operating Cell Temperature (NOCT) $\ldots \ldots \ldots \ldots \ldots \ldots \ldots \ldots \ldots$ A-13

Optical Axis $\ldots \ldots \ldots \ldots \ldots \ldots \ldots \ldots \ldots \ldots \ldots \ldots \ldots \ldots \ldots \ldots \ldots \ldots \ldots \ldots$ A-13

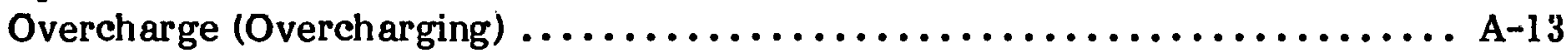

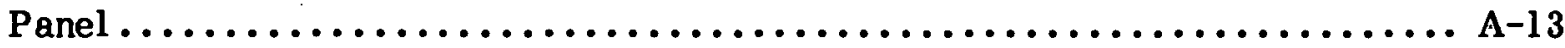

Permissive Control Functions.$\ldots \ldots \ldots \ldots \ldots \ldots \ldots \ldots \ldots \ldots \ldots \ldots \ldots \ldots$ A -13

Photovol taic Power System Monitor

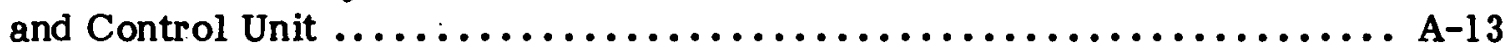

Photovol taic (PV) System.$\ldots \ldots \ldots \ldots \ldots \ldots \ldots \ldots \ldots \ldots \ldots \ldots \ldots \ldots \ldots$ A -14

Power Conditioning Subsystem Monitor

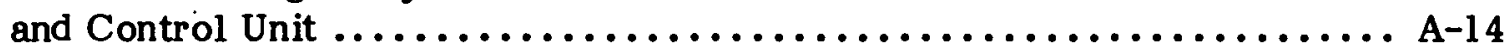

Power Conditioning Unit (PCU) $\ldots \ldots \ldots \ldots \ldots \ldots \ldots \ldots \ldots \ldots \ldots \ldots \ldots \ldots \ldots \ldots \ldots \ldots \ldots \ldots \ldots$

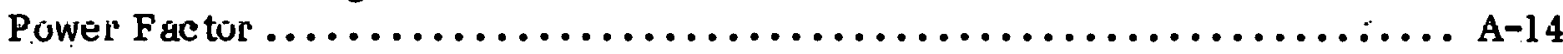

D ispl acem ent Power F actor $\ldots \ldots \ldots \ldots \ldots \ldots \ldots \ldots \ldots \ldots \ldots \ldots \ldots . . \ldots$ A-14

Power Transfer Map $\ldots \ldots \ldots \ldots \ldots \ldots \ldots \ldots \ldots \ldots \ldots \ldots \ldots \ldots \ldots \ldots \ldots$ A -14

Rated Module Electrical Ef ficiency (Flat-Plate) $\left(\eta_{\mathrm{FPM}}\right) \ldots \ldots \ldots \ldots \ldots \ldots \ldots$. 15

Receiver ........................................... A-15

Receiver Active Cell Area $\left(A_{R C}\right) \ldots \ldots \ldots \ldots \ldots \ldots \ldots \ldots \ldots \ldots \ldots \ldots$ A-15

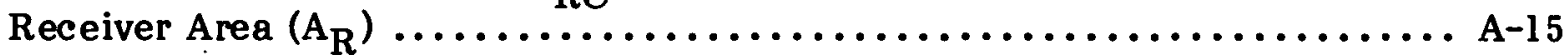

Receiver Packing Ef ficiency $\left(\eta_{R P}\right) \ldots \ldots \ldots \ldots \ldots \ldots \ldots \ldots \ldots \ldots \ldots \ldots \ldots, \ldots \ldots \ldots, 15$

Reference Irradiance Spec trum (RIS) $\ldots \ldots \ldots \ldots \ldots \ldots \ldots \ldots \ldots \ldots \ldots \ldots \ldots$ A-15

Ripple Current Ratio .................................... A-15

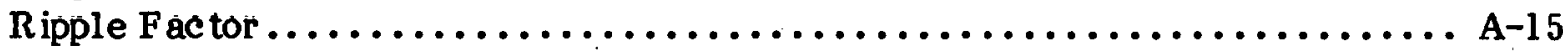

Solar Cell ..............................................A-16

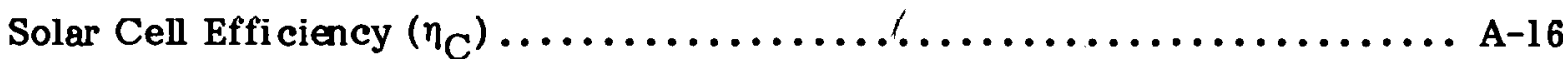

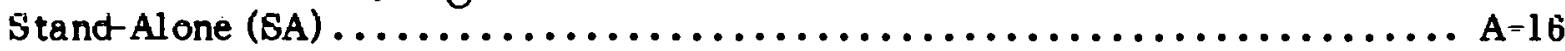

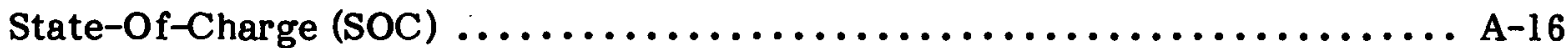

Subsystem Monitor and Control Unit $\ldots \ldots \ldots \ldots \ldots \ldots \ldots \ldots \ldots \ldots \ldots \ldots$ A-16

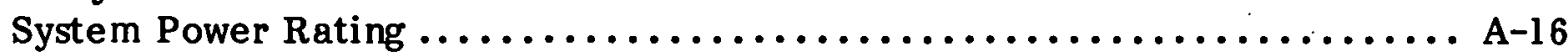

Uninterruptible Power System (UPS) $\ldots \ldots \ldots \ldots \ldots \ldots \ldots \ldots \ldots \ldots \ldots \ldots$ A-17

Unli mited Interac tive Source/Sink $\ldots \ldots \ldots \ldots \ldots \ldots \ldots \ldots \ldots \ldots \ldots \ldots \ldots$ A-17

Utility In teractive (UI) $\ldots \ldots \ldots \ldots \ldots \ldots \ldots \ldots \ldots \ldots \ldots \ldots \ldots \ldots \ldots \ldots \ldots, \ldots \ldots \ldots$

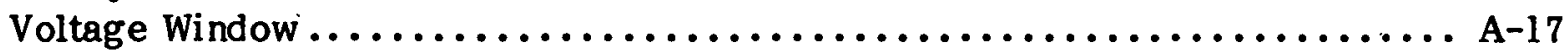

Weighted Ref erence Irradiance Spec trum (WRIS) $\ldots \ldots \ldots \ldots \ldots \ldots \ldots \ldots . . \ldots$ A-17 


\section{GLOSSARY}

\section{INTRODUCTION}

This glossary is a collection of some terms and.nomenclature used in this document and defined by the task groups who developed the performance criteria. In some instances, definitions need to be reviewed and many accepted definitions may not apply to photovoltaic applications; hence, some new definitions have been derived that apply to current technology.

\section{Algorithm}

A prescribed set of well-defined rules or processes for the solution of a problem in a finite number of steps; for example, a full statement of an arithmetic procedure for evaluating $\sin \mathrm{x}$ to a stated precision.

\section{Array}

A mechanically integrated assembly of modules or panels with a support structure and foundation, tracking, thermal control, and other components, as required, to form a DC power producing unit.

\section{Array Field}

The aggregate of all solar photovoltaic arrays generating power within a given system.

Array Subfield

A group of solar photovoltaic arrays associated by a distinguishing feature such as field geometry, electrical interconnection, or power conditioning.

\section{Battery}

A battery consists of two or more cells electrically connected for producing electrical energy. Common usage permits this designation to be applied also to a single cell used independently.

\section{Battery Capacity}

Generally, the total number of ampere-hours that can be withdrawn from a fully charged cell or battery.

Ampere-Hour Capacity (Coulombic)-The ampere-hour capacity of a storage battery is the number of ampere hours which can be delivered under specified conditions as to temperature, rate of discharge, and final voltage.

Available Capacity-The total number of ampere-hours that can be withdrawn from a cell or battery for a specific set of operating conditions including discharge rate, temperature, initial state of charge, age, and cutoff voltage. 
Installed Capacity-The total number of ampere-hours that can be withdrawn from a new cell or battery when discharged to the system specified cutoff voltage at the system design rate and temperature (i.e., discharge to the system design specified máximum depth of discharge).

Rated Capacity-The rated capacity of a storage battery is the number of amperehours and/or watt-hours which it is capable of delivering when fully charged and under specified conditions of temperature, rate of discharge, final voltage, and specific gravity.

Watt-Hour (Energy) Capacity-The total number of watt-hours (kilowatt-hours) that can be withdrawn from a fully-charged cell or battery. The energy capacity of a given cell varies with temperature, rate, age, and cutoff voltage. This term is more common to system designers than it is to the battery industry where capacity usually refers to ampere-hours.

\section{Capacity Tests-}

Acceptance Test (lead storage batteries): A capacity test made on a new battery to determine that it meets specifications or manufacturer ratings.

Performance Test (lead storage batteries): A capacity test made on a battery, as found, after being in service to detect any change in the capacity determined by the acceptance test.

Service Test (lead storage batteries): A special capacity test made to demonstrate the capability of the battery to meet the design requirements of the system to which it is connected.

\section{Battery Cell}

A storage cell is a galvanic cell for the generation of electrical energy in which the cell, after being discharged, may be restored to a fully charged condition by an electric current flowing in a direction opposite the flow of current when the cell discharges.

\section{Battery Cycle Life}

The number of cycles, to a specified depth of discharge, that a cell or battery can undergo before failing to meet its specified capacity or efficiency performance criteria.

For example, with lead-acid batteries, end-of-life is generally taken as the point in time when a fully charged cell can dellver only 80\% of its ruted capacity. Beyond this state of aging, deterioration and loss of capacity begin to accelerate rapidly. Life may be measured in cycles and/or years, depending on the type of service for which the cell or battery is intended.

\section{Battery Final Cutoff Voltage}

The final (cutoff) voltage of a battery is the prescribed voltage at which the discharge is considered complete.

The cutoff or final voltage is usually chosen so that the useful capacity of the battery is realized. The cutoff voltage varies with the type of battery, the rate 
of discharge, the temperature, and the kind of service. The term "cutoff voltage" is applied more particularly to primary batteries, and the term "final voltage" to storage batteries.

\section{Battery Efficiency}

The efficiency of a storage battery is the ratio of the output of the cell or battery to the input required to restore the initial state of charge under specified conditions of temperature, current rate, and final voltage.

Ampere-Hour (Coulombic) Efficiency $\left(\eta_{\mathrm{Ah}}\right)$-The ampere-hour efficiency of a storage battery is the electrochemical efficiency expressed as the ratio of the ampere-hours output to the ampere-hours input required for the recharge.

$$
\eta_{\text {Ah }}=\frac{\text { ampere-hours discharged }}{\text { ampere-hours of charge }}=\frac{\int_{0}^{t}{ }^{d} d_{d t}}{\int_{0}^{t} c_{i} d t}
$$

where $i_{d}$ and $i_{c}$ are the discharging and charging currents, respectively, and $t_{d}$ and $t_{c}$ are the discharging and charging times, respectively.

Voltage Efficiency $\left(\eta_{v}\right)$-The voltage efficiency of a storage battery is the ratio of the average voltage during the discharge to the average voltage during the recharge.

$$
\eta_{v}=\frac{\text { avg. discharge vol tage }}{\text { avg. charging voltage }}=\frac{\frac{1}{t}}{\frac{1}{t}} \frac{\int_{c}^{t} d v_{d} d t}{\int_{0}^{t} v_{c} d t} \text {, }
$$

where $v_{d}$ and $v_{c}$ are the discharging and charging currents, respectively, and $t_{d}$ and $t_{c}$ are the discharging and charging times, respectively.

Watt-Hour Energy Efficiency $\left(\eta_{W}\right)$-The watt-hour efficiency of a storage battery is the energy efficiency expressed as the ratio of the watt-hours output to the watt-hours of the recharge.

$$
\eta_{W}=\frac{\text { watt-hours discharged }}{\text { watt-hours charged }}=\frac{\int_{0}^{t}{ }^{d} i_{d} v_{d} d t}{\int_{0}^{t}{ }^{t} i_{c} v_{c} d t},
$$

where $i_{d}$ and $i_{c}$ are the discharging and charging currents, respectively; $v_{d}$ and $v_{c}$ are the corresponding voltages, and $t_{d}$ and $t_{c}$ are the discharging and charging 
time, respectively. The watt-hour efficiency is approximately equal to the product of the voltage and ampere-hour efficiencies.

\section{Battery Self-Discharge (Local Action)}

Self-discharge is the loss of otherwise useable chemical energy by spontaneous currents within the cell or battery regardless of its connections to an external circuit.

- Branch Circuit

A number of modules or paralleled modules connected in series to provide DC power at the system voltage.

Cell Efficiency (at peak electrical performance operating conditions, $\eta_{\mathrm{c}}$ ).

The ratio of solar cell peak power at $28^{\circ} \mathrm{C}$ junction temperature to total irradiant power of RIS spectrum incident on the illuminated cell area. Flat-plate cells are normally referenced to $1000 \mathrm{~W} / \mathrm{m}^{2}$ RIS irradiance level; cells designed for concentrated sunlight applications are normally referenced to the RIS irradiance level expected in service.

\section{Charge Rate}

The current applied to a cell or battery to restore its available capacity.

The charge rate can be expressed in amperes (or watts if a constant power is applied) but is commonly normalized with respect to the rated capacity of the battery. For example, given the rated ampere-hour capacity, $C$, and the actual charging current, $I_{c}$, the charging rate is expressed as:

$$
\frac{C}{C / T_{c}}=\frac{C}{T_{N}}
$$

where $T_{N}$ is a nominal unit of time in hours.

Therefore, given a 500-ampere-hour battery being charged by a 50-ampere current, the charge rate becomes

or, $\quad+\cdots \frac{C}{500750}$

the $\mathrm{C} / 10$ rate.

It must be noted that $\mathrm{T}_{\mathrm{N}}$ cannot be taken as the charging time. That is, the charge current cannot always be calculated by dividing $\mathrm{C}$ by $\mathrm{T}_{\mathrm{N}}$ except when the recharge is started from approximately a $90 \%$ discharged status and the battery is then fully recharged. Ninety percent is commonly the ampere-hour efficiency of a lead-acid storage battery, and a full charge would therefore restore the battery to $100 \%$ of 
its rated capacity. For example, if less than $90 \%$ of the rated capacity were removed from a battery, then the time required to completely recharge would be less than what was indicated by $\mathrm{T}_{\mathrm{N}}$. Similarly, if greater than $90 \%$ were removed, the actual recharge time would be greater than $\mathrm{T}_{\mathrm{N}}$.

\section{Collector Efficiency $\left(\eta_{\mathrm{CL}}\right)$}

Ratio of the total WRIS irradiant power incident on the receiver area divided by . the total WRIS irradiant power incident on the module active aperture area.

In practice, the WRIS irradiant power is usually measured using a RIS spectrum and a measurement device with the same spectral sensitivity as the encapsulated cell to be used in service.

\section{Commutation}

The action of transferring current from one switching device to another in a power conditioning unit.

Stand-alone inverters must be self-commutated but utility interactive inverters may make use of line commutation where the circuit operation depends on the utility line connection. Utility interactive inverters may also be selfcommutated. Other types of commutation have been used, such as natural and load commutation, but generally in special applications.

\section{Concentrator Optics}

The optical concentrating portion of a module designed to operate with concentrated sunlight on the receiver.

Concentrator Cell Assembly

The smallest complete assembly of solar cell(s) (which may be environmentally protected) designed to generate DC power under concentrated terrestrial sunlight.

\section{Control Functions}

Control functions can be divided into three broad categories: permissive; protective; and optimization. Startup and automatic shutdown are permissive and protective functions, respectively.

\section{Depth of Discharge (DOD)}

The ampere-hours removed from a fully charged cell or battery, expressed as a percentage of rated capacity.

For example, the removal of 25 ampere-hours from a fully charged 100 amperehours rated cell results in a 25\% depth of discharge. Under certain conditions, such as discharge rates lower than that used to rate the cell, depth of discharge can exceed $100 \%$.

\section{Discharge Rate}

The current removed over a specific period of time from a cell or battery.

The rate can be expressed in amperes (or watts if the load is of constant power) but is sometimes normalized with respect to the rated capacity of the battery to comply with the charge rate terminology. For example, given the rated ampere- 
hour capacity, $C$, and the actual discharging current, $I_{d}$, the discharge rate can be expressed as:

$$
\frac{C}{C / I_{d}}=\frac{C}{T_{N}}
$$

where $\mathrm{T}_{\mathrm{N}}$ is a nominal unit of time in hours (see Charge Rate). Again, it must be noted that $\mathrm{T}_{\mathrm{N}}$ is not the discharge time. It is only equal to the discharge time when $100 \%$ of the rated ampere-hour capacity is removed from the battery. However, the final (end) voltage can interfere with the ampere-hour removal, hence an alternative expression to describe the rate is more commonly used. This rate is expressed as:

$$
\left.\begin{array}{l}
\text { Actual number of hours taken to } \\
\text { reach the rated end voltage. }
\end{array}\right\}=\text { hour rate. }
$$

For example, given that a battery's rated capacity is 500 Ah at the 5-h rate to an end voltage of $1.75 \mathrm{~V} /$ cell, the $3-\mathrm{h}$ rate would be equal to the current (in amperes) necessary to discharge the battery to $1.75 \mathrm{~V} /$ cell in three hours. The $10-\mathrm{h}$ rate would be the current necessary to discharge the battery to $1.75 \mathrm{~V} /$ cell in ten hours. Unfortunately, the battery's available capacity is not constant with discharge rate. Therefore, the discharge current cannot be calculated by dividing the rated capacity by the hour rate, except at the manufacturer's rating. In nther words, for the above case, the current necessary to fully discharge the $500 \mathrm{Ah}$ battery to $1.75 \mathrm{~V} / \mathrm{cell}$ in $5 \mathrm{~h}$ would be $500 / 5=100$ amperes. But the current at the 3-h rate might only be $145 \mathrm{~A}$ rather than $167 \mathrm{~A}$, due to the fact that less than $500 \mathrm{Ah}$ would be removed at the faster rate to the given end voltage of $1.75 \mathrm{~V} / \mathrm{cell}$. Similarly, at a slower rate, more than 500 Ah would be removed by the time the voltage reached $1.75 \mathrm{~V} /$ cell.

\section{Electrolyte}

An electrolyte is a conducting medium in which the flow of electric current takes place by the migrations of ions.

The electrolyte for a lead-acid storage cell is an aqueous solution of sulfuric acid. (See Specific Gravity of Electrolyte.)

Encapsulated Solar Cell Efficiency $\left(\eta_{E C}\right)$

Solar cell efficiency measured with protective encapsulation in place.

End-of-Charge-Voltage

The cell or battery voltage at which the finishing charge is normally terminated by the charging source. 
Equalization

The process of restoring all cells in a battery to an equal state-of-charge.

For lead-acid batteries, this is a charging process designed to bring all cells to $100 \%$ state-of-charge. Some battery types may require a complete discharge as a part of the equalization process.

Equalizing Charge

A continuation of normal battery charging, at a voltage level slightly greater than the normal end-of-charge voltage and at the finishing rate or less, in order to provide cell equalization of voltage and specific gravity within a battery.

Finishing Rate

The finishing rate for a storage battery is the rate of charge expressed in amperes to which the charging current for some types of lead batteries is reduced near the end of charge to prevent excessive gassing and increases in temperature.

Formation

The process, during manufacture or installation, by which the electrode materials are transf ormed into the compositions required for cell operation.

A battery upon installation is not necessarily fully formed and could require several cycles before complete formation. The battery will be able to give its usable capacity, but not its rated capacity.

Gassing

The evolution of gas from one or more of the electrodes in a cell.

Gassing commonly results from local action (self-discharge) or from the electrolysis of water in the electrolyte during charging.

Geometric Concentration Ratio ( $R$ )

Module active aperture area divided by receiver area.

Illuminated Cell Area (A, (.) )

The total surface area of the cell designed for illumination.

For flat-plate cells, it is the total cell area; for concentrator cells, bus areas not designed for illumination are excluded.

Illumination Mismatch Efficiency ( $\eta_{\text {IM }}$ )

Ratio of cell efficiency under specified nonuniform illumination conditions to cell efficiency under ideal uniform illumination conditions.

Inverter

A unit which changes a DC input to an AC output.

Levelized Energy Cost

The cost of a PV system expressed as an equivalent uniform (levelized) annual amount, taking into account the time value of money divided by the annual energy generated by the PV system. 
Maximum Power Point $\left(\mathrm{P}_{\mathrm{m}}\right)$

The operating point on a PV array I-V characteristic at which maximum power is delivered.

Maximum Power Point Tracker

A control strategy whereby system operation is always at or sufficiently close to the PV array maximum power point.

Maximum power point tracking requires the presence of a load that can accept a variable power; for example, a storage battery or a utility line connection.

Mismatch Efficiency $\left(\eta_{\text {MIS }}\right)$

The ratio of the efficiency of a series/parallel assemhly of cells or modules measured under unlf orm illumination conditions to the average efficiency of the individual elements (includes interconnect series resistance losses).

Module

The smallest complete, environmentally protected assembly of solar cells, optics, and other components (exclusive of tracking), designed to generate DC power under unconcentrated terrestrial sunlight.

Module Active Aperture Area $\left(\mathbf{A}_{\mathbf{A}}\right)$

That portion of the total aperture area of a concentrator module designed to contribute receiver illumination when the sun is on the optical axis.

Module Aperture Area Efficiency $\left(\eta_{\text {AA }}\right)$

Ratio of the active aperture area to the total aperture area for a concentrator module.

Module Packing Efficiency $\left(\boldsymbol{\eta}_{\mathrm{p}}\right)$

The ratio of the total active solar cell area to the total aperture area for a flatpla te module.

Module Total Aperture Area $\left(\mathbf{A}_{\mathrm{TA}}\right)$

Total module projected area normal to the optical axis.,

Motive Puwer (Truclion) Battery

A cell or battery that is intended to power electrically operated mubile equipment and is designed to be operated in a daily deep-cycle regime at moderate $(\mathrm{C} / 6)$ discharge rates.

Net Present Value

The present value of all savings resulting from the PV system minus the present value of all costs associated with the PV system, including initial investment, replacements, and operation and maintenance (less salvage value).

Present value denotes the equivalent value at the present time of future cash

flows; it is found by discounting future cash flows to the present to account for 
the time value (earnings potential) of money. The time value of money is indicated by a discount rate (interest rate) for which the value of a dollar received at some future time is equivalent to the value of a dollar received at the present time.

\section{Nominal Operating Cell Temperature (NOCT)}

The equilibrium solar cell junction temperature corresponding to nominal module service operating conditions in a standard reference environment of $800 \mathrm{~W} / \mathrm{m}^{2}$ irradiance, $20^{\circ} \mathrm{C}$ ambient air temperature, $1 \mathrm{~m} / \mathrm{s}$ wind, and electrically open circuit.

\section{Optical Axis}

A reference axis for a module or concentrator generally chosen as the module/illumination-source line which maximizes power output (of ten an axis of symmetry).

\section{Overcharge (Overchiarging)}

To put into a storage cell or battery a charge in excess of that needed to return full capacity to the cell. Such overcharging can result in "gassing" or decomposition of the water in the electrolyte into hydrogen and oxygen gases.

Panel

A collection of modules fastened together, pre-assembled and wired, and designed to provide a field-installable unit.

Permissive Control Functions

Permissive control facilitates operation of the power conditioning unit, as well as the operation of the subsystems connected to it. In addition, permissive control determines the interconnections of the internal components within the power conditioning unit.

Permissive control actions allow the power conditioning unit to start up, synchronize, and interact with other systems, such as the utility. Closing a switch is a permissive control action since it allows interaction between connected components separated by the open circuit. Since permissive control actions allow specific components to interact, it is necessary, to ensure safe operation, that all possible control actions do not violate electrical/mechanical constraints specified by the manufacturer. Simple control actions such as closing a switch could cause damage to equipment, decrease the life of the system, and harm the operators. Transients caused by control actions shall be within the manufacturer's specifications. Relays, like the under-voltage relay, initiate specific actions; these actions must not endanger other components, subsystems connected to the power conditioning subsystem, or the operator by creating electrical mismatches between components.

\section{Photovoltaic Power System Monitor and Control Unit}

The highest level of control that receives information from and sends signals to the thermal and electrical power conditioning subsystems through their monitor and control units.

Typically, the operator interacts with this functional unit. 


\section{Photovol taic (PV) System}

The total components and subsystems that combine to convert solar energy into el ectrical energy suitable for connection to an application load.

The major subsystems and their interfaces are the array, power conditioning, monitor and control, storage, cabling, and power distribution units. The auxiliary energy subsystem is not part of the PV system but is included in the total energy system.

\section{Power Conditioning Subsystem Monitor and Control Unit}

Second highest level of control that monitors and controls the components within, and the subsystems connected to, the power conditioning subsystem.

\section{Power Conditioning Unit (PCU)}

Equipment that pertains to a specific power conversion factor. A PCU is used to change input voltage level or waveform (or both) into a desired output voltage level or waveform.

It can be specified and tested independently of the PVPS and generally includes all auxiliary functions required to control individual power handling devices, such as internal power supplies, error amplifiers, and self-protection features. A PCU will normally fall in one of the following general categories based on whether the input and output are primarily $A C$ or $D C$ :

DC-DC-Both input and output are DC. Power conversion may take place internally at high frequencies. Sometimes referred to as a regulator.

DC-AC-The output is usually a single frequency sinusoid while the input is DC. Usually referred to as an inverter.

AC-DC--The input is AC, usually sinusoidal and the output is DC. Usually referred to as a rectifier, a DC power supply, or battery charger.

$\mathrm{DC}-\mathrm{AC} / \mathrm{AC}-\mathrm{DC}-\mathrm{A}$ bidirectional inverter that combines the above two functions (rectifier and inverter) in a single unit.

$\mathrm{AC}-\mathrm{AC}-\mathrm{The}$ input is $\mathrm{AC}$ and the output is $\mathrm{AC}$, usually sinusoidal, of a frequency different from that of the input. Usually called a frequency converter. One circuit that has been used to perfor $m$ this function is a cycloconverter.

\section{Power F actor}

The ratio of real power (watts) to apparent power (volt-amps) in an AC circuit. Displacement power factor is the ratio of fundamental watte to fundamontal RMS volts times RMS amps, exeluding the cffects of all harmonic components; it could be called fundamental power $f$ actor.

\section{Power Transfer Map}

A graphical means of presenting complex load characteristics which can be accommodated by a PCU (see next page). 


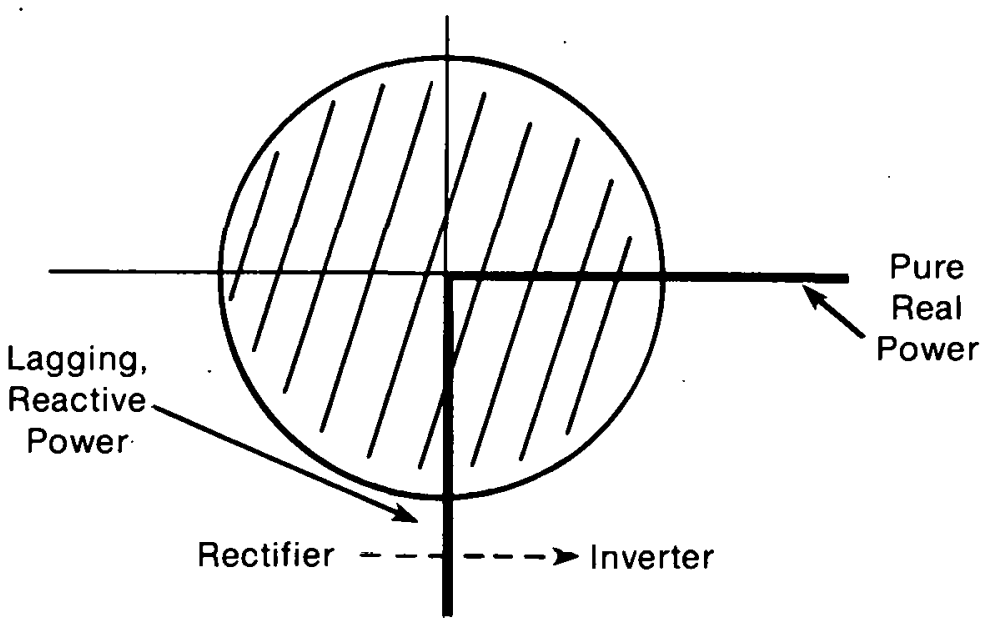

Power Transfer Map

Rated Module Electrical Efficiency (Flat-Plate, $\eta_{\text {FPM }}$ )

The amount of electrical power (watts) generated by a module at its maximum power point and $1000 \mathrm{~W} / \mathrm{m}^{2}$, AM 1.5 , NOCT divided by the product of $1000 \mathrm{~W} / \mathrm{m}^{2}$ and the gross module area $\left(\mathrm{m}^{2}\right)$.

Receiver

The component designed to operate under concentrated sunlight, incorporating the concentrator cell assembly, and providing thermal energy removal.

Receiver Active Cell Area $\left(A_{\mathrm{RC}}\right)$

Total active solar cell surface area within the receiver area.

Receiver Area $\left(A_{R}\right)$

Total receiver surface area (not projected area) designed for illumination when the sun is on the optical axis and measured in the intended plane(s) of the solar cell outer surfaces.

Receiver Packing Ef ficiency $\left(\eta_{\mathrm{RP}}\right)$

The ratio of the receiver active cell area to receiver area.

Reference Irradiance Spectrum (RIS)

Air mass 1.5 reference solar spectrum as defined in NASA TM-73702, "Terrestrial Photovoltaic Measurement Procedures," June 1977.

Ripple Current Ratio

The ratio of the AC component to the DC component (average) of the current at a PCU interface, either input or output.

\section{Ripple Factor}

Ripple factor is an expression of an AC ripple superimposed on a DC average value. IEC Standard 411-1, Power Converters for Electric Traction Part 1, Sec. 4.2 defines it as: 


$$
\text { R.F. }=\frac{x_{\max }-x_{\min }}{X_{\max }+X_{\min }} \times 100 \%,
$$

where $X_{\max }$ and $x_{\min }$, respectively, represent the maximum and minimum values of the variable $X$. This is equivalent to

$$
\text { R.F. }=\frac{X(\text { peak-to-peak })}{2 X \text { (average) }} \text {. }
$$

Solar Cell

The basic photovoltaic device, which generates electricity when exposed to sunlight.

Solar Cell Efficiency $\left(\eta_{C}\right)$ (See Cell Efficiency.)

Specific Gravity

The specific gravity of an electrolyte is the ratio of the weight of a given volume of electrolyte to the weight of an equal volume of water at a specified temperature.

Stand-Alone (SA)

A PCU or system that operates independently of the utility lines. It may draw supplementary power from the utility but is not capable of providing power to the utility.

\section{State-nf-Charge (SOC)}

The available capacity in a cell or battery expressed as a percentage of rated capacity.

For example, if 25 ampere-hours have been removed from a fully charged 100-ampere-hours cell, the new state of charge is $75 \%$.

\section{Subsystem Monitor and Control Unit}

This unit supervises the subsystem energy flow and storage state and controls the subsystem in a safe and timely manner in response to internal signals and external signals from other subsystems.

Earh majnr suhsystem typically will contain a Monitor and Control Unit. This may or may not exist as a separate unit. This unit will inform the external controller of imponding unsafe conditions and act infependently if system control docs not respond or if it commands an unsafe astion. Refer to the Monitor and Control section of this document for details.

\section{System Power Rating}

The rated power of the PV array at NOCT and an irradiance level of $1000 \mathrm{~W} / \mathrm{m}^{2}$ modified by cabling and power conditioning subsystem losses at this array power level. 
Uninterruptible Power System (UPS)

A power system that has sufficient redundant power sources and backup configurations so that output power can be continuously supplied (uninterrupted) even though the primary source of power has failed (interrupted) or the equipment has failed.

Unlimited Interactive Source/Sink

An element that can act as a source or a sink and has unlimited capacity. An example of this type of element is a utility line connection.

Utility Interactive (UI)

A PCU system capable of operating in parallel with and supplying power to the utility line.

Voltage Window

The range of voltages over which the array, power conditioning unit, or battery is to be operated.

Weighted Reference Irradiance Spectrum (WRIS)

Convolution of reference irradiance spectrum and the short-circuit current spectral response of the particular solar cell. 
APPENDIX B

TEST METHODS 
THIS PAGE

\section{WAS INTENTIONALLY \\ LEFT BLANK}




\section{TEST METHODS}

Introduction

Test

TE.AR.E.1

TE.AR.E.2

TE.AR.M.1

TE.AR.M.2

TE.AR.M.3

TE.AR.M.4

TE.AR.M.5

TE.AR.M.6

TE.AR.M.7

TE.AR.M.8

TE.AR.M.9

TE.AR.M.10

TE.AR.M.11

TE.AR.D.1

TE.AR.D.2

TE.AR.D.3

TE.AR.D.4

\section{Title}

Electrical Performance Test-Flat-Plate Cells, Modules, and Arrays

Electrical Performance Test-Concentrator Solar

Cells

Structural Loading Test-Flat-Plate

Modules (Cyclic Pressure Load Test)

Temperature Cycling Test-Flat-Plate

Modules.

Temperature Cycling Test-Concentrator

Modules................................

Hail Test-Flat-Plate Modules

Hail Test-Concentrator Modules

Temperature Cycling Test-Concentrator

Receiver .

Contact Pull Strength (Wire Pull Test)-

Solar Cells

Nominal Operating Cell Temperature

Determination-Flat Plate.

Antireflection Coating Adhesion Test-

Solar Cells

Dielectric Voltage Withstand Test

$B-48$

Structural Stress Test-Solar Cells.

B-50

Solar Radiation Weathering Tests-Materials and

Components

Solar Radiation Weathering Tests-Modules and

Minimodules

Humidity Test-Solar Cells

B-66

Humidity Test-Array Elements

B-68 
TAST METHODS (concluded)

TE.PC.E.1

Power Conditioning Unified Test Procedure

for Solid-State Power Inverters

B-72

TE.ST.E.1

Test Procedure for Measuring Battery Capacity

and Round-Trip Effi ciericy ....................

B-77

TE.ST.E.2

Test Procedure for Measuring Total Bat tery

In/Out Efficiency

B-79 


\section{INTRODUCTION}

A secondary yet critically important purpose of this document is to establish a unified body of test procedures for the evaluation of PV subsystem performance criteria. In several isolated cases (primarily for established areas such as storage and power conditioning) accepted concensus standard test methods exist. Because PV technology has matured only recently, the majority of performance criteria in this document cannot be evaluated using established standard test methods because none exist. Test methods in this section have been developed from past experience gathered from and reviewed by experts in the PV field. They are recommended evaluation procedures; however, these methods are not consensus standards tests.

The test methods contained herein are, therefore, "best knowledge" techniques and should be viewed as such. They will no doubt serve as a starting basis for consensus standards development in the area of PV measurement and testing techniques. Developed primarily from the single-crystal silicon experience base, they may, nonetheless, apply to a wide range of technologies. However, just as users must carefully select the performance criteria in this document, so these test procedures must also be used with care. Some are applicable for qualification testing (e.g., destructive Reliability/Durability Tests) whereas others lend themselves to usage on all components (e.g., Electrical Performance testing). Under no presently foreseeable circumstance is it appropriate to make a blanket requirement that all test methods be carried out for a particular application. Just as the main body of this document is an evolutionary entity, these test methods will be revised and expanded as further information and data are obtained.

The test methods in this section are coded to the particular subsystem performance attributes of interest. Hence, TE.MO.E.1 indicates a Test Method (TE) for testing a module (MO) for some electrical (E) attribute, and it is the first in the sequence (1) of such test methods listed here. Generally, the test methods are further subdivided to contain, where appropriate, the following topies (in order): Purpose, Commentary, Apparatus, Preparation, Procedure, Evaluation, and References. 
TEST TE.AR.E.1

\section{BLECTRICAL PERPORMANCE TEST - PLAT-PLATE CRLLS, MODULES, AND ARRAYS*}

\section{PURPOSE}

This electrical performance test is used indoors or outdoors to measure the I-V curve; or a portion of it, of a photovoltaic cell, module, panel, array, or array field to determine the electrical output parameters at specified reporting conditions of temperature and irradiance level.

\section{COMMENTARY}

The I-V curve is the primary electrical performance measurement of a photovoltaic device. Important electrical performance characteristics can be derived from I-V performance curves. Cell temperature and incident irradiance both have a great effect on the I-V curve. Hence, a set of specified reporting conditions have been developed to facilitate comparison. See Table B-1 for these conditions.

Table B-1. ELECTRICAL PERFORMANCE REPORTING CONDITIONS: FLAT-PLATE CELLS, MODULES, PANELS, AND ARRAYS

\begin{tabular}{|c|c|c|c|}
\hline & Peak & $\begin{array}{l}\text { Reference } \\
\text { Design } \\
\text { Condltions }\end{array}$ & $\begin{array}{l}\text { Nominal } \\
\text { Operating } \\
\text { Conditions }\end{array}$ \\
\hline Cells & $\begin{array}{l}1000 \mathrm{~W} / \mathrm{m}^{2}, 28^{\circ} \mathrm{C} \\
\mathrm{AM} 1.5 \text { spectrum }\end{array}$ & N/A & N/A \\
\hline Modules, & $1000 \mathrm{~W} / \mathrm{m}^{2}, 28^{\circ} \mathrm{C}$ & $1000 \mathrm{~W} / \mathrm{m}^{2}$ NOCT ${ }^{\mathrm{b}}$ & $800 \mathrm{~W} / \mathrm{m}^{2}, \mathrm{NOCT}^{\mathrm{b}}$ \\
\hline Arrays & AM 1.5 spectrum ${ }^{a}$ & AM 1.5 spectrum ${ }^{a}$ & AM 1.5 spectrum \\
\hline
\end{tabular}

The output of a solar cell is also a function of the spectrum of the incident irradiance. A cell may have very different outputs under two different spectral distributions of irradiance, even when the total intensities, measured by a blackbody detector, are the same. To reduce spectral mismatch errors, two restrictions are made on the measurement procedures:

*ASTM Committee E44 on Solar Energy Conversion is developing a relevant recommended práctice. 
(1) A calibrated reference cell, which is used to transform the I-V data from the measured spectral irradiance distribution to the standard spectrum, shall be used to monitor the incident irradiance.

(2) The choice of a light source for solar simulation shall be limited to those that give a good spectral match to terrestrial sunlight.

The calibrated reference cell is a solar cell with a spectral response that matches that of the test device. Currently, there is no accepted procedure for matching spectral response curves, and until one is developed, matching such curves will continue to be based on a subjective judgment of their shape or choosing a reference cell which is known to be typical of the cells in a module or panel. The reference cells are calibrated by measuring their output under terrestrial sunlight of a known standard spectral distribution.

This standard spectrum is a calculated direct-beam spectrum using air mass $1.5,2 \mathrm{~cm}$ of precipitable water vapor and an atmospheric turbidity of 0.12 (see Ref. 1). Currently, there is no commercial source for primary reference cells; thus, they must be made and calibrated for the application, generally using similar cells.

\section{APPARATUS}

The apparatus consists of:

- Reference cell-a calibrated reference cell, whose spectral response matches that of the test device, used to measure incident irradiance.

- A test bed-a temperature-controlled cell holder if an individual cell is being measured; or suitable mounting gear if modules or panels are being measured.

- Temperature measurement equipment-to measure the cell temperature of modules, panels, etc., to within $1^{\circ} \mathrm{C}$.

- Current and voltage measurement equipment-to measure current and voltage of the test device and current of the reference cell to within $0.5 \%$.

- Variable load-to take the test device from open-circuit voltage to short-circuit current. The load may be a set of resistors, an electronic load, a plus/minus power supply, etc.

- Data recording equipment-the response times and scale ranges shall be compatible with the transducers being used.

- Solar simulator-measurements are taken indoors of either the steady-state or pulsed type.

The choice of a steady-state solar simulator is restricted to those meeting the following requirem ents:

- Light source-restricted to those having a good spectral match to terrestrial sunlight. The following are acceptable: Xenon arc and dichoric filtered tungsten (such as ELH lamps).

- Total irradiance-between 700 and $1050 \mathrm{~W} / \mathrm{m}^{2}$ measured with the reference cell. 
- Uniformity-the irradiance must be uniform over the test plane to within $\pm 2 \%$ during the average irradiance.

- Temporal stability-the irradiance must be constant within $\pm 1 \%$ during the time of measurement.

- Solar beam subtense angle-the angle subtended by the apparent source of the simulator on a point on the test device must be less than $30^{\circ}$.

The choice of a pulsed solar simulator is restricted to those meeting the specifications of the steady-state simulator with two exceptions:

- The light source must be a Xenon arc.

- Tho tomporal otability requirement is relaxed to $\perp 10 \%$ with tlie guldiliunal requirement that flash irradiance be measured at each data point.

A pulsed simulator usually takes all data for an I-V curve within a few milliseconds. The user of a pulsed simulator must determine that the response time of the device he is testing is fast enough to be tested in such a short time interval.

\section{PREPARATION}

Three separate methods of preparation are described that pertain to tests performed with a steady-state simulator, tests performed with a pulsed solar simulator, and tests performed outdoors.

\section{Steady-State Solar Simulator}

Step 1- The simulator is turned on and stabilized. The irradiance is adjusted to the test intensity as measured by the calibrated ref erence cell, which is núrinal tó tlı́ beain.

Step 2- Attach separate current and voltage leads to the test device.

Step 3- For individual cell measurements, the cell is mounted on a temperaturecontrolled mount normal to the simulator beam and in the same plane as the reference cell in Step 1. If the uniform area of the beam is large enough, both test sample and reference cell can be coplanar in the same beam. If not, the reference cell is replaced by the test sample.

\section{Pulsed Solar Simulator}

Step 1- Attach separate current and voltage leads to the test device.

Step 2- Mount the reference cell and test device coplanar with and normal to the test beam.

Step 3- Adjust the test plane to an irradiance level of $1000 \mathrm{~W} / \mathrm{m}^{2}$. 
Note: Because the pulsed simulator normally takes data only within the power quadrant, complete transformations of the I-V curve from below standard irradiance levels cannot be made. It is therefore advisable to have the test plane irradiance no lower than $1000 \mathrm{~W} / \mathrm{m}^{2}$.

\section{Outdoor Tests in Natural Sunlight}

Step 1- Determine that suitable measurement conditions exist before conducting the test. Outdoor measurements should be made only under stable, sunny conditions with an incident irradiance intensity of at least $700 \mathrm{~W} / \mathrm{m}^{2}$ as measured by the reference cell. Variations of intensity over the time span required to take $\mathrm{I}-\mathrm{V}$ data must be less than 1\%. The solar incident angle (direct-beam) must be less than $40^{\circ}$.

Step 2- Attach separate current and voltage leads to the test device.

Step 3- The test cell and reference cell are mounted coplanar, in temperaturecontrolled holders. If the reference cell cannot be maintained at the reference temperature, the temperature coefficient of calibration is used to correct to $28^{\circ} \mathrm{C}$. If temperature control is not possible with arrays, modules, or panels, then the temperature is measured and corrections made to NOCT.

\section{PROCEDURE}

Three separate test procedures are described, pertaining to tests performed with $a$ steady-state simulator, tests performed with a pulsed simulator, and tests performed outdoors.

\section{Steady-State Simulator}

Step 1- Adjust the cell temperature to $28^{\circ} \pm 2^{\circ} \mathrm{C}$. For larger area panels, it may not be possible to temperature control the panel. This could result in nonuniform cell temperatures throughout the panel and lack of temperature equilibrium, making I-V. curve transformations to electrical performance reporting conditions extremely difficult. In this case, shade the panel until just before I-V measurement. The panel will be at, or very near, ambient temperature. The panel temperature must be measured and corrections made to NOCT.

Step 2- Measure the I-V curve or appropriate discrete points on it. All temperature and irradiance should be monitored to ensure that they are at the desired level during the test.

\section{Pulsed Simulator}

Step 1- $\quad$ Adjust test device lemperature to $28^{\circ} \pm 2^{\circ} \mathrm{C}$. 
Step 2- Measure the I-V curve or appropriate discrete points on it. Cell temperature and irradiance should be monitored to ensure that they are at the desired level during the test.

\section{Outdoors-Natural Sunlight}

Step 1- Adjust test device temperature to $28^{\circ} \pm 2^{\circ} \mathrm{C}$. For larger area panels where temperature control is difficult, the panel may be shaded prior to testing as described in the section on the Steady-State Simulator.

Step 2- Measure the I-V curve or appropriate discrete points on it. Cell temperature and irradiance should be monitored to ensure that they are at the desired level during the test.

\section{EVALUATION}

I-V Curve Adjustment: Data is reported at the conditions noted in Table B-1. Data should be measured at, or close to, these conditions because of the difficulty of transformations. If this is not feasible, a transformation of the I-V curve to the reporting conditions may be made using the following equations:

$$
\begin{aligned}
& \dot{\Delta I}=I_{S_{1}}\left(\frac{J_{2}}{J_{1}}-1\right)+\alpha\left(T_{2}-T_{1}\right) A \\
& I_{2}=I_{1}+\Delta I \\
& V_{2}=V_{1}+\beta\left(T_{2}-T_{1}\right)-\Delta R_{S}-K_{2}\left(T_{2}-T_{1}\right) I_{2}
\end{aligned}
$$

where $I_{2}, V_{2}, J_{2}$, and $T_{2}$ are current, voltage, irradiance, and temperature at the desired conditions; $\mathrm{I}_{1}, \mathrm{~V}_{1}, \mathrm{~J}_{1}$, and $\mathrm{T}_{1}$ are the measured values, respectively; $\alpha$ and $\beta$ are the temperature coefficients for current and voltage, respectively ( $\beta$ is negative); $R_{s}$ is series resistance; $K$ is a curve correction factor; and $A$ is area. A method for determining $R_{g}$ is given in Ref. 2. The $K$ value must be determined by experimental means; $\alpha$ and $\beta$ are defined as the change in either short-circuit current or opencircuit voltage per one-degree temperature change. The above transformations were originally intended for single cells. It is unclear how they behave in the case of multicell modules, panels, etc.

Output Parameters from I-V Curve: A typical I-V curve is shown in Fig. B-l. Current is the $y$-axis while voltage is the $x$-axis. The electrical parameters that may be derived from the I-V curve are as follows:

- Short-Circuit Current $\left(I_{s e}\right)$-the current value where the I-V curve crosses the voltage axis at $V=0$ (point $A$ ).

- Open-Circuit Voltage $\left(V_{o c}\right)^{-t h e}$ voltage value where the I-V curve crosses the current axis at $I=0$ (point $B$ ). 


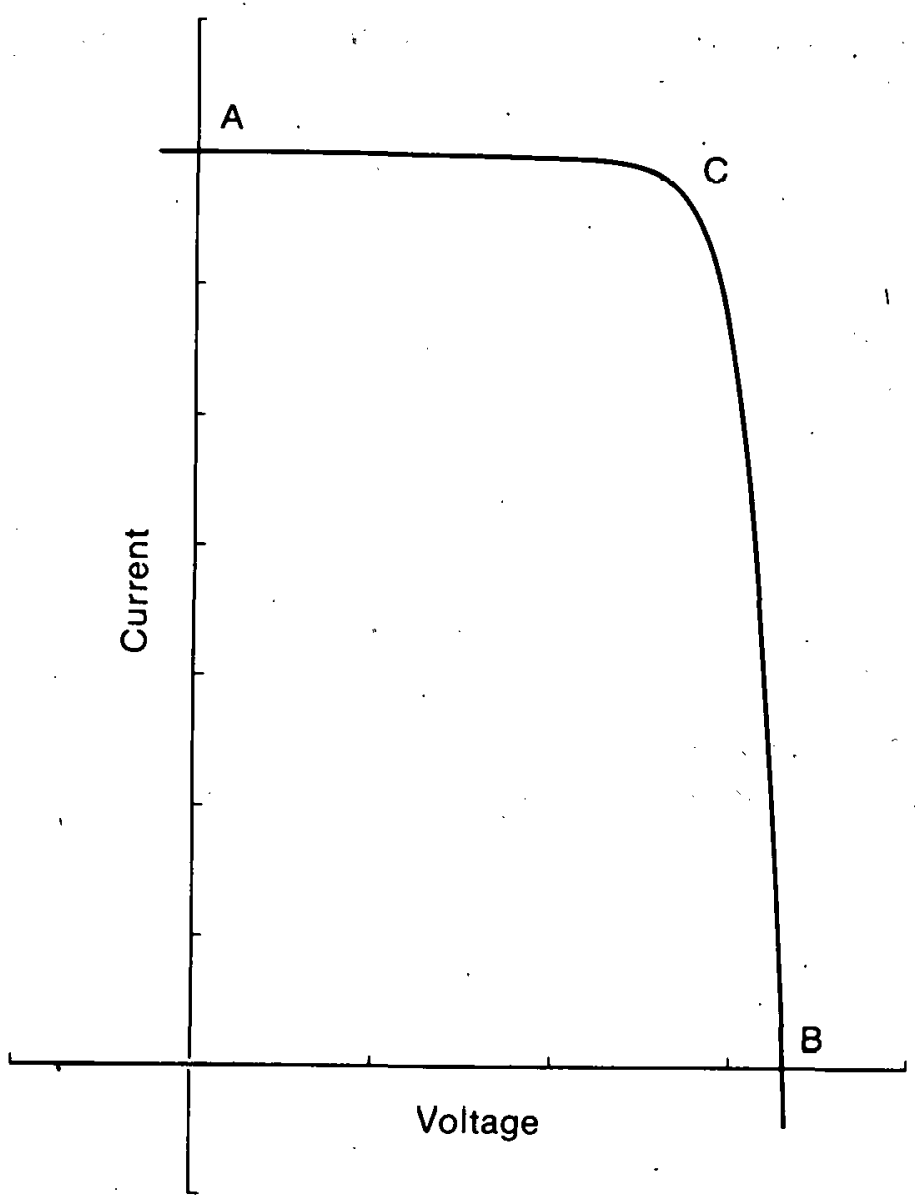

Figure B-1. Typical Current-Voltage Curve 
- Maximum Power ( $\left.P_{m}\right)$-the point on the I-V curve where the product of current and voltage is maximum. These current and voltage values are called $I_{m}$ and $V_{m}$ respectively (point $\mathrm{C}$ ).

- Fill Factor (FF)-defined as the ratio of $\mathrm{P}_{\mathrm{m}}$ to the product of $\mathrm{I}_{\mathrm{sc}}$ and $\mathrm{V}_{\mathrm{oc}}$ :

$$
\mathrm{FF}=\frac{\mathrm{P}_{\mathrm{m}}}{\mathrm{I}_{\mathrm{sc}} \mathrm{V}_{\mathrm{oc}}}
$$

- Efficiency $(\eta)$-defined as the ratio of $P_{m}$ to the product of area (A) and incident irrađiance $(J)$.

$$
\eta=\frac{P_{m}}{J A}
$$

The area is defined slightly differently for cells, modules, panels, etc. See the individual criteria for details.

\section{REPERENCES}

1. "Terrestrial Photovoltaic Measurement Procedures." ERDA/NASA/1022-77/161; NASA TM 73702; June 1977.

2. Wolf, M. and Rauschenbach, H. "Series Resistance Effects in Solar Cell Measurements." Advanced Energy Conversion (Vol. 3); Apr./June 1963. 


\section{TEST TE.AR.E.2 \\ ELECTRICAL PERFORMANCE TEST - CONCENTRATOR SOLAR CELLS}

\section{PURPOSE}

The electrical performance test for concentrator solar cells is used indoors or outdoors to measure the I-V curve, or a portion of it, of a concentrator solar cell to determine the electrical output parameters at specified reporting conditions.

\section{COMMENTARY}

The test used to measure the $I-V$ curve for concentrator solar cells is similar to the method used for flat-plate cells, Test TE.AR.E.1. The following aspects of establishing and measuring test conditions require special consideration in testing concentrator cells:

- As levels of irradiance increase, establishing a uniform temperature across the cell becomes more difficult. A nonuniform thermal bond between the cell and the cell holder can cause a portion of the cell to have a significantly higher temperature than that measured by the temperature sensor.

- It is difficult to establish uniform illumination when optical systems are used. It may be necessary to use some type of neutral density filter, a mask, or other modification of the optical system to establish a more uniform illumination.

- It is difficult to measure the incident irradiance when testing concentrator solar cells. The procedure described here assumes that the short-circuit current of the cell is equal to the light-generated current and proportional to incident irradiance. This assumption is valid, but to a limited level of irradiance which may vary from cell to cell.

The use of a calibrated, matched reference cell is an accepted method of referencing solar cell measurements made under different light sources to the reference irradiance spectrum. Because at present such reference cells are not always easily and quickly obtainable, a pyrheliometer is included in this method as an alternative reference irradiance instrument. If a pyrheliometer is used for irradiance measurement, the spectrum of sunlight present during the test is unknown. This factor reduces the comparability of data based on reference irradiances. Tests performed using a pyrheliometer should be performed only on days with very clear, stable, sunny conditions.

\section{APPARATUS}

The apparatus consists of:

- Reference cell-a calibrated reference cell, whose spectral response matches that of the test device, is used to measure irradiance.

- Pyrheliometer-if a properly matched reference cell is not available, a pyrheliometer may be used to measure irradiance.

- Collimating tube-an appropriate collimating tube is used if the test is conducted using sunlight with a pyrheliometer as the reference intensity instrument (see Ref. 1). 
- Test bed-a temperature-controlled cell holder. For outdoor tests, the cell holder must be mounted in a two-axis tracking device with a tracking accuracy of $0.1^{\circ}$.

- Temperature measurement equipment-equipment to measure the cell temperature to within $1^{\circ} \mathrm{C}$.

- Current and voltage measurement equipment-equipment to measure current and voltage of the test device and current of the reference cell to within $0.5 \%$.

$\therefore$ Variable load-a load to take the test device from open-circuit voltage to shortcircuit current. The load may be a set of resistors, an electronic load, a plus/minus power supply, etc.

- Data recording equlpment-respunse linies arid scale ranges shall be compatible with the transducers used.

- Optics-a solar simulator for indoor tests or suitable lenses or reflectors for sunlight tests.

Uniform irradiance is desired across the cell in the test bed. Experience to date indicates that variations of $\pm 20 \%$ have only a small effect on electrical performance. If the nonunif ormity present during the test is greater than $\pm 20 \%$, it is recommended that indications of uniformity (e.g., irradiance profiles) be reported with test results.

\section{PREPARATION}

Step 1- Prepare the cell holder with a temperature sensor located at the cell holder/cell interface in a position corresponding to the center of the back of the test cell. Additional temperature sensors may be installed at other locations on the cell holder or cell to monitor temperature uniformity or provide temperature measurement redundancy or both.

Step 2- Mount the cell to the cell holder in a manner that yields good thermal contact between the cell and cell holder. A good thermal bond may not be needed if a flash simulator is used and the test can be conducted fast enough so that the cell temperature does not change. Note: One technique that has been used to bond silicon solar cells to copper cell holders 13 to solder the cell witl jure indium solder. Indium is desirable because of its melting temperature (about $160^{\circ} \mathrm{C}$ ) and high ductility.

Step 3- Attach separate current and voltage leads (Kelvin probe) to the cell. Care should be taken to prevent errors in cell voltage measurement because of voltage drops along the cell busbar or in lead connections.

\section{PROCEDURE}

Two separate procedures are described, pertaining to indoor testing and outdoor sunlight testing, respectively. 


\section{Indoor Testing}

Step 1- Measure the one-sun electrical performance of the cell following the appropriate procedures in Test TE.AR.E.1. Establish the ratio of shortcircuit current to incident irradiance.

Step 2- Place the cell in the concentrated light at the desired level of irradiance. The level of irradiance may be determined by dividing the short-circuit current of the cell under concentration by its ratio of shortcircuit current to incident irradiance as determined by the one-sun test. A matched reference cell may also be used for this irradiance measurement. Note: Appropriate testing may be necessary in order to establish that the short-circuit current is equal to the light-generated current.

Step 3- Adjust the cell temperature to the desired level, preferably. within $2^{\circ} \mathrm{C}$.

Step 4- Measure the I-V curve or appropriate discrete points on it. Cell temperature and irradiance should be monitored to ensure that they are at the desired level during the test.

\section{Outdoor Sunlight Testing}

Step 1- If a pyrheliometer is used as the irradiance reference instrument, verify that the sunlight conditions are stable with a direct normal irradiance greater than $800 \mathrm{~W} / \mathrm{m}^{2}$.

Step 2- Measure the one-sun electrical performance of the cell following the appropriate procedure in Test TE.AR.E.l. The test cell and reference cell must have the same field of view. If a properly matched reference cell is not available, a pyrheliometer may be used to measure irradiance. The test cell must be under a collimating tube with aperture and slope angles that match those of the pyrheliometer. The use of a pyrheliometer provides no correction for differences between the sunlight spectrum during the test and the reference irradiance spectrum.

Step 3- Place the cell in the concentrated light at the desired level of irradiance. The level of irradiance may be determined by dividing the short-circuit current of the cell under concentration by its ratio of shortcircuit current to incident irradiance as determined by the one-sun test. Note: Appropriate testing may be necessary in order to establish that the short-circuit current is equal to the light-generated current.

Step 4- Adjust the cell temperature to the desired level, preferably within $2^{\circ} \mathrm{C}$.

Step 5- Measure the I-V curve or appropriate discrete points on it. Cell temperature and irradiance should be monitored to ensure that they are at the desired level (i.e., $\pm 1 \%$ ) during the test. 


\section{EVALUATION}

The electrical performance parameters for concentrator solar cells are determined as described in Test TE.AR.E.1. Reporting conditions include condition $l$ and either condition 2 or 3 as follows:

(1) One-sun, $28^{\circ} \mathrm{C}$, short-circuit current to irradiance ratio at reference irradiance spectrum.

(2) Fixed $28^{\circ} \mathrm{C}$ temperature, and various specified irradiance levels.

(3) Design operating temperature and irradiance.

If the measured data must be corrected to a reporting temperature other than the test temperature, the approach outlined in Test TE.AR.E.l may be used. The correction will be more complex because the related coefficients are a function of the irradiance level. A plot of open-circuit voltage versus the natural logarithm of short-circuit current at a constant temperature may be prepared in order to verify adequate temperature control during the test (see, for example, Fig. B-2). If the slope of the curve falls below $\mathrm{kT} / \mathrm{q}$, cell temperature, temperature uniformity, or illumination uniformity may not be adequately controlled. If this is the case, X-ray, liquid crystal, or ultrasonic techniques may be applied to examine the quality of the thermal bond between the cell and its substrate.

\section{REPERENCES}

1. Chai, An-Ti. "Some Basic Considerations of Measurements Involving Collimated Direct Sunlight." Terrestrial Photovoltaic Measurements II. ERDA/NASA1022/76/10. Baton Rouge, LA; Nov. 10-12, 1976; pp. 233-246. 


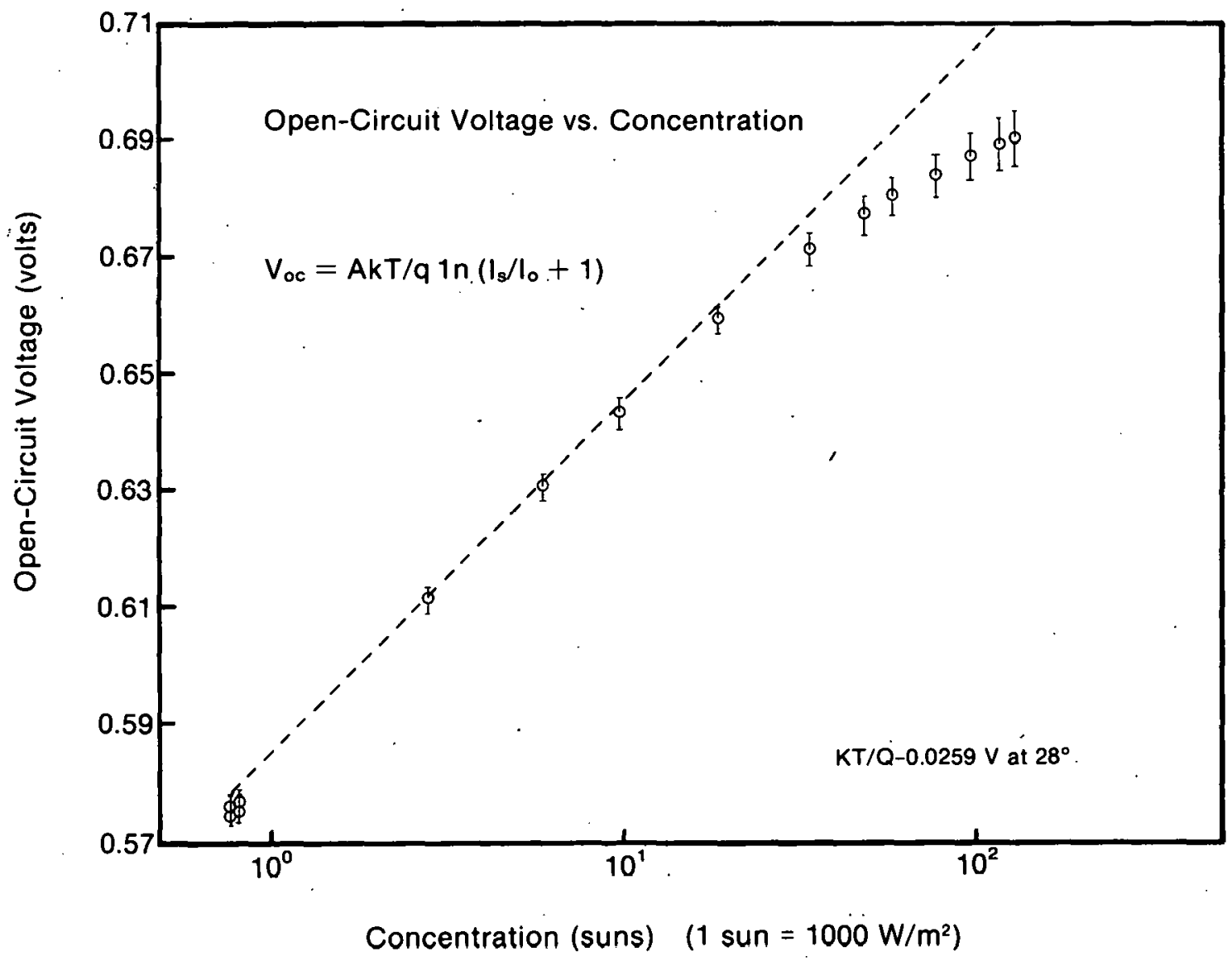

Figure B-2. Typical Concentrator Solar Cell Electrical Performance 
TEST TE.AR.M.1

\section{STRUCTURAL LOADING TEST-PLAT-PLATE MODULES (CYCHC PRESSURE LOAD TEST)}

\section{PURPOSE}

The cyclic pressure load test is used to determine the ability of a photovoltaic module design to withstand specific levels of positive and negative normal pressure loads applied cyclically.

\section{COMMENTARY}

The test is generally perfomed on a sample lot of photovoltaic modules of a given design to verify this aspect of the structural integrity of the design. Further discussion of the required apparatus and test methodology may be found in LSSA Project Task Report No. 5101-19, "Cyclic Pressure Load Developmental Testing of Solar Panels," February 28, 1977.

When tested against specific levels, a certain percentage of properly designed photovoltaic modules will probably show evidence of failure of solar cells and other brittle materials (glass superstrates, for example) employed in their construction. This is because the failure of brittle materials is probabilistic. It may be prohibitively expensive to test enough modules to show that the probability of failure is acceptably low in these cases.

The cyclic pressure load test is intended to uncover design weaknesses of cell interconnects, encapsulant systems, and cells. Broken interconnects, a common field failure in early photovoltaic modules, were attributed by some people to mechanical fatigue from long-term response to wind gusting, although subsequent studies have shown that interconnect fatigue is more likely to result from thermal cycling.

\section{APPARATUS}

The apparatus consists of cyclic pressure load equipment that induces uniform peak pressure loads across the surface of the module; load sensors and monitoring equipment; electrical continuity and short circuit equipment; and a test frame.

The cyclic pressure load equipment includes the following features:

- Inflatable air bags and reaction frame or other means to automatically apply a uniform normal pressure load alternately to the front and back surfaces of the module until the specificed number of cycles is attained.

- Pressure gauges or other instrumentation suitably located to verify that the specified loading is applied to only one side of the module at any given time.

- Automatic means of applying pressure to front and back surfaces of the module alternately, one side at a time, cyclically, until a specified minimum number of cycles is reached. 
- A means to count the number of complete cycles applied to the module.

- An automatic means to stop application of pressure and stop the cycle counter if an open circuit or short is detected.

A schematic diagram of the overall cyclic pressure load equipment is shown in Fig. B-3.

\section{PREPARATION}

Step 1- Verify that pretest electrical performance and visual inspection data are available for the module being tested.

Step 2- Check out and adjust the automatic pressure cycling system to verify that it applies the required pressure at a rate not to exceed 20 cycles/minute.

Step 3- Install the module into a mounting frame that properly simulates the mounting method intended by the manufacturer. 


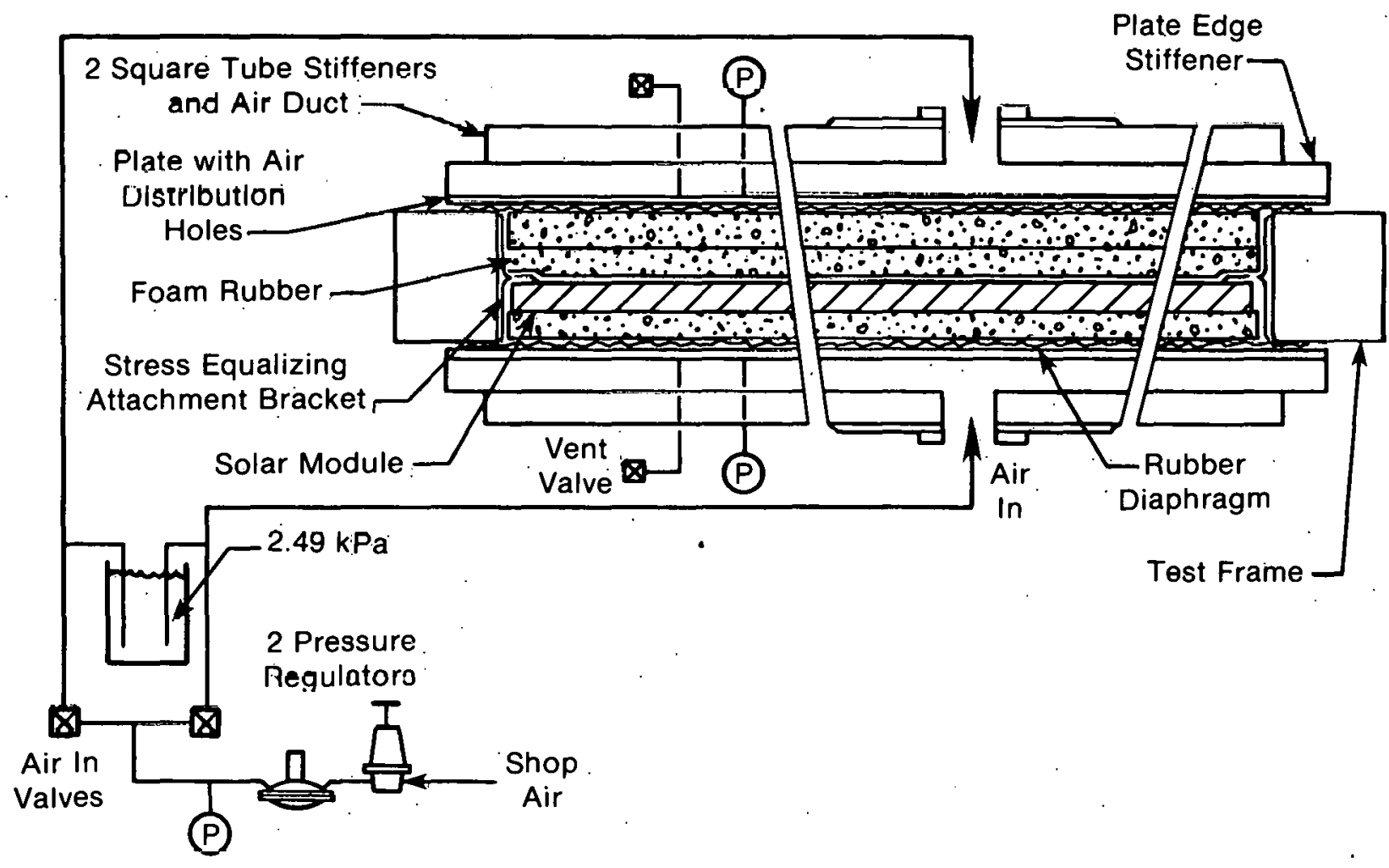

Figure B-3. Schematic of Apparatus for Cyclic Pressure Load Test 


\section{PROCEDURE}

Step 1- Install the module in the test fixture and connect the open circuit and short-detection circuitry.

Step 2- Zero the pressure cycle counter.

Step 3- Turn on all test equipment and begin application of cyclic pressure loading and counting.

Step 4- The open-/short-circuit detection system may detect a problem and shut down the pressure cycling apparatus before attaining the 10,000 cycle minimum requirement. In this case, record the number of cycles attained, remove the module, and proceed to the Evaluation.

Step 5- In the event that a minimum of 10,000 pressure cycles are attained without module circuit malfunction, remove the module and proceed to the Evaluation.

\section{EVALUATION}

There shall be no occurrence of open- or short-circuit conditions during this test.

Modules malfunctioning at less than 10,000 cycles. These modules are considered to have failed the criteria that there shall be no occurrences of open-circuit or short-circuit conditions during tests in which the module circuitry is instrumented. Attempt to pinpoint the source of the open or short circuit. Record the findings of this investigation. Note that this type of circuit malfunction may be intermittent and may depend on whether or not the module is flexed because of pressure loading.

All modules. All modules shall receive a thorough visual examination, and any irregularities (including cracked cells) shall be noted. The allowable level of observable mechanical degradation (such as cracks, delamination of coatings, etc.) shall be determined by the manufacturer's approved module acceptance testing plan. Modules shall pass the Dielectric Voltage Withstand Test (TE.AR.M.10) when retested at the completion of this test. The module electrical performance shall be measured at the completion of this test. Power degradation shall not exceed $5 \%$ of baseline performance, previously determined per Test TE.AR.E.1. 
TEST TE.AR.M.2

TEMPERATURE CYCLNG TEST-FLAT-PLATE MODULES

\section{PURPOSE}

The temperature cycling test is conducted to determine the effects of thermal stresses that could appear on modules during use.

\section{APPARATUS}

Temperature chamber with temperature rate controller; auxiliary thermal sensors with associated recording devices; electrical continuity and short-circuit monitoring equipment; test frame.

\section{PREPARATION}

Step 1- Verify that pretest electrical performance data for the module is available.

Step 2- Inspect modules to detect evidence of physical degradation (e.g., delamination or broken cells).

Step 3- Prepare and provide programming devices to perform the temperature cycling program of Fig. B-4.

Step 4- Install one thermocouple behind a solar cell on the back of the module at a point approximately one-third of the module width and one-third of the module length.

Etcp 5- Mount modules in a test frame in accordance with manufacturer's installation instructions and recommended mounting hardware. The test frame shall be designed to simulate the support rigidity and differential thermal expansion likely to occur in service between the module and its supporting structure. 


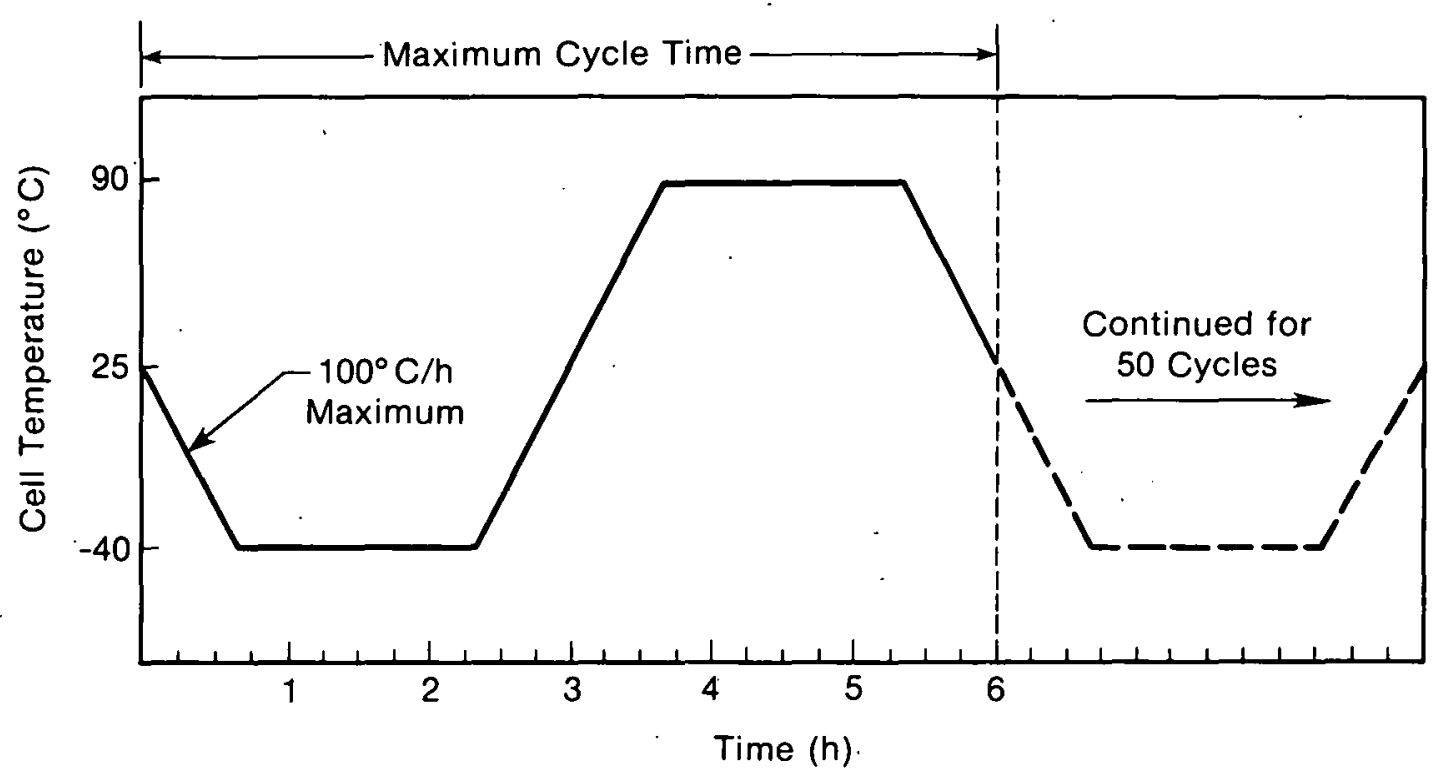

Figure B-4. Temperature Cycling Test

Flat-Plate Modules 


\section{PROCEDURE}

Step 1- Install modules into temperature chamber. If there are more than one, install them so that all are exposed equally to air supply; that is, parallel to the air flow. Connect the electrical leads from the thermocouples to the temperature recording device. Connect the electrical leads from the module terminals to the electrical continuity and short-circuit monitoring equipment. Note: Concurrent testing of several modules in the same chamber is permitted provided the test requirements for each module are identical.

Step 2- Verify that each module has electrical continuity and no short circuits.

Step 3- Subject the modules to 50 temperature cycles in accordance with Hig: K-4. A temperulure cyole consists of starting from ambient, approximatcly $1.6 \mathrm{~h}$ at $-40^{\circ} \Gamma_{\circ} \pm ?^{\circ} \mathrm{C}$ module cell temperature, and appromixately $1.6 \mathrm{~h}$ at $+90^{\circ} \mathrm{C} \pm 2^{\circ} \mathrm{C}$ module cell temperature and return to ambient with a maximum eycle lime of $6 \mathrm{~h}$. During transition periods, the temperature shall vary approximately linearly with time at a rate not to exceed $100^{\circ} \mathrm{C} / \mathrm{h}$. Note: The cycle time can be shortened by reducing the dwell time at $+90^{\circ} \mathrm{C}$ and $-40^{\circ} \mathrm{C}$, providing the modules' cell temperatures reach $+90^{\circ} \mathrm{C} \pm 2^{\circ} \mathrm{C}$ and $-40^{\circ} \mathrm{C} \pm 2^{\circ} \mathrm{C}$, respectively. Thus, programming the chamber to reach $+93^{\circ} \mathrm{C}$ and $-43^{\circ} \mathrm{C}$ may result in the module temperatures reaching the proper temperatures in 20-40 min; however, the maximum temperature change rate of $100^{\circ} \mathrm{C} / \mathrm{h}$ shall not be exceeded.

Step 4- Verify that no open circuits or short circuits occur during the exposure.

Step 5- Inspect modules to detect evidence of physlcal degrudution (such as delamination, terminal corrosion, broken interconnects, and broken cells) af ter 25 cycles (optional).

Step 6- Following removal of modules from test chamber, obtain pust-test electrical performance data for each module.

Step 7- Inspect modules to detect evidence of physical degradation (such as delamination, terminal corrosion, broken interconnects, and broken cells).

\section{EVALUATION}

Upon completion of the temperature cycling test each module shall be inspected to detect evidence of physical degradation (such us delumination, terminal corrosion, broken interconnects, and broken cells). In addition, thc post-test electrical performance of each module shall be measured using Test TE.AR.E.l. Excessive physical deterioration, electrical degradation below design levels, the presence of interinittent open circuits, or the occurrence of short circuits to ground shall be cause to classify the module as having failed. 


\section{TEST TE.AR.M.3}

\section{TEMPERATURE CYCLING TEST-CONCENTRATOR MODULES}

\section{PURPOSE}

The temperature cycling test is conducted to determine the effects of thermal stresses on modules that could occur during service use.

\section{APPARATUS}

Temperature-humidity chamber with temperature rate controller; electrical continuity and short-circuit monitoring equipment; test frame.

\section{PREPARATION}

Step 1- Verify that pretest electrical performance data for the module is available.

Step 2- Inspect modules to detect evidence of physical degradation (e.g., delamination or broken cells).

Step 3- Prepare and provide programming devices to perform the temperature cycling program of Fig. B-5.

Step 4- Mount modules in a test frame in accordance with manufacturer's installation instructions and recommended mounting hardware. The test frame shall be designed to simulate the support of the module in the actual use environment. 


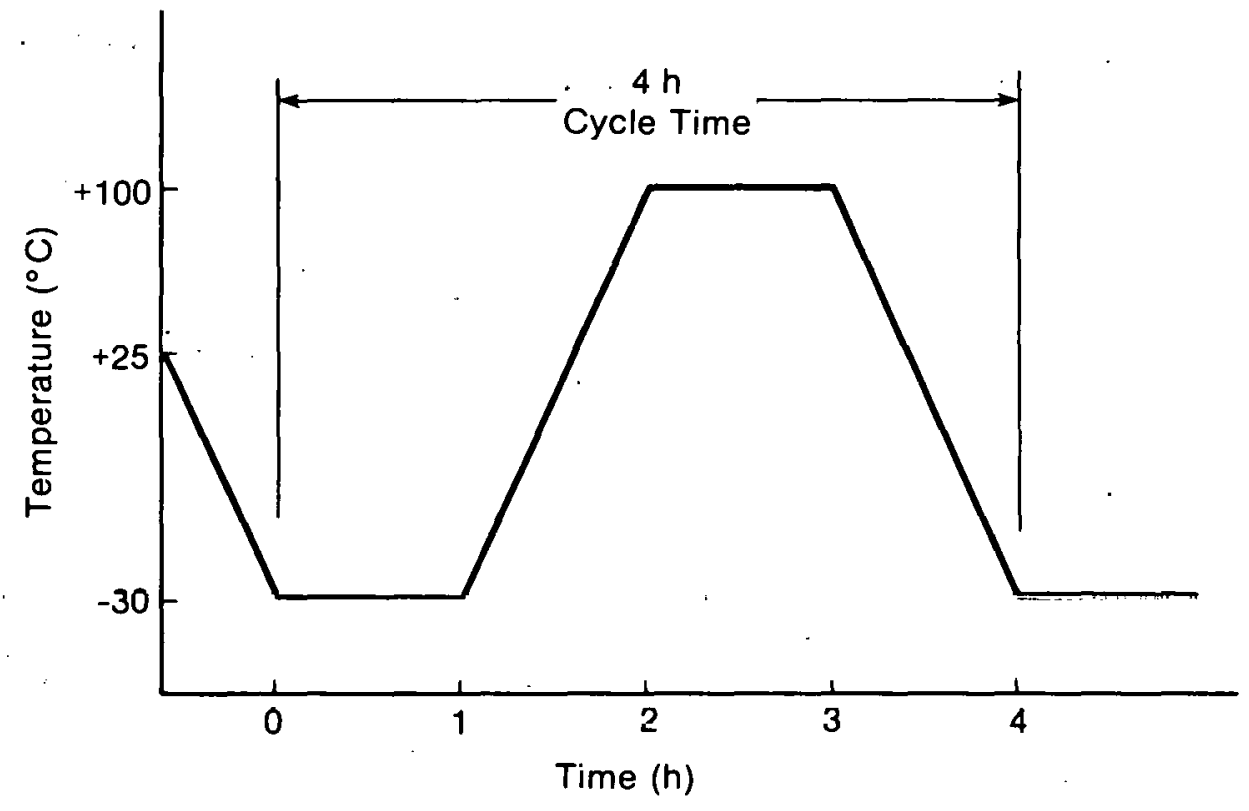

Note: Relative Humidity Shall Be $85 \%$ at $60^{\circ} \mathrm{C}$

Figure B-5. Photovoltaic Module Test Profile 


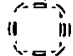

\section{PROCEDURE}

Step 1- Install modules into the chamber. If there is more than one, install them so that all are exposed equally to air supply; that is, parallel to the air flow. Connect the electrical leads from the module terminals to the electrical continuity and short circuit monitoring equipment. Note: Concurrent testing of several modules in the same chamber is permitted provided the test requirements for each module are identical.

Step 2- Verify that each module has electrical continuity and no short circuits.

Step 3- Subject the modules to 50 temperature cycles in accordance with Fig. B-4. A temperature cycle consists of $1 \mathrm{~h}$ at $-30^{\circ} \mathrm{C}$; followed by $1 \mathrm{~h}$ at $+60^{\circ} \mathrm{C}$. The transition periods between these extremes shall be of $1 \mathrm{~h}$ duration, yielding a cycle time of $4 \mathrm{~h}$. During transition periods, the temperature shall have a rate of change of not more than $200^{\circ} \mathrm{C} / \mathrm{h}$. The relative humidity shall be $85 \%$ at $60^{\circ} \mathrm{C}$ for each cycle.

Step 4- Verify that no open circuits or short circuits occurred during the exposure.

Step 5- Inspect modules to detect evidence of physical degradation (such as delamination, terminal corrosion, broken interconnects, broken cells, and broken, cracked, or delaminated optical components) after 25 cycles (optional).

Step 6- Following removal of modules and test chamber, obtain post-test electrical performance data for each module.

Step 7- Inspect modules to detect evidence of physical degradation (such as delamination, terminal corrosion, broken interconnects, broken cells, and broken, cracked, or delaminated optical components).

\section{EVALUATION}

Uंpon completion of the temperature cycling test each module shall be inspected to detect evidence of physical degradation (such as delamination, terminal corrosion, broken interconnects, broken cells and broken, cracked or delaminated optical components). In addition, the post-test electrical performance of each module shall be measured using a test method to be developed. Excessive physical deterioration, electrical degradation below design levels, the presence of intermittent open circuits, or the occurrence of short circuits to ground shall be cause to classify the module as having failed. 


\section{HAIL TEST-FLAT-PLATE MODULES}

\section{PURPOSE}

The hail test is used to demonstrate the ability of a photovoltaic module design to withstand specified levels of hailstone impact likely to be encountered at a specific site.

\section{COMMENTARY}

The test is an application-dependent test performed on a sample lot of modules of a given design intended for use in a hail-prone geographic area. The test consists of propelling ice balls of the required hailstone diameter at terminal velocity at the three most sensitive points on the test specimen. The selection of huil diumeter is determined by the user, based on an assessment of the hailstorm likelihood at a particular application. Typical hailstone characteristics are provided in Table B-2. For solar collectors, HUD recommends using a hailstone diameter equal to $8 \mathrm{~mm}(0.3$ in.) times the average number of hail-days per year at the application site.

Ice balls are the only acceptable hailstone simulation. Dropped steel balls shall not be used.

Table B-2. TYPICAL HAIL CHARACTERISTICS ${ }^{a}$

\begin{tabular}{ll}
\hline $\begin{array}{c}\text { Diameter } \\
\text { cm (in.) }\end{array}$ & $\begin{array}{c}\text { Terminal Velocity } \\
\mathrm{m} / \mathrm{s}(\mathrm{mph})\end{array}$ \\
\hline $1.27(0.50)$ & $16.1(36.0)$ \\
$1.90(0.75)$ & $20.1(45.0)$ \\
$2.54(1.00)$ & $23.2(52.0)$ \\
$3.18(1.25)$ & $25.9(58.0)$ \\
$3.81(1.50)$ & $28.1(63.0)$ \\
$5.08(2.00)$ & $32.6(73.0)$ \\
$6.35(2.50)$ & $36.2(81.0)$ \\
$7.62(3)$ & $39.8(89.0)$ \\
\hline
\end{tabular}

${ }^{a}$ Density of ice taken as $0.9 \mathrm{~g} / \mathrm{cm}^{3}$.

\section{APPARATUS}

Pneumatic or spring-actuated guns for projecting ice balls, velocity monitoring equipment, a mold for forming spherical ice balls, a cold storage compartment. Representative acceptable hail test equipment is shown in Figs. B-6, and B-7, and-in a schematic set-up in Fig. B-8. 


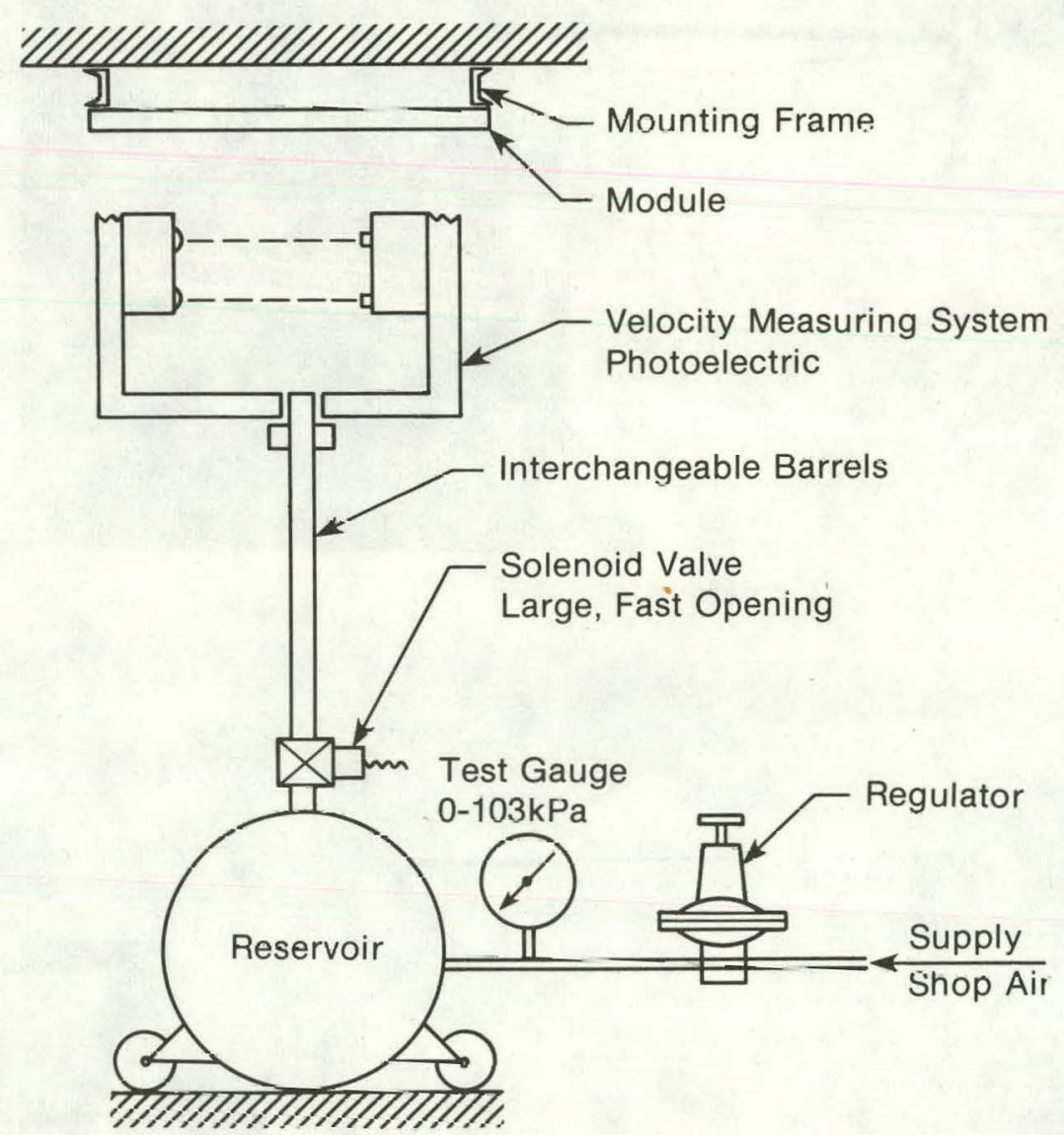

Figure B-8. Schematic Hail Test Set-Up 


\section{PREPARATION}

Step 1- Prepare ice balls of the required diameter. After forming, place the ice balls in a freezer at $-8^{\circ} \mathrm{C} \pm 2^{\circ} \mathrm{C}$ for a minimum of $8 \mathrm{~h}$ before use. Ice balls shall be generally spherical in shape with a maximum deviation in diameter of $\pm 3 \mathrm{~mm}( \pm 1 / 8$ in.).

Step 2- Calibrate the gun by measuring the velocity of the required diameter ice ball as it approaches the target. If it can be demonstrated that ice ball velocity can be repeated $\pm 5 \%$, it will not be necessary to measure the velocity of each shot. If the speed cannot be so controlled by setting pressure or spring force, each shot shall be electronically timed. Note: Calibration can best be done by electronically measuring the time it takes the ice ball to interrupt two photo cells. It may be necessary to add some coloring to the water before freezing it to increase the opacity of the ice ball.

Step 3- Verify that pretest electrical performance data are available for the module being tested.

Step 4- Inspect module being tested to detect evidence of physical degradation (broken cell or damaged outer cover).

The next three steps are to be performed if a precursor destructive test of a sample module is desired.

Step 5- Verify that the sample module intended for destructive testing is of identical design to the test specimen module.

Step 6- Test the sample panel destructively to determine the most sensitive exposed point on a test specimen experimentally. Ice balls of the required diameter shall be fired at candidate sensitive points with increasing velocity until the panel is broken. Several different points on the panel should be broken, and the points broken at the lowest velocities should be used for subsequent testing.

The candidate points selected should include the following (where applicable):

- corners and edges of the module;

- edges of cells, especially around electrical contacts;

- points of minimum spacing between cells;

- points of support for any superstrate material; ; and

- points of maximum distance from points of support.

Step 7- Identify at least 10 different points of impact from the destructive test results to be struck during the regular test. 


\section{PROCEDURE}

Step 1- Mount the module normal to the path of the ice ball. The module shall be installed in a test figure using mounting hardware that simulates the support rigidity of the intended field installation.

The following steps are applied if a precursor destructive test is to be performed.

Step 2- After removing an ice ball from the freezer and inserting it in the gun, shoot the ice ball at the module at the required terminal velocity and at one of the ten most sensitive exposed points as determined during the destructive test. Note: The time between freezer removal and shooting shall be less than 1 min and all gun surfaces shall be $20^{\circ} \mathrm{C} \pm 5^{\circ} \mathrm{C}$. Some scatter is expected in hitting a location on the module. Error up to 15 $\mathrm{mm}$ in the location hit is acceptable.

Step 3- Inspect the module in the area of impact for signs of cell cracking or top surface damage.

Step 4- Repeat steps 2-4 for at least nine additional sites on the module as determined during the destructive test.

The following steps are applied when there is no precursor destructive test.

Step 2'- After removing an ice ball from the freezer and inserting it in the gun, shoot the ice ball at the module at the required terminal velocity and at a location given in Table B-3. Note: The time between freezer removal and shooting shall be less than $1 \mathrm{~min}$ and all gun surfaces shall be $20^{\circ} \mathrm{C} \pm$ $5^{\circ} \mathrm{C}$. Some scatter is expected in hitting a location on the module. Error up to $15 \mathrm{~mm}$ in the location hit is acceptable.

Step $3^{\prime}-\quad$ Inspect the module in the area of impact for signs of cell cracking or top surface damage.

Step 4'- Repeat steps $2^{\prime}$ and $3^{\prime}$ two more times at different sites of the samo generic type (e.g., corners and edges).

Step 5'.... Repeat steps $2^{\prime}-4^{\prime}$ for the four additional generic types of sites on the module.

Table B-3. LOCATIONS FOR ICE BALL IMPACT

\begin{tabular}{|c|c|c|c|}
\hline Shot & . & Location & $\begin{array}{c}\text { Location } \\
\text { on } \\
\text { Sketch }\end{array}$ \\
\hline $\begin{array}{l}1,2,3 \\
4,5,6\end{array}$ & $\begin{array}{l}(1) \\
(2)\end{array}$ & $\begin{array}{l}\text { Corncrs and edges of the invululc. } \\
\text { Edges of cells, especially around } \\
\text { electrical contacts. }\end{array}$ & $\begin{array}{l}\text { A } \\
\text { B }\end{array}$ \\
\hline $\begin{array}{l}7,8,9 \\
10,11,12\end{array}$ & $\begin{array}{l}(3) \\
(4)\end{array}$ & $\begin{array}{l}\text { Points of minimum spacing between cells. } \\
\text { Points of support for any superstrate } \\
\text { material. }\end{array}$ & $\begin{array}{l}\mathrm{C} \\
\mathrm{D}\end{array}$ \\
\hline $13,14,15$ & (5) & $\begin{array}{l}\text { Points of maximum distance from points } \\
\text { of support in (4). }\end{array}$ & $\mathbf{E}^{\mathbf{a}}$ \\
\hline
\end{tabular}

${ }^{a}(E)$ represents a channel bridge or other area deemed to be particularly vulnerable. 

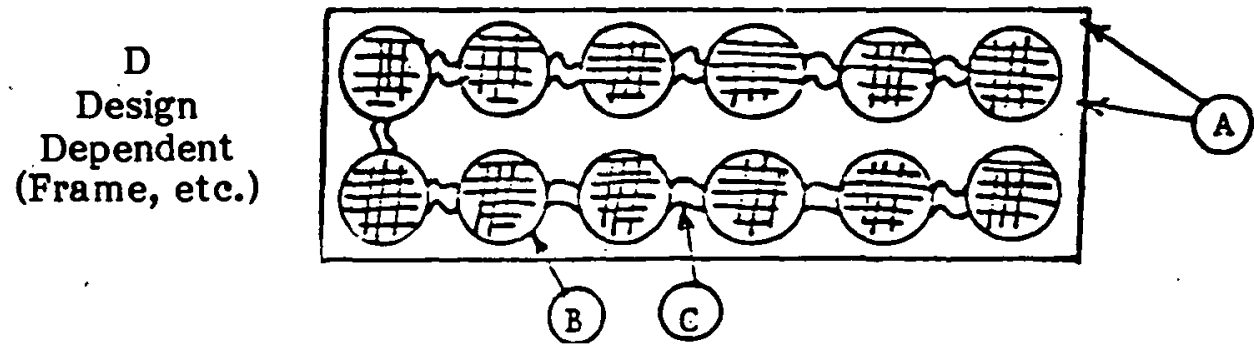

Step 5,6'- Obtain post-test electrical performance data for each modulé.

Step 6,7'- Inspect module to detect evidence of physical degradation (broken cells or damaged outer cover).

\section{EVALUATION}

Upon completion of the hail test, each module shall be inspected to detect evidence of physical degradation (such as broken interconnects, broken cells, and damaged outer cover). In addition, the post-test electrical performance of each module shall be measured using Test TE.AR.E.1. Excessive physical deterioration, electrical degradation below design levels, the presence of intermittent open circuits, or the occurrence of short circuits to ground shall be cause to classify the module as having failed. 
TEST TE.AR.M.5

\section{HAIL TEST-CONCENTRATOR MODULES}

\section{PURPOSE}

The hail test is used to demonstrate the ability of a photovoltaic module design to withstand specified levels of hailstone impact that are likely to be encountered at a specific site.

\section{COMMENTARY}

The test is an application-dependent test performed on a sample of modules of a given design intended to be used in a hail-prone area. The test consists of propelling ice balls of specific hailstone diameters at terminal velocity toward the three most sensitive points on the test specimen. 'The hailstone diameter is determined by the user based on his assessment of hailstorms at the particular application. Typical hailstone characteristics are provided in Table B-4. For solar collectors, HUD recommends a hailstone diameter equal to $8 \mathrm{~mm}(0.3 \mathrm{in})$ times the average number of hail-days per year at the application site. Ice balls are the only acceptable hailstone simulation. Dropped steel balls should not be used.

Table B-4. TYPICAL HAIL CHARACTERISTICs ${ }^{\mathrm{a}}$

\begin{tabular}{|c|c|}
\hline $\begin{array}{l}\text { Diameter } \\
\text { cm (in.) }\end{array}$ & $\begin{array}{c}\text { Terminal Velocity } \\
\mathrm{m} / \mathrm{s}(\mathrm{mph})\end{array}$ \\
\hline $\begin{array}{l}1.27(0.50) \\
1.90(0.75) \\
2.54(1.00) \\
3.18(1.25) \\
3.81(1.50) \\
5.08(2.00) \\
6.35(2.50) \\
7.62(3.00)\end{array}$ & $\begin{array}{l}16.1(36.0) \\
20.1(45.0) \\
23.2(52.0) \\
25.9(58.0) \\
28.2(63.0) \\
32.6(73.0) \\
36.2(81.0) \\
39.8(89.0)\end{array}$ \\
\hline
\end{tabular}

\section{APPARATUS}

Apparatus consists of pneumatic or spring-actuated guns for projecting ice balls, velocity monitoring equipment, a mold for forming spherical ice balls, and a cold storage compartinent.

\section{PREPARATION}

Step 1- Prepare ice balls of the required diameter. After forming them, place the ice balls in a freezer at $-8^{\circ} \mathrm{C} \pm 2^{\circ} \mathrm{C}$ for a minimum of $8 \mathrm{~h}$ before 
Step 2- Calibrate the gun by measuring the velocity of the required diameter ice ball as it approaches the target. If it can be demonstrated that ice ball velocity can be repeated $\pm 5 \%$, it will not be necessary to measure the velocity of each shot. Note: Calibration can best be done by electronically measuring the time it takes the ice ball to interrupt two photo cells. It may be necessary to add some coloring to the water before freezing it to increase the opacity of the ice ball.

3tep 3- Verify that pretest electrical performance data are available for the module being tested.

Step 4- Inspect module being tested to detect evidence of physical degradation (broken cell or damage to outer cover).

\section{PROCEDURE}

Step 1- Mount the module so that the ice ball will achieve impact on a path parallel with the optical axis of the module. The module shall be installed in a test fixture using mounting hardware that simulates the support rigidity of the intended field installation.

Step 2- After removing an ice ball from the freezer and inserting it in the gun, shoot the ice ball at the module at the required terminal velocity and at a location given in Table B-5. Note: The time between freezer removal and shooting shall be less than $1 \mathrm{~min}$ and all gun surfaces shall be $20^{\circ} \mathrm{C}$ $\pm 5^{\circ} \mathrm{C}$. Some scatter is expected in hitting a location on the module. Errors up to $15 \mathrm{~mm}$ in the location hit are acceptable.

Step 3- Inspect the module in the area of impact for signs of damage to the optical surfaces, including cracking, denting, or crazing.

Step 4- Repeat steps 2 and 3 two more times. Three impacts are required to determine if a sensitive point has been struck.

Step 3- Repcat steps 2-4 at four additional sites on the module.

Step 6- Mount the module so that the ice balls impact on the surfacc of the cells on the receiver. The module configuration will determine the window through which hailstones can impact the receiver. The direction from which the hail comes shall be approximately the middle of this "window." If the design of the module precludes direct hail impact, this step can be omitted.

Step 7- Implement step 2 for various points along the receiver, including the cells and interfaces between adjacent cells or cover glasses. At least three impacts are required for each generic area of the receiver.

Step 8- Inspect the receiver for signs of cell or cover glass cracking.

Step 9- Obtain post-test electrical performance data for each module.

Step 10- Inspect module to detect evidence of physical degradation. 
Table B-5. LOCATIONS FOR ICE BALL IMPACT

\begin{tabular}{ll}
\hline Shot & Location \\
\hline $1,2,3$ & (1) Corners and edges of the module \\
$3,4,5$ & (3) Points of support for any \\
superstrate material \\
$6,7,8$ & (4) Points of maximum distance from \\
points of support in (4)
\end{tabular}

\section{EVALUATION}

Upon completion of the hail test, each module shall be inspected to detect evidence of physical degradation (such as cracked, dented, or crazed optical surfaces, broken interconnects, broken cells). In addition, the post-test electrical performance of each module shall be measured using a test method to be developed. Excessive physical deterioration, cracking of surfaces such that moisture will be admitted (directly or through capillary action) in such a way that latter degradation of the module is likely shall cause the module to fail. Dents in the optical surfaces should be considered in regard to their effect on the performance of the module. If they cause more than $5 \%$ loss in performance, the module will be determined to have failed. 


\section{TEST TE.AR.M.6}

\section{TEMPERATURE CYCLING TEST-CONCENTRATOR RECEIVER}

\section{PURPOSE}

The temperature cycling test is conducted to determine the effects of thermal stresses that could occur on receivers during use.

\section{APPARATUS}

Apparatus consists of a temperature-humidity chamber with temperature rate controller; electrical continuity and short-circuit monitoring equipment; and a test frame.

\section{PREPARATION}

Step 1- Verify that pretest electrical performance data for the module is available.

Step 2- Inspect receiver to detect evidence of physical degradation (e.g., delamination or broken cells).

Step 3- Prepare and provide programming devices to perform the temperature cycling program of Fig. B-9.

Step 4- Mount receiver in a test frame in accordance with manufacturer's installation instructions and recomm ended mounting hardware.

\section{PROCEDURE}

Step 1- Install receiver into temperature chamber. If there are more than one, install them so that all are exposed equally to air supply; that is, parallel to the air flow. Connect the electrical leads from the receiver terminals to the electrical continuity and short-circuit monitoring equipment. Note: Concurrent testing of several receivers in the same chamber is permitted provided the test requirements for each receiver are identical.

Step 2- Verify that each receiver has electrical continuity and no short circuits.

Step 3- Subject the receiver to 50 temperature cycles in accordance with Fig. B-10. A temperature cycle consists of $1 \mathrm{~h}$ at $-30^{\circ} \mathrm{C}$, followed by $1 \mathrm{~h}$ at $100^{\circ} \mathrm{C}$. The transition period between these extremes should be of $1 \mathrm{~h}$ duration yielding a cycle time of $4 \mathrm{~h}$. During transition periods, the temperature shall change at a rate of not more than $200^{\circ} \mathrm{C} / \mathrm{h}$. The relative humidity shall be $85 \%$ at $100^{\circ} \mathrm{C}$ for each cycle.

Step 4- Verify that no open circuits or short circuits occur during the exposure.

Step 5- Inspect receivers to detect evidence of physical degradation (such as delamination, terminal corrosion, broken interconnects, and broken cells) after 25 cycles (optional). 


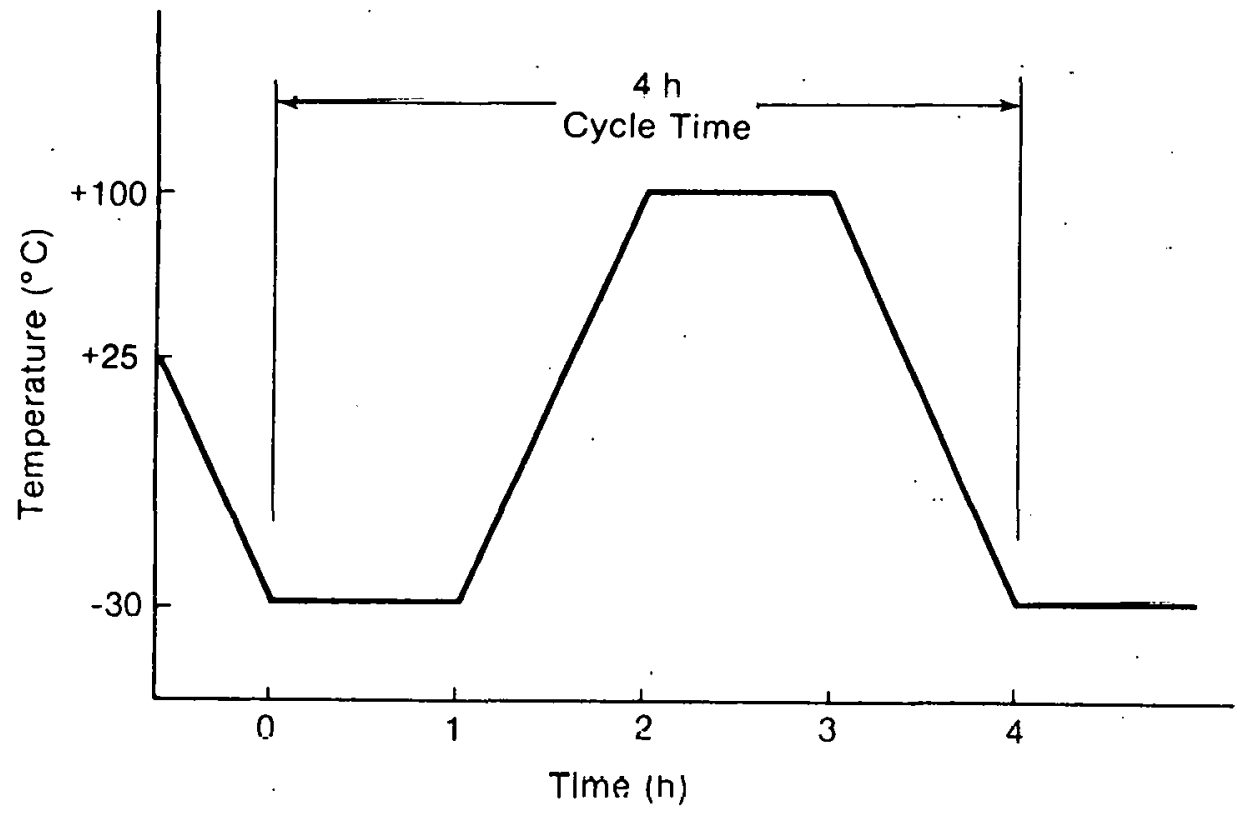

Note: Relative Humidity Shall Be $85 \%$ at $100^{\circ} \mathrm{C}$

Figure B-9. Photovoltaic Receiver Test Profile 


\section{EVALUATION}

Upon completion of the temperature cycling test, each receiver shall be inspected to detect evidence of physical degradation (such as delamination, terminal corrosion, broken interconnects, and broken cells). In addition, the post-test electrical performance of each receiver shall be measured using Test TE.AR.E.2 (Method for Measuring the Electrical Performance of Concentrater Cells and Receivers). Excessive physical deterioration, electrical degradation below design levels, the presence of intermittent open circuits, or the occurrence of short circuits to ground shall be cause to classify the receiver as having failed. 
TEST TE.AR.M.7

CONTACT PULL STRENGTH (WIRE PULL TEST)-SOLAR CELLS

\section{PURPOSE}

The solar cell contact pull strength test is used to determine how well a contact is adhering to the cell surface and thus to evaluate the integrity of interconnections to these contacts.

\section{APPARATUS}

Pull tester equipped with a dynamometer for measuring pull force and a clamp for holding cell and the attached wire (Unitek Micropull Model 6-092-03 or equivalent); No. 26 gauge wire (Fed. Spec. QQ-W-343D or equivalent); soldering iron and solder.

\section{PREPARATION}

Step 1- Cut piece of No. 26 gauge wire (Fed. Spec. QQ-W-343D or equivalent) of sufficient length for clamping in tester.

Step 2- Bend wire at $0.89 \pm 0.13 \mathrm{~mm}\left(0.035 \pm 0.005\right.$ in.) from end into $a 90^{\circ} \pm 3^{\circ}$ bend with a $0.25 \mathrm{~mm}(0.010 \mathrm{in.}$ ) radius.

Step 3- Solder the bent wire tab onto the "N" contact (or "P" depending on the contact of test) of the cell so that the whole $.089 \mathrm{~mm}(0.035 \mathrm{in}$.) dimension of the wire has a smooth uniform solder fillet. Position tab at $90^{\circ}$ from cell surface according to Fig. B-10. 
Front

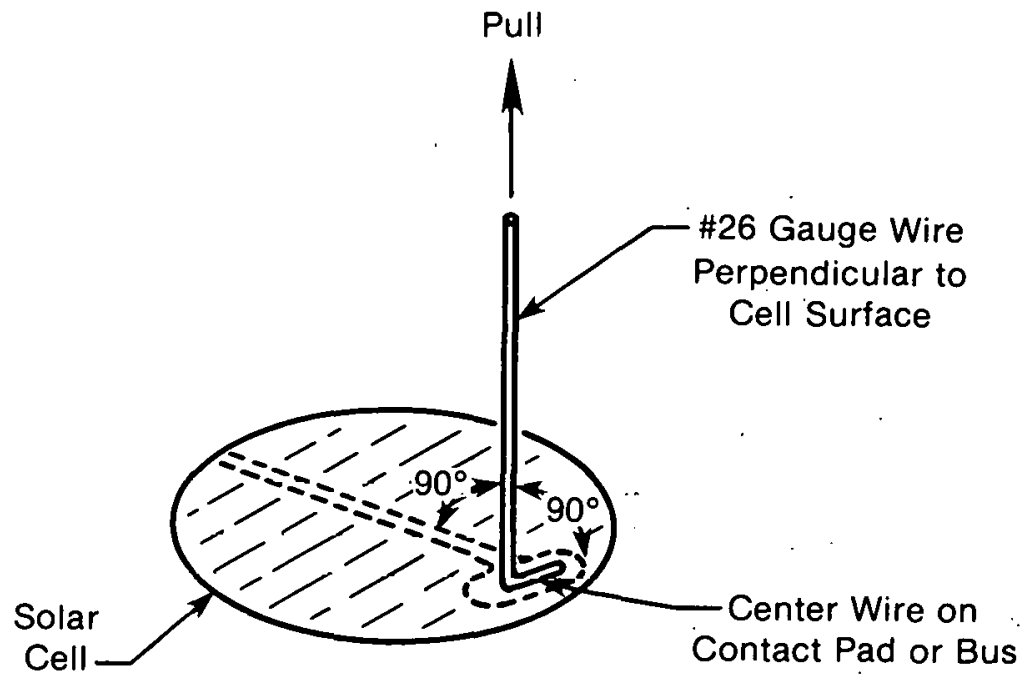

Back

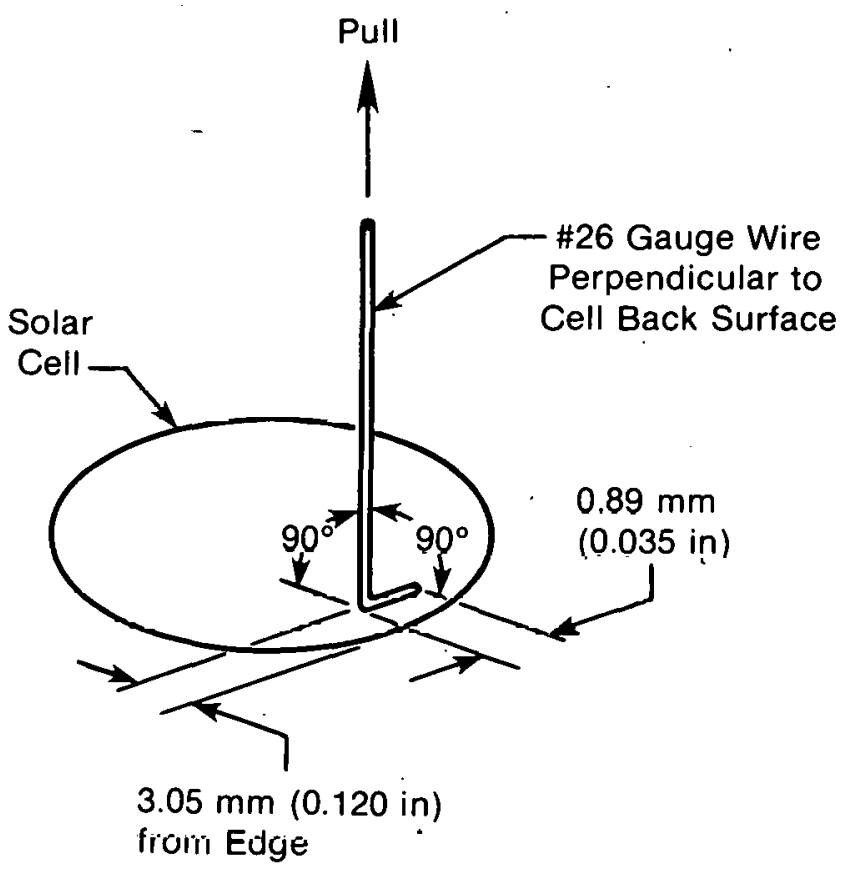

Note: Solder wire to cell with uniform smooth fillet

Figure B-10. Contact Pull Strength Test 


\section{PROCEDURE}

Step 1- Clamp cell with attached wire into pull tester.

Step 2- Pull wire tab with increasing force until a predetermined acceptable contact strength level is reached (typically about 5 newtons) or until a mechanical failure in the contact or the cell itself is experienced.

Step 3- Record the maximum force achieved and the observed mode of failure.

\section{EVALUATION}

If the solar cell contacts are able to withstand the predetermined minimum acceptable strength criteria, then the contact design and processes are acceptable and should be highly reliable. If failure occurs below the acceptable minimum and the mode of failure is contact peeling, then that manufacturing batch (or possibly that contact design) should be disqualified. 
1 TEST TE.AR.M.8

\section{NOMWAL OPERATING CELL TEMPERATURE DETERMINATION-FLAT PLATE}

\section{PURPOSE}

The purpose of this test is to acquire sufficient data to permit an accurate determination of the nominal operating cell temperature (NOCT) of the solar cells of a flat-plate terrestrial solar array module.

\section{COMMENTARY}

NOCT is defined as the temperature of a cell at the following operating conditions:

$\begin{array}{ll}\text { Irradiance }= & 800 \mathrm{~W} / \mathrm{m}^{2} \\ \text { Air Temperature }= & 20^{\circ} \mathrm{C} \\ \text { Wind Average Velocity }= & 1 \mathrm{~m} / \mathrm{s} \\ \text { Mounting - } & \begin{array}{l}\text { Oriented normal to solar noon either open or } \\ \text { closed back }\end{array} \\ \text { Electrical Load - } & \text { Open circuit }\end{array}$

The temperature of a solar cell ( $\mathrm{T}$ cell) is primarily a function of the air temperature ( $\mathrm{T}$ air), the average wind velocity (v), configuration of the module (e.g., open back, closed back), and the total solar insolation (L) impinging on the active side of the solar array module. The approach for determining NOCT is based on the fact that the temperature difference ( $T$ cell-T air) is largely independent of air temperature and is essentially linearly proportional to the insolation level.

The NOCT test procedure is based on gathering actual measured cell temperatures via temperature sensor leads attached directly to the cells of interest, for a range of environmental conditions similar to Nominal Terrestrial Environment (NTE).* The data is then presented in a way that permits accurate and repeatable interpolation of NOCT temperature.

If the modules are for residential use, then they shall be tested in a rack so as to simulate the residential environment. Residential roof application comes under two categories: modules suspended from the roof and those with a hard mounting to the roof. The NOCT test shall be conducted according to the end-use application.

The plot of ( $\mathrm{T}$ cell-T air) vs. insolation shall be determined by conducting a minimum of two field tests in which the module being characterized is tested under terrestrial environmental conditions approximating the NTE in accordance with the testing procedure that follows.

*The air temperature and wind velocity defined above are known as the Nominal Terrestrial Environment (NTE). 
APPARATUS

Pyranometer: $\quad$ An Eppley PSP or an equivalent Class 1 pyranometer as defined by the World Meteorological Organization.

Wind Transducer: Both the wind direction and wind speed shall be measured.

Temperature

Sensors:

Racks:

Data Recording Equipment:
Measurements shall be accurate to $\pm 1^{\circ} \mathrm{C}$. (Note: an average local air temperature is desired. If a thermocouple is used, this is obtained satisfactorily by increasing the thermal mass of the thermocouple by imbedding it in a solder sphere of approximately $6.4 \mathrm{~mm}$ (0.25 in.). For measurement of ambient air temperature, sensors must be appirupirialely slitelded turd vented. If a thermocouple is used to measure cell temperature, the thermocouples shall be 36 gauge.

The module shall be. located in a rack similar to the application to be used. For a roof-mounted application, the simulated rack shall consist of a $1.2 \mathrm{~m} \times 1.2 \mathrm{~m}$ panel enclosed by a triangular box.

The response time and scale ranges shall be compatible with the transducers used.

\section{PREPARATION}

Step 1- The module shall be located in the interior of the $1.2 \mathrm{~m} \times 1.2 \mathrm{~m}$ subarray. Black aluminum panels or other modules of the same design shall be used to fill in any remaining open area of the subarray structure. The plane of the module shall be positioned so that it is normal to the sun $\left( \pm 5^{\circ}\right)$ at solar noon. For open field application, the back of the subarray shall be exposed. The bottom edge of the module shall be located $61 \mathrm{~cm}$ or more above the horizontal plane or ground level. For residential roof application, where the module is suspended from the roof, the module shall be located $7.6 \mathrm{~cm}$ from the simulated roof. For hard mounting roof applications, the modules shall be located directly on the simulated roof.

Step 2- Mount the pyranometer on the plane of the module within $0.3 \mathrm{~m}$ of the array.

Step 3- Locate the wind transduccr at the approximate height of the module and as near to one of the sides of the module as feasible.

Step 4- For ambient air temperature measurement, the temperature sensor shall be located at the approximate height of the module. The measurement shall be made in the shadow of the module.

Step 5- For cell temperature measurement, the sensor probes shall be directly attached to the monitored cells. If thermocouples are used, they shall be soft soldered to the backs of the cells. At least two cells shall be measured. 
Step 6- There shall be no obstructions to prevent full irradiance of the module beginning a minimum of $4 \mathrm{~h}$ before solar noon and up to $4 \mathrm{~h}$ af ter solar noon. The ground surrounding the module shall not have a high solar reflectance and shall be flat and/or sloping away from the test fixture. Grass and various types of ground covers, blacktop, and dirt are recommended for the local surrounding area. Buildings having a large solar reflective finish shall not be in the immediate vicinity. Good engineering judgment shall be exercised to assure that the module, front and back, is receiving a minimum of reflected solar energy from the surrounding area.

Step 7- The wind shall be predominantly either northerly or southerly; wind flow parallel to the plane of the array is not acceptable and can result in a lower than typical operating cell temperature.

Step 8- Data shall be obtained for a module open-circuit condition corresponding to zero electrical power output.

Step 9- The active side of the solar cell module and the pyranometer bulb shall be cleaned before the start of each test. Dirt shall not be allowed to build up. Cleaning with mild soap followed by a rinse with distilled water is effective.

Step 10- A calibration check shall be made of all the equipment before the start of the test.

\section{PROCEDURE}

Step 1- Acquire a semicontinuous record of ( $T$ cell- $T$ air) over a one- or two-day period, together with insolation and other measurements as required to characterize the terrestrial environment during the testing period. All data shall be printed out approximately every $5 \mathrm{~min}$. In addition, solar intensity, wind speed, wind direction, and air temperature shall be continuously recorded. Acceptable data shall consist of measurements made when the average wind velocity is $1 \mathrm{~m} / \mathrm{s} \pm 0.75 \mathrm{~m} / \mathrm{s}$ and with gusts less than $4 \mathrm{~m} / \mathrm{s}$ for a period of $5 \mathrm{~min}$ prior to and up to the time of measurement. Local air temperature during the test period shall be $20^{\circ} \mathrm{C} \pm$ $15^{\circ} \mathrm{C}$. The two sets of measurements can be combined into a single set provided the average air temperature of the two sets does not differ by more than approximately $5^{\circ} \mathrm{C}$.

Step 2- Using only acceptable data as so defined, a plot shall be constructed, from a set of measurements made either before or after solar noon, that defines the relationship between ( $T$ cell- $T$ air) and the solar irradiance level $(J)$ for $J=800 \mathrm{~W} / \mathrm{m}^{2}$.

Step 3- Using the plot of ( $T$ cell-T air) versus $J$, the value of ( $T$ cell- $T$ air) at NTE is determined by interpolating the average value of ( $T$ cell-T air) for $\mathrm{J}=800 \mathrm{~W} / \mathrm{m}^{2}$.

Step 4- A correction factor to the preliminary NOCT for average air temperature and wind velocity is determined from Fig. B-11. This value is added to the preliminary NOCT and corrects the data to $20^{\circ} \mathrm{C}$ and $1 \mathrm{~m} / \mathrm{s}$. 


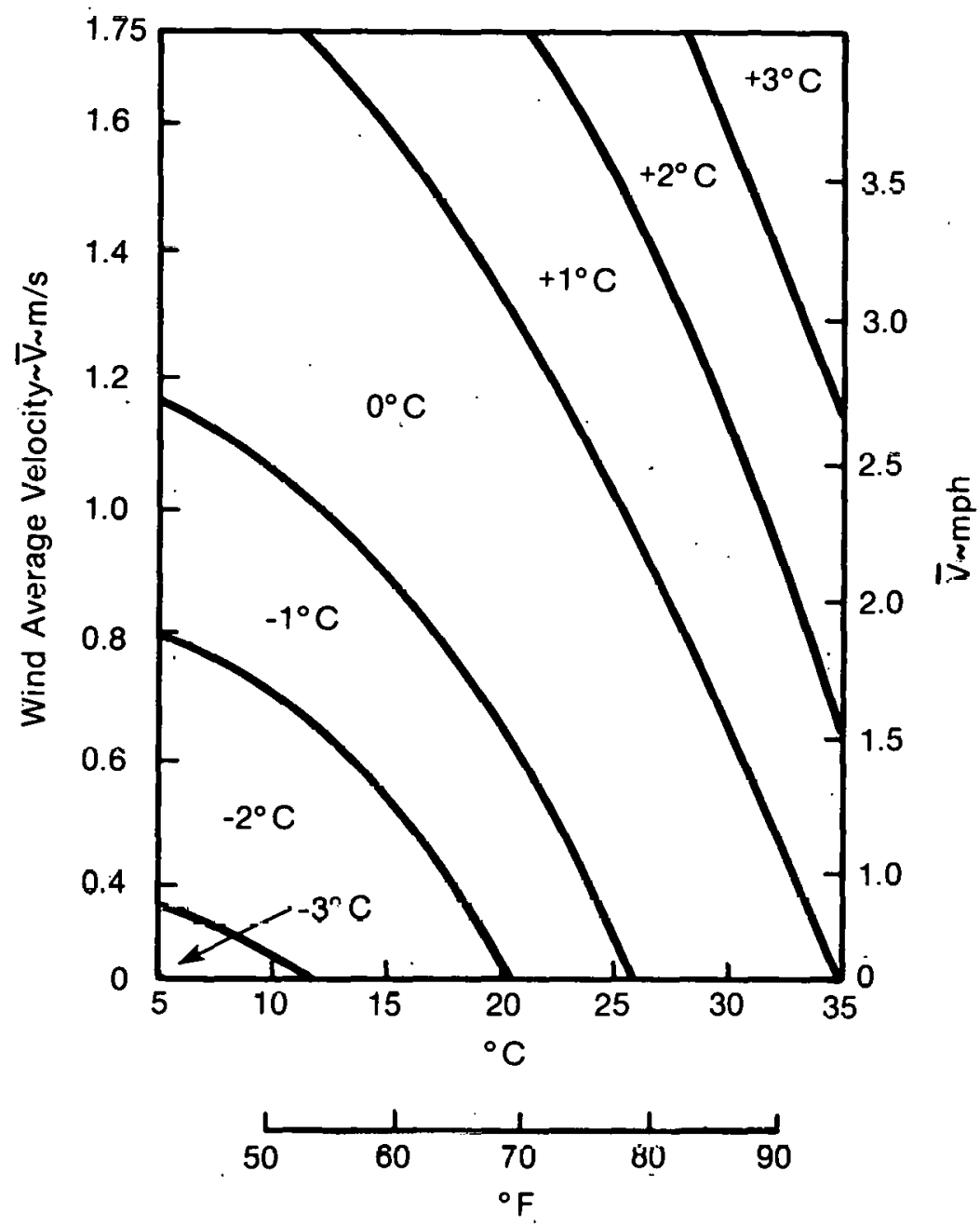

Average Air Temperature T

Figure B-11. NOCT Correction Factor 
TEST TE.AR.M.9

\section{ANTIREPLECTION COATING ADHESION TEST-SOLAR CELLS}

\section{PURPOSE}

The AR coating adhesion test is used to determine the ability of solar cells with AR coatings, either flat-plate or concentrator, to withstand handling and exposure to water vapor without delamination of the coating.

\section{APPARATUS}

The test equipment consists of a container of boiling water; a fixture for dipping the cells into the boiling water; and an eraser rubbing fixture (a Pink Pearl No. 101 or equivalent) that can be applied with the proper pressure.

\section{PREPARATION}

Step 1- Inspect cells visually to determine AR coating color and identify any nonunif ormities.

Step 2- Put fresh deionized water in container.

Step 3- Heat water to boiling temperature.

Step 4- Load cells into dipping fixture.

\section{PROCEDURE}

Step 1- Immerse fixture with cells into boiling water for $15 \mathrm{~min}$.

Step 2- Raise fixture above boiling water so that cells are still exposed to water vapors for $15 \mathrm{~min}$.

Step 3- Remove cells from water vapor and air dry.

Step 4- Subject cells to rubbing with eraser. The eraser is pressed against the cell's AR-coated surface with a pressure of from 120 to $147 \mathrm{kPa}$ (17.4 to $21.3 \mathrm{psi}$ ) and is rubbed across the surface on the same path for $20 \mathrm{com}-$ plete cycles.

\section{EVALUATION}

Upon completion of the test each cell is visually inspected for evidence of removal or delamination of the AR coating using the unaided eye. Excessive color change or delamination of the AR coating shall be cause to disqualify cells. 
TEST TE.AR.M.10

\section{DIELECTRIC VOLTAGE WITHSTAND TEST}

\section{PURPOSE}

The dielectric voltage withstand test is used to determine the ability of electrical insulation systems to withstand specific levels of voltage stress without breakdown or excessive leakage current. The test is written for use in evaluating the voltage isolation between the active solar cell circuit and external conductive surfaces of photovoltaic assemblies such as solar cell modules and concentrator receivers. The test is of ten used as a product quality verification test during product development and as an acceptance test procedure used for $100 \%$ inspection of the manufactured product.

\section{APPARATUS}

Dielectric withstanding voltage test equipment shall consist of a variable output DC power supply of $500 \mathrm{VA}$ minimum capacity equipped with suitable display of test voltage and current. The equipment shall be capable of detecting dielectric breakdown by limitation of current and interruption of voltage application at a leakage current of $50 \mu \mathrm{A}$.

\section{PREPARATION}

Step 1- Verify that pretest electrical performance and visual inspection data are available.

Step 2- Short the solar cell circuit of the test article by connecting a suitable jumper between the positive and negative terminals of the solar cell circuit. Ensure that the jumper is well isolated from the remainder of the test article.

\section{PROCEDURE}

Step 1- 'Iurn on the test equipment and allow adequate time for warmup per manufacturer's recommendation.

Step 2- Adjust the current limit to $50 \mu$ A and the initial output voltage to zero.

Step 3- Connect the test equipment high-voltage DC positive output to the test article's short-circuited output terminations. Connect the test equipment ground (negative) to the test article ground terminal, or, if no ground terminal exists, directly to the exposed conductive external surface of interest. If the test article has no exposed conductive surfaces, use the mounting hardware as a test ground.

Step 4- Switch on the output voltage and quickly increase the applied potential from zero to the required test level at an approximately constant rate not to exceed $500 \mathrm{~V} / \mathrm{s}$. In no case shall a voltage ramp rate be chosen that would result in exceeding the leakage current limit strictly because of capacitive charging effects related to test article configuration. Hold the applied potential at the test level for a period of one minute. 
Step 5- During the high voltage application, the sample should be observed for signs of flashover, arcing, and excessive leaking current.

Step 6- Switch off the applied voltage and discharge any stored charge in the test article before disconnecting it.

\section{EVALUATION}

During the high-voltage application there shall be no visually observable evidence of flashover, arcing; or corona phenomena, or current leakage in excess of $50 \mu \mathrm{A}$ as evidenced by the test equipment leakage current detection circuitry. An insulation resistance test (in preparation) may be employed after completion of the high voltage application to verify that the insulation resistance has not degraded to less than $50 \mu \mathrm{A}$ as evidenced by the test equipment leakage current detection circuitry. An insulation resistance test (in preparation) may be employed after completion of the high voltage application to verify that the insulation resistance has not degraded to less than $50 \mathrm{k} \Omega$. 


\section{TEST TE.AR.M.11}

\section{STRUCTURAL STRESS TEST-SOLAR CELLS}

\section{PURPOSE}

A thermal cycle procedure is an effective method of determining if surface imperfections on solar cells are cracks or simply benign marks.

\section{COMMENTARY}

This procedure has been particularly useful in resolving questions involving edge chips and the imperfections of ten found within and surrounding the chips. Rather than being a $100 \%$ inspection procedure, this method is intended primarily to verify product quality and resolve inspection questions.

\section{APPARATUS}

Testing equipment includes an inspection microscope; heated metal plate; temperature sensor; and indicator for hotplate.

\section{PROCEDURE}

Step 1- Inspect cell and map any suspect imperfections.

Step 2- Bring hotplate to temperature (hotplate temperature should be as high as possible without damaging or dcgrading cell metallization system).

Step 3- Place cell on hotplate for 2 to $3 \mathrm{~min}$.

Step 4- Remove cell from hotplate and allow cell to cool.

Step 5- Inspect cell and note any changes in suspect imperfections mapped in step 1 .

\section{EVALUATION}

The absence of any change in an imperfection is a strong indication that it is not a crack or fracture. 
TEST TE:AR.D.I

\section{SOLAR RADIATION WEATHERING TESTS-MATERIALS AND COMPONENTS}

\section{PURPOSE}

Solar radiation weathering tests for photovoltaic materials and components (excluding cell studies) are conducted to determine the effects of extended outdoor exposureinduced stress that occurs during service life. These tests are intended as materials and components qualification tests prior to their utilization in the construction of modules.

\section{COMMENTARY}

These tests are applicable to transparent covers, transparent superstrates, full-sized mirrors and lenses, encapsulants, adhesives, substrate materials, and any frontal surface component of a module that will be illuminated by the sun during its service life. Expected effects are stress-induced deterioration of the structural (physical) and optical (transparency) characteristics of materials and components employed in module construction. Structural deterioration of concern includes cracking and loss in tensile, impact, flexual, or adhesive strength. Optical deterioration includes the development of haze and coloration-both of which may significantly reduce transmittance or specular reflectance.

These tests are intended as materials screening and qualification tests and are not required where experience or verifiable exposure durability tests have been previously done by either the module manufacturer, the materials supplier, or by third parties.

Provision is made in this test method for use of both natural and artificial weathering tests. Both real-time and accelerated natural solar irradiance test procedures are included; the artificial weathering test procedures here are considered to be accelerated exposure test methods. The rationale for choosing one or the other is presented in the section on Test Procedures.

\section{APPARATUS}

\section{Solar Irradiance Measurements}

Suitable solar irradiance measuring detectors shall be employed to determine the irradiance level (exposure amount) of materials and components to the natural and simulated solar irradiance sources represented by the three test procedures used to satisfy the requirements of this test method. All solar irradiance measuring detectors continuously exposed shall, for purposes of this requirement, be calibrated and traceable to a nationally recognized reference no less frequently than every 6 months. 
Pyranometer: A WMO* Class 1 pyranometer shall be mounted either coplanar with, or at the same tilt as, specimens being exposed to natural weathering.

Pyrheliometer: A WMO Class 1 pyrheliometer. with a field of view of approximately $6^{\circ} \pm 1^{0}$ shall be employed to assess the total irradiance level deposited by the accelerated weathering machines described in the Test Procedure, Accelerated Natural Exposure Testing. A suitable instrument is an Eppley model NIP pyrheliometer.

Total Untraviolet Radiometer: A total ultraviolet pyranometer filtered to exclude all irradiance above $385-\mathrm{nm}$ wavelength may be employed to assess the ultraviolet irradiance level of specimens exposed to real-time natural weathering. It shall be mounted either coplanar with or at the same tilt as the test specimens. A suitable ultraviolet radiometer is the Eppley Model TUVR.

Total Ultraviolet Radiometer for Concentrated Ultraviolet: A photodiode, or other suitable photodetector, appropriately filtered to exclude all energy above 385-nm wavelength, which shall be of compact size adequate for insertion into the concentrated beam of accelerated test instrumentation, may be employed to assess the ultraviolet irradiance level attained when employing accelerated test methods of natural and artificial irradiance.

\section{Test Apparatus}

Procedure 1-Natural, Real-'lime Exposure Testing (Including Optical Components): Adjustable exposure test racks such as described in the ASTM test methods listed in the Test Procedure for Natural Real-Time Exposure Testing shall be employed. Materials and components should be mounted with un appiopriate substratc to simulate, if pnssible, the intended end use.

Procedure 1A-(Alternate, optical components only) Natural, Real Exposure Testing of Optical Systems: An equatorial (or other periodically adjustable) sun-following test platform equpped with a tracking device and water spray mechanism may be employed to expose mirror and lens specimens and assemblies at or near normal incidence throughout the test day. Provision may be made for periodic depositions of distilled or deionized water for $8 \mathrm{~min}$ each hour of operation. This is particularly necessary when testing mirrors.

Procedure 2-Accelerated Natural Exposure Testing: Sunlight concentrating test equipment may be employed for accelerated exposure testing using natural solar irradiance as a source. This equipment shall provide for uniform illumination of test specimens (uniformity of $\pm 5 \%$ across the test specimen), provide cooling of test specimens between $0^{\circ} \mathrm{C}$ and $15^{\circ} \mathrm{C}$ above the one-sum stagnation temperature under identical mounting and environmental conditions, and, optionally, provide periodic distilled/deionized water

*World Meteorological Organization. 
spray on the target specimen. A Fresnel reflecting concentrator test apparatus such as the one referred to in paragraph 4.3.2 of ANSI Test Method Z 97.1-1975 has been found suitable for this test and meets these criteria*. This test is currently being developed as an ASTM standard by the ASTM Committee E44 Solar Energy Conversion.

Procedure 3-Accelerated, Artificial Exposure Testing: Apparatus required for exposure testing with artificial solar irradiance sources are described in the ref erenced test methods presented in Procedure 3, Accelerated Artificial Exposure Testing. Suitable exposure apparatus meeting ASTM Standards G26 and D2565 is the

- Xenon-arc type Weather-Ometer**

Suitable exposure apparatus meeting ASTM Standard G53 are the

- QUV Fluorescent Weathering Cabinet,***

- UVCON Fluorescent.Weathering Cabinet.****

\section{PREPARATION}

Step 1- Verif $\dot{y}$ that an adequate number of test specimens of the appropriate size and shape are available. Note: Their number, size, and shape depend on the specific optical and physical properties to be determined.

Step 2- Clean test specimens with soap and water (mild detergents such as Lux or Alconox) and thoroughly rinse with deionized water before testing.

Step 3- Inspect test specimen to detect evidence of physical degradation.

Step 4- Obtain pre-test optical and physical property data as appropriate.

Step 5- Mount materials and components in test frames in accordance with the requirements and guidance provided in the relevant test methods.

\section{PROCEDURES}

\section{General Considerations}

Although natural, real-time exposure testing is the preferred method, the necessity of performing accelerated testing to make materials and components decisions quickly is well recognized. This is particularly true for tests in support of extended lifetime

*For guidance purposes, such machines are used at DSET Laboratories, Inc., Phoenix, Arizona 85029.

**Weather-Ometer ${ }^{\text {TM }}$ is a Registered Trademark of the Atlas Electric Company, Chicago, Ill. 60613.

***QUV $\mathrm{TM}^{\mathrm{TM}}$ is a Trademark of the Q-Panel Company, Cleveland, Ohio 44135.

**** $\mathrm{UVCON}^{\mathrm{TM}}$ is a Trademark of the Atlas Electric Company, Chicago, Ill. 60613. 
requirements. However, accelerated testing should be accompanied (preferably preceded) whenever possible by natural, real-time testing in order to validate accelerated weathering by providing correlation factors for early exposure stages.

Materials and components exposed to natural solar radiation, or simulated solar radiation, shall be weathered for an equivalent of 36 months in southern U.S. latitudes. For the purposes of these tests, 36 months at southern lgtitudes is defined as representing an irradiance level, or a total deposition, of $2.39 \times 10^{10} \mathrm{~J} / \mathrm{m}^{2}\left(3.23 \times 10^{10} \mathrm{~J} / \mathrm{m}^{2}\right.$ for optical components) of sunlight (equivalent to 570,000 langleys; 770,000 langleys for optical components).

This exposure level represents a total ultraviolet irradiance of $9.56 \times 10^{8} \mathrm{~J} / \mathrm{m}^{2}$ $\left(1.29 \times 10^{10} \mathrm{~J} / \mathrm{m}^{2}\right.$ for optical components) of energy below 385-nm wavelength (or, an average of $4 \%$ of total sunlight on an annual basis). Bereuse of variations in natural sunlight from month to month and from site to site and the variations in total energy output by natural sunlight and artificial sources, it is recommended that exposure levels be timed on the basis of ultraviolet energy deposited rather than total solar energy.

The determination of relevant optical and physical property measurements at intermediate exposure levels is necessary if degradation-rate information is sought to establish a correlation between real-time and accelerated test procedures. Appropriate exposurelevel information is presented in the following table (extended exposure levels are also given as guidance when testing for extended lif etime requirements).

Table B-6. OUTDOOR EXPOSURE VALUES-SOUTHERN U.S. LATITUDES ${ }^{a}$

\begin{tabular}{cccc}
\hline \multirow{2}{*}{$\begin{array}{c}\text { Equivalent } \\
\text { Years }^{a}\end{array}$} & \multicolumn{2}{c}{ Total Sunlight $^{\mathrm{b}}$} & \multicolumn{1}{c}{ Total Ultraviolet $^{\mathrm{d}}$} \\
\cline { 2 - 3 } & langleys $^{\mathrm{c}}$ & $\mathrm{J} / \mathrm{m}^{2}$ & $\mathrm{~J} / \mathrm{m}^{2}$ \\
\hline 1 & $190 \mathrm{k}$ & $7.97 \times 10^{9}$ & $3.19 \times 10^{8}$ \\
3 & $380 \mathrm{k}$ & $1.59 \times 10^{10}$ & $6.37 \times 10^{8}$ \\
5 & $570 \mathrm{k}$ & $2.39 \times 1010$ & $9.56 \times 10^{8}$ \\
10 & $950 \mathrm{k}$ & $3.98 \times 10^{10}$ & $1.59 \times 10^{9}$ \\
15 & $1900 \mathrm{k}$ & $7.97 \times 1010$ & $3.19 \times 10^{9}$ \\
20 & $2850 \mathrm{k}$ & $1.20 \times 10^{11}$ & $4.78 \times 10^{9}$ \\
& $3800 \mathrm{k}$ & $1.59 \times 10^{11}$ & $6.37 \times 10^{9}$
\end{tabular}

$a_{\text {These }}$ are not the average southern latitude values; the average is somewhat lower. These are weighted to the Southwest, where photovoltaics may find greater deployment. ${ }^{b}$ All wavelengths, global, measured in plane of specimen.

$c_{1}$ langley $=1 \mathrm{~g}-\mathrm{cal} / \mathrm{cm}^{2}$.

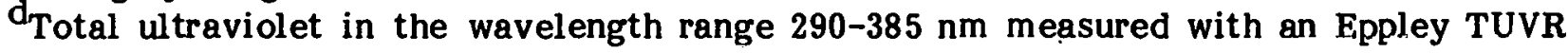
ultraviolet radiometer, measured in the plane of the device.

\section{Procedure 1-Natural Real-Time Exposure Testing}

Step 1- Determine the most appropriate applicable ASTM test method from the following reference methods: 
- D1006-73 Conducting Exterior Exposure Tests of Paints on Wood

- D1014-66 Conducting Exterior Exposure Tests of Paints on Steel (1973)

- D1425-75 Outdoor Weathering of Plastics

- D1828-70 Atmospheric Exposure of Adhesive Bonded Joints and Structures

- G7-77 Atmospheric Environmental Exposure Testing of Nonmetallic Materials

- G11-72 Effects of Outdoor Weathering on Pipeline Coatings

- G24-73 Conducting Natural Light Exposure Under Glass

Step 2- Mount the test specimens in an outdoor adjustable test rack in accordance with the selected ASTM test method.

Step 3- Expose specimens to a minimum irradiance level of $2.39 \times 10^{8} \mathrm{~J} / \mathrm{m}^{2}$ (570,000 langleys). Note: Timing exposures on the basis of ultraviolet deposited is preferred; see Table B-6 for guidance.

Step 4- (Optional) At intermediate exposure levels, remove specimens from test rack, record irradiance level, evaluate, and return specimens to test rack.

Step 5- Inspect test specimens to detect evidence of physical degradation. (See guidelines under Evaluation.)

Step 6- Evaluate optical properties of test specimens in accordance with the guidelines under Evaluation.

Procedure 1A (Alternate for Optical Components)-Natural, Real-Time Exposure Testing.

Note: This procedure is the preferred method for real-time testing of optical componeyts and requires $25 \%$ less time to accumulate the required exposure of $3.23 \times 10^{10} \mathrm{~J} / \mathrm{m}^{2}$ of sunlight $\left(1.29 \times 10^{9} \mathrm{~J} / \mathrm{m}^{2}\right.$ of ultraviolet $)$.

Step 1- Mount the mirrors and lenses, or specimens prepared from them, in the sun-following test device described in the Test Procedure $1 \mathrm{~A}$.

Step 2- Expose specimens to a minimum irradiance level of $3.23 \times 10^{10} \mathrm{~J} / \mathrm{m}^{2}$ of sunlight $\left(1.29 \times 10^{9} \mathrm{~J} / \mathrm{m}^{2}\right.$ of ultraviolet) with the test device operated from sunup to sundown.

Step 3- Carefully wash specimens each week with chamois and a dilute solution of a mild detergent such as Lux or Alconox, or an equivalent, and rinse with distilled water.

Step 4- (Optional) Subject specimens to water spray for a period of $8 \mathrm{~min}$ during each $60 \mathrm{~min}$ of sunlight exposure, or to other regular, periodic spray cycles as agreed upon.

Step 5- (Optional) At intermediate exposure levels, remove specimens from test device, record fluence, evaluate optical characteristics, and return to the test device for the next exposure level requirements.

Step 6- (Optional) For structural integrity determinations at intermediate exposure levels, remove specimens from test device, record fluence, and perform structural testing as appropriate. 
Step 7- Inspect test specimens to detect evidence of physical degradation. (See guidelines under Evaluation.)

Step 8- Evaluate optical properties of test specimens in accordance with the guidelines under Evaluation.

\section{Procedure 2-Accelerated Natural Bxposure Testing}

Step 1- Mount test specimens in an accelerated weathering machine in accordance with standard practice.

Step 2- Expose specimens to concentrated natural solar irradiance for a total irradiance level of $2.89 \times 10^{10} \mathrm{~J} / \mathrm{m}^{2}\left(5.37 \times 10^{10} \mathrm{~J} / \mathrm{m}^{2}\right.$ for components that track the sun). Note: The preferred method for determining exposure level is ultraviolet deposited; in this case, specimens should be exposed to an ultraviolet irradiation level of $9.56 \times 10^{8} \mathrm{~J} / \mathrm{m}^{2}$ $\left(2.15 \times 10^{9} \mathrm{~J} / \mathrm{m}^{2}\right.$ for components that track the sun). The minimum exposure when testing specimens of components that track the sun (mirrors and lenses) under accelerated weathering is greater than for realtime exposure testing. Actually; while 5 years' equivalent of natural real-time weathering would be an impractical mandatory requirement from an elapsed-time standpoint, it is nonetheless desirable. Conversely, the highly desirable mandatory accelerated exposure testing for an "equivalent" of 5 years of real-time testing does not impose a significant elapsed-time problem.

Step 3- (Optional) Adjust the cooling system to maintain the specimen temperature between $0^{\circ} \mathrm{C}$ and $15^{\circ} \mathrm{C}$ above the temperature it would reach if it were similarly mounted under one-sun intensity.

Step 4- (Optional) Subject specimens to water spray for a period of $8 \mathrm{~min}$ during oach $60 \mathrm{~min}$ nf sunlight exposure, or to other regular, periodic spray cycles as agreed upon. Note: This step is recommended for materials and surface components that are exposed to dew and rainfall during service. For components not exposed to exterior environment under normal operating conditions but subjected to sunlight illumination, the water spl'uy shall not be included in the procedure.

Step 5- (Optional). At intermediate exposure levels, remove specimens from weathering machine, record fluence, evaluate and return specimens to weathering machine. Note: Intermediate exposure levels should be determined using Table B-6.

Step 6- (Optional, Alternate) At intermediate exposure levels, remove replicate specimens from weathering machine, record irradiance level, and evaluate. Do not return samples to weathering machine.

Step 7- Inspect test specimens to detect evidence of physical degradation. (See guideline under Evaluation.)

Step 8- Evaluate optical properties of test specimens in accordance with the guidelines under Evaluation. 


\section{Procedure 3-Accelerated, Artificial Exposure Testing}

Step 1- Determine the most appropriate applicable ASTM test method from the following reference methods:

- G25-70 Operating Light and Water Exposure Apparatus (Xenon arc-type) for Exposure of Nonmetallic Materials

- G53-77 Operating Light and Water Exposure Apparatus (fluorescent UVcondensation type) for Exposure of Nonmetallic Materials

- D2565-75 Operating Xenon Arc Type (Water-Cooled) Light and Water Exposure Apparatus for Exposure of Plastics

Step 2- Mount the test specimens in the weathering machine in accordance with the selected ASTM test method.

Step 3- Expose specimens to simulated solar irradiance for a period sufficient to deposit $9.56 \times 10^{8} \mathrm{~J} / \mathrm{m}^{2}\left(2.15 \times 10^{9} \mathrm{~J} / \mathrm{m}^{2}\right.$ for optics $)$ of ultraviolet as defined in Table B-6. Note: This step is recommended for materials and surface components that are exposed to dew and rainfall during service. For components not exposed to the exterior environment under normal operating conditions but subjected to sunlight illumination, the water spray shall not be included in the procedure.

Step 4- (Optional) Subject specimens to a water spray for a period of $5 \mathrm{~min}$ during each $60 \mathrm{~min}$ of the light exposure when employing Xenon arc-type exposure testing.

Step 5- (Optional) At intermediate exposure levels, remove specimens from test rack, record fluence, evaluate, and return specimens to test rack.

Step 5'- (Optional, Alternate) At intermediate exposure levels, remove replicate samples, record fluence, and evaluate. Do not return samples to test rack.

Step 6- Inspect test specimens to detect evidence of physical degradation. (See guidelines under Evaluation.)

Step 7- Evaluate optical properties of test specimens in accordance with the guidelines under Evaluation.

\section{EVALUATION}

The surfaces of components or materials shall be visually inspected before and after aging to ensure that no signs of excessive deterioration, such as dimensional changes, cracking, fiber bloom, or other visually detectable changes (that could significantly affect the performance of the components in the system) are present. Evaluation techniques shall be selected to measure the effect of the aging procedures on important properties of the components or materials. Evaluation at intermediate exposure levels is suggested as a way to determine degradation-rate effects.

The absorptance, transmittance, and specular reflectance of coated glass, polymeric cover, mirrors, Fresnel lenses, plate materials, and encapsulants shall be evaluated before and after aging in the relevant photovoltaic active spectrum, as appropriate, using the following ASTM method: 
- E424-71 (Method A)* Solar Energy Transmittance and Reflectance of Sheet Materials (for Air Mass 1.5)

The specular reflectance of mirrors and mirror specimens shall be determined before and after exposure testing, and at any intermediate exposure levels selected. Both spectral and total (all-inclusive wavelengths) reflectance techniques may be employed (spectral measurements are preferred). Applicable ASTM Standards (m easurement) may be:

- E167-77 Standard Recommended Practice for Goniophotometry of Objects and Materials

- E179-77 Standard Recommended Practice for Selection of Geometric Condilivis for Measurement of Refleotance and Transmittance

- E429-78 Standard Method for Meusurement and Calculating of Reflerting Characteristics of Metallic Surfaces Using Integrating Sphere Instruments

Instrumentation that combines classical V-W optics external to integrating spheres or other transfer optics associated with spectrophotometric devices, and external bidirectional optics attachments to these devices, is preferred to properly assess changes in the specular component of reflectance of mirror surfaces. The important consideration is that the field-of-view of the measuring device be as nearly matched as possible to the field-of-view of the focusing optics of interest.

Other evaluation procedures shall be used as appropriate. The following ASTM procedures dealing with physical deterioration are illustrative of the types of procedures that may be used.

- D618 Conditioning Plastics and Electrical Materials for Testing

- D638 Tensile Properties of Plastics

- D794 Rccommendod Practice for Determining the Permanent Effect of Heat on Plastics

- D882 Tensile Properties of Thin Plastic Sheeting

- D1042 Linear Dimensional Changes of Plastics Under Acceleratcd Service Conditions

- D1181 Warpage of Sheet. Plastics

- D1204 Linear Dimensional Changes of Nonrigid Thermoplastic Sheeting or Film at Elevated Temperature

- Exxx Standard Practice for Deleirnining Reslstance of Solar Collector Covers to Impact by Hail**

- $\quad$ 8897 Tensile Properties of Adhesive Bonds

\footnotetext{
*Being revised by ASTM Committee E44 Solar Energy Conversion.

**Being developed by ASTM Committee E44 Solar Energy Conversion.
} 
TEST TE.AR.D.2

SOLAR RADIATION WEATHERING TESTS-MODULES AND MINIMODULES

\section{PURPOSE}

Solar radiation weathering tests for photovoltaic modules and minimodules are conducted to determine the effects of extended outdoor exposure-induced stress that occurs during service life. The minimodule tests are qualification tests conducted before the construction of full-sized modules.

\section{COMMENTARY}

These tests are applicable to minimodules and full-sized modules. Small modules; or minimodules, may be designed and constructed to verify the integrity of the sandwich construction method chosen for full-sized modules. Expected effects are stress-induced deterioration of the structural, optical, and electrical performance characteristics of modules and minimodules. Exposure testing of minimodules also has as one objective the early assessment of possibly harmful materials and components interactions that could affect the electrical performance, reliability, and durability of modules so constructed.

Structural and optical deterioration here include discoloration of encapsulants and transparent covers, delamination, moisture intrusion, cell cracking, carbonation, contact corrosion, etc.

Provision is made in this test method for use of both natural and artificial weathering tests. Both real-time and accelerated natural sunshine test procedures are included; the artificial weathering test procedures included are accelerated exposure test methods. The real-time and accelerated natural sunshine tests are suitable for exposure testing of both modules and minimodules. -The artificial (simulated) weathering test procedures are suitable only for appropriately sized minimodules.

\section{APPARATUS}

\section{Solar Radiation Measurements}

Suitable solar radiation measuring detectors shall be employed to determine the irradiance level (exposure amount) of modules and minimodules to the natural and simulated solar radiation sources represented by the three test procedures that may be employed to satisfy the requirements of this test method. All solar radiation measuring detectors exposed continuously shall, for the purposes of these requirements, be calibrated traceable to nationally recognized reference no less frequently than every 6 moinths.

Pyranometer: A WMO Class 1 pyranometer shall be mounted either coplanar with, or at the same tilt as, specimens exposed to natural weathering. 
Pyrheliometer: A WMO Class 1 pyrheliometer having a field of view of $6^{\circ} \pm 1^{\circ}$ shall be employed to assess the total fluence of sunlight deposited by the accelerated weathering machines described later in Procedure 2, Accelerated Natural Exposure Testing, under Test Procedure. A suitable instrument is an Eppley Model pyrheliometer.

Total Ultraviolet Radiometer: A total ultraviolet pyranometer filtered to exclude all radiation above $385-\mathrm{nm}$ wavelength may be employed to assess the ultraviolet fluence of specimens exposed to real-time natural weathering. It shall be mounted either coplanar with, or at the same tilt as, the test specimens. A suitable ultraviolet radiom eter is the Eppley Model TUVR.

Total Ultraviolet Radiometer for Concentrated Ultraviolet: A photodiode, or other suitable photodetector, appropriately filtered to exclude all energy above 385-nm wavelength, which shall be compact enough for insertion into the concentrated beam of accelerated test instrumenluliui, nuy be used to assess the ultraviolet exposure level attained when employing accelerated test methods Procedures 2 and 3.

\section{Test Apparatus}

Procedure 1-Natural, Real-Time Exposure Testing: Adjustable exposure test racks such as described in the ASTM test methods listed in Procedure 1 , Natural Real-Time Exposure Testing (see Test Procedures), shall be employed. Materials and components should be mounted with an appropriated substrate to simulate, if possible, the intended end use.

Procedure 2 (Method A)-Accelerated Natural Expusure Testing: Sunlight concentrating test equipment may be used for accelerated exposure testing using natural sunshine as the source. This equipment provides for uniform illumination of test specimens (uniformity of $\pm 5 \%$ across the test specimen), provide cooling of test specimens between $0^{\circ} \mathrm{C}$ to $15^{\circ} \mathrm{C}$ above the one sun stagnation temperature under identical mounting and environmental conditions, and optionally provide periodic distilled/deionized water spray on the target specimens. A Fresnel-reflecting concentrator test equipment such as referenced in paragraph 4.3.2 of ANSI Test Method 97.1-1975 has been found that is suitable for this testing and meets these criteria.* A test method entitled ASTM Exxx, "Standard Practice for Performing Accelerated Outdoor Weathering Using Concentrated Natural Sunlight," is currently being developed as an ASTM Standard in ASTM Committee E44 Solar Energy Conversion.

Procedure 2 (Method B)-Accelerated Natural Exposure Testing: 'I'he sunlight concentrating test equipment, except for size and target cooling, is identical

\footnotetext{
*For guidance purposes, such machines are used at DSET Laboratories, Inc., Phoenix,
} Arizona 85029. 
to that described in Method A above. This method is intended for accelerated solar radiation weathering of half-to-full-sized modules $(45 \mathrm{~cm} \times 30 \mathrm{~cm}$ to $15 \mathrm{~cm} \times 90 \mathrm{~cm})$.

Procedure 3-Accelerated, Artificial Exposure Testing: Apparatus required for exposure testing with artificial sunlight sources are described in the referenced test methods presented under Test Procedures. Suitable exposure apparatus meeting ASTM Standard G26 and D2565 is the:

- Xenon-arc type Weather-Ometer.*

Suitable exposure apparatus meeting ASTM Standard G53 are the:

- QUVTM Fluorescent Weathering Cabinet,** and

- UVCON ${ }^{\mathrm{TM}}$ Fluorescent Weathering Cabinet.***

\section{PREPARATION}

Step 1- Verify that an adequate number of test specimens of the appropriate size and shape are available.

Step 2- Clean test specimens with soap and water (mild detergents such as Lux or Alconox) and thoroughly rinse with deionized water before testing.

Step 3- Inspect test specimen to detect evidence of physical degradation.-

Step 4- Verify that pretest electrical performance data for the test specimens are available.

Step 5- Mount modules and minimodules in test frames in accordance with the requirements and guidance provided in relevant test methods.

\section{PROCEDURES}

\section{General Considerations}

Although natural, real-time exposure testing is the preferred method, the necessity of performing accelerated testing to make module design and construction decisions quickly is well recognized. This is particularly true when testing in support of extended lifetime requirements. However, accelerated testing should be accompanied (preferably preceded) whenever possible by natural, real-time testing in order to validate accelerated weathering by providing correlation factors for the early exposure stages.

Modules and minimodules exposed to natural solar radiation, or simulated solar radiation, shall be weathered for an equivalent of 36 months in southern U.S. latitudes. For

*Weather-Ometer ${ }^{\mathrm{TM}}$ is a Registered Trademark of the Atlas Electric Company, Chicago, Illinois 60613 .

**QUV ${ }^{\mathrm{TM}}$ is a Trademard of the Q-Panel Company, Cleveland, Ohio 44135.

***UVCON ${ }^{\mathrm{TM}}$ is a Trademark of the Atlas Electric Company, Chicago, Illinois 60613. 
purposes of these tests, 36 months at southern latitude is defined as representing an irradiance, or a total deposition, of $2.39 \times 10^{10} \mathrm{~J} / \mathrm{m}^{2}$ of sunlight (equivalent to 570,000 langleys). This exposure level represents total ultraviolet irradiance of $9.56 \times 10^{8} \mathrm{~J} / \mathrm{m}^{2}$ $\left(1.29 \times 10^{10} \mathrm{~J} / \mathrm{m}^{2}\right.$ for optical components) of energy below $385-\mathrm{nm}$ wavelength (or an average of $4 \%$ of total annual sunlight). Because of variations in the amount of ultraviolet deposition by natural sunlight from month to month and from site to site and variations in total energy output by natural sunlight and artificial sources, it is recommended that exposure levels be timed on the basis of ultraviolet energy deposited rather than total solar energy.

The determination of relevant structural and performance property measurements at intermediate exposure levels is necessitated if degradation-rate information is sought to establish a correlation between real-time and accelerated test procedures. Appropriate exposure-level information is presented in Table B-7 (extended exposure levels are also given as guidance when tésting for extended lifetime requirements).

Table B-7. OUTDOOR EXPUSUKE VALUES-SOUTHERN U.3. LATITUDES ${ }^{a}$

\begin{tabular}{cccc}
\hline \multirow{2}{*}{$\begin{array}{c}\text { Equivalent } \\
\text { Years }^{\mathrm{a}}\end{array}$} & Total Sunlight $^{\mathrm{b}}$ & & Total Ultraviolet $^{\mathrm{d}}$ \\
\cline { 2 - 3 } langleys $^{\mathrm{c}}$ & $190 \mathrm{k}$ & $\mathrm{J} / \mathrm{m}^{2}$ & $\mathrm{~J} / \mathrm{m}^{2}$ \\
\hline 2 & $380 \mathrm{k}$ & $7.97 \times 10^{9}$ & $3.19 \times 10^{8}$ \\
3 & $570 \mathrm{k}$ & $1.59 \times 10^{10}$ & $6.37 \times 10^{8}$ \\
5 & $950 \mathrm{k}$ & $2.39 \times 10^{10}$ & $9.56 \times 10^{8}$ \\
10 & $1900 \mathrm{k}$ & $3.98 \times 10^{10}$ & $1.59 \times 10^{9}$ \\
15 & $2850 \mathrm{k}$ & $7.97 \times 10^{10}$ & $3.19 \times 10^{9}$ \\
20 & $3800 \mathrm{k}$ & $1.20 \times 10^{11}$ & $4.78 \times 10^{9}$ \\
\hline
\end{tabular}

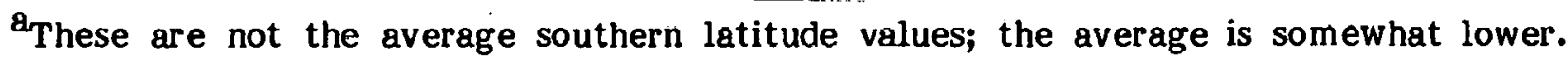
These are weighted to the Southwest, where photovoltaics may find greater deployment.

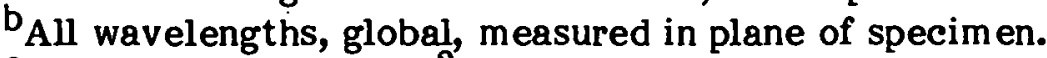

$c_{1}$ langley $=1 \mathrm{~g}-\mathrm{cal} / \mathrm{cm}^{2}$.

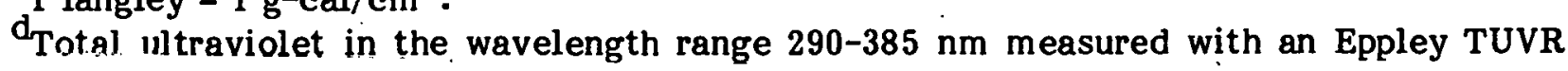
ultraviolet radiometer, measured in the plane of the device.

\section{Procedure 1-Natural Real-Time Exposure Testing}

Step 1- Determine the most appropriate applicable ASTM test method from the following reference methods:

- D1006-73 Conducting Exterior Exposure Tests of Paints

- D1014-66 Conducting Exterior Exposure Tests of Paints on Steel (1973)

- D1425-75 Outdoor Weathering of Plastics

- D1828-70 Atmospheric Exposure of Adhesive Bonded Joints and Structures 
- G7-77 Atmospheric Environmental Exposure Testing of Nonmetallic Materials

- G.11-72 Effects of Outdoor Weathering on Pipeline Coatings

- G24-73 Conducting Natural Light Exposure Under Glass

Step 2- Mount the test specimens in an outdoor adjustable test rack in accordance with the selected ASTM test method.

Step 3- Verify that the electrical leads from the module terminals are in the required configuration.

Step 4- Expose specimens to a minimum fluence of $2.39 \times 10^{8} \mathrm{~J} / \mathrm{m}^{2}(570,000$ langleys). Note: Timing exposures on the basis of ultraviolet energy deposited is preferred.

Step 5- (Optional) At intermediate exposure levels, remove specimens from test rack, record fluence, evaluate, and return specimens to test rack.

Step 6- Inspect test specimens to detect evidence of physical degradation. (See guidelines under Evaluation.)

Step 7- Evaluate electrical performance of test specimens in accordance with the guidelines under Evaluation. Note: Modules may be exposed to realtime natural weathering in the open-circuit, short-circuit or under-load condition.

\section{Procedure 2-Aceelerated Natural Exposure Testing (Methods A and B)}

Step 1- Mount the test speecimens in an accelerated weathering machine according to standard practice. For Method B, modules having large accelerated weathering equipment may have to be off-mounted to an extent that, when combined with an adjusted high-speed air flow, the cooling system maintains the module temperature at or near NOCT.

Step 2- Verify that the electrical leads from the module are in the required configuration (i.e., open-circuited, short-circuited or under-load). Caution: Modules exposed to accelerated solar radiation weathering under load or in the short-circuit condition may experience excessive deleterious effects.

Step 3- Expose specimens to concentrated natural solar radiation for a total irradiance of $3.98 \times 10^{10} \mathrm{~J} / \mathrm{m}^{2}$. Note: The preferable method for determining exposure level is ultraviolet energy deposited; in this case, specimens should be exposed to an ultraviolet irradiance of $1.59 \times 10^{9} \mathrm{~J} / \mathrm{m}^{2}$. The minimum exposure for testing modules and minimodules under accelerated weathering is greater than for real-time exposure testing.

Actually, while 5 years' equivalent of natural real-time weathering is an impractical mandatory requirement from an elapsed-time standpoint, it is nonetheless desirable. Conversely, the highly desirable mandatory 
accelerated exposure testing for an "equivalent" of 5 years of real-time testing does not impose a significant elapsed-time problem.

Step 4- (Optional) Adjust the cooling system to maintain the specimen temperature between $0^{\circ}$ and $15^{\circ} \mathrm{C}$ above the temperature it would reach if it were similarly mounted under one-sun intensity. For testing in large accelerated weathering machines, adjust the cooling system to maintain the module temperature at or near NOCT.

Step 5- (Optional) Subject specimens to water spray for a period of $8 \mathrm{~min}$ of sunlight exposure, or to other regular, periodic spray cycles as agreed upon. Note: This step is recommended for materials and surface components exposed to dew and rainfall during service. For components not exposed to operating conditions, but subjected to sunlight illumination, the water spray shall not be included in the procedure.

Step 6- (Optional) At intermediate exposure levels, remove specimens from weathering machine, record fluence, evaluate, and return specimens to weathering machine. Note: Intermediate exposure levels should be determined using Table B-7.

Step 6'- (Optional, Alternate) At intermediate exposure levels, remove replicate specimens from weathering machine, record fluence, and evaluate. Do not return samples to weathering machine.

Step 7- Inspect test specimens to detect evidence of physical degradation. (See guideline under Evaluation.)

Step 8- Evaluate electrical performance of test specimens in accordance with the guidelines under Evaluation.

\section{Procedure 3-Accelerated, Artificial Exposure Testing}

Step 1- Determine the most appropriate applicable ASTM test method from the following ref erence methods:

- G26-70 Operating Light and Water Exposure Apparatus (Xenon are type) for Exposure of Nonm etallic Materials

- G53-77 Operating Light and Water Exposure Apparatus (fluorescent UV-condensation type) for Exposure of Nonm etallic Materials

- D2565-75 Operating Xenon Arc Type (Water-Cooled) Light and Water Exposure Apparatus for Exposure of Plastics

Step 2- Mount the test specimens in the weathering machine in accordance with the selected ASTM test method. 
Step 3- Verify that the electrical leads from the module are in the required configuration (i.e., open-circuited, short-circuited, or under-load).

Step 4- Expose specimens to sjimulated solar radiation for a period sufficient to deposit $9.56 \times 10^{8} \mathrm{~J} / \mathrm{m}^{2}\left(2.15 \times 10^{9} \mathrm{~J} / \mathrm{m}^{2}\right.$ for optics $)$ of ultraviolet.

Step 5- (Optional) Subject specimens to a water spray for a period of $5 \mathrm{~min}$ during each $60 \mathrm{~min}$ of the light exposure when using Xenon arc type exposure testing.

Step 6- (Optional) At intermediate exposure levels, remove specimens from test rack, record fluence, evaluate, and return specimens to test rack.

Step 7- Inspect test specimens to detect evidence of physical degradation. (See guidelines under Evaluation.)

Step 8- Evaluate optical properties of test specimens in accordance with guidelines under Evaluation.

\section{EVALUATION}

The surfaces of modules and minimodules shall be visually inspected before and after aging to ensure that no signs of excessive deterioration, (such as dimensional changes, cracking, fiber bloom, or other visually detectable changes which could significantly affect the performance of the module or minimodule) are present.

Evaluation procedures shall be selected to measure the effect of the aging procedures on important properties of the modules or minimodules. Evaluation at intermediate exposure levels is suggested as a way to determine degradation-rate effects.

The post-test electrical performance of each module or minimodule shall be measured using Test TE.AR.E.l. Excessive physical deterioration, electrical degradation below design levels, the presence of intermittent open circuits, or the occurrence of short circuits to ground shall be cause to classify the test specimen as having failed. 


\section{TEST TE.AR.D.3 \\ HUMIDITY TEST-SOLAR CELLS}

\section{PURPOSE}

The solar cell humidity test is used to determine if solar cells to be used in modules are capable of withstanding exposure to moisture without experiencing corrosion, power output degradation, or loss of contact strength.

\section{APPARATUS}

The apparatus consists of a humidity chamber with temperature controller; auxiliary thermal and humidity sensors with associated recording instruments; and solar cell electrical performance measuring test equipment.

\section{PREPARATION}

Step 1- Verify that pretest electrical performance data are available for the cells to be tested.

Step 2- Inspect cells visually for stains, missing areas of antireflection coating, 'missing or stained contacts, or any delaminated contacts.

Step 3- Set up humidity chamber to proper temperature and humidity and stabilize operation:

Step 4- Set solar cells to be tested vertically in clean, uncontaminated mounting fixture made from inert plastic material such as polyethylene or teflon.

\section{PROCEDURE}

Step 1- Fixture holding solar cells to be tested is inserted into humidity chamber that has been stabilized and set to operate at $90 \%$ relative humidity and $45^{\circ} \mathrm{C}$.

Step 2- Turn on temperature and humidity instrumentation and monitor through test.

Stcp 3- Loavo eolar oolle in humidity chamber for 30 days.

Step 4- After humidity exposure test period is complete, remove solar cells from chamber, dry, then inspect cells for stains, delaminated contacts or delaminated antireflection coatings, and perform electrical performance tests using Test TE.AR.E.l. 


\section{EVALUATION}

On completion of the humidity test, each cell shall be inspected to detect evidence of physical degradation of the antireflection coatings and the metal contacts. In addition, the post-electrical performance test data will be compared to the pretest data and excessive degradation of output beyond design limits shall be cause to disqualify cells. 
TEST TE.AR.D.4

\section{HUMIDITY TEST-ARRAY ELEMENTS*}

\section{PURPOSE}

The humidity cycling test is conducted to determine the effects of humidity cycling stresses that could occur during use on flat-plate modules, concentrator modules, concentrator receivers, or concentrator optics.

\section{COMMENTARY}

This is an exaggerated environmental test, accomplished by the continuous exposure of the equipment to high relative humidity at cycling elevated temperatures. These conditions impose a vapor pressure on the tested equipment, which can be a major cause of moisture migration and penetration.

Corrosion is one of the principal effects of humidity. Hygroscopic materials are sensitive to moisture and may deteriorate rapidly under humid conditions. Absorption of moisture by many materials results in swelling, which destroys their functional utility and causes loss of physical strength and changes in other important mechanical properties. Insulating materials that absorb moisture may suffer degradation of their electrical and thermal properties. Cycling temperature and humidity may cause condensation of moisture inside the equipment, which in turn could cause the equipment to malfunction because of electrical shorts, dull or obscure reflecting or transmitting optics, corrosion of terminals, or cell metallization.

\section{APPARATUS}

Equipment includes a humidity-temperat ure chamber and associated equipment; auxiliary thermocouples with associated recording devices; and a test frame.

\section{Chamber}

The chamber and accessories shall be constructed and arranged so as to prevent condensate dripping on the test item. The chamber shall be trap-vented to the atmosphere to prevent the buildup of total pressure. Relative humidity shall be determined from the dry bulb-wet bulb thermom eter comparison method or an equivalent method approved by the procuring activity. When readout charts are used, they shall be capable of being read with a resolution within $0.6^{\circ} \mathrm{C}\left(1^{\circ} \mathrm{F}\right)$. When the wet bulb control method is used, the wet bulb and tank shall be cleaned and a new wick installed at least every 30 days. The air velocity flowing across the wet bulb shall be not less than $4.57 \mathrm{~m} / \mathrm{s}(900 \mathrm{ft} / \mathrm{min})$. Provisions shall be made for controlling the flow of air throughout the internal chamber test space where the velocity of air shall not exceed $0.76 \mathrm{~m} / \mathrm{s}$ $(150 \mathrm{ft} / \mathrm{min})$. Steam or distilled, demineralized, or deionized water having a pH value

*Flat-Plate Modules, Concentrator Modules, Receivers, Concentrator Optics. 
between 6.0 and 7.2 at $23^{\circ} \mathrm{C}\left(73^{\circ} \mathrm{F}\right)$ shall be used to obtain the specified humidity. No rust or corrosive contaminants shall be imposed on the test item by the test facility.

\section{PREPARATION}

Step 1- (Flat-plate modules, concentrator modules, and receivers.) Verify that electrical performance data for the test item is available.

Step 2- (Concentrator modules and concentrator optics.) Verify that optical performance data for the test item is available.

Step 3- Inspect the test item to detect evidence of physical degradation (such as delamination, corrosion, and cracked cells).

Step 4- Prepare and provide programming devices to perform the humidity cycling program shown in Fig. B-12.

Step 5- Install at least one thermocouple on the test item. For flat-plate modules, install one thermocouple behind a solar cell on the back of the module at a point approximately one-third of the module width and one-third of the module length.

Step 6- Verify that the electrical terminals of the test item are short-circuited.

Step 7- Mount the test item in a test frame in accordance with manufacturer's installation instructions and recommended mounting hardware. The test frame shall be designed to simulate the support rigidity and differential thermal expansion likely to, occur in service between the item and its supporting structure.

\section{PROCEDURE}

Step 1- Install the test items into the humidity chamber. If there are more than one, install them so that all are exposed equally to the air supply. Connect the electrical leads from the thermocouples to the temperature recording device. Note: Concurrent testing of several test items in the same chamber is permitted provided the test requirements for each item are identical.

Step 2- Dry the test item at $54^{\circ} \mathrm{C}\left(129^{\circ} \mathrm{F}\right)$ for 24 hours (h).

Step 3- Condition the test item at $23^{\circ} \mathrm{C}\left(73^{\circ} \mathrm{F}\right)$ and $50 \pm 10$ percent relative humidity for $24 \mathrm{~h}$.

Step 4- Subject the test item to five (5) 24-h humidity cycles in accordance with Fig. B-12. A humidity cycle consists of raising the internal chamber temperature to $40.5^{\circ} \mathrm{C}\left(105^{\circ} \mathrm{F}\right)$ and $90 \%$ relative humidity in $2 \mathrm{~h}$, maintaining the internal chamber temperature at $40.5^{\circ} \mathrm{C}\left(105^{\circ} \mathrm{F}\right)$ and the relative humidity at $90 \%-95 \%$ for $16 \mathrm{~h}$, decreasing the internal chamber temperature to $21^{\circ} \mathrm{C}\left(70^{\circ} \mathrm{F}\right)$ and increasing the relative humidity to $95 \%$ in $2 \mathrm{~h}$, and maintaining the internal chamber temperature at $21^{\circ} \mathrm{C}\left(70^{\circ} \mathrm{F}\right)$ and the relative humidity at $95 \%$ for $4 \mathrm{~h}$. 


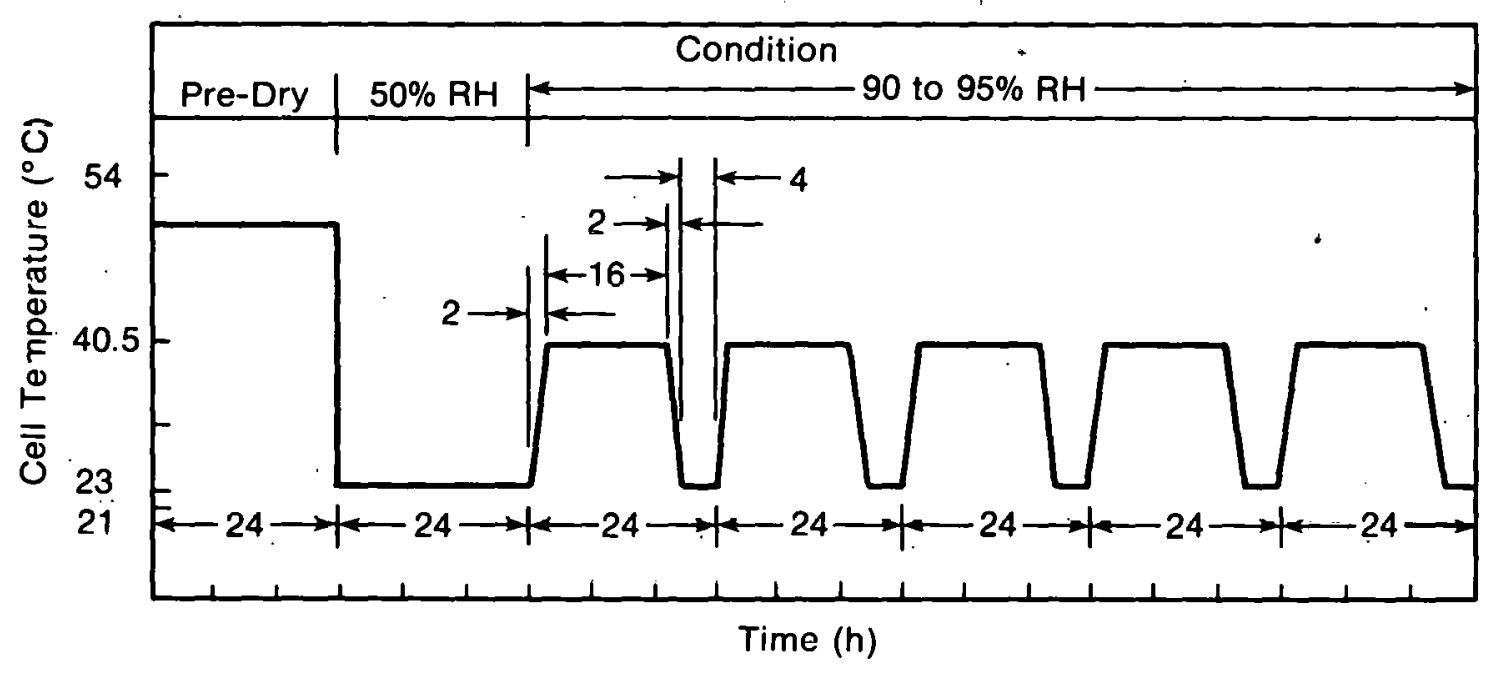

Figure B-12. Humidity Cycling Test 
Step 5- (Flat-plate modules, concentrator modules, and receivers.) Following removal from the test chamber, obtain post-test electrical performance data for each test item.

Step 6- (Concentrator modules and concentrator optics.) Obtain post-test electrical performance data.

Step 7- Inspect modules to detect evidence of physical degradation (such as delamination, obscuration of reflect or transmitting optics, corrosion of terminals or polished surfaces). 
TEST TE.PC.E.1

\section{POWER CONDITIONING UNIFIED TEST PROCEDURE FOR SOLD-STATE POWER INVERTERS}

\section{PURPOSE}

This unified test procedure provides a method to test DC to AC inverters, which are to be used in both stand-alone and utility-interactive applications. These applications are discussed in the introduction to Section 4.0 .

Master Test Code for Electricul Measurements in Power Circuits, IEEE Std 120-1955, provides a good introduction to the subject, although some of the test instrument ref erences are obsolete because of the uge of the spccification.

\section{APPARATUS}

Digital Voltmeter. The basic measuring instrument to be used should be a digital voltmeter with a 2000-count minimum full-scale and true RMS AC capability. The accuracy of the instrument should be verified before and after use by comparing it to standards traceable to the National Bureau of Standards. Ranges should be chosen so that readings fall in the upper half of the chosen range, with recorded data provided to a minimum of three significant digits.

Current should be measured by measuring the $\mathrm{AC}$ to $\mathrm{DC}$ voltage drop across a temperature-stable precision shunt. These shunts should have been compared to a standard traceable to the National Bureau of Standards, and adjusted to within $0.1 \%$ of each other at the muxiıuin currente measured. Ry using matched shunts and the same digital instrument for all measurements, the correlation between the input and outpul variable should be as accurate as the absolule measurem cnte.

Oscilloscope. Both AC and DC currents should be observed with an oscilloscope furnished with clip-on DC-responding current probes. Alternatively, both AC and DC currents may be observed with an oscilloscope across precision shunts with connections that minimize inductive effect errors. The system bandwidth should be suitably restricted or high frequency spikes rejected visually, so that waveform deviations above 2-5 $\mathrm{kHz}$ are not considered to be ripple.

Wattmeter. AC power should be measured with instruments capable of an overall accuracy of $\pm 1 \%$. Various methods are available to measure real power, such as Hall Effect multipliers and precision wattmeters. Calibration should be checked at the maximum currents and voltages to be measured.

Transformer $\mathrm{Tl}$ is a transformer or other low-voltage, high-current unit on which a custom secondary can be wound (see Fig. B-13). The variac is increased until a digital (RMS) voltmeter (which is used for all other test measurements and has been calibrated) indicates a voltage corresponding to the desired full operating current. Voltage and current are then recorded and observed simultaneously on an oscilloscope. Power is then 
the product of volts, amps, and the cosine of the phase angle between them, which should be less than $5^{\circ}$.

It can then be assumed that the instrument is correct at nonunity power factor and harmonics if the construction and operating principle is inherently a multiplication function. If it is desirable to check nonunity power factor operation, the applied voltage can be easily phase-shifted.

DC power can be measured either by a Hall Effect multiplier or by multiplying DC amps by DC volts, provided that the AC component of the DC input voltage is less than $1 \%$ peak-to-peak. It can be shown that if the $\mathrm{AC}$ component of either voltage or current is zero, then no power, other than DC, can be transferred. See Note 1 to Test Procedure, p. B-76.

Harmonic Analyzer. Harmonic analysis of the $\mathrm{AC}$ voltage or current can be done in several ways. It can be done directly from the current shunt or output voltage, but a more convenient method involves the use of a harmonic analyzer and an oscilloscope.

The oscilloscope provides the voltage waveform (from a probe) or current waveform, either across a shunt or by using a DC wideband clip-on current probe. The high-level oscilloscope output (with no common mode problems) is then connected to a tunable harmonic analyzer. The fundamental is adjusted to indicate $100 \%$, and the higher order harmonics are then recorded directly as a percentage of the fundamental voltage or current flow.

An oscillographic spectrum analyzer can also be used to provide Polaroid photographs for data analysis. Components less than $0.5 \%$ of the fundamental may be neglected.

\section{PREPARATION}

\section{Configuration}

The inverter to be tested must have both an appropriate power source and a suitable load. Any maximum power-point tracking capability must be temporarily disabled before testing.

PV Array Simulation or Power Supply. The ideal method of providing power to the inverter to be tested would be to employ an actual PV array, or a PV array simulator. If neither of these is available, power could be provided by means of a power supply with an output impedance low enough to reduce the peak-to-peak input voltage ripple (caused by injected current) to a value less than the ripple that would be obtained with an actual P.V array.

Suitable Load. The load must absorb the output power from the inverter to be tested without undue drif $t$ for the duration of the test. The load must be adjustable, both resistively and reactively, to required values. For three-phase inverters, each phase should be individually adjustable for unbalanced load measurements. For utilityinteractive inverters, a suitable utility-line connection becomes the load. The line impedance should be measured over a range of determined frequencies and adjusted as required to provide a specified test impedance. 


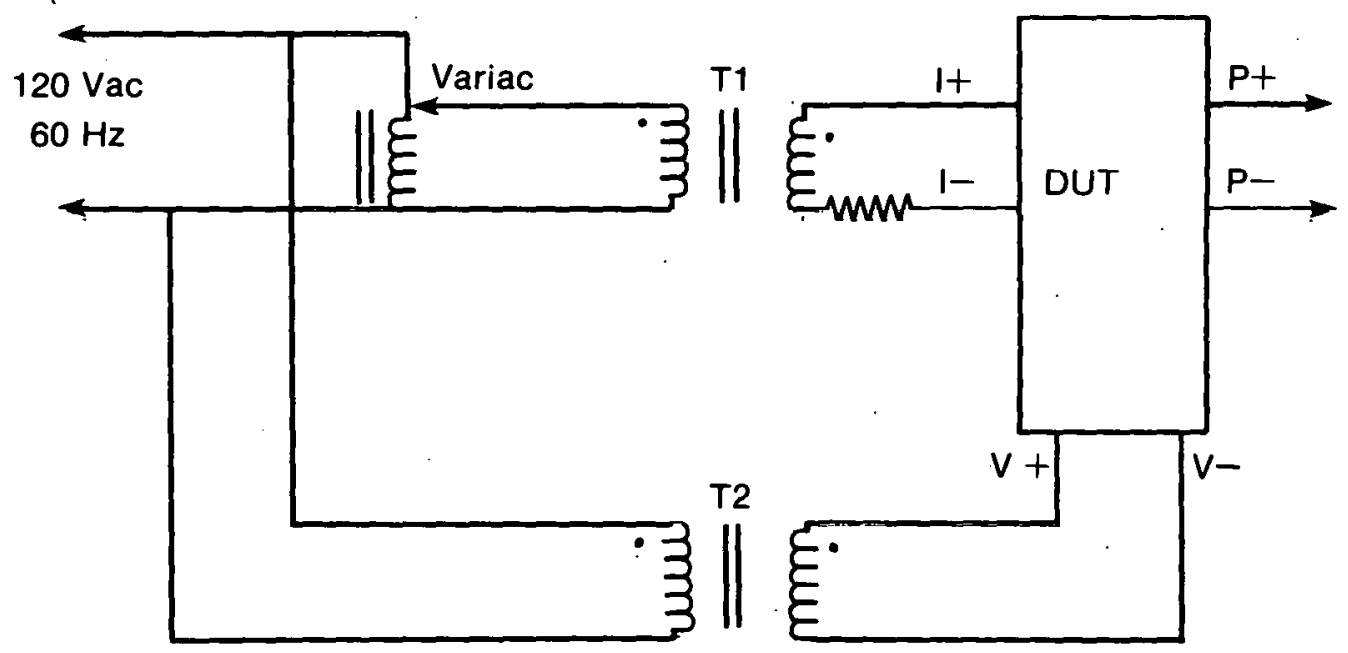

KaY:

DUT: Device under test.

T1: $120 \mathrm{~V}$ primary, secondary one or two turns of suitable wire.

T2: $120 \mathrm{~V}$ primary, cocondary voltage to euit DUT.

Hi: Frarision ciurreant shunt.

Figure B-13. Test Circuit 


\section{PROCEDURE}

\section{Test Plan}

With the preparation completed, the inverter shall be tested by the use of a test plan which lists the complete range of input and output variables to be tested. The test plan shall state all the operating points required by the test data in an organized step-by-step sequence. Test voltages shall be chosen in convenient steps; for example, $160 \mathrm{~V}, 180^{\circ}$, $200 \mathrm{~V}, 220 \mathrm{~V}, 240 \mathrm{~V}$. DC test powers shall be chosen in convenient steps, starting at zero and ending in full or overload rated power/current in no less than five steps $(0.0, .25, .5$, $.75,1.0)$. If required, each test procedure of the test plan shall be repeated for operation at various temperatures, pressures, and humidity conditions. At each operating condition, transi ent load data shall be recorded where applicable.

\section{Test Procedure}

The test plan shall be carried out by means of the proper test instrumentation. Voltages and currents observed by the oscilloscope should be noted for any signs of oscillation or unusual waveforms:

\section{EVALUATION}

The following is a list of suggested measurements:

- VDC, DC input voltage

- VDCPP, input voltage peak-to-peak ripple

- VDCRMS, input voltage RMS ripple

- IDC, DC input current

- IDCPP, input current peak-to-peak ripple

- IDCRMS, input current RMS ripple

- PDC, input power (if measured)

- VACRMS, AC output RMS voltage

- VACF, AC output voltage at individual frequencies (include fundamental)

- IACRMS, AC output RMS current

- IACF, AC output current individual frequencies (include fundamental)

Steps (VACF) and (IACF) should be measured to frequencies at least 15 times the fundamental of $60 \mathrm{~Hz}$. If DUT is pulsewidth modulation or high frequency link type, frequency components should be measured up to 4 times internal operating frequencies. Step (IACF) only applies to utility-interactive inverters. Utility-line harmonic voltages will be recorded with DUT not operating if they are greater than $0.5 \%$ of fundamental line voltage. Step (1) is PAC, AC output power. 


\section{DERIVED QUANTITIES}

- $\quad$ PDC, DC input power $=$ VDC $\times$ IDC

- IRF, current ripple factor $=$ IDCPP/IDC

- VAT, volt amps total = VACRMS $\times$ IACRMS

- PFT, power factor total = PAC/VAT

- VART, reactive power total $=\sqrt{(\mathrm{VAT})^{2}-(\mathrm{PAC})^{2}}$

- EFT, efficiency total $=\mathrm{PAC} / \mathrm{PDC}$

- Input current ripple if operated on solar array. Further explanation of this subject follows.

Actual input ' current ripple can be measured only when the inverter to be tested is operated from an actual PV array or suitable simulator.

\section{Note 1 to Test Procedure:}

$$
\begin{aligned}
\text { If } v(t)= & v_{D C}+v_{A C}(t) \\
\text { then } P=\overline{p(t)}= & =\left[V_{D C}+i_{A C}(t)\right. \\
& =v_{D C} I_{D C}+\overline{\left.V_{A C}(t)\right] i_{A C}(t)} \\
& \left.=P_{D C}+P_{A C} . i_{A C}(t)\right]
\end{aligned}
$$

The maximum value of $\mathrm{P}_{A C}$ will occur if $\mathrm{V}$ and $\mathrm{i}$ are both square waves in phase.

$$
\mathrm{P}_{A C}(\max )=1 / 4 \mathrm{~V}_{\mathrm{pp}} \cdot \mathrm{J}_{\mathrm{pp}}
$$

where $V_{p p}$ and $I_{p p}$ are peak-to-peak values.

If $\frac{V_{p p}}{V_{D C}}=\frac{I_{p p}}{I_{D C}}=10 \%$,

then the error is

$$
\frac{\mathrm{P}_{\mathrm{AC}}}{\mathrm{P}}=1 / 4 \%
$$




\section{TEST TE.ST.E.1}

\section{TEST PROCEDURE FOR MEASURING BATTERY CAPACITY AND ROUND-TRIP EFFICIENCY}

\section{PREPARATION}

- The final discharge voltage, $V_{\text {min }}$, final charge voltage, $V_{\text {max }}$, and equalizing voltage, $v_{e}$, shall be specified by the manufacturer in consultation with the system designer. These voltages should fall within the voltage window specified by the PV system designer.

- The charge and discharge rates shall be specified by the manufacturer in consultation with the user. These rates will depend upon the type of capacity test selected. The rates may be constant current (more common) or constant power, depending upon which one the PV system is capable of delivering and receiving.

- The electrolyte temperature, $\mathrm{T}_{\mathrm{B}}$, must be read and recorded at the start of any test discharge. In general, cell temperature should be within the range of $22^{\circ} \mathrm{C}$ to $31^{\circ} \mathrm{C}\left(72^{\circ} \mathrm{F}\right.$ to $\left.87^{\circ} \mathrm{F}\right)$ at the start of the discharge, and within the range of $18^{\circ} \mathrm{C}$ to $46^{\circ} \mathrm{C}\left(65^{\circ} \mathrm{F}\right.$ to $\left.115^{\circ} \mathrm{F}\right)$ during the test charge. During each discharge/charge, the temperature will increase and should be monitored.

- The battery must be fully charged and equalized, as specified by the manufacturer, before the start of the test. The electrolyte level and specific gravities should be checked for uniformity at the end of the equalization as specified by the manufacturer. Cell voltage, temperature, and charging rate should also be recorded.

\section{PROCEDURE}

- The battery must be discharged at the specified rate until the battery terminal voltage equals the specified final voltage, $V_{\text {min }}$.

- The cell voltages and the battery terminal voltage should be periodically recorded. The readings should be taken at the beginning and end of the discharge and at specified intervals. Attention must be given to any cell that is approaching 1.0 volt or less (polarity reversal). For nickel-cadmium batteries, the lower voltage is 0.5 volt or less.

- The battery must be fully charged at the specified rate to the specified end charging voltage, $\mathrm{V}_{\text {max }}$.

- The battery terminal voltage shall be periodically recorded throughout the charge.

- The time taken to fully charge the battery, $t_{c}$, shall be recorded. The amount of charge restored to the battery, $Q_{c}$, is the product of the average charge rate in amperes and the time in hours taken to fully charge the battery to its end charging voltage.* The energy restored to the battery, $\mathrm{E}_{c}$, is the product of the ampere-hours restored $\left(Q_{c}\right)$ and the average charge voltage.*

*For greater accuracy, use $Q_{i}=\int_{0}^{t_{i}}(I) d t$, or $E_{i}=\int_{0}^{t_{i}}(V)(I) d t$, where $i=c$ or $d$. 
- Repeat the first step (discharging the battery). Refer also to "Important," below.

- Repeat the next step (recording cell voltages and battery terminal voltages).

- The time taken to discharge the battery, $t_{d}$ to its final voltage shall be recorded. The amount of charge removed from the battery, $Q_{d}$, is the product of the average discharge rate in amperes and the time taken in hours to reach the final voltage.* The energy removed from the battery, $E_{d}$, is the product of the ampere-hours removed $\left(Q_{d}\right)$ and the average discharge voltage.*

- The actual battery ampere-hour capacity is $Q_{d}$ and the energy capacity is $E_{d^{*}}$ If the cell temperature at the start of the discharge differs from $25^{\circ} \mathrm{C}\left(77^{\circ} \mathrm{F}\right)$, the ampere-hour capacity must be temperature corrected:

$$
\text { Corrected Capacity at } 77^{\circ} \mathrm{F}=\frac{\text { Capacity at Temperature, } \mathrm{T}\left({ }^{\circ} \mathrm{F}\right)}{1+0.0025(\mathrm{~T}-77)}
$$

(Different for nickel-cadium batteries.)

- The battery round-trip coulombic efficiency, $\eta_{Q}$, is the ratio of the ampere-hours removed to the ampere-hours restored $\left(Q_{d} / Q_{c}\right) \cdot{ }^{Q}$ The energy efficiency, $\eta_{E}$, is the ratio of the watt-hours removed to the watt-hours restored ( $\left.E_{d} / E_{c}\right)$.

IMPORTANT: The second test discharge is not always necessary, depending upon whether or not the manufacturer or user deems it so. If it is not required, the battery capacity is calculated from the first discharge, and the efficiency is calculated from the first discharge and the following full charge.

*See note on preceding page. 


\section{TEST TE.ST.E.2}

\section{TEST PROCEDURE POR MEASURING TOTAL BATTERY IN-OUT EPFICIENCY}

\section{PREPARATION}

- The important point in this test is that the starting and ending states-of-charge should be equal and should be specified by the user. It is recommended that the end of an equalizing charge mark the beginning and end of the efficiency test.

- The ambient and cell temperatures over the period of the test should remain as constant as possible; for example, the ambient temperature should be within the range of $21^{\circ} \mathrm{C}$ to $35^{\circ} \mathrm{C}\left(70^{\circ} \mathrm{F}\right.$ to $\left.95^{\circ} \mathrm{F}\right)$.

- The length of time of the test shall be specified by the user, and might equal some weeks or months.

\section{PROCEDURE}

- The starting and ending states of charges shall be clearly recorded by the tester. Ambient and cell temperatures, terminal voltage, specific gravities of pilot cells (generally, every sixth cell), and state-of-charge shall also be recorded.

- The battery shall be cycled and operated normally, while the ambient and cell temperatures are recorded, for the specified length of time.

- The amount of ampere-hours removed and restored to the battery and the average charge and discharge voltages shall be monitored and recorded throughout the test.

- In the last hour of the equalizing period, each cell voltage shall be taken and recorded. At the end of the equalizing charge, each cell's specific gravity and cell temperature shall be read and recorded.

- A check shall be made of the readings for any large variations in specific gravities and voltages: i.e., if the specific gravity variation is greater than 0.020 $\mathrm{g} / \mathrm{cm}^{3}$ or the voltage variation is greater than $0.100 \mathrm{~V} /$ cell, then the battery manufacturer should be notified, further checks or tests should be made on the suspect cell(s) and the equalizing period might have to be performed more often or for longer time periods.

- When the specified test time has been completed, the end of the test shall be marked by the reaching of a state-of-charge terminal voltage; and specific gravity equivalent to those at the start of the test.

- The total in/out ampere-hour efficiency of the battery is the ratio of the total number of ampere-hours removed within the specified test time to the total number of ampere-hours restored within the specified test time. The total in/out energy efficiency is the ratio of the total watt-hours removed (total amperehours removed times the average discharge voltage) to the total watt-hours restored (total ampere-hours restored times the average charge voltage) to the battery within the specified test time. 
- If the average cell temperature (at the start of each discharge) throughout the test was not $25^{\circ} \mathrm{C}$, then a temperature correction should be performed:

Corrected ampere-hours $(\mathrm{Ah})$ removed at $77^{\circ} \mathrm{F}=\frac{\text { Ah removed at temp. } \mathrm{T}\left({ }^{\circ} \mathrm{F}\right)}{1+0.0025(\mathrm{~T}-77)}$.

(Different factor for nickel-cadmium batteries.)

Note: Cycle Plus Equalizing Efficiency. To determine the average round-trip efficiency, including periodic equalizing charges, the following equation may be used:

$$
\eta_{Q} \text { total }=\frac{\Sigma Q_{d}}{\Sigma Q_{c}{ }^{+} \Sigma Q_{e}}
$$

where $\eta_{Q}, Q_{d}$ and $Q_{c}$ are as in TE.ST.E.l.

$Q_{e}=$ amount of charge returned to the battery during equalizing. 


\section{NOMENCLATURE}

A

AC

Ah

AM

ANL

ANSI

AR

ASME

ASTM

$A_{A}$

${ }^{A} \mathrm{C}$

$\mathrm{A}_{\mathrm{R}}$

$\mathrm{A}_{\mathrm{RC}}$

$\mathrm{A}_{\mathrm{TA}}$

BOCA

C

DC

DOE

EIS

EMI

EPRI

$\mathrm{E}_{\mathrm{c}}$

$E_{\text {d }}$

$\mathbf{E}_{\mathrm{E}}$

FF

FCC

HUD

I

IAS

IEEE

IPC

IPCEA

I-V

$I_{v}$ ampere or amperes

alternating current

ampere-hours

air mass

Argonne National Laboratory

American National Standards Institute

antireflection

American Society of Mechanical Engineers

American Society for Testing and Materials

concentrator module active aperture area

illuminated cell area

receiver area

receiver active cell area

module total aperture area

Building Officials Congress Administration

battery rated capacity

direct current

Department of Energy

Environmental Impact Statement

electromagnetic interference

Electric Power Research Institute

energy restored to a battery

energy removed from a battery

energy to equalize a battery

current-voltage curve fill factor

Federal Communication Commission

(U.S. Department of) Housing and Urban Development

current

Industrial Application Society

Institute of Electrical and Electronics Engineers

Interim Performance Criteria

Insulated Power Cable Engineers Association

current-voltage

output current at a specified voltage 
$I_{m}$
$I_{s c}$
$i_{c}$
$i_{d}$
$J$
$J P L$

LSA

MIT/LL

NASA

NBS

NEC

NEMA

NEPA

NFPA

NOCT

NTE

NTIS

OSHA

PCU

PV

$\mathrm{PV} /$ thermal

$\mathbf{P}_{\mathrm{m}}$

$Q_{c}$

$Q_{d}$

$Q_{e}$

R

RIS

RMS

$\bar{r}_{S}$

SA

SAE

Sandia

SBCC

SERI

SOC output current at maximum power

output current at short circuit conditions

battery or cell charging current

battery or cell discharging current

irradiance

Jet Propulsion Laboratory

Low Cost Solar Array Project

Massachusetts Institute of Technology/Lincoln Laboratories

National Aeronautics and Space Administration

National Burea! of Standards

National Electrical Code

National Electrical Manufacturers Association

National Environmental Policy Act

National Fire Protection Association

nominal operating cell temperature

nominal terrestrial environment

National Technical Information Service

Occupational Safety and Health Association

power conditioning unit

photovoltaics

photovoltaics/thermal

maximum power

amount of charge restored to a battery

amount of charge removed from a battery

amount of charge to equalize a battery

module geometric concentration ratio

reference irradiance spectrum

root mean square.

cell turius rusistance

stand-alone

Society of Automotive Engineers

Sandia National Laboratories

Southern Building Code Conference

Solar Energy Research Institute

state of charge of battery or cell 
STD

$\mathrm{T}$

$\mathrm{T}_{\mathbf{B}}$

$t_{c}$

$t_{d}$

$t_{e}$

UBC

UI

UL

UPS

$\mathrm{V}$

VAR

$\mathrm{V}_{\mathbf{e}}$

$\mathrm{V}_{\mathrm{m}}$

$\mathrm{V}_{\text {min }}$

$v_{\text {max }}$

$v_{\text {oc }}$

$\mathbf{v}$

WRIS standard

temperature

battery electrolyte temperature

time interval to fully charge a battery

time interval to discharge a battery to its final voltage

recommended equalization interval

Uniform Building Code

utility interactive

Underwriters Laboratories, Inc.

uninterruptible power supply

volts or volt

volt-amperes-reactive

battery equalizing voltage

output voltage at maximum power

battery final discharge voltage

battery final charge voltage

output voltage at open circuit condition

wind velocity average

weighted reference irradiance spectrum

\section{Greek Symbols}

$\alpha$

$\dot{\beta}$

$\mathbf{K}$

$\eta$

$\eta_{\text {AA }}$

$\eta_{\mathrm{C}}$

$\eta_{\mathrm{CL}}$

$\eta_{\mathrm{E}}$

$\eta_{\mathrm{EC}}$

$\eta_{\mathrm{FPM}}$

$\eta_{\text {IM }}$

$\eta_{\text {MIS }}$

$\eta_{\text {NOCT }}$

$\eta_{\mathrm{P}}$

$\eta_{Q}$

$\eta_{\mathrm{RP}}$ temperature coefficient for solar cell current

temperature coefficient for solar cell voltage

current-voltage curve correction factor

electrical conversion efficiency

concentrator module aperature area efficiency

solar cell efficiency

collector efficiency

battery energy efficiency

encapsulated cell efficiency

flat-plate module efficiency

cell illumination mismatch efficiency

mismatch efficiency

nominal operating cell temperature (NOCT) efficiency

flat-plate module packing efficiency

battery round trip coulombic efficiency

receiver packing efficiency 


\section{THIS PAGE}

\section{WAS INTENTIONALLY \\ LEFT BLANK}

$N-4$ 


\section{SUBJECT INDEX FOR PERFORMANCE CRITERIA*}

Accessibility: SY.I.3

Antireflection coating: CE.M.1

Application-specific criteria/comments

central station: CA.I.2

intermediate load center: CA.I.2

stand-alone: SY.E.5; SY.E.6; SY.E.7; PC.E.1; PC.E.4; PC.E.6; PC.E.8; PC.E.10; PC.E.16; PC.E.17; CA.I.2;

utility interactive: SY.E.2; SY.E.3; SY.E.5; SY.E.6; PC.E.1; PC.E.5; PC.E.9;

PC.E.11; PC.E.16; PC.E.17; CA.I.2; PD.E.2

Array/array field

accessibility: SY.I.3

capability for system (generic): SY.E.4

cleaning tolerance: MO.M.10

concentrated light, damage by: AR.S.1

design: SY.B.3; MO.M.12; AR.S.1

efficiency: AR.E.1; AR.E.2

electrical output: AR.E.l; AR.E.2

flammability: MO.S.2

hail resistance: MO.M.8

humidity stress: MO.D.3

installation hazard: SY.S.6; SY.I.1

lightning protection: SY.E.8

loading (physical): AR.M.1; AR.M.2

maintainability: SY.I.2

manual: SY.I.2

matching or modules and arrays: MO.E.4

monitor and control, provisions for: AR.I.6

rain: MO.D.4

safety procedures: SY.S.I

soiling: MO.M.9

shadowing: SY.B.1

tracking and control: AR.I.6

Array subsystem (see also solar cell, module, receiver, array/array field)

accessibility: SY.I.3

capability for system (generic): SY.E.4

design: SY.E.4; SY.E.8; SY.B.3

handling: SY.M.2

ligh tning: SY.E.8

maintainability: SY.I.3

output voltage range: PC.E.1

PV/thermal design: SY.E.8

shadowing: SY.B.1

shipping: SY.M.1

*For Performance Criteria Code:

SY SM CE MO CK AK PC̈ MC ST CA PD

See Document Section:

$\begin{array}{lllllllllll}2 & 2 & 3 & 3 & 3 & 3 & 4 & 5 & 6 & 7 & 8\end{array}$ 


\section{SUBJECT INDEX FOR PERFORMANCE CRITERIA* (continued)}

Battery

abuse: ST.D.1

capability for system (generic): SY.E.6

capacity: ST.E.1

design: SY.E.6; ST.I.2

discharge rate: ST.E.4

efficiency: ST.E.2

equalizing charge: ST.E.5

fire protection: ST.S.4

hazardous gas: ST.S.3

life: ST.D.1

maintainability: ST.T.?

manual: ST.I.I

normalization: ST.E.5

operating temperatures: ST.T.I

plumbing: ST.B.1

safety: ST.S.1; ST.S.2; ST.I.2; ST.B.1

shelter: ST.S.5

shock hazard: ST.S.2

spills, protection against: ST.S.1

temperature, operating and extremes: ST.T.1

voltage window: ST.E.3

Cabling

clearance: CA.S.2

design: SY.E.8

fire codes and standards: CA.S.3

flammability: CA.S.I

grounding, SY.S.2

installation: CA.I.2

lightning, SY.E.8

loading (physical): CA.D்.2

maintenance: SY.I.1; CA.I.3

manual: SY.I.1; CA.I.1

moist ure resistance: CA.D.4

aising, wire: CA.E.1

solar degradation: CA.D.3

Cleaning tolerance: MO.M.10

Design aspects

array/array ficld: SY.8.6; BY.B.3; MO.M.12; AR.S.1

array subsystem: SY.E.4; SY.E.8; SY.B.3

battery: SY.E.6; ST.I.2

cabling: SY.E.8

module: SY.E.8; SY.S.6; MO.E.2; MO.E.3; MO.E.4; MO.M.1; MO.M.5; MO.M.6;

MO.M.8; MO.M.9; MO.M.12; MO.M.18

monitor and control (power conditioning) subsystem: MC.E.7; MC.S.1; MC.I.3

\footnotetext{
*For Performance Criteria Code: SY SM CE MO CR AR PC MC ST CA PD 


\section{SUBJECT INDEX FOR PERPORMANCE CRITERIA* (continued)}

power conditioning subsystem: SY.E.5; SY.E.8; PC.E.2; PC.E.7

PV system: SY.E.8; SY.I.4; SY.B.3; ST.E.3; ST.E.4

PV system monitor and control: SM.E.1

receiver: MO.E.3; MO.E.4; MO.M.7; MO.M.12

Efficiency

array/array field: AR.E.1

battery: ST.E.2

cell: CE.E.1; CE.E.2

module: MO.E.1

power conditioning: PC.E.14

receiver: CR.E.1

Electromagnetic interference (EMI): PC.E.2

Energy feedback (to utility): PD.E.2

Environmental impact: SY.B.2

Environmental/use stress

general: 'MO.E.2; MC.I.5

hail: MO.M.8

humidity: CE.D.2; MO.D.3

lightning: SY.E.8

moisture: CA.D.4

rain: MO.D.4

soiling: MO.M.9

solar weathering: MO.D.2; CA.D.3

temperature cycling: CE.D.1; MO.E.2; MO.M.7; MO.D.1

temperature-humidity cycling: CR.D.1

Fire

codes and standards: CA.S.3

protection: ST.S.4

safety: SY.S.5

Flammability: MO.S.2; C $\Lambda . S .1$

Grounding: SY.S.2; SY.S.3; PC.S.4

Hail resistance: MO.M.8

Handling: SY.M.2; CE.M.2; CE.M.3

Harmonics: PC.E.10; PC.E.11

Hazards

burn: SY.S.7; SY.I.3

concentrated light: MO.M.11

gas: ST.S.3

installation: SY.S.6; SY.I.I

shock: PC.S.1; ST.S.2

$\begin{array}{lccccccccccc}\text { *For Performance Criteria Code: } & \text { SY } & \text { SM } & \text { CE } & \text { MO } & \text { CR } & \text { AR } & \text { PC } & \text { MC } & \text { ST } & \text { CA } & \text { PD } \\ \text { See Document Section: } & 2 & 2 & 3 & 3 & 3 & 3 & 4 & 5 & 6 & 7 & 8\end{array}$ 


\section{SUBJECT INDEX FOR PERFORMANCE CRITERIA* (continued)}

Hot spot heating: MO.E.3

Insurability: SY.I.4; SY.B.3

Interference susceptibility: MC.E.7

Loading (physical): MO.M.1; MO.M.2; MO.M.6; AR.M.1; AR.M.2; CA.D.2

Maintainability: SY.I.2; SY.I.3

Manual (installation, operation, and maintenance): SY.I.1; PC.I.1; MC.I.1; ST.I.1

Matching of cells, modules: MO.E.3; MO.E.4

Material compatibility: MO.M.12; CR.M.4; CR.M.5; CR.M.6; CR.M.7; CR.M.8

Module

accessibility: SY.I.3

cleaning tolerance: MO.M.10

concentrated light, damage by: MO.M.11

design: SY.E.8; SY.S.6; MO.E.2; MO.E.3; MO.E.4; MO.M.1; MO.M.5; MO.M.6;

MO.M.8; MO.M.9; MO.M.12; MO.M.18

efficiency: MO.E.1

electrical insulation: MO.S.1

electrical interconnects: MO.M.7

electrical output: MO.E.1

environmental stress: MO.E.2; MO.M.7; MO.M.8; MO.D.1; MO.D.2; MO.D.3; MO.D.4

flammability: MO.S.2

hail resistance: MO.M.8

handling: SY.M.2

hot spot heating: MO.E.3

humidity stress: MO.D.3

matching of cells: MO.E.3; MO.E.4

material compatibility: MO.M.12; CR.M.4; CR.M.5; CR.M.6; CR.M.7; CR.M.8

monitor and control, provisions for: SY.I.2; AR.I.6

loading (physical): MO.M.1; MO.M.2

PV/thermal: SY.E.8

replacement: MO.I.1

rain exposure: MO.D.4

shipping: SY.M.1

soiling: MO.M.9

solar weathering: MO.D.2

support structure: MO.M.5; MO.M.6

temperature control: MO.M.18

temperature cycling stress: MO.D.1

terminals: MO.E.2

twist capability: MO.M.6

Monitor and control (power conditioning) subsystem

accessibility: SY.I.3

cabling: CA.D.1

*For Performance Criteria Code: See Document Section:
SY SM CE MO CR AR PC MC ST CA PD

$\begin{array}{lllllllllll}2 & 2 & 3 & 3 & 3 & 3 & 4 & 5 & 6 & 7 & 8\end{array}$




\section{SUBJECT INDEX FOR PERFORMANCE CRITERIA* (continued)}

capabilities for system (generic): SM.E.1

control panels: MC.I.2

design: MC.E.7; MC.S.1; MC.I.3

environment, tolerance to: MC.I.5

interference susceptibility: MC.E.7

maintainability: MC.I.3

manual: SY.I.l; MC.I.1

power consumption: MC.E.6

protective action: MC.E.4; MC.S.1

shutdown: MC.E.3; MC.E.4

sof tware: MC.I.1

start up: MC.E.1; MC.E.2

Power conditioning subsystem

accessibility: SY.I.3

burn hazard: SY.S.7

capability for PV system (generic): SY.E.5

design: SY.E.5; SY.E.8; PC.E.2; PC.E.7

efficiency: PC.E.14

electrical characteristics

input: PC.E.1; PC.E.2; PC.E.3

output: PC.E.4; PC.E.5

fire safety: SY.S.5

frequency output: PC.E.12

grounding: PC.S.4

harmonics: PC.E.10; PC.E.11

insulation: PC.S.4

lightning: SY.E.8

maintainability: SY.I.2

monitor and control, provisions for: PC.I.4; PC.I.5; PC.I.6

operating conditions: PC.M.1

overload capability: PC.E.7

power factor: PC.E.8; PC.E.9

protective action: PC.E.15; PC.E.16; PC.E.17; PC.T.1

ripple, input: PC.E.2

shock hazard: PC.S.1

turn-on characteristics: PC.E.13

unbalanced load: PC.E. 6

voltage regulation: PC.E.4

Power distribution subsystem

code conf ormity: PD.S.1

electrical capability: PD.E.1

manual disconinect: PD.S.2

utility interface: PD.E.2

Protective action: SM.E.4; PC.E.15; PC.E.16; PC.E.17; PC.T.1; MC.E.4; MC.S.1

*For Performance Criteria Code:

See Document Section:
SY SM CE MO CR AR PC MC ST CA PD

$\begin{array}{lllllllllll}2 & 2 & 3 & 3 & 3 & 3 & 4 & 5 & 6 & 7 & 8\end{array}$ 


\section{SUBJECT INDEX FOR PERFORMANCE CRITERIA* (continued)}

PV system

accessibility: SY.I.3

auxiliary energy subsystem: SY.E.7

burn hazards: SY.S.7

codes, building, and safety: SY.S.1; SY.I.5

computer simulation programs: SY.E.2

design: SY.E.8; SY.I.4; SY.B.3; ST.E.3; ST.E.4

economic performance: SY.E.3

electrical interrupts: SY.S.4

energy performance: SY.E.2

energy rating: SY.E.2

environmental impact: SY.B.2

fire safety: SY.S.5

grounding: SY.S.2; SY.S.3

handling: SY.M.2

installation hazards: SY.S.6; SY.I.1

insurability: SY.I.4; SY.B.3

lightning protection: SY.E.8

maintainability: SY.I.2

manual: SY.I.I

power performance: SY.E.1

parts replacement: SY.I.2

power rating: SY.E.1

safety: SY.S.1; SY.I.1; SY.I.2; SY.I.3

shadowing: SY.B.1

shipping: SY.M.1

test locations: SY.I.2

warranty: SY.I.I

PV system monitor and control

capabilities of: SM.E.1

design: SM.E.1

electrical disconnects: SM.E.4; SM.E.5

load management: SM.E.3

power flow controls SM.E.2

protective action: SM.E.4

Receiver

concentrated light, damage by: MO.M.11

cleaning tolerances: MO.M.10

design: MO.E.3; MO.E.4; MO.M.7: MO.M.12

efficiency: CR.E.1

electrical interconnects: MO.M.7

electrical output: CR.E.1

humidity: MO.D.3

materials, compatibility of: MO.M.12; CR.M.4; CR.M.5; CR.M.6; CR.M.7; CR.M.8 monitor and control, provisions for: AR.I.6

rain: MO.D.4

*For Performance Criteria Code:

See' Docum ent Section:

SY SM CE MO CR AR PC MC ST CA PD

$\begin{array}{lllllllllll}2 & 2 & 3 & 3 & 3 & 3 & 4 & 5 & 6 & 7 & 8\end{array}$




\section{SUBJBCT INDEX FOR PERPORMANCE CRITERIA* (concluded)}

replacement: CR.M.1

soiling: MO.M.9

solar weathering: MO.D.2

temperature cycling: MO.E.2; MO.D.1

temperature-humidity cycling stress: CR.D.1

terminals: MO.E.2

Replacement: SY.I.2; MO.E.1; CR.M.1

Ripple: PC.E.2

Safety

acid spills: ST.S.1; ST.B.1

burn hazards: SY.S.7

cable clearance: CA.S.2

code conformance: SY.S.1; PD.E.2; PD.S.1; CA.S.3

concentrated light: AR.S.1

electrical interrupts: SY.S.4; SY.I.3; SM.E.4; SM.E.5; MC.S.1

fire protection/safety: SY.S.4; ST.S.5; CA.S.3

flammability: MO.S.2; CA.S.1

grounding: SY.E.8; SY.S.2; SY.S.3; PC.S.4

hazardous gas: ST.S.3

installation hazards: SY.S.6; SY.I.1

insulation: SY.E.8; MO.S.1; PC.S.4

manual: SY.I.1; PC.I.1; ST.I.1

manual/automatic disconnect: PD.S.2; MC.S.1

plumbing: ST.B.1

safety practices: SY.S.6; SY.I.1; SY.I.2; SY.I.3

shock hazard: PC.S.1; ST.S.2

Shadowing: SY.B.l

Shipping: SY.M.1

Software: MC.I.l

Soiling: MO.M.9

Solar Cell

antireflection coating: CE.M.1

efficiency: CE.E.1; CE.E.2

electrical output: CE.E.1; CE.E.2

handling: CE.M.2; CE.M.3

humidity stress: CE.D.2

metallization (contact): CE.M.3; CE.D.1

temperature cycling stress: CE.D.1

Storage subsystem (see battery)

Terminals: MO.E.2

Warranty: SY.I.1

* For Performance Criteria Code:

SY SM CE MO CR AR PC MC ST CA PD

See Document Section:

$\begin{array}{lllllllllll}2 & 2 & 3 & 3 & 3 & 3 & 4 & 5 & 6 & 7 & 8\end{array}$




\begin{tabular}{|c|c|c|}
\hline $\begin{array}{l}\text { Document Control } \\
\text { Page }\end{array}$ & \begin{tabular}{|r|r|} 
1. SERI Report No. & 2. NTIS Accession No. \\
TR $-742-65.4$ & \\
\end{tabular} & 3. Recipient's Accession No. \\
\hline \multirow{2}{*}{\multicolumn{2}{|c|}{$\begin{array}{l}\text { 4. Title and Subtitle } \\
\text { Interim Performance Criteria for Photovoltaic Energy } \\
\text { Systems }\end{array}$}} & $\begin{array}{l}\text { 5. Publication Date } \\
\text { December } 1980\end{array}$ \\
\hline & & 6. \\
\hline \multicolumn{2}{|c|}{$\begin{array}{l}\text { 7. Author(s) } \\
\text { R. DeBlasio et al. and the IPC Task Groups }\end{array}$} & 8. Performing Organization Rept. No. \\
\hline \multirow{2}{*}{\multicolumn{2}{|c|}{ 9. Ferforming Organization Name and Address }} & $\begin{array}{l}\text { 10. Project/Task/Work Unit No. } \\
6128,10\end{array}$ \\
\hline & & $\begin{array}{l}\text { 11. Contract (C) or Grant (G) No. } \\
\text { (C) } \\
\text { (G) }\end{array}$ \\
\hline \multirow{2}{*}{\multicolumn{2}{|c|}{$\begin{array}{l}\text { 12. Sponsoring Organization Name and Address } \\
\text { Solar Energy Research Institute } \\
-7617 \text { Cole Bnulpvard } \\
\text { Golden, Colorado } 80401\end{array}$}} & $\begin{array}{l}\text { 13. Type of Report \& Period Covered } \\
\text { Tcchnical Report }\end{array}$ \\
\hline & & 14. \\
\hline
\end{tabular}

15. Supplementary Notes

16. Abstract (Limit: 200 words) This document is a response to the Photovoltaic Research, development, and Demonstration Act of 1978 ( $P . L$. . 95-590) which required the generation of performance criteria for photovoltaic energy systems. Since the document is evolutionary and will be updated, the term "interim" is used. More than 50 experts in the photovoltaic field have contributed in the writing and review of the 179 performance criteria listed in this document. The performance criteria addreas chardcteristics of present-day photovoltaic systems that are of interest to manufacturer government agencies, purchasers, and all others interested in various aspects of photovoltaic system performance and safety. The performance criteria apply to the system as a whole and to its possible subsystems: array, power conditioning, monitor and control, storage, cabling, and power distribution. They are further categorized according to the following performance attributes: electrical, thermal, mechanical/ structural, safety, durability/reliability, installation/operation/maintenance, and building/site. Each criterion contains a statement nf expected performance (nonprescriptive), a method of evaluation, and a commentary with further information or justification, Over 50 references for background informalion are also given. A glossary with definitions relevant to photovoltaic systems and a section on test methods are presented in the appendices. Twenty test methods are included to measure performance characteristics of the subsystem elements. These test methods and

17. Document Analysis other parts of the document will be expanded or revised as future

a. Descriptors experience and needs dictate.

Crystal Structure; Electricity; Energy Storage Systems:Q2 ; Evaluation:Q1; Insta1lation; Maintenance; Mechanical Properties; Operation; Performance:Q2; Photovoltaic

$\therefore$ Cells:T2; Pinotovoltaic Conversion:T1; Power Conditioning Circuits; Reliability;

Residential Sector; Safety; Site Selection; Solar Cell Arrays; Testing:Q2; Thermal Efficiency; Photovoltaic Power Plants; Power Plants; Solar Power Plants; Photovaltic Kesearch, Development, and Demonstration Act of 1978.

c. UC Categories

63

${ }^{18}$ Natilability Statementcal. Information Service

U.S. Department of Commerce

5285 Port Royal Road

Springfield, Virginia 22161

19. No. of Pages 247

20. Price

$\$ 9.50$ 